KAREN KATAGUIRI

PROPOSIÇÃO DE CRITÉRIOS TÉCNICOS E AMBIENTAIS PARA CRIAÇÃO DE BANCO DE SOLOS PARA A REGIÃO METROPOLITANA DE

SÃO PAULO

São Paulo-SP

2017 
KAREN KATAGUIRI

PROPOSIÇÃO DE CRITÉRIOS TÉCNICOS E AMBIENTAIS PARA CRIAÇÃO DE BANCO DE SOLOS PARA A REGIÃO METROPOLITANA DE SÃO PAULO

Dissertação apresentada à Escola Politécnica da Universidade de São Paulo para obtenção do título de Mestre em Ciências. 


\title{
PROPOSIÇÃO DE CRITÉRIOS TÉCNICOS E AMBIENTAIS PARA CRIAÇÃO DE BANCO DE SOLOS PARA A REGIÃO METROPOLITANA DE SÃO PAULO
}

\author{
Dissertação apresentada à Escola \\ Politécnica da Universidade de São \\ Paulo para obtenção do título de \\ Mestre em Ciências.
}

Área de Concentração:

Engenharia de Construção Civil e Urbana

Orientador:

Prof. Dr. Sérgio Cirelli Angulo

Co-orientador:

Prof $\stackrel{a}{a}$. Dr ${ }^{a}$. Maria Eugênia Gimenez Boscov 
Este exemplar foi revisado e corrigido em relação à versão original, sob responsabilidade única do autor e com a anuência de seu orientador.

São Paulo, de de

Assinatura do autor::

Assinatura do orientador:

Kataguiri, Karen

PROPOSIÇÃO DE CRITÉRIOS TÉCNICOS E AMBIENTAIS PARA CRIAÇÃO DE BANCO DE SOLOS PARA A REGIÃO METROPOLITANA DE SÃ̃O PAULO / K. Kataguiri - versão corr. -- São Paulo, 2017.

$123 \mathrm{p.}$

Dissertação (Mestrado) - Escola Politécnica da Universidade de São Paulo. Departamento de Engenharia de Construção Civil.

1.resíduos de construção civil 2.solos de escavação 3.reuso de solo 4.caracterização geotécnica 5.qualidade ambiental I.Universidade de São Paulo. Escola Politécnica. Departamento de Engenharia de Construção Civil II.t. 
Dedico este trabalho a meus pais, Francisco e Akimi (em memória), e a meu irmão, Gustavo. 


\section{AGRADECIMENTOS}

Mais uma etapa que se concretiza e, sem a ajuda e o apoio de um grande time, isso não seria possível. Deixo aqui meu sincero agradecimento a:

Prof. Dr. Sergio Cirelli Ângulo, pela confiança creditada em mim desde nossa primeira reunião, por todas as orientações e conselhos dados, pela determinação em nossa pesquisa, e pela bacalhoada mais deliciosa que já experimentei.

Prof ${ }^{\mathrm{a}} \mathrm{Dr}^{\mathrm{a}}$ Maria Eugênia Gimenez Boscov, por ser sempre tão paciente e prestativa, por ter me acudido em todos os (muitos) momentos de desespero, pelos ensinamentos em geotecnia e disponibilização do laboratório de mecânica dos solos (LMS).

Prof ${ }^{\mathrm{a}}$ Dr $^{\mathrm{a}}$ Claudia Echevenguá Teixeira, pela alegria e entusiasmo sempre tão contagiantes, pelas parcerias e disponibilização de todos os meios necessários para execução dos ensaios de caracterização ambiental.

Rafael Yoshio, grande parceiro de ensaios geotécnicos, por estar sempre sorridente e tranquilo, apesar de todo peso carregado e poeira respirada.

Joaquim, Toninho e Val, por todo trabalho que tiveram comigo e com minhas amostras no LMS.

Edson, Vanderley, Robson, Erasmo e Diomaria, pelo apoio e auxílio nos ensaios realizados no PTR.

Nestor, Alexandre, Fernanda, Vera, Reginaldo e Fábio, pela prestatividade em me ensinar, acompanhar e ajudar em todos os ensaios realizados no LRAC.

Valdecir, Sergio Lima, Raphael Baldusco e técnicos do LMCC, pela disponibilização de amostras, análises químicas e mineralógicas e ajuda nos quarteamentos.

IPT/FIPT pela bolsa de pesquisa do Programa Novos Talentos.

Pri e Leandro/Jamis, pelo companheirismo desde 2003, foram tantas caronas, almoços, conversas, abraços e apoio, que perdi a conta. 
Fernandinha, Kátia, Bia, Tânia, Van, Camis, Tatu e Carolzinha, pela amizade incondicional, que nem o tempo e nem a distância mudam, por tantas risadas e sábios conselhos.

Má A., Má B., Memê, Lu, Ju, Flavinha e Tayná, por sempre acreditar e torcer pelas minhas loucuras e empreitadas, por não medir esforço para estarmos juntas e por tantos anos dessa amizade tão linda.

Novos amigos da Poli, em especial Winnie, Carol, Camila, Natalia, Felipe, Tiago e Liz, por todos os cafés, bolos e biscoitos compartilhados, pelas conversas espairecedoras, pelos trabalhos realizados em conjunto, por todos os convites de almoços, cervejas, peruanos, festinhas, shows e bloquinhos.

Wandrea e Eliany, pela prestatividade, sempre dispostas a ajudar nas correrias de última hora.

Tia Atsuko, por toda dedicação, carinho, atenção e cuidados.

Gustavo, meu irmão e maior orgulho, por estar sempre um passo à frente, pelo apoio, compreensão e amor desmedidos.

Francisco e Akimi, meus pais e maiores torcedores, por priorizar minha educação sempre, por me entender melhor do que eu mesma, pela paciência, amor e união, pelas escolhas e por todos os caminhos em que pude seguir.

Muitos ficaram aqui por nomear, por razões que certamente compreenderão e cujo apoio e incentivo foi inestimável. A todos vocês, ofereço esta módica expressão de meu carinho e gratidão.

MUITO OBRIGADA!!!

Karen Kataguiri 


\section{RESUMO}

Considerando a necessidade de soluções sustentáveis para a destinação de solos de escavação de obras em áreas urbanas, este estudo apresenta a caracterização de materiais de escavação recebidos em um aterro de resíduos de construção civil (RCC) localizado na Região Metropolitana de São Paulo (MRSP). As amostras foram classificadas visualmente como predominantemente solo de escavação ou mistura de diferentes tipos de RCC, e submetidas a testes de caracterização química, mineralógica, ambiental e geotécnica. Os materiais de escavação destinados ao aterro são compostos, principalmente, por mistura de solos e outros tipos de RCC. Materiais cimentícios estão presentes em todas as frações granulométricas das amostras. As propriedades geotécnicas dos solos de escavação não são prejudicadas pela mistura com outros tipos de RCC. Os materiais são basicamente granulares e bem graduados, com resistência mecânica adequada para algumas aplicações geotécnicas ou de pavimentação. Nitrato e sulfato dissolvidos podem poluir aquíferos e águas superficiais; entretanto, as concentrações observadas não representam risco à saúde. No caso de concentrações superiores aos valores máximos permitidos pela regulamentação de resíduos, a avaliação do risco a possíveis receptores deve ser efetuada conforme o uso pretendido da construção. Foi sugerido um critério preliminar de triagem de materiais de escavação para potenciais reusos na RMSP.

Palavras-chave: resíduos de construção civil; solo de escavação; reuso de solo; caracterização geotécnica; qualidade ambiental. 


\section{ABSTRACT}

Considering the need of sustainable solutions for disposal of excavation soils from construction works in urban areas, this study presents characterization of excavation materials received in a CDW landfill located in the Metropolitan Region of São Paulo (MRSP). Samples were visually classified as predominantly excavation soil or mixtures of different types of CDW, and submitted to chemical, mineralogical, environmental and geotechnical characterization tests. The excavation material disposed of in the landfill is mainly composed of a mixture of soils and other types of CDW. Cementitious materials are present in all grain size fractions. Geotechnical properties of excavation soils are not impaired by the mixture with other types of CDW. The materials were basically granular and well-graded, with appropriate mechanical resistance for some geotechnical or pavement applications. Dissolved nitrate and sulfate may pollute aquifers and superficial waters; however, the observed concentrations do not represent health concern. In the case of concentrations higher than the maximum allowed values, risk assessment to possible receptors shall be carried out according to the intended construction purpose for potential reuse screening. A preliminary criteria screening for potential reuses was suggested for excavation materials of the MRSP.

Keywords: construction and demolition waste; excavation soil; soil reuse; geotechnical characterization; environmental quality. 


\section{LISTA DE FIGURAS}

Figura 2-1 Fluxograma de caracterização e classificação de resíduos sólidos.26

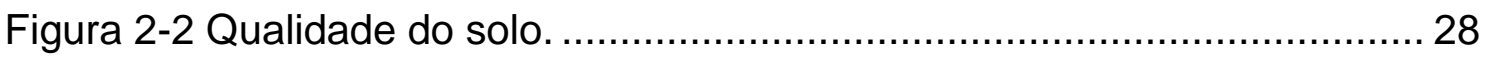

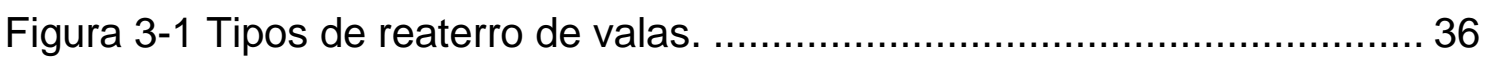

Figura 3-2 - Terminologia e camadas em valas para tubulação. ...................... 36

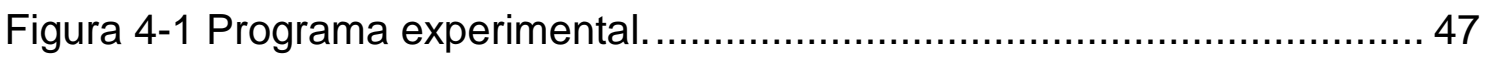

Figura 4-2 Desenho esquemático da coleta das amostras.............................. 48

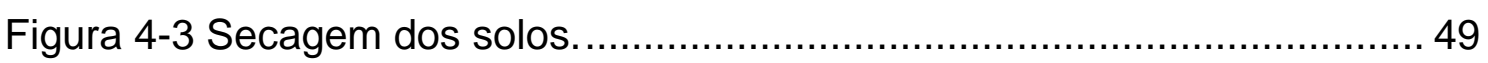

Figura 4-4 Quarteamento de amostras com quarteador tipo Jones. ................ 50

Figura 4-5 Quarteamento de amostras com quarteador rotativo...................... 51

Figura 4-6 Hirox Auto XY Stage (XY-GE-US) ............................................ 51

Figura 4-7. Classificação visual preliminar de amostras (a) B-23, (b) B-15 e (c) B-7 com predominância de solos, e amostras (d) B-12, (e) B-4, (f) B-5, (g) B-19 e (h) B-22 constituídas por misturas de solos e outros tipos de RCC (majoritariamente materiais cimentícios)..................................................... 52

Figura 4-8. Observação em microscópio digital de: (a) grãos de cimento com diâmetro entre 0,6 mm e 0,4 mm, (b) grãos cerâmicos com diâmetro entre 0,6 $\mathrm{mm}$ e $0,4 \mathrm{~mm}$, e (c) grãos de solo com diâmetro entre 1,2 mm e 0,6 mm.......53

Figura 5-1. Composição das amostras em termos de grãos naturais ou artificiais, com diâmetro entre 2,0 e 0,4 mm, por observação de imagens de microscopia. Os números nas barras indicam as quantidades de grãos naturais ou artificiais em cada fração, contadas individualmente. 58

Figura 5-2 Padrões DRX das amostras RCC-solo. São indicados os picos principais de caolinita $(K)$, muscovita $(M)$, quartzo $(Q)$, gibbsita $(G)$, feldspato $(F)$, hematita $(H)$, goethita $(G t)$ e calcita $(C)$. 60

Figura 5-3 Padrões DRX das amostras RCC-mistura. São indicados os picos principais de caolinita $(K)$, muscovita $(M)$, quartzo $(Q)$, gibbsita $(G)$, feldspato

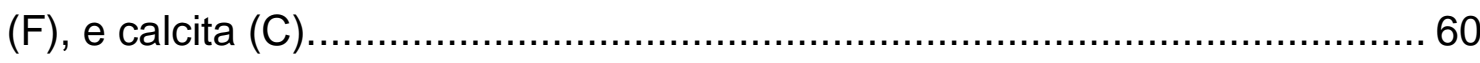

Figura 5-4 Correlação entre CTC e (a) teor de argila, e (b) $\mathrm{pH}$........................61 61 
Figura 5-5 Correlação entre teor de matéria orgânica e concentração de nitrato das amostras 63

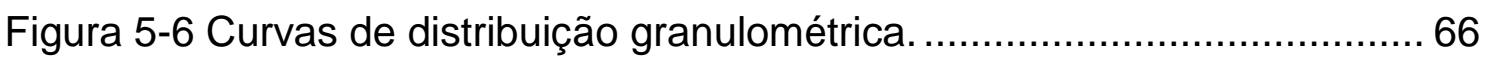

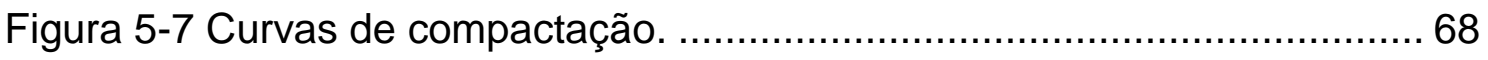

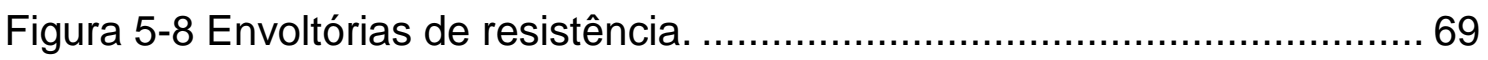

Figura 5-9 Curvas mini-CBR e expansão após imersão. ………………….... 70

Figura 5-10 Proposta de critério preliminar de triagem para potenciais reusos

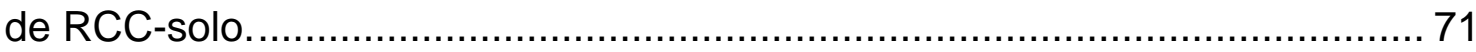

Figura 5-11 Proposta de critério preliminar de triagem para potenciais reusos

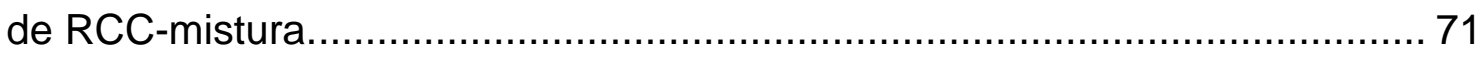




\section{LISTA DE TABELAS}

Tabela 2-1 Representatividade dos resíduos de construção e demolição em relação ao total de resíduos gerados em diversos países. 18

Tabela 2-2 Representatividade (percentual) de solos escavados em obras em relação ao total de RCC gerados em diversos países. 20

Tabela 2-3 Países/regiões da União Europeia com regulamentação de solos contaminados.

Tabela 2-4 Países/regiões da União Europeia com diretrizes para reuso de solos

Tabela 3-1. Categorias de solos para a construção de valas segundo a norma ASTM C1479M.

Tabela 3-2. Materiais recomendados para cada tipo de instalação e de aplicação conforme a norma ASTM C1479M.

Tabela 3-3 - Parâmetros para classificação dos solos e parâmetros de compactação.

Tabela 3-4 - Classificação MCT, propriedades e aplicações em pavimentação de solos

Tabela 3-5 - Ensaios e determinações da classificação MCT, e propriedades físicas associadas.

Tabela 3-6 - Relação dos principais critérios técnicos para reuso de solos em obras de terra.

Tabela 5-1 Composição química (\%) semi-quantitativa das amostras determinada por FRX.

Tabela 5-2 Concentração $(\mathrm{mg} / \mathrm{l})$ de compostos em extrato solubilizado dissolvidos e respectivos Valores Máximos Permitidos (VMP).

Tabela 5-3 Teor de matéria orgânica, $\mathrm{pH}$ e capacidade de troca catiônica (CTC).

Tabela 5-4 Propriedades físicas e classificação. 67

Tabela 5-5 Propriedades mecânicas. 70 


\section{SUMÁRIO}

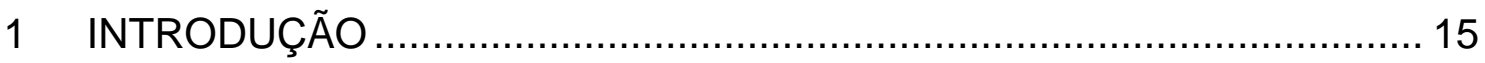

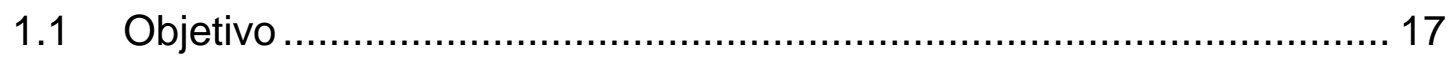

1.1.1 Objetivos específicos ............................................................ 17

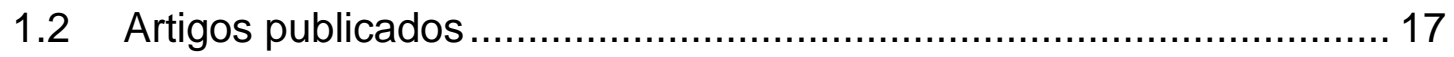

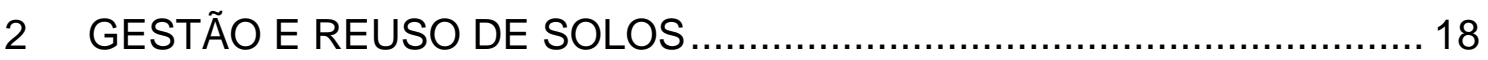

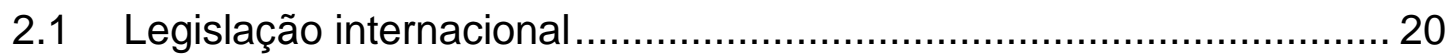

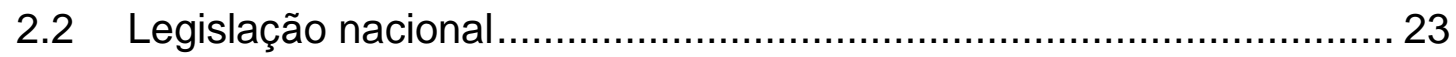

2.3 Critérios ambientais para reuso de solos de escavação …………...... 29

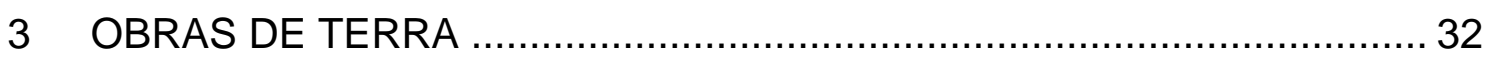

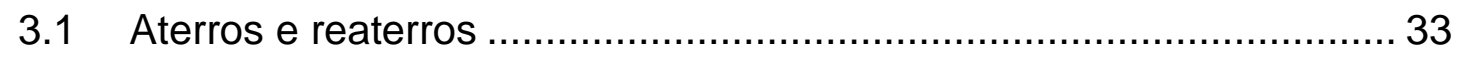

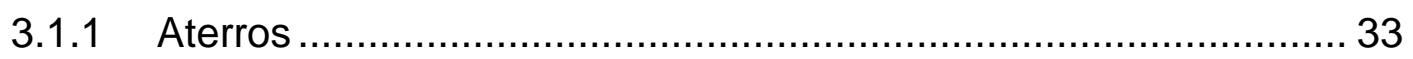

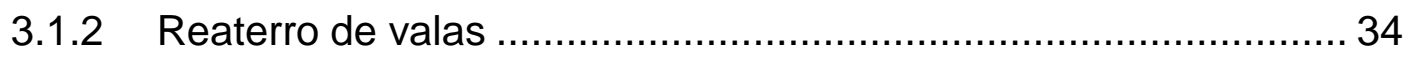

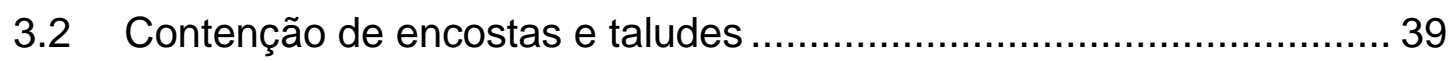

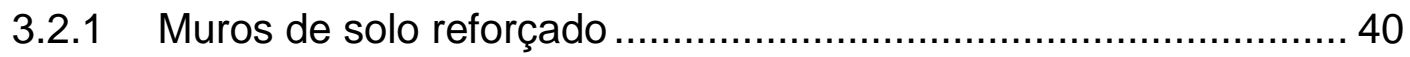

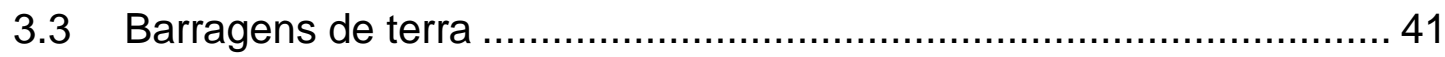

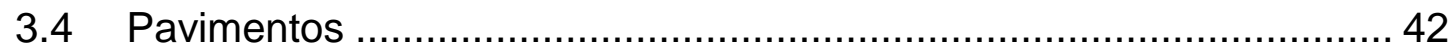

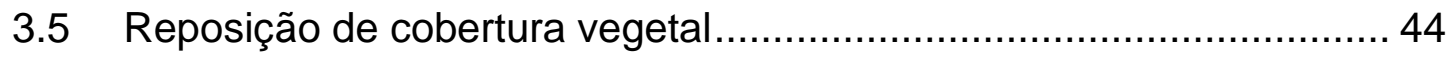

3.6 Critérios técnicos para reuso de solos de escavação .......................... 45

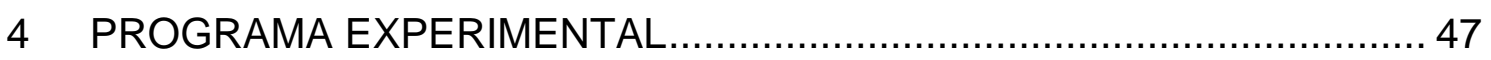

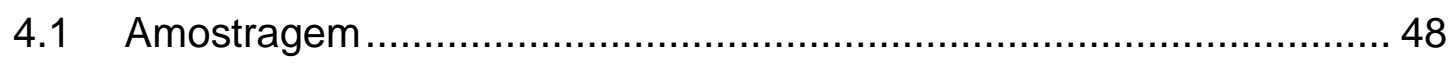

4.1.1 Coleta de amostras no aterro de RCC...................................... 48

4.1.2 Preparação de amostras para ensaios laboratoriais..................... 49

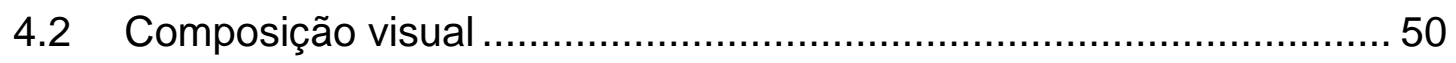

4.3 Caracterização química e mineralógica ............................................ 53

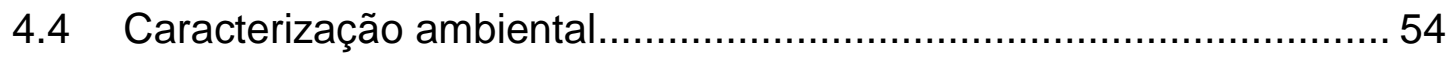




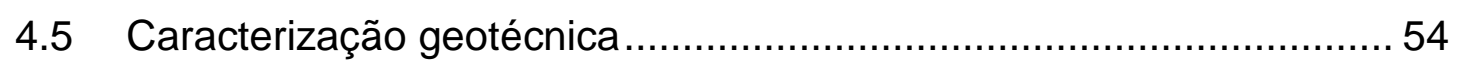

4.6 Proposição de fluxograma de triagem para potenciais reusos............ 56

5 RESULTADOS DA CARACTERIZAÇÃO DOS MATERIAIS ......................57

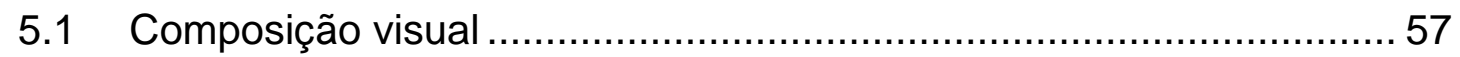

5.2 Composição química e mineralógica................................................. 58

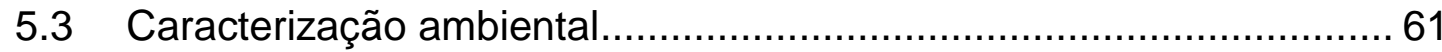

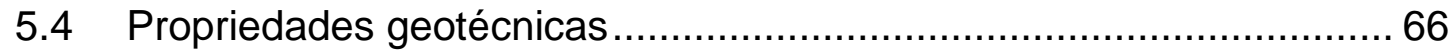

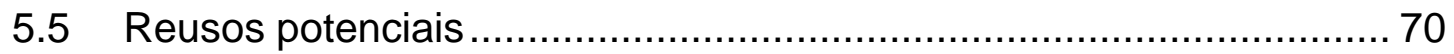

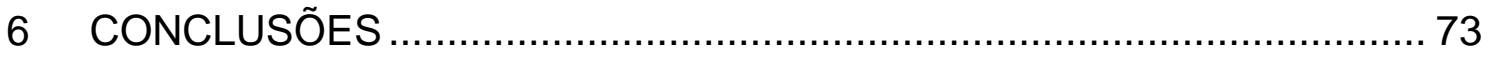

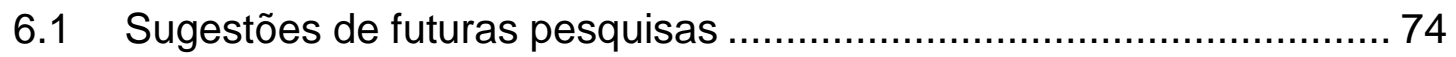

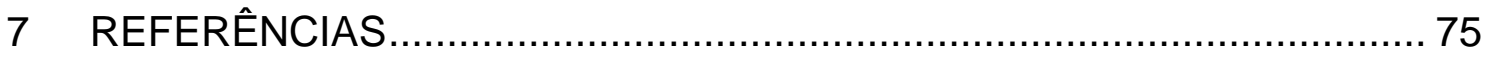

Apêndice A - Cálculo da massa mínima representativa ................................... 85

Apendice B - Resultados dos ensaios geotécnicos da amostra B-7 …............ 90

Apendice C - Resultados dos ensaios geotécnicos da amostra B-15 ….......... 96

Apendice D - Resultados dos ensaios geotécnicos da amostra B-23 ............ 103

Apendice E - Resultados dos ensaios geotécnicos da amostra B-4 ............. 110

Apendice F - Resultados dos ensaios geotécnicos da amostra B-5.............. 112

Apendice G - Resultados dos ensaios geotécnicos da amostra B-12 ........... 114

Apendice H - Resultados dos ensaios geotécnicos da amostra B-19 ........... 116

Apendice I - Resultados dos ensaios geotécnicos da amostra B-22 .............. 118

Apendice $\mathrm{J}$ - Resultados dos ensaios geotécnicos da amostra RCC-mistura

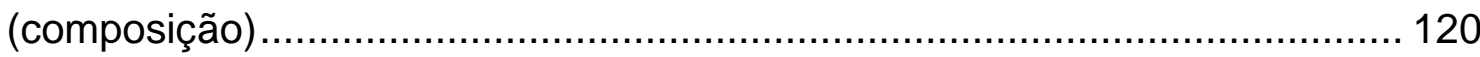




\section{INTRODUÇÃO}

Em regiões densamente urbanizadas e em contínuo crescimento populacional, obras de infraestrutura urbana, tais como sistemas de transporte (rodovias, estradas, viadutos, etc.), projetos de prevenção de inundações, e redes de abastecimento de energia, gás, água e esgoto, consomem a maior quantidade dos materiais minerais de construção (Hashimoto et al., 2007; Huang \& Hsu, 2003) e, portanto, podem apontados como grandes geradores de resíduos de construção civil (RCC) (Llatas, 2011; Shang et al., 2013; Sinduscon-SP, 2015).

Por falta de ferramentas mais eficientes de gestão e da adoção de novas tecnologias, a indústria de construção aparece como responsável pela geração de mais de $50 \%$ da massa de resíduos sólidos urbanos em diversos países (ABRELPE, 2014; AUSTRALIAN GOVERNMENT, 2011; MONIER et al., 2011; POON et al., 2013; SMA; SINDUSCON-SP, 2012). No Brasil, mais de 70 milhões de toneladas de RCC são gerados anualmente, e mais de $40 \%$ desse total é proveniente da Região Metropolitana de São Paulo-SP (ULSEN et al., 2013). Cabe ressaltar que o nível de desenvolvimento da tecnologia de construção impacta a quantidade gerada de resíduos de RCC.

Nesse contexto, materiais de escavação, limpeza do terreno e agregados representam a maior fração dentre os RCC (AUSTRALIAN GOVERNMENT, 2011; BÖHMER et al., 2008; DESTATIS, 2013; EUROSTAT, 2015; HASHIMOTO; TANIKAWA; MORIGUCHI, 2007; HUANG; HSU, 2003a; MONIER et al., 2011; POON et al., 2013; SINDUSCON-SP, 2015). No entanto, apesar de representar uma fração significativa dos RCC, poucas pesquisas têm sido conduzidas em relação à fração de solos de escavação (MAGNUSSON et al., 2015), e diversas publicações não incluem informações sobre estes materiais nos estudos de RCC (KARTAM et al., 2004; KOFOWOROLA et al., 2009; MYHRE, 2000; WEISLEDER \& NASSERI, 2006).

Há uma falta de informações técnicas na literatura referente ao gerenciamento de solos escavados em áreas urbanas (MAGNUSSON et al., 2015). Solos escavados são frequentemente descartados em locais de disposição de resíduos (Llatas, 2011; Magnusson et al., 2015; Poon et al., 2013; Shang et al., 
2013) ou mesmo em áreas não licenciadas (AUSTRALIAN GOVERNMENT, 2011; BLENGINI; GARBARINO, 2010; BÖHMER et al., 2008; GANGOLELLS et al., 2014; HUANG; HSU, 2003b; MAGNUSSON et al., 2015; POON et al., 2013). A depender da contaminação, os RCC podem ser dispostos em aterros de resíduos inertes, não inertes não perigosos (em aterros industriais ou em codispoisção em aterros sanitários) ou perigosos. A prática de aterramento desses materiais acelera o esgotamento da vida útil dos poucos aterros de resíduos disponíveis em áreas urbanas como a RMSP. Evidencia-se então a necessidade de proposições de soluções de menor impacto ambiental para a destinação de solos de escavação urbanas.

Solos escavados podem ser reutilizados na própria obra ou destinados a outros projetos (CONAMA, 2002; DEFRA, 2009; MAGNUSSON et al., 2015; MOON et al., 2007), em uma gama de atividades de engenharia, tais como aterros (DEFRA, 2009; GRIFFITHS; RADFORD, 2012), reaterros de valas (DEFRA, 2009; GRIFFITHS \& RADFORD, 2012; WRAP, 2005, 2007), barragens de terra e de enrocamento (GRIFFITHS \& RADFORD, 2012; WRAP, 2010), camadas de pavimentos (DEFRA, 2009; GRIFFITHS \& RADFORD, 2012; WRAP, 2005, 2007), estruturas de contenção como muros de solos reforçados (GRIFFITHS \& RADFORD, 2012; SANTOS, 2007; WRAP, 2010), bem como reposição de cobertura vegetal em jardins, acostamentos de estradas e paisagismo (DEFRA, 2009; SEPA, 2010).

Os solos como materiais de construção devem atender aos parâmetros geotécnicos para reuso em obras, de forma a garantir a segurança e a estabilidade das construções. Em centros urbanos, como a RMSP, são frequentes as contaminações de solos por efluentes domésticos e industriais (GÜNTHER, 2006); assim, além de propriedades técnicas, o reuso de solos de escavação também deve atender a padrões de qualidade ambiental e de saúde pública, para definição de restrições e mitigação de riscos de contaminação.

Diante do exposto, a determinação de critérios técnicos e ambientais de qualidade do solo de escavação, para a identificação de possíveis alternativas de reuso do material em obras urbanas, faz-se necessária para a avaliação do potencial de reuso de solos de escavação da RMSP, de acordo com suas características ambientais e geotécnicas. 


\subsection{Objetivo}

Esta pesquisa objetiva propor critérios técnicos e ambientais para a criação de banco de solos para a Região Metropolitana de São Paulo-SP (RMSP), visando o reuso dos materiais em obras de construção civil e infraestrutura urbana, com base em levantamento bibliográfico e em estudo de caracterização de materiais de escavação destinados a um aterro de RCC.

\subsubsection{Objetivos específicos}

Como objetivo específicos tem-se:

- Levantamento bibliográfico sobre a gestão e o uso de solos de escavação, para definição dos principais critérios técnicos e ambientais para reuso em obras;

- Caracterização química, mineralógica, ambiental e geotécnica de resíduos de escavação (solos e outros tipos de RCC) destinados a um aterro de RCC;

- Determinação de potenciais reusos por meio da comparação dos resultados de caracterização dos materiais de estudo com os principais critérios técnicos e ambientais para reuso de solos do levantamento bibliográfico; e

- Proposição de um critério de triagem preliminar - técnico e ambiental - para potenciais reusos de materiais de escavação na RMSP.

\subsection{Artigos publicados}

Durante o período da pesquisa, foram elaborados dois artigos referentes ao tema estudado:

Artigo 1: Preliminary characterization of excavated soils collected at a CDW landfill of São Paulo city (Proceedings of the III Progress of Recycling in the Built Environment Conference)

Artigo 2: Characterization of excavation materiais in São Paulo city and reuse alternatives (submetido à Waste Management) 


\section{GESTÃO E REUSO DE SOLOS}

A indústria da construção civil requer o uso de materiais de construção, a realização de obras de terra, e o transporte e o gerenciamento de grandes volumes de materiais, tais como agregados e solos de aterro ou escavados. Os impactos ambientais negativos relativos à indústria da construção civil estão, principalmente, relacionados ao elevado consumo de recursos naturais e ao grande volume de resíduos gerado (BÖHMER et al., 2008; ERAS et al., 2013; ESIN \& COSGUN, 2007; HAO et al., 2007; MÁLIA et al., 2013; MERINO et al., 2010; SÁEZ et al., 2011).

No Brasil, os serviços de construção e demolição geram aproximadamente $70 \%$ dos resíduos sólidos de maneira geral (SMA; CETESB, 2015) e mais de $50 \%$ da massa dos resíduos sólidos urbanos (ABRELPE, 2014; SMA; SINDUSCON-SP, 2012). As quantidades anuais de RCC gerados em diversos países são apresentadas na Tabela 2-1.

Tabela 2-1 Representatividade dos resíduos de construção e demolição em relação ao total de resíduos gerados em diversos países.

\begin{tabular}{|c|c|c|}
\hline País & $\begin{array}{l}\text { Resíduos de construção e demolição } \\
\text { (\% massa do total de resíduos) }\end{array}$ & $\begin{array}{l}\text { Ano } \\
\text { Referência }\end{array}$ \\
\hline Alemanha & 52 & $2011^{a}$ \\
\hline Áustria & 57 & $2012^{b}$ \\
\hline Austrália & 42 & $2008^{c}$ \\
\hline Brasil & $41-70$ & $1999^{d}$ \\
\hline Dinamarca & 24 & $2012^{b}$ \\
\hline Finlândia & 32 & $2006^{b}$ \\
\hline França & 72 & $2012^{b}$ \\
\hline Hong Kong & 85 & $2014^{\mathrm{e}}$ \\
\hline Itália & 33 & $2012^{b}$ \\
\hline Noruega & 15 & $2008^{b}$ \\
\hline Reino Unido & 42 & $2012^{b}$ \\
\hline \multicolumn{3}{|c|}{$\begin{array}{l}\text { a (DESTATIS, 2013) } \\
\text { b(EUROSTAT, 2015) } \\
\text { "(EMITH; O'FARRELL; BRINDLEY, 2011) } \\
\text { d (SMinto, 1999 apud SMA (2015); Cetesb, 2015) } \\
\text { ('(ENVIRONMENTAL PROTECTION DEPARTMENT, 2015) }\end{array}$} \\
\hline
\end{tabular}

Cabe ressaltar que os dados disponíveis sobre a geração de RCC são incertos, dada à falta de informações referentes às atividades informais e à disposição irregular desses resíduos (ANGULO et al., 2011; CORONADO et al., 2011; DE MELO et al., 2011; DUAN et al., 2015; KARTAM et al., 2004; KOFOWOROLA \& 
GHEEWALA, 2009; MAGNUSSON et al., 2015) e, também, devido à não uniformidade nas definições de RCC, que podem incluir ou não solos de escavação (BERGSDAL et al., 2007; BLENGINI et al., 2010; BRODERSEN et al., 2002; COCHRAN et al., 2007; DE MELO et al., 2011; MÁLIA et al., 2013; MONIER et al., 2011; POON et al., 2013).

'Solos escavados' compreendem todos os materiais gerados nas escavações e nas regularizações de terrenos para fins de construção e, dependendo das condições geológicas locais e atividades antrópicas, podem ser rochas, pedras, pedregulhos, areia, argila, material orgânico e materiais de construções ou atividades industriais anteriores (AUSTRALIAN GOVERNMENT, 2012; MAGNUSSON et al., 2015; MONIER et al., 2011; POON et al., 2013).

Apesar de representar uma grande fração dos RCC (Tabela 2-2), diversas publicações não incluem informações sobre solos escavados nos estudos de RCC por não considerá-los um importante problema ambiental (KARTAM et al., 2004; KOFOWOROLA et al., 2009; MYHRE, 2000; WEISLEDER \& NASSERI, 2006).

Em projetos de infraestrutura, o manuseio e o transporte de solos escavados e materiais provenientes de pedreiras/jazidas podem representar até $30 \%$ do custo total da obra (MAGNUSSON et al., 2015). A otimização do gerenciamento de solos escavados em projetos tem grande potencial para reduzir os custos e os impactos ambientais da obra, por meio de reuso do material na própria obra ou em outros projetos (AUSTRALIAN GOVERNMENT, 2011; BÖHMER et al., 2008; CHITTOORI et al., 2012; ERAS et al., 2013; KENLEY \& HARFIELD, 2011; POON et al., 2013).

Neste contexto, a coordenação de projetos - com a gestão e o reuso de solos escavados - pode mitigar os impactos ambientais negativos, diminuir as distâncias de transporte, reduzir os volumes de material depositado em aterros e a necessidade de recursos naturais provenientes de jazidas. 
Tabela 2-2 Representatividade (percentual) de solos escavados em obras em relação ao total de RCC gerados em diversos países.

\begin{tabular}{|c|c|c|}
\hline País & $\begin{array}{l}\text { Solos de escavação } \\
\text { (\% massa do total de RCC) }\end{array}$ & Ano referência \\
\hline Alemanha & 55 & $2011^{a}$ \\
\hline Austrália & 50 & $2011^{b}$ \\
\hline Áustria & 65 & $2012^{c}$ \\
\hline Brasil & 32 & $2011^{d}$ \\
\hline Dinamarca & 53 & $2012^{c}$ \\
\hline Finlândia & 75 & $2011^{\mathrm{e}}$ \\
\hline França & 69 & $2012^{c}$ \\
\hline Hong Kong & 70 & $2013^{f}$ \\
\hline Itália & 24 & $2012^{c}$ \\
\hline Noruega & 44 & $2008^{c}$ \\
\hline Reino Unido & 40 & $2012^{c}$ \\
\hline \multicolumn{3}{|c|}{$\begin{array}{l}\text { a (DESTATIS, 2013) - inclui rochas e lamas de dragagem } \\
\text { b (AUSTRALIAN GOVERNMENT, 2011) } \\
\text { c (EUROSTAT, 2015) } \\
\text { d (Menezes et al., 2011 apud SMA (2015)); Cetesb, 2015) } \\
\text { d (MANFREDI; RANA, 2011) } \\
\text { e (MONIER et al., 2011) } \\
\text { (MOON et al., 2013) - inclui lamas de dragagem }\end{array}$} \\
\hline
\end{tabular}

\subsection{Legislação internacional}

A União Europeia possui diretrizes que exigem que os países membros atinjam metas relativas à proteção dos solos, gerenciamento de resíduos e aterros. $\mathrm{A}$ Diretriz de Resíduos (Waste Directive 2008/98/EC) estabelece que os solos escavados não reutilizados no local de origem devem ser considerados como resíduos e geridos como tal quanto ao seu tratamento e/ou descarte, no âmbito das respectivas políticas nacionais. Em contrapartida, estabelece como necessária a redução da quantidade de resíduos gerados e o reuso ou reciclagem dos mesmos, atentando para a avaliação de riscos e a determinação de valores limites (BHUIYAN et al., 2011; DELGADO et al., 2009; SUER et al., 2014).

$\mathrm{Na}$ Holanda é proibida a disposição de solos contaminados em aterros. $\mathrm{Na}$ Bélgica há uma regulamentação do reuso de solos escavados e impõe a rastreabilidade do solo por meio de uma organização independente para gestão do solo. Alguns países permitem que os solos contaminados sejam 
recuperados; por exemplo, a Alemanha, que permite reuso de solos contaminados na construção em aterros (DOAK, 2004).

Um aspecto relevante que dificulta o reuso de solos recuperados é o fato da legislação não os diferenciar dos resíduos e, ainda, dentre as definições de resíduos, também poder considerar solos contaminados como resíduos perigosos (DOAK, 2004; WALLACE, 2004). Essas definições têm significativo impacto na viabilidade de reuso de solos escavados nos diversos países da União Europeia (WALLACE, 2004).

Nove dos doze países/regiões-membros da União Europeia possuem legislação específica de solos contaminados (Tabela 2-3). Holanda, Alemanha, Bélgica, Itália e República Tcheca possuem políticas abrangentes com recomendações, diretrizes e critérios para o reuso de solos contaminados (Tabela 2-4), inclusive com valores-limites para casos específicos de reuso (com exceção da República Tcheca) e testes de lixiviação de contaminantes (apenas a Alemanha e a Holanda) (FRAYE \& VISSER, 2006; SUER et al., 2014).

A França não possui regulamentação específica para reuso de solo, embora realize a gestão de solos contaminados (FRAYE et al., 2006). O Reino Unido possui guias com procedimentos e práticas para a escavação, o manuseio, o armazenamento, o transporte e o reuso de solos em aplicações específicas, como preenchimento de valas, geossistemas, reposição de cobertura vegetal em jardins, parques, acostamentos de estrada e paisagismo (DEFRA, 2009; SAEFL, 2002; WRAP, 2005, 2007, 2010).

De forma geral, a legislação atenta para a qualidade ambiental para reuso do RCC, ressaltando-se a importância da determinação de concentrações aceitáveis de compostos que podem estar presentes nos materiais (SUER et al., 2014). O valor limite varia conforme as diferentes metas de proteção ambiental; por exemplo, na Holanda visa-se proteger 95\% das espécies terrestres potencialmente afetadas, enquanto na Bélgica visa-se a proteção de 90\% (SUER et al., 2014). O estabelecimento do valor limite também considera a avaliação do risco de exposição aos contaminantes para a saúde humana e preservação dos ecossistemas conforme o uso previsto da construção onde se 
dará o reuso. Na avaliação de risco, se for o caso, também pode ser considerado o reuso/reciclagem de materiais após demolição da construção (SUER et al., 2014; SUSSET \& GRATHWOHL, 2011).

Tabela 2-3 Países/regiões da União Europeia com regulamentação de solos contaminados.

\begin{tabular}{ll}
\hline Países / Região & Legislação \\
\hline Bélgica (Flandres) & Soil Remediation Decree (1995, revisado em 2006) \\
\hline Bélgica (Bruxelas) & $\begin{array}{l}\text { Ordinance Pertaining to the Management of Contaminates Soil } \\
(2004)\end{array}$ \\
\hline Bélgica (Wallonia) & $\begin{array}{l}\text { Decree Pertaining to the Remediation of Contaminated Soil } \\
(2004)\end{array}$ \\
\hline Holanda & Soil Protection Act (1987) \\
\hline Alemanha & Federal Soil Protection Law (1998) \\
\hline Reino Unido & $\begin{array}{l}\text { Inglaterra, Escócia: Contaminated Land Regulations (2000) } \\
\text { País de Gales: Contaminated Land Regulations (2001) } \\
\text { Irlanda do Norte: Waste and Contaminated Land Order (1997) }\end{array}$ \\
\hline Espanha & Royal Decree (2005) \\
\hline Itália & Ministerial Decree 471 (1999) \\
\hline Suécia & Environmental Code (1998) \\
\hline
\end{tabular}

Fonte: Adaptado de FRAYE \& VISSER (2006).

Tabela 2-4 Países/regiões da União Europeia com diretrizes para reuso de solos

\begin{tabular}{ll}
\hline Países / Região & Legislação \\
\hline \multirow{2}{*}{ Bélgica (Flandres) } & $\begin{array}{l}\text { Decree on Waste Prevention and Management (1981) } \\
\text { Regulation on Soil Remediation (2004) } \\
\text { Material Management Act (2011) }\end{array}$ \\
\hline \multirow{2}{*}{ Holanda } & $\begin{array}{l}\text { Building Materials Decree (1999) } \\
\text { Soil Quality Decree (2008) }\end{array}$ \\
\hline \multirow{2}{*}{ Alemanha } & Länder Working Group on Waste (“LAGA”) \\
& Federal Soil Protection Act (1998) \\
\hline \multirow{2}{*}{ República Tcheca } & $\begin{array}{l}\text { Regulation 383/2001, complementada pela Regulation } \\
\text { 294/2005 }\end{array}$ \\
\hline \multirow{2}{*}{ Itália } & Decreto del Ministero dell'Ambiente e della tutela del \\
& Territorio e del Mare no 161 (2012) \\
\hline
\end{tabular}

Fonte: Adaptado de FRAYE \& VISSER (2006).

Segundo SAEFL (2002), o solo escavado pode ser classificado em três categorias, que indicam o tipo de reuso habilitado de acordo com a presença e a concentração de possíveis contaminantes:

- não contaminados: reuso irrestrito; 
- levemente contaminados: fertilidade não assegurável, sem riscos à saúde - reuso na própria obra ou em outras obras (calçadas, ilhas de tráfego etc.) e aterros;

- altamente contaminados: representa riscos e não deve ser reutilizado.

O Ministério do Ambiente, Alimentação e Assuntos Rurais do Reino Unido desenvolveu um manual contendo recomendações para práticas de construção com uso sustentável de solos em canteiros de obras (DEFRA, 2009). O manual apresenta recomendações a serem implantadas antes e no início da obra, envolvendo todas as etapas e atores (ou profissionais) do projeto de construção, desde desenvolvedores, projetistas, empreiteiros, subempreiteiros e regulamentadores (DEFRA, 2009).

\subsection{Legislação nacional}

No Brasil, não há uma normativa que trate especificamente de requisitos e critérios para o reuso de solos escavados em obras. Contudo, a legislação ambiental vigente fornece algumas bases para o controle de solos para reuso:

- a Resolução 307 (Conama, 2002) e a norma da ABNT NBR 10.004, que tratam da classificação e destinação de resíduos sólidos, e

- a Resolução Conama no 420/2009 e as normas da ABNT NBR 15.515 (partes 1, 2 e 3), que tratam das áreas contaminadas.

Segundo a Resolução 307 (Conama, 2002), os solos escavados e excedentes em obras são considerados RCC e, portanto, o seu reuso deve atender às leis e normas aplicáveis ao gerenciamento desses resíduos. Também deve ser realizado um diagnóstico da qualidade do solo com base nos procedimentos para investigação de áreas contaminadas, de forma a garantir os padrões de qualidade ambiental e de saúde pública.

Entende-se como 'área contaminada' um "[...] local onde há comprovadamente poluição ou contaminação, confirmada por análises, devido à introdução de quaisquer substâncias ou resíduos que nela tenham sido depositados, 
acumulados, armazenados, enterrados ou infiltrados de forma planejada, acidental ou até mesmo natural, e que possam causar danos ou riscos à saúde humana ou ao ambiente" (CETESB, 2001).

A seguir são apresentados e discutidos os principais critérios ambientais das regulamentações vigentes que respaldam o reuso de solos escavados em obras de construção civil no Brasil.

A Lei n 12.305, de 2 de agosto de 2010, estabeleceu a Política Nacional de Resíduos Sólidos (PNRS), onde são apresentadas as diretrizes para o gerenciamento de resíduos sólidos, incluindo os resíduos de construção resultantes da preparação e escavação de terrenos para obras civis. Dentre os objetivos da lei, destacam-se: i) a proteção da saúde pública e da qualidade ambiental, ii) a reutilização dos resíduos sólidos e iii) a disposição final adequada dos rejeitos. O solo escavado e excedente em obras civis é considerado um resíduo e, portanto, o seu reuso, desde que atendendo aos padrões de qualidade ambiental e de saúde pública, alinha-se aos objetivos da lei.

Dentre os instrumentos da PNRS, o Plano de Gerenciamento de Resíduos (PGR) - em níveis nacional, estadual e municipal - é exigido aos grandes geradores de resíduos (geração de mais de $1000 \mathrm{~m}^{3}$ por dia), de acordo com o enquadramento das obras de construção civil. A PNRS determina que deve ser elaborado um PGR da obra, contemplando soluções para a prevenção e a mitigação dos impactos negativos da geração de resíduos, incluindo o reuso de solos.

A Resolução 307 (Conama, 2002) estabelece diretrizes, critérios e procedimentos para a gestão dos resíduos da construção civil. A resolução classifica solos provenientes de terraplenagem como: i) resíduos classe $A$ (reutilizáveis ou recicláveis para uso como agregado) ou ii) resíduos classe $D$ (perigosos), no caso de solos contaminados.

A resolução estabelece que, para os resíduos classe $A$, deve ser realizado o seu reuso ou reciclagem ou o seu armazenamento em aterro de resíduos classe A, para usos futuros. Como os solos geralmente não possuem características adequadas para a sua utilização como agregados, 
frequentemente são destinados a aterros de inertes, onde eventualmente podem ser utilizados para nivelamento topográfico. Vale ressaltar que os resíduos classe $D$ devem ser armazenados, transportados e destinados em conformidade com normas técnicas específicas para gerenciamento de áreas contaminadas.

A Resolução 307 (Conama, 2002), em consonância com a PNRS, estabelece o Plano de Gerenciamento de Resíduos de Construção Civil (PGRCC) a ser elaborado pelos grandes geradores, o qual deve contemplar as etapas de: i) caracterização, ii) triagem, iii) acondicionamento, iv) transporte e v) destinação. A resolução enfatiza que deve ser priorizada a não geração de resíduos e, secundariamente, a redução, a reutilização, a reciclagem, o tratamento e a disposição final ambientalmente adequada dos resíduos.

A norma ABNT NBR 10.004 (ABNT, 2004a) classifica os resíduos sólidos quanto ao risco à saúde pública e ao meio ambiente, para que possam ser adequadamente gerenciados. A classificação dos resíduos sólidos envolve a identificação do processo ou atividade que thes deu origem, de seus constituintes e características, e a comparação de concentrações de diversas espécies químicas resultantes de ensaios de lixiviação e de solubilização com os valores de referência constantes nos anexos da norma ABNT NBR 10.004 (Figura 2-1). Os valores de referência são baseados em padrões de potabilidade de água desenvolvidos pela agência americana de proteção ambiental, USEPA (United States Environmental Protection Agency) (USEPA, 2004). De acordo com a norma, os resíduos são classificados em:

- classe I - perigosos: resíduos que apresentam características de inflamabilidade, corrosividade, reatividade, toxicidade ou patogenicidade;

- classe IIA - não perigosos, não inertes: resíduos que não se enquadram nas Classes I ou IIB, que podem apresentar propriedades como biodegradabilidade, combustibilidade ou solubilidade em água;

- classe IIB - não perigosos, inertes: resíduos que, quando amostrados de forma representativa e submetidos a testes de 
solubilização, não apresentam nenhum de seus constituintes solubilizados a concentrações superiores aos padrões de potabilidade de água, excetuando-se aspecto, cor, turbidez, dureza e sabor.

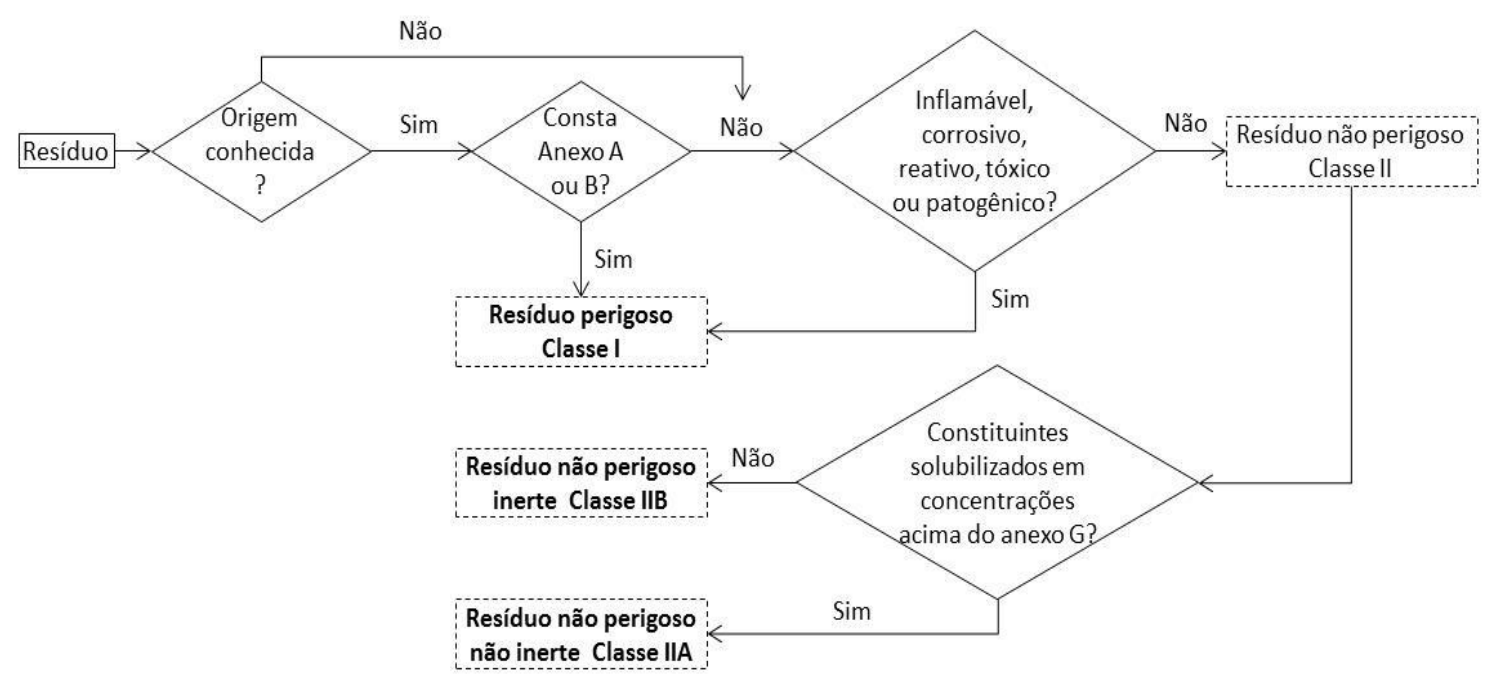

Figura 2-1 Fluxograma de caracterização e classificação de resíduos sólidos.

Fonte: Adaptado de ABNT (2004a).

Solos escavados em obras na RMSP podem ser classificados como resíduo não perigoso não inerte (ABNT, 2004a) devido a altas concentrações de $\mathrm{Al}$ (alumínio), Fe (ferro) ou Mn (manganes), características de solos tropicais (BIONDI, 2010; CAIRES, 2009; FERREIRA, 2006), que ultrapassam o valor máximo permitido (VMP) pela norma $(0,2 \mathrm{mg} / \mathrm{L}$ para $\mathrm{Al}, 0,3 \mathrm{mg} / \mathrm{L}$ para $\mathrm{Fe}$ e 0,1 $\mathrm{mg} / \mathrm{L}$ para $\mathrm{Mn}$ no extrato solubilizado). São então classificados como resíduos não inertes e devem ser destinados conforme a classe, sendo os aterros sanitários um destino comum para os solos de escavação.

Cabe ressaltar que, de acordo com as características qualitativas do resíduo, os custos são diferenciados para cada tipo de aterro, sendo menos onerosa a disposição em aterros de inertes e mais custosas em aterros de não inertes e em aterros de resíduos perigosos, nesta ordem.

A Resolução 420 (Conama, 2009) dispõe critérios e valores orientadores de qualidade do solo também baseados em padrões de potabilidade de água. $\mathrm{A}$ resolução estabelece diretrizes para a investigação e o gerenciamento de áreas contaminadas por substâncias em decorrência de atividades antrópicas. 
As etapas de uma investigação de áreas contaminadas- Avaliação Preliminar, Investigação Confirmatória e Investigação Detalhada - visam o fornecimento de orientações técnicas e de procedimentos para identificação e avaliação de indícios de contaminação em determinados locais.

Segundo a Resolução 420 (Conama, 2009), a avaliação da qualidade do solo deve ser realizada com base em Valores Orientadores de Referência de Qualidade (VRQ), Valores de Prevenção (VP) e Valores de Investigação (VI), a saber:

- VRQ refere-se a substâncias naturalmente presentes, sem interferência antrópica, ou seja, é a concentração de determinada substância que define a qualidade natural do solo, determinado com base em análises físico-químicas de amostras das principais classes de solos representativas de uma dada região;

- VP é o valor de concentração limite que indica uma possível alteração prejudicial da qualidade natural dos solos, estabelecida com base em ensaios de fitotoxicidade ou em avaliação de risco ecológico. Possui caráter preventivo e disciplinador e, quando excedido, requer monitoramento, identificação das fontes de poluição e seu controle;

- VI é o limite de concentração de uma substância no solo ou água subterrânea, acima do qual existe risco potencial de efeito deletério à saúde humana, havendo necessidade de ações imediatas na área, dentre as quais estão uma investigação detalhada e a adoção de medidas emergenciais e remediação, visando a minimização das vias de exposição e a proteção dos receptores de risco.

A partir da concentração de substâncias químicas, são definidas classificações de solo, conforme apresenta a Figura 2-2. 


\begin{tabular}{|c|c|c|cc} 
& & & \\
\hline solo classe 1 & solo classe 2 & solo classe 3 & solo classe 4 \\
(sem restrição) & (sem restrição & (com restrição de uso agrícola, & (intervenção) \\
VRQ & & VP & residencial ou industrial) & VI
\end{tabular}

VRQ = Valor de Referência de Qualidade de solo $/ \mathrm{VP}=$ Valor de Prevenção / VI = Valor de Investigação

Figura 2-2 Qualidade do solo.

Fonte: Adaptado de CONAMA (2009).

Os valores orientadores de qualidade do solo apresentados na Resolução 420 (Conama, 2009) são baseados nos dados da Companhia Ambiental do Estado de São Paulo (CETESB), pioneira na questão no Brasil (CETESB, 2001).

A determinação de teores naturais de substâncias químicas no solo, especialmente metais, sem introdução antrópica, é fundamental para a definição de valores orientadores de contaminação (CETESB, 2001; CONAMA, 2009). Para tanto, o Conselho Nacional de Meio Ambiente (Conama) recomenda a identificação dos tipos de solos mais representativos em cada Estado que servirão de base para determinação de $V R Q$ específicos da região. Deve-se evitar comparação de valores orientadores de solos de regiões distintas, uma vez que estes não representam os solos característicos locais e podem resultar em avaliações equivocadas quanto à qualidade do material escavado e consequente destinação final. A Resolução 420 (Conama, 2009) determina que os órgãos ambientais competentes dos Estados deveriam estabelecer os respectivos VRQ do solo até dezembro de 2014.

Em função das características dos solos tropicais brasileiros, a Cetesb excluiu o alumínio (Al), o ferro ( $\mathrm{Fe})$ e o manganês $(\mathrm{Mn})$ em extrato lixiviado e solubilizado da lista mais atual de valores orientadores (CETESB, 2014). Para os Estados que ainda não possuem uma lista específica para a região, continua sendo aplicável a Resolução 420 (CONAMA, 2009), cujos valores orientadores de qualidade do solo são baseados na primeira lista da Cetesb (2001) - não mais em vigor no Estado de São Paulo.

O conjunto de normas da ABNT NBR 15.515 (NBR 15.515-1/2007, NBR 15.515-2/2011 e NBR 15.515-3/2013) é baseado nos procedimentos de gestão de áreas contaminadas desenvolvido pela Cetesb (2001) e estabelece as etapas para a identificação e a avaliação de passivo ambiental em solo e em 
água subterrânea. Mais especificamente, estabelece procedimentos para a etapa de Avaliação Preliminar (NBR 15.515-1/2007), de Investigação Confirmatória (NBR 15.515-2/2011) e de Investigação Detalhada (NBR 15.5153/2013) de áreas contaminadas.

A Avaliação Preliminar objetiva encontrar indícios de possível contaminação e fundamentar a suspeita de contaminação de uma área, com base em informações disponíveis, como levantamento histórico, entrevistas, imagens, fotos e inspeções em campo. Havendo indícios de contaminação, torna-se necessária a Investigação Confirmatória. A confirmação da contaminação é realizada pela coleta e análise química de amostras representativas de solo e/ou água subterrânea de locais considerados com potencial ou suspeita de contaminação pela Avaliação Preliminar para substâncias químicas de interesse (SQI). Os valores de concentração nas amostras de solo e/ou água obtidos a partir dos resultados analíticos laboratoriais são comparados aos valores orientadores definidos pelos órgãos ambientais competentes para cada região ou conforme a Resolução 402 (CONAMA, 2009). Confirmando-se a contaminação no local, torna-se necessária a realização da Investigação Detalhada, para delimitação das plumas de contaminação e o estudo de Análise de Risco à Saúde Humana.

Após a investigação de áreas contaminadas, pode-se então delimitar as áreas de restrição devido à contaminação de solos. Os solos escavados nessas áreas deverão ter disposição ou reuso adequados de acordo com suas características.

\subsection{Critérios ambientais para reuso de solos de escavação}

No Reino Unido, um dos objetivos da estratégia governamental para gestão de materiais de escavação é evitar a sua disposição em aterros por meio de incentivos e regulamentação menos onerosa para o reuso ou a reciclagem de solos. Para isso, foram desenvolvidas guias com recomendações para o reuso de solos em aplicações específicas.

$\mathrm{Na}$ Holanda e na Alemanha, há políticas abrangentes com diretrizes e critérios ambientais para reuso de solos, levando em consideração seu potencial de 
contaminação. Estas regulamentações e recomendações apresentam valores orientadores de concentração de contaminantes para casos específicos de reuso, testes de lixiviação e as condições específicas nas quais o reuso é aceito.

$\mathrm{Na}$ Suíça, estudos e diretrizes vêm sendo desenvolvidos para que solos contaminados sejam recuperados de modo a garantir a sua qualidade ambiental para reuso. Na Suíça, o reuso de solos é regulamentado desde 1983 pela Lei de Proteção Ambiental e a regulamentação determina a forma de disposição e a reciclagem do material de escavação em caso de contaminação. No Brasil, o reuso de solos de escavação é indiretamente regulamentado pelas leis relativas à gestão de resíduos e áreas contaminadas. A partir das quais, conclui-se que:

- há metodologia consolidada para a investigação de áreas contaminadas e avaliação de riscos (Resolução Conama no 420/2009);

- as metodologias regulamentadas para a classificação de resíduos e para a determinação de níveis de contaminação em solos apresentam incompatibilidades, que dificulta o reuso de solos escavados e excedentes em obras (ABNT NBR 10.004/2004, Conama no 420/2009; e DD Cetesb 045/2014/E/C/I); e

- o desenvolvimento de diretrizes específicas para gestão de solos considerando aspectos de segurança e qualidade ambientais de solos escavados pode evitar intervenções inadequadas e melhorar a sua utilização como material de construção.

Para a garantia da qualidade ambiental e segurança à saúde no reuso de solos de escavação, deve-se atentar para as propriedades geoquímicas dos materiais. Análise de propriedades como $\mathrm{pH}$, teor de material orgânico, composição química e mineralógica, solubilidade e comportamento lixiviante de contaminantes orienta quanto às condições em que os solos de escavação podem ser reutilizados do ponto de vista ambiental. Faz-se necessária também a determinação de valores limites de concentração de substâncias com 
potencial de contaminação, a partir de avaliação de risco à saúde humana e ao ambiente, com base em:

- fontes potenciais de contaminação;

- vias de exposição aos possíveis contaminantes;

- concentração de compostos solubilizados e potencial de lixiviação;

- forma de reuso do material (misturado com outros materiais ou natural); e

- finalidade do reuso (agrícola, residencial, industrial). 


\section{OBRAS DE TERRA}

Obras de terra podem ser entendidas como estruturas construídas com solo ou blocos de rocha, nas quais o solo e a rocha são os materiais de construção (MASSAD, 2010). Estas obras usualmente englobam uma gama de atividades de engenharia, tais como a escavação de solo e rocha, e transporte do material para outras áreas. Compreendem barragens de terra e de enrocamento, aterros, reaterro de valas, valas de drenagem, fundações (especialmente as de infraestrutura linear), camadas de pavimentos, preenchimento estrutural de estruturas de contenção (como muros de solos reforçados), barreiras verticais e horizontais para confinamento de áreas contaminadas, entre outras (GRIFFITHS \& RADFORD, 2012; GRIFFITHS et al., 2012).

Previamente à execução de qualquer obra de terra, deve-se proceder a uma avaliação técnica inicial para verificar a adequação de técnicas construtivas e a segurança necessária. Este estudo preliminar poderá subsidiar eventuais avaliações econômicas, ambientais e estéticas futuras e, portanto, deve atentar em especial para os seguintes fatores (GRIFFITHS et al., 2012; WRAP, 2010):

- avaliação da geologia local;

- descrições precisas da natureza e das propriedades dos materiais utilizados;

- compatibilidade dos materiais de aterro com os demais componentes do sistema;

- determinação dos métodos de escavação de materiais;

- avaliação da estabilidade das escavações a curto e longo prazo;

- facilidade no atendimento aos requisitos de construção, acesso, plantas e trabalho, considerando a necessidade de manuseio e equipamentos de proteção individuais e coletivos (EPI / EPC); e

- operações e manutenções pós-construção, e procedimentos de reparo em caso de danos causados por impactos, incêndio ou vandalismo. 
A seguir são apresentados alguns tipos de obras de terra e respectivas propriedades geotécnicas relacionadas.

\subsection{Aterros e reaterros}

De forma geral, os aterros e reaterros empregam a compactação de solo em sua execução. A compactação de solo é a redução do índice de vazios - por processo mecânico - devido à expulsão ou compressão do ar dos vazios dos poros, que objetiva fornecer ao solo uma homogeneização e melhoria de suas propriedades de engenharia (permeabilidade, deformabilidade e resistência) (LAMBE, 1951; MASSAD, 2010; TAYLOR, 1948; TERZAGHI et al., 1996).

\subsubsection{Aterros}

Aterros de solo compactado são construídos com diversas finalidades, desde a configuração de terrenos para receber obras civis, como a implantação de indústrias, loteamentos, edifícios, etc., à infraestrutura de pavimentos viários e à construção de barragens e diques.

Usualmente, uma obra se inicia com a terraplenagem, que é a transformação da configuração topográfica inicial do terreno para atender às condições de um determinado projeto. Os serviços de terraplenagem são sempre os primeiros a serem executados em uma obra, pois mesmo para a instalação do canteiro esse serviço se faz necessário.

A seleção do solo para a construção do aterro se baseia na finalidade e na configuração da obra, assim como nos materiais disponíveis dentro de uma distância adequada. A escolha da área de empréstimo (jazida) depende do tipo de solo desejado, da distância de transporte até a obra, do volume de material necessário para a obra e do volume de material disponível na jazida, do teor de umidade e da homogeneidade da jazida (BOSCOV, 2015).

As etapas para a execução do aterro compreendem a escolha da área de empréstimo (jazida), desmatamento, limpeza do terreno, escavação, transporte, espalhamento, acerto de umidade (irrigação ou aeração), homogeneização e destorroamento, compactação propriamente dita e controle de compactação (BOSCOV, 2015). 
As especificações de compactação são estabelecidas em função da curva de compactação do solo e dos valores desejados dos parâmetros geotécnicos. A curva de compactação é obtida em laboratório por procedimentos normalizados pelas normas NBR6457 (ABNT, 2016) Amostras de solo - Preparação para ensaios de compactação e ensaios de caracterização - e NBR7182 (ABNT, 1986) Solo - Ensaio de compactação.

\subsubsection{Reaterro de valas}

Obras de instalação de tubulação ou fiação enterradas, como as de água, esgoto e gás, basicamente consistem nos seguintes processos (HOWARD et al., 2013):

- escavação de vala;

- preparo do subleito;

- alocação de tubulação;

- ligação/acoplamento da tubulação;

- preenchimento das laterais da tubulação com material para suporte; e

- aterramento da tubulação.

Nestas obras, é grande o volume de material escavado; exceto pelas atividades de alocar e acoplar a tubulação, todos os processos envolvem remoção e realocação de materiais escavados (HOWARD et al., 2013).

$\mathrm{Na}$ Grã-Bretanha, obras e serviços de manutenção das redes de água e gás geram cerca de 4,8 milhões de toneladas de resíduos por ano, que equivalem a $4,5 \%$ do total de resíduos de construção, demolição e escavação na região (WRAP, 2005). Desta forma, o setor é pressionado a reduzir os impactos negativos da grande geração de resíduos, mediante a adoção de práticas de reuso e reciclagem destes materiais (WRAP, 2007).

Podem-se definir cinco tipos básicos de valas para dutos, baseados na construção da camada de envolvimento da tubulação, que refletem na mobilização de diferentes equipamentos e mão de obra, bem como diferenças no dimensionamento das obras e nos materiais utilizados (HOWARD, 2011). 
Os procedimentos de instalação devem ser baseados nas condições do solo e de projeto; o projeto de tubulação se adequará a um dos cinco tipos de aterramento de valas, de acordo com as condições do solo, disponibilidade e reuso de materiais disponíveis e configurações rurais ou urbanas (HOWARD, 2011; WRAP, 2007).

De acordo com Howard (2011), os tipos de vala são (Figura 3-1):

Tipo 1 - vala padrão, na qual a tubulação é disposta sobre subleito de pedregulho ou outro solo não coesivo, e o solo (coesivo ou não coesivo) ao redor da tubulação é compactado em camadas de 0,1 a 0,3 m de espessura, dependendo do tipo de material e grau de compactação necessário; esse método demanda mais tempo e trabalho, e fornece menor suporte para tubulação em relação aos outros 4 métodos;

Tipo 2 - a tubulação é disposta sobre subleito de pedregulho ou outro solo não coesivo, compactado em uma única camada utilizando água e vibração interna; esse método fornece excelente suporte para tubulação e demanda pouco tempo e trabalho. Porém, como é um método pouco utilizado, requer um teste piloto inicial. É aplicável a solos com menos de $15 \%$ de grãos finos (com diâmetro menor que 0,075mm);

Tipo 3 - despejo de solo não coesivo para envolvimento na lateral da tubulação e mesmo material no subleito, sendo o método mais comum, que demanda pouco tempo e trabalho, mas que fornece o menor suporte para tubulação, pois não há compactação;

Tipo 4 - utiliza mistura de solo não coesivo, cimento e água para suporte da tubulação; é um método rápido, que fornece excelente suporte para tubulação e demanda pouco trabalho, sem compactação; normalmente utilizado em áreas urbanas, as quais dispõem de pouco tempo disponível para execução do serviço, porém é um método caro devido ao uso de cimento; e

Tipo 5 - combinação do tipo 4 e algum dos outros três tipos (1, 2 ou 3), a mistura solo-cimento é utilizada como preenchimento apenas na zona de apoio da tubulação; fornece bom suporte para tubulações com diâmetros maiores que $3 \mathrm{~m}$, com mais economia que o tipo 4 , pois utiliza métodos menos dispendiosos para o restante do suporte da tubulação. 

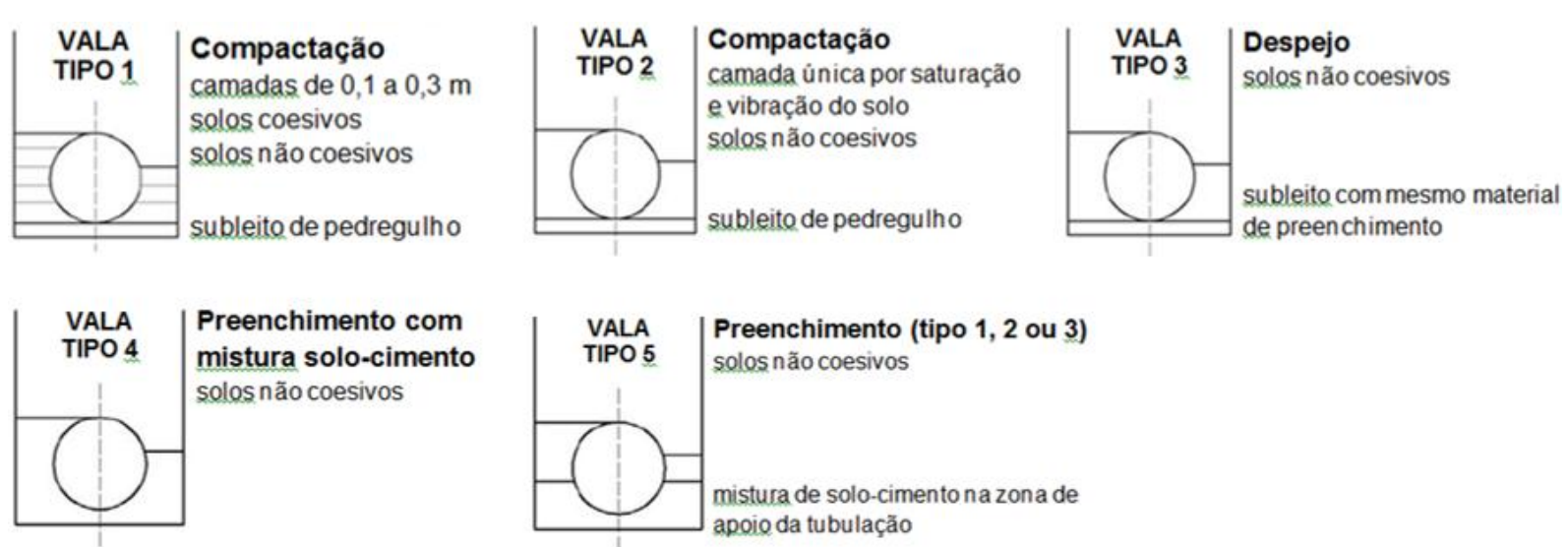

Figura 3-1 Tipos de reaterro de valas.

Fonte: Adaptado de HOWARD (2011).

Os termos utilizados para a instalação de tubulação em valas são ilustrados na Figura 3-2.

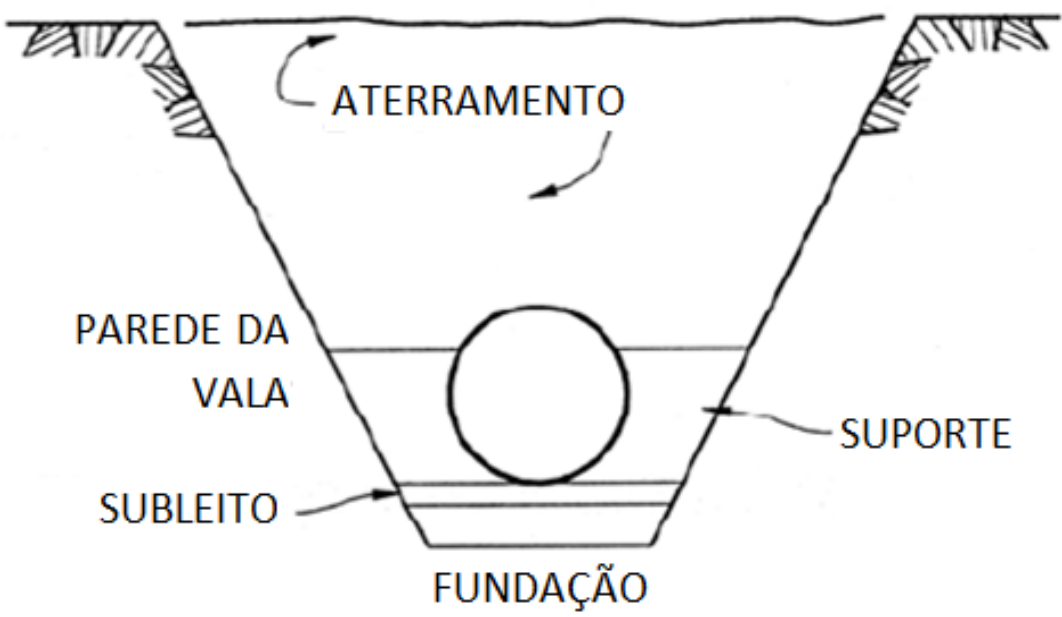

Figura 3-2 - Terminologia e camadas em valas para tubulação.

Fonte: Adaptado de HOWARD (2011).

Para os cinco tipos de aterramento de valas, de forma geral, o solo utilizado deve atender a parâmetros especificados em projeto, tais como grau de compactação, densidade seca, teor de umidade, distribuição granulométrica, limites de consistência, resistência à penetração (Índice de Suporte Califórnia ISC) e ao cisalhamento (HOWARD, 2011; PMSP, 2004; SABESP, 2006).

Em cada camada do processo de aterramento de valas (fundação, subleito, suporte, aterramento) devem ser utilizados materiais adequados, com propriedades específicas que garantam bom desempenho e preservação da 
estrutura do sistema de tubulação aterrada (HOWARD, 2011; HOWARD et al., 2013).

A norma norte-americana ASTM C1479M classifica os solos do país em 4 (quatro) categorias para utilização em valas (Tabela 3-1), e indica as categorias mais adequadas para cada tipo de instalação (tipos 1 a 5) e aplicação na vala (subleito, suporte ou aterramento), conforme apresentado na Tabela 3-2 (HOWARD, 2011). Na Tabela 3-1 constam também as classes dos materiais que compõem cada categoria, segundo o sistema unificado de classificação de solos.

Tabela 3-1. Categorias de solos para a construção de valas segundo a norma ASTM C1479M.

\begin{tabular}{|c|c|}
\hline Categoria de solo & Classificação Unificada de Solos \\
\hline Categoria I & $\begin{array}{l}\text { SW: areia bem graduada } \\
\text { SP: areia mal graduada } \\
\text { GW: pedregulho bem graduado } \\
\text { GP: pedregulho mal graduado }\end{array}$ \\
\hline \multirow{2}{*}{ Categoria II } & $\begin{array}{l}\mathrm{GM} \geq 12 \% \text { finos }(\leq 75 \mu \mathrm{m}): \text { pedregulho siltoso } \\
\mathrm{GC} \geq 12 \% \text { finos }(\leq 75 \mu \mathrm{m}): \text { pedregulho argiloso } \\
\mathrm{SM} \geq 12 \% \text { finos }(\leq 75 \mu \mathrm{m}) \text { : areia siltosa } \\
\mathrm{SC} \geq 12 \% \text { finos }(\leq 75 \mu \mathrm{m}): \text { areia argilosa }\end{array}$ \\
\hline & $\begin{array}{l}\mathrm{CL} \geq 30 \% \text { finos }(\leq 75 \mu \mathrm{m}) \text { : argila de baixa plasticidade } \\
\mathrm{ML} \geq 30 \% \text { finos }(\leq 75 \mu \mathrm{m}): \text { silte de baixa plasticidade } \\
\mathrm{CL}-\mathrm{ML} \geq 30 \% \text { finos }(\leq 75 \mu \mathrm{m}) \text { : argila siltosa de baixa } \\
\text { plasticidade }\end{array}$ \\
\hline Categoria III & $\begin{array}{l}\mathrm{CL} \leq 30 \% \text { finos }(\leq 75 \mu \mathrm{m}) \text { : argila de baixa plasticidade } \\
\mathrm{ML} \leq 30 \% \text { finos }(\leq 75 \mu \mathrm{m}) \text { : silte de baixa plasticidade } \\
\mathrm{CL}-\mathrm{ML} \leq 30 \% \text { finos }(\leq 75 \mu \mathrm{m}) \text { : argila siltosa de baixa } \\
\text { plasticidade }\end{array}$ \\
\hline Categoria IV & $\begin{array}{l}\text { MH: silte com alta plasticidade } \\
\text { CH: argila com alta plasticidade } \\
\text { OL: argila e/ou silte orgânico de baixa plasticidade } \\
\text { OH: argila e/ou silte orgânico com alta plasticidade } \\
\text { PT: solo com elevado teor de material orgânica }\end{array}$ \\
\hline
\end{tabular}


Tabela 3-2. Materiais recomendados para cada tipo de instalação e de aplicação conforme a norma ASTM C1479M.

\begin{tabular}{lll}
\hline Tipo de instalação & Camada de reaterro & Categoria de solo \\
\hline \multirow{2}{*}{ Tipo 1 } & Subleito & Categoria I - pedregulho \\
\cline { 2 - 3 } & Suporte & Categoria I, II, III - coesivos e não coesivos \\
\cline { 2 - 3 } Tipo 2 & Aterramento & Categoria I, II, III, IV - coesivos e não coesivos \\
\cline { 2 - 3 } & Subleito & Categoria I - pedregulho \\
\cline { 2 - 3 } & Suporte & Categoria I - não coesivos \\
\hline \multirow{3}{*}{ Tipo 3 } & Aterramento & Categoria I, II, III, IV - coesivos e não coesivos \\
\cline { 2 - 3 } & Subleito & Categoria I, II - não coesivos \\
\hline \multirow{3}{*}{ Tipo 4 } & Suporte & Categoria I, II - não coesivos \\
\cline { 2 - 3 } & Aterramento & Categoria I, II, III, IV - coesivos e não coesivos \\
\hline \multirow{2}{*}{ Tipo 5 } & Subleito & Categoria I, II - materiais de baixa resistência \\
\cline { 2 - 3 } & Suporte & Categoria I, II - materiais de baixa resistência \\
\cline { 2 - 3 } & Aterramento & Categoria I, II, III, IV - coesivos e não coesivos \\
\hline & Subleito & Categoria I, II - pedregulho, não coesivos, \\
& materiais de baixa resistência \\
\cline { 2 - 3 } & Suporte & Categoria I, II, III - coesivos e não coesivos \\
\cline { 2 - 3 } & Aterramento & Categoria I, II, III, IV - coesivos e não coesivos \\
\hline
\end{tabular}

A classificação unificada de solos baseia-se na curva de distribuição granulométrica e nos limites de consistência, conforme apresentado na Tabela 3-3. Quando a porcentagem em massa seca de finos (silte + argila) for menor do que $50 \%$, o solo será classificado como pedregulho $(G)$ ou areia (S), segundo a fração predominante. Por outro lado, quando a porcentagem em massa seca de finos (silte + argila) for maior do que 50\%, o solo será classificado como silte (M) ou argila (C), segundo o limite de liquidez e o índice de plasticidade.

Os pedregulhos e areias com poucos finos são adicionalmente classificados como bem (W) ou mal (P) graduados; com muitos finos, em siltosos (M) ou argilosos (C); e com quantidade intermediária de finos, das duas maneiras (W ou $\mathrm{P}$ e $\mathrm{M}$ ou $\mathrm{C})$.

Os siltes e argilas são adicionalmente classificados como de alta $(\mathrm{H})$ ou baixa (L) compressibilidade, ainda segundo o limite de liquidez e o índice de plasticidade.

Enquanto a curva granulométrica e os limites de consistência são características do solo, o teor de umidade e a densidade seca podem variar, resultando em diferentes valores de resistência, deformabilidade e 
permeabilidade. Na Tabela 3-3 são apresentados os parâmetros de classificação, consistência e compactação, necessários para as especificações de solos e para o controle de atividades no campo.

Tabela 3-3 - Parâmetros para classificação dos solos e parâmetros de compactação.

\begin{tabular}{|c|c|}
\hline Parâmetro & Detalhes \\
\hline \multirow{4}{*}{ Distribuição granulométrica } & pedregulho (\%) \\
\hline & areia $(\%)$ \\
\hline & silte (\%) \\
\hline & argila (\%) \\
\hline \multirow{3}{*}{ Limites de consistência } & limite de liquidez (LL) (\%) \\
\hline & limite de plasticidade (LP) (\%) \\
\hline & índice de plasticidade (IP) (\%) \\
\hline \multirow{2}{*}{ Compactação } & densidade seca máxima $\left(\mathrm{kN} / \mathrm{m}^{3}\right)$ \\
\hline & teor de umidade ótima (\%) \\
\hline
\end{tabular}

\subsection{Contenção de encostas e taludes}

Talude é um plano de terreno inclinado que tem como função garantir a estabilidade de uma massa de solo, em corte ou aterro, natural ou artificial. A instabilidade de taludes pode ser relacionada à geologia e fatores geotécnicos, presença de água, fenômenos de erosão, e ações externas que podem acarretar em deslocamentos de solo para a base do talude - como ravinas, deslizamentos, escorregamentos, etc. (MASSAD, 2010; SOUZA PINTO, 2000).

A estabilidade de taludes pode ser avaliada por métodos que são baseados na hipótese de haver equilíbrio numa massa de solo, tomada como corpo rígidoplástico, na iminência de entrar em um processo de escorregamento (LAMBE, 1951; MASSAD, 2010). Os escorregamentos são causados por diminuição de resistência do solo ou por aumento das tensões cisalhantes, e a chuva é um dos principais agentes dos escorregamentos (MASSAD, 2010).

Define-se resistência ao cisalhamento do solo como a máxima tensão de cisalhamento que o solo pode suportar sem sofrer ruptura sob uma determinada tensão confinante (SOUZA PINTO, 2000). A resistência ao cisalhamento do solo é, fundamentalmente, devida ao ângulo de atrito interno e à coesão de seus grãos (LAMBE, 1951; SOUZA PINTO, 2000; TAYLOR, 1948). 
O ângulo de atrito interno do solo depende da compacidade do solo, tipo de material, densidade, rugosidade, tamanho e forma dos grãos, e distribuição granulométrica (SOUZA PINTO, 2000; TAYLOR, 1948). A coesão é uma característica de solos finos com grãos de forma lamelar e elevada atividade coloidal, que resultam em grande atração físico-química entre as partículas do solo, como é o caso de solos argilosos; solos não coesivos são predominantemente areias e pedregulhos, que apresentam grãos arredondados e angulosos, com pequenas área de contato e sem atração físico-química entre os grãos (SOUZA PINTO, 2000). Em solos granulares não saturados, a presença de água em baixos teores gera tensões capilares que aproximam os grãos de areia, resultando em uma coesão aparente, que pode representar uma parcela da resistênca mecânica nesses materiais.

A norma NBR 11682 (ABNT, 2009) estabelece as condições necessárias para estudo e controle da estabilidade de taludes em solo, rocha ou mistos, componentes de encostas naturais ou resultantes de cortes, e aborda também as condições para projeto, execução, controle e conservação de obras de estabilização de taludes.

\subsubsection{Muros de solo reforçado}

Muros de solo reforçado são estruturas de contenção que utilizam elementos de reforço para correção das características de resistência do solo e, consequentemente, melhoria no suporte da construção (SANTOS, 2007; WRAP, 2010). O elemento de reforço pode ser fabricado a partir de aço, polímeros, fibra natural, madeira, concreto, dentre outros materiais (WRAP, 2010). Os materiais de preenchimento e aterro dos muros devem ter adequada capacidade de drenagem, baixa expansão e boa capacidade de compactação e resistência ao cisalhamento, de acordo com altura da estrutura e tipo de reforço utilizado (PALMEIRA, 2009; SANTOS, 2007; WRAP, 2010). A depender do elemento de reforço utilizado, análises complementares do solo devem ser realizadas para investigação da compatibilidade entre material de reforço e solo (SANTOS, 2011). No Brasil, devido às características dos solos tropicais, além de material granular utilizam-se também solos com grande fração de finos na construção de muros de solo reforçado (BENJAMIM; BUENO; ZORNBERG, 
2007; EHRLICH; BECKER, 2010; RICCIO; EHRLICH, 2010). Em outros países, tais como nos Estados Unidos da América e na Inglaterra, também são empregados solos coesivos sob determinadas condições (SANTOS, 2017).

\subsection{Barragens de terra}

Barragens são estruturas construídas transversalmente à direção de escoamento de um curso d'água, para criação de um reservatório artificial de água, e podem ser de diversos tipos, dentre eles as barragens de terra (MASSAD, 2010).

As barragens de terra são construídas com um tipo de solo (barragem homogênea) ou mais tipos de solos (barragem zoneada) compactados, além de solos granulares usados na construção de filtros, drenos e camadas de transição.

$\mathrm{O}$ projeto de uma barragem de terra deve garantir segurança quanto ao (MASSAD, 2010):

- transbordamento;

- fenômeno de areia movediça causados por percolação em fluxo ascendente;

- piping (erosão retrogressiva tubular);

- erosão; e

- ruptura dos taludes.

A erosão em taludes pode evoluir para cavidades maiores no corpo da barragem acarretando em ruptura da mesma. Dentre as diferentes medidas de segurança à montante e a jusante dos taludes das barragens de terra contra a erosão, pode-se destacar (MASSAD, 2010):

- ondas provocadas por ventos sobre a superfície do reservatório quebram-se no contato com o talude de montante, e podem resultar na formação de sulcos de erosão. Este efeito pode ser evitado com a construção de camadas de enrocamento e transição no talude à montante; 
- incidência de chuvas no talude à jusante pode provocar sulcos de erosão, que podem ser evitados com aplicação de camada de pedrisco, plantio de grama ou geossintéticos (geomantas).

Assim, em relação ao solo utilizado na construção de barragens de terra, é necessária adoção de medidas para evitar ou mitigar fugas d'água pelas fundações da barragem; devem ser avaliadas as condições de compactação, percolação e cisalhamento, coesão, tipo e distribuição granulométrica do solo (MASSAD, 2010).

\subsection{Pavimentos}

Diante dos comportamentos peculiares dos solos tropicais, Nogami \& Villibor (1995) desenvolveram o método expedito de classificação MCT (Miniatura, Compactada, Tropical) que auxilia na escolha de solos tropicais compactados para aplicação em pavimentação e, eventualmente, outros tipos de obras, com base no comportamento de contração, consistência, expansão e permeabilidade do solo. Os solos são divididos em duas classes principais, subdivididas em sete grupos (NOGAMI; VILLIBOR, 1995):

- solos de comportamento laterítico (L):

- areias lateríticas com pouca argila (LA);

- areias argilosas lateríticas (LA'); e

- argilas lateríticas e argilas lateríticas arenosas (LG');

- solos de comportamento não-laterítico $(\mathrm{N})$ :

- areias siltosas com siltes quartzosos e siltes argilosos nãolateríticos (NA);

- areias siltosas e areias argilosas não-lateríticas (NA');

- argilas, argilas siltosas e argilas arenosas não-lateríticas (NG'); e

- siltes cauliníticos e micáceos, siltes arenosos e siltes argilosos não-lateríticos (NS'). 
A partir da classificação MCT de um solo, é possível prever suas aplicações para pavimentação, conforme apresenta a Tabela 3-4.

A Tabela 3-5 relaciona as propriedades geotécnicas dos solos com as propriedades físicas de camadas acabadas de pavimentos, e os principais problemas construtivos observados nesta aplicação.

Tabela 3-4 - Classificação MCT, propriedades e aplicações em pavimentação de solos (NOGAMI; VILLIBOR, 1995).

\begin{tabular}{|c|c|c|c|c|c|c|c|c|c|}
\hline \multicolumn{3}{|c|}{ GRANULOMETRIAS TIPICAS } & \multirow{3}{*}{ 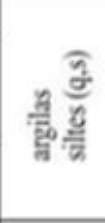 } & \multirow{3}{*}{ 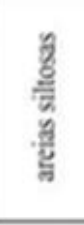 } & \multirow{3}{*}{ 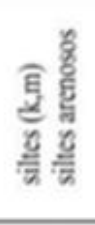 } & \multirow{3}{*}{ 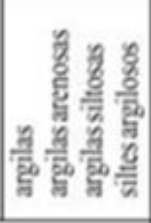 } & \multirow{3}{*}{ 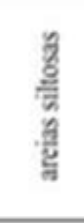 } & \multirow{3}{*}{ 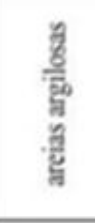 } & \multirow{3}{*}{ 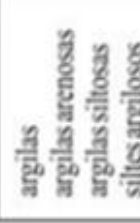 } \\
\hline \multicolumn{3}{|c|}{$\begin{array}{l}\text { Designapoes do T1-71 do DER-SP } \\
\text { (equivaientes da Mississipi Rivor } \\
\text { Commission, USA) }\end{array}$} & & & & & & & \\
\hline \multicolumn{3}{|c|}{$\begin{array}{l}k=\text { caolinitico } \\
p=\text { sericitico }\end{array}$} & & & & & & & \\
\hline \multicolumn{3}{|c|}{ COMPORTAMENTO } & \multicolumn{4}{|c|}{$N=$ Nab Lateritio } & \multicolumn{3}{|c|}{$\mathrm{L}=\mathrm{Lateriti \infty}$} \\
\hline \multicolumn{3}{|c|}{ GRUPO MCT } & NA & NA & NS & NG & LA & LA' & LG \\
\hline \multirow{6}{*}{ 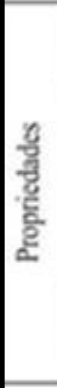 } & $\begin{array}{l}\text { MINI- } \\
\text { CBR (\%) }\end{array}$ & $\begin{array}{c}\text { sem imersib } \\
\text { perda por imersab }\end{array}$ & $\begin{array}{l}\mathrm{M}, \mathrm{E} \\
\mathrm{B}, \mathrm{M}\end{array}$ & $\begin{array}{l}\mathrm{E} \\
\mathrm{B}\end{array}$ & $\underset{\mathrm{E}}{\mathrm{M}, \mathrm{E}}$ & $\begin{array}{l}\mathrm{E} \\
\mathrm{E}\end{array}$ & $\begin{array}{l}\mathrm{E} \\
\mathbf{B}\end{array}$ & $\begin{array}{c}\text { E, EE } \\
\text { B }\end{array}$ & $\begin{array}{l}\mathrm{E} \\
\mathrm{B}\end{array}$ \\
\hline & EXPANSÁO & & B & B & E & $\mathrm{M}, \mathrm{E}$ & B & B & B \\
\hline & CONTRAÇA & & B & B. M & M & M, E & B & B, M & M, E \\
\hline & COEF. DE & PERMEABILIDADE (k) & $\mathrm{M}, \mathrm{E}$ & B & B, M & B, M & B, M & B & B \\
\hline & COEFICIEN & TE DE SORÇĀO & $E$ & B, M & E & $\mathrm{M}, \mathrm{E}$ & B & B & B \\
\hline & \multicolumn{2}{|c|}{$\begin{array}{l}\text { Corpos de prova compectados na } \\
\text { mases especifica aparente seca mb́cima } \\
\text { da energia norma }\end{array}$} & \multicolumn{3}{|c|}{$\begin{array}{l}E E=\text { Muito Elevado (a) } \\
E=\text { Elevado (a) }\end{array}$} & \multicolumn{2}{|c|}{$\begin{array}{l}M=\text { Médio }(a) \\
B=B a \times o(a)\end{array}$} & \multicolumn{2}{|c|}{$\begin{array}{l}\text { Vide Tabeia III. } 3 \\
\text { para equivalente } \\
\text { numerico }\end{array}$} \\
\hline \multirow{6}{*}{ 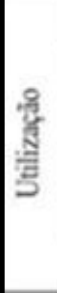 } & \multicolumn{2}{|c|}{ Base de pavimento } & n & $4^{\circ}$ & n & n & $2^{\circ}$ & $1^{\circ}$ & $3^{\circ}$ \\
\hline & \multicolumn{2}{|c|}{ Reforgo do subleito compactado } & $4^{\circ}$ & $5^{\circ}$ & n & n & $2^{\circ}$ & $1^{\circ}$ & $3^{\circ}$ \\
\hline & \multicolumn{2}{|c|}{ Subleito compactado } & $4^{\circ}$ & $5^{\circ}$ & 70 & $6^{\circ}$ & $2^{\circ}$ & $1^{\circ}$ & $3^{\circ}$ \\
\hline & \multicolumn{2}{|c|}{ Aterro (corpo) compactado } & $4^{\circ}$ & $5^{\circ}$ & $6^{\circ}$ & 70 & $2^{\circ}$ & $1^{\circ}$ & $3^{\circ}$ \\
\hline & \multicolumn{2}{|c|}{ Proteglo à crosto } & n & $3^{\circ}$ & n & $n$ & $\mathbf{n}$ & $2^{\circ}$ & $1^{\circ}$ \\
\hline & \multicolumn{2}{|c|}{ Revestimento primário } & $5^{\circ}$ & $3^{\circ}$ & n & $\mathbf{n}$ & $4^{\circ}$ & $1^{\circ}$ & $2^{\circ}$ \\
\hline
\end{tabular}


Tabela 3-5 - Ensaios e determinações da classificação MCT, e propriedades físicas associadas (VILLIBOR et al., 2009).

\begin{tabular}{|c|c|c|}
\hline $\begin{array}{c}\text { ENSAIO E } \\
\text { DETERMINAÇŌES }\end{array}$ & $\begin{array}{l}\text { PROPRIEDADES FÍSICAS } \\
\text { ASSOCIADAS }\end{array}$ & PROVÁVEIS DEFEITOS \\
\hline Mini-CBR & Capacidade de Suporte (Previsão) & $\begin{array}{l}\text { - Deformação Excessiva } \\
\text { - Ruptura do Pavimento }\end{array}$ \\
\hline Expansão & Aumento de Volume com Teor de Umidade & $\begin{array}{l}\text { - Deformação da Base } \\
\text { - Trincas da Capa }\end{array}$ \\
\hline $\begin{array}{l}\text { Coeficiente de Sucção } \\
\text { Capilar D’água }\end{array}$ & $\begin{array}{l}\text { Ve locidade de Penetração da Frente de } \\
\text { Umidade e Qua ntidade de Água Associada } \\
\text { a Penetraçăo dessa Frente }\end{array}$ & $\begin{array}{l}\text { - Amolecimento da Parte Supe rior da Base na Época } \\
\text { de Construção de vido às Chuvas } \\
\text { - Amolecimento da Borda } \\
\text { - Drenabilidade Lenta e Problemas Construtivos } \\
\text { Associados } \\
\text { - Crescimento das Panelas }\end{array}$ \\
\hline Permeabilidade & Percolação da Água & - Não Drenante \\
\hline Contração & Contração da Base & $\begin{array}{l}\text { - Desagregação pelo Trânsito de Serviço } \\
\text { - Trincas de Reflexão na Capa } \\
\text { - Entrada Excessiva Dágua na Base e Suble ito }\end{array}$ \\
\hline Compactaçăo & $\begin{array}{l}\text { Gra u de Compactação do Material em } \\
\text { Relação a Umidade Ótima }\end{array}$ & $\begin{array}{l}\text { - Deformação Excessiva } \\
\text { - Lamelas } \\
\text { - Ruptura do Pavimento } \\
\text { - Trincamentos Excessivos }\end{array}$ \\
\hline Penetração da Imprimadura & $\begin{array}{l}\text { Espessura e Quantidade de Material } \\
\text { Betum inoso Penetra do }\end{array}$ & $\begin{array}{l}\text { - Escorregamento da Camada de Rolamento } \\
\text { - Exsudação de Asfalto na Superfície do Pavimento }\end{array}$ \\
\hline Mini-CBR in situ & Capacidade (Real) de Suporte & $\begin{array}{l}\text { - Deformação Excessiva } \\
\text { - Ruptura doPavimento }\end{array}$ \\
\hline $\begin{array}{l}\text { Razão: Mini -CBR na } \\
\text { Umidade de Moldagem / } \\
\text { Mini-CBR Após Imersão }\end{array}$ & $\begin{array}{l}\text { Diminuição da Capacidade com Aumento } \\
\text { da Umida de }\end{array}$ & $\begin{array}{l}\text { - Deformação da Base na Época de Construçăo } \\
\text { devido às Chuvas } \\
\text { - Deformação Excess iva na Borda do Pavimento } \\
\text { devido a Pene traçăo Lateral da Água } \\
\text { - Ruptura do Pavimento em Capas Permeá ve is }\end{array}$ \\
\hline
\end{tabular}

\subsection{Reposição de cobertura vegetal}

Solos que podem ser utilizados para reposição de cobertura vegetal são listados a seguir (SEPA, 2010):

- não contaminado, proveniente de área não desenvolvida - solos em seu estado natural, em geral, apresentam características físicas, como permeabilidade, estrutura, densidade do solo e índice de vazios, desejáveis para recomposição de cobertura vegetal (ANDREOLA et al., 2000);

- não contaminado, proveniente de áreas agrícolas e florestais; e

- não contaminado estéril, proveniente de novas minas e pedreiras. 
Além dos solos, outros materiais são empregados na recomposição da cobertura vegetal, tais como grama, turfa, palha e restos de folhas (não inclui tocos de árvores) - resíduos vegetais - que irão constituir o húmus, influenciando propriedades físicas, químicas e biológicas do solo (PINHEIRO et al., 2008).

Solos arenosos apresentam limitações para recomposição da cobertura vegetal, pois, em geral, apresentam baixa fertilidade natural, presença de alumínio em forma tóxica e baixo teor de matéria orgânica, responsável pela maior parte da capacidade de troca catiônica (CTC - cargas negativas existentes no solo e provenientes principalmente dos argilominerais e da matéria orgânica). Além disso, os baixos teores de matéria orgânica aliados aos baixos teores de argila e à estrutura desses solos, com grande volume de macroporos, determinam sua baixa retenção de água (SANTOS \& ALBUQUERQUE FILHO, 2007).

Nesse contexto, a acidez dos solos favorece o aparecimento de alumínio em forma tóxica e diminui a disponibilidade de nutrientes, assim, faz-se necessária correção do pH do solo entre 6,0 - 6,5 (LOPES, 1990).

\subsection{Critérios técnicos para reuso de solos de escavação}

O reuso de materiais de escavação deve considerar as propriedades geotécnicas do material, que dependem de suas características físicas (distribuição granulométrica, estado, composição química e mineralógica) e propriedades mecânicas (resistência, deformabilidade, permeabilidade). A Tabela 3-6 apresenta os principais critérios técnicos para reuso de solos em obras de terra. 
Tabela 3-6 - Relação dos principais critérios técnicos para reuso de solos em obras de terra.

\begin{tabular}{|c|c|}
\hline Obra de terra & $\begin{array}{l}\text { Critérios técnicos a serem avaliados (parâmetros de } \\
\text { referência) }\end{array}$ \\
\hline Reaterro de vala & $\begin{array}{l}\text { Resistência ao cisalhamento (coesão e ângulo de atrito) } \\
\text { Expansão e perda de resistência por molhagem } \\
\text { Grau de compactação (densidade seca e umidade ótima) } \\
\text { Distribuição granulométrica }\end{array}$ \\
\hline Muros de solo reforçado & $\begin{array}{l}\text { Resistência ao cisalhamento (coesão e ângulo de atrito) } \\
\text { Expansão e perda de resistência por molhagem } \\
\text { Deformabilidade }\end{array}$ \\
\hline Barragens de terra & $\begin{array}{l}\text { Compressibilidade (adensamento) } \\
\text { Resistência ao cisalhamento (coesão e ângulo de atrito) } \\
\text { Grau de compactação (densidade seca e umidade ótima) } \\
\text { Expansão e perda de resistência por molhagem } \\
\text { Coeficiente de permeabilidade } \\
\text { Erodibilidade }\end{array}$ \\
\hline Pavimentos & $\begin{array}{l}\text { Expansão } \\
\text { CBR (resistência à penetração e expansão) } \\
\text { Distribuição granulométrica }\end{array}$ \\
\hline $\begin{array}{l}\text { Reposição de cobertura } \\
\text { vegetal }\end{array}$ & $\begin{array}{l}\text { Teor de alumínio } \\
\text { Teor de matéria orgânica } \\
\text { Teor de argila } \\
\text { Capacidade de troca catiônica } \\
\text { Coeficiente de permeabilidade } \\
\text { Teor de umidade } \\
\text { pH }\end{array}$ \\
\hline Drenagem & $\begin{array}{l}\text { Distribuição granulométrica } \\
\text { Perda de resistência por molhagem }\end{array}$ \\
\hline
\end{tabular}




\section{PROGRAMA EXPERIMENTAL}

Como parte do programa experimental do estudo, 35 (trinta e cinco) amostras representativas de resíduos de escavação foram coletadas em um aterro de RCC localizado na RMSP (Figura 4-1). Dentre elas, 8 (oito) amostras foram aleatoriamente selecionadas e visualmente classificadas como predominantemente solos de escavação (RCC-solo) ou misturas de RCC (RCC-mistura) (Figura 4-1). As amostras também foram submetidas a ensaios de caracterização química, mineralógica, ambiental e geotécnica (Figura 4-1); as amostras RCC-solo também foram submetidas à classificação MCT para caracterização geotécnica de solos tropicais (NOGAMl; COZZOLINO; VILLIBOR, 1990). Os resultados foram confrontados com os principais critérios técnicos e ambientais para reusos de solos de escavação.

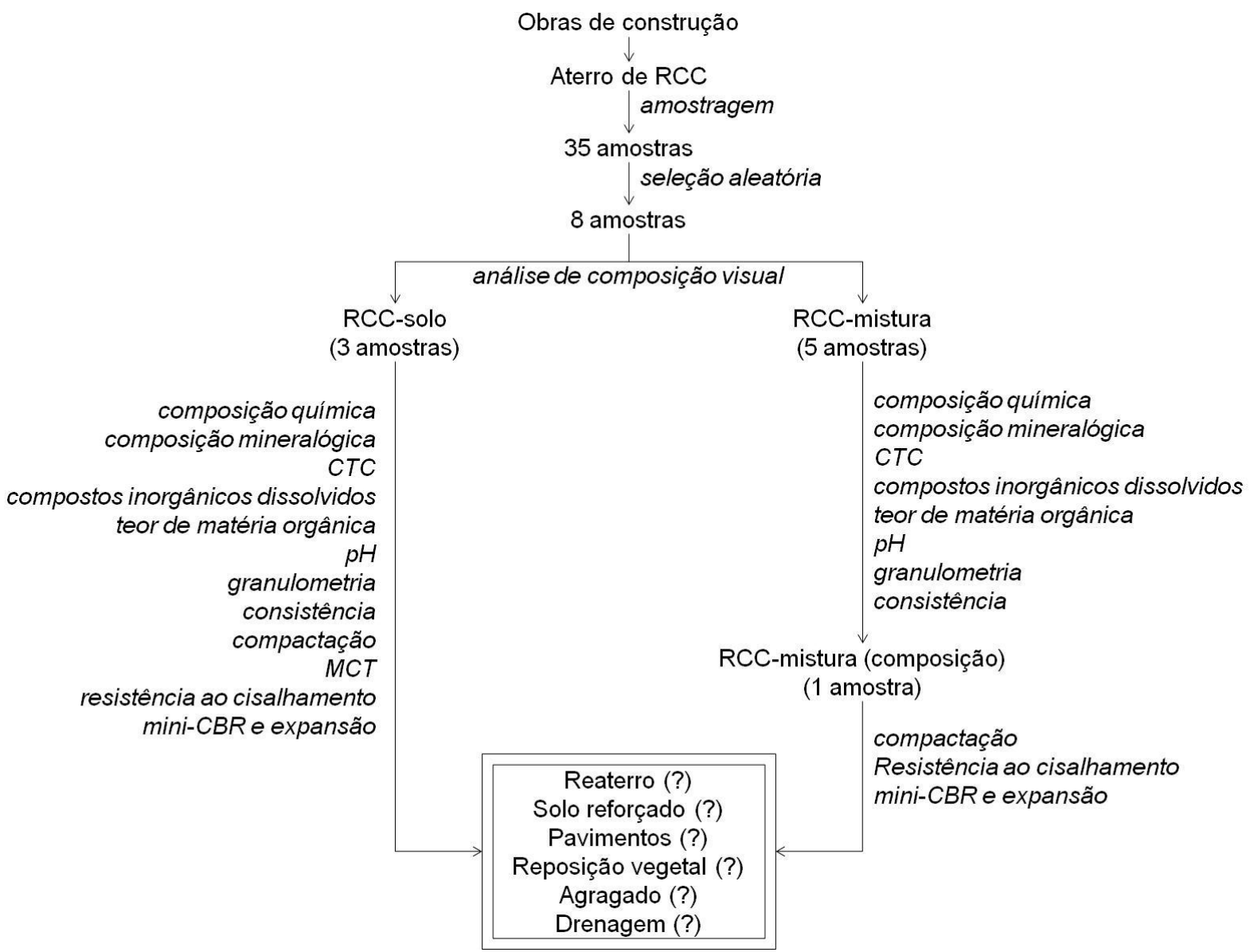

Figura 4-1 Programa experimental. 


\subsection{Amostragem}

\subsubsection{Coleta de amostras no aterro de RCC}

As amostras foram coletadas na Central de Tratamento de Resíduos de Construção Civil (CTR-Grajau), que atende a toda Zona Sul e parte da Zona Oeste do município de São Paulo-SP, além de Embu-SP, Embu Guaçu-SP, Itapecerica da Serra-SP e Grande ABC. No período de amostragem, o aterro estava recebendo resíduos de escavação e demolição de obras das Prefeituras de diversas localidades, e solos de escavação das obras de fundação do Complexo Parque da Cidade, zona sul de São Paulo-SP.

As amostras foram coletadas logo após a descarga do caminhão de forma aleatória (Figura 4-2). O volume de solo (em formato de pilha cônica) foi espalhado em uma área $5 \mathrm{~m} \times 5 \mathrm{~m}$, que resultou em uma camada de material de 0,3 $\mathrm{m}$ de espessura. A área foi subdividida em 16 partes iguais, das quais amostras foram coletadas de diferentes posições definidas aleatoriamente, abrangendo toda espessura da camada. Esse procedimento altera a dimensionalidade do lote de material (de 3D para 2D), garantindo melhor representatividade na amostragem (PETERSEN; MINKKINEN; ESBENSEN, 2005).

Figura 4-2 Desenho esquemático da coleta das amostras.

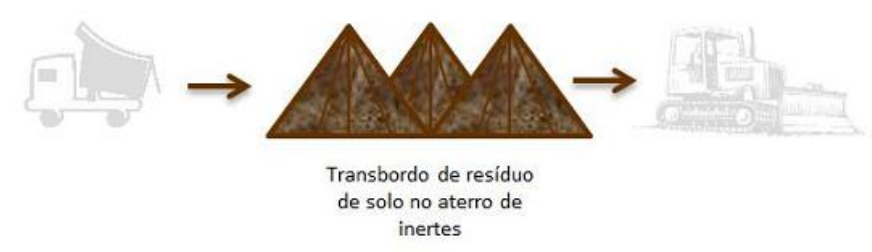

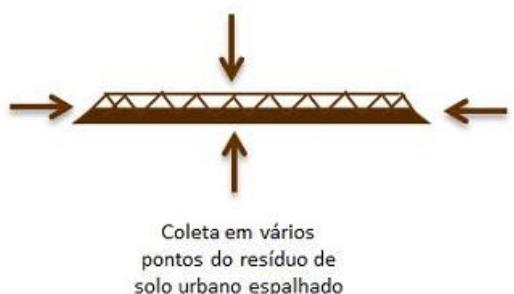

solo urbano espalhado

O programa consistiu em 3 (três) amostragens por semana (segundas, quartas e sextas-feiras), durante 12 (doze) semanas (de outubro a dezembro/2014), preenchendo-se um recipiente plástico de 40 (quarenta) litros por dia (aproximadamente $40 \mathrm{~kg}$ de material), totalizando 35 amostras coletadas. 


\subsubsection{Preparação de amostras para ensaios laboratoriais}

Entre as amostras coletadas, identificou-se a possibilidade de que uma sequência de amostras poderiam ser originadas de uma mesma obra. Assim, 8 (oito) dentre as 35 amostras foram aleatoriamente selecionadas para condução dos ensaios de caracterização (PETERSEN; MINKKINEN; ESBENSEN, 2005). No Laboratório de Materiais de Construção Civil do Instituto de Pesquisas Tecnológicas do Estado de São Paulo (LMCC/IPT) os materiais de cada amostra foram secos ao ar, sem exposição direta ao sol, até atingir a umidade higroscópica (umidade de equilíbrio com o ar atmosférico) (Figura 4-3 ).

A massa inicial coletada (aproximadamente $40 \mathrm{~kg}$ ) foi reduzida às massas necessárias para execução dos ensaios (em torno de $10 \mathrm{~kg}$ ), usando o quarteador de amostras do tipo riffle splitter ("Jones") (Figura 4-4) (PETERSEN; MINKKINEN; ESBENSEN, 2005). Dessas massas reduzidas, $2 \mathrm{~kg}$ foram submetidos às análises química, mineralógica e ambiental e os outros $8 \mathrm{~kg}$ às análises de caracterização geotécnica.

Diante da heterogeneidade do material, o planejamento da coleta das amostras e a redução de massas por quarteamento foram considerados fundamentais neste trabalho.

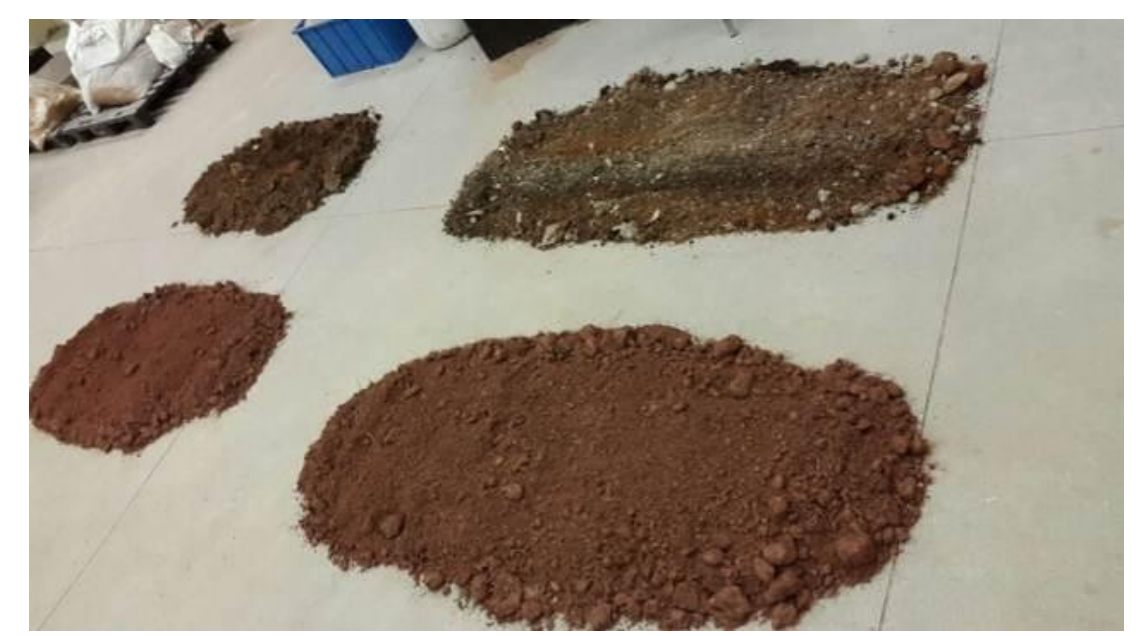

Figura 4-3 Secagem dos solos. 


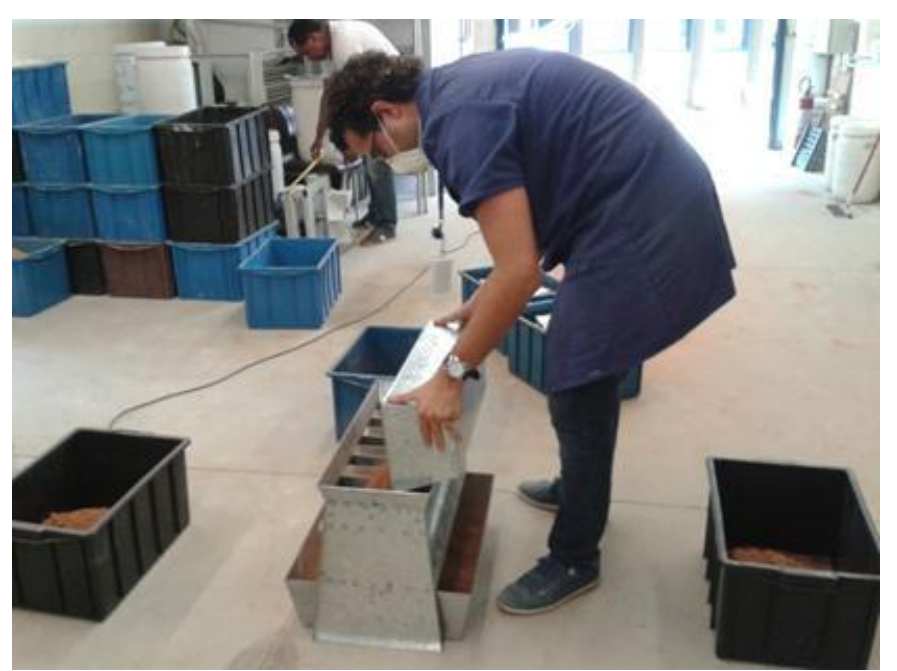

Figura 4-4 Quarteamento de amostras com quarteador tipo Jones.

\subsection{Composição visual}

As amostras foram classificadas por observação visual, de acordo com 0 material predominante: i) solos de escavação (RCC-solo), ou ii) mistura de solos com outros tipos de RCC (fragmentos de materiais cimentícios, de telhas, de blocos de cerâmica vermelha, etc) (RCC-mistura) (Figura 4-7).

As amostras RCC-mistura foram divididas, por peneiramento mecânico, em 4 (quatro) frações granulométricas: 2,0-1,2 mm; 1,2-0,6 mm; 0,6-0,4 mm; e 0,40,1 mm. A massa mínima representativa foi calculada com coeficiente de variação de $10 \%$ para cada fração granulométrica (Apendice / Tabela A-1) (ANGULO; MUELLER, 2008; PETERSEN; MINKKINEN; ESBENSEN, 2005). As massas de cada fração das amostras foram reduzidas à massa mínima representativa com uso do quarteador rotativo para partículas finas (Figura 4-5) (PETERSEN; MINKKINEN; ESBENSEN, 2005).

As frações com as massas reduzidas das amostras foram analisadas no Laboratório de Microestrutura da Escola Politécnica da Universidade de São Paulo (EP/USP) por meio de imagens ampliadas (Apêndice /Tabela A-2 e Tabela A-3) obtidas a partir de um microscópio digital Hirox Auto XY Stage (modelo XY-GE-US) composto de câmera, lentes e objetivas com aumento de até 400 vezes (Figura 4-6). Para frações de 2,0 a 0,6 mm utilizou-se aumento de 50 vezes, e de 0,6 a 0,4 mm aumento de 100 vezes; a iluminação do microscópio foi mantida sempre constante com tempo de exposição de 1/250 s. 


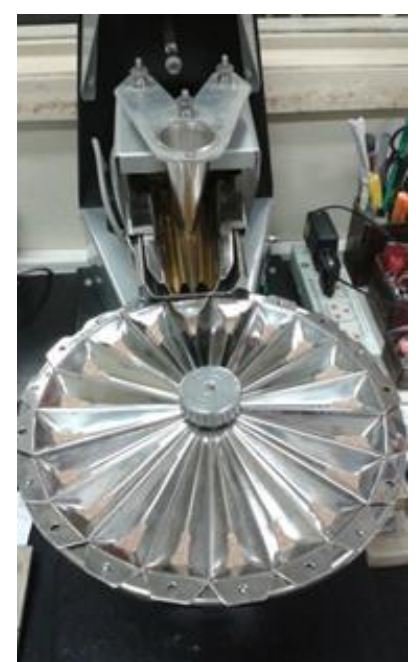

Figura 4-5 Quarteamento de amostras com quarteador rotativo.

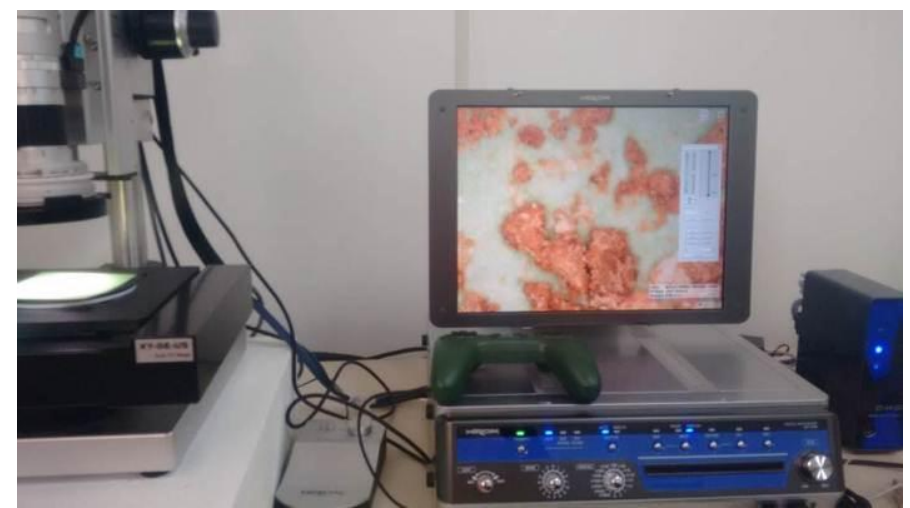

Figura 4-6 Hirox Auto XY Stage (XY-GE-US).

O critério de análise microscópica para detecção de materiais cimentícios não pode ser aplicado em grãos menores que $0,4 \mathrm{~mm}$ devido à dificuldade em distinguir grãos com materiais cimentícios de grãos de feldspatos, uma vez que ambos apresentaram coloração cinza.

Em cada imagem do microscópio, os grãos foram individualmente numerados e classificados como: i) naturais (grãos sem pasta de cimento) ou ii) materiais cimentícios (grãos com pasta de cimento). A seguir, foi feita a contagem um a um dos grãos, classificando-os como naturais (imagens sem manchas) ou cimentícios (imagens com manchas), conforme mostra a Figura 4-8a. Apesar de simples, este procedimento possui limitação, pois partículas cerâmicas (Figura 4-8b) podem ser visualmente similares a grãos de solo (Figura 4-8c). Grãos com diâmetro maior do que 2,0 mm foram classificados por observação 
direta (sem microscópio). Ressalta-se que os grãos observados em microscópio e a olho nu foram previamente lavados em água corrente para eliminação de pós aderidos à superfície dos grãos, dado que a presença de pós dificulta a análise visual dos grãos.

(a)

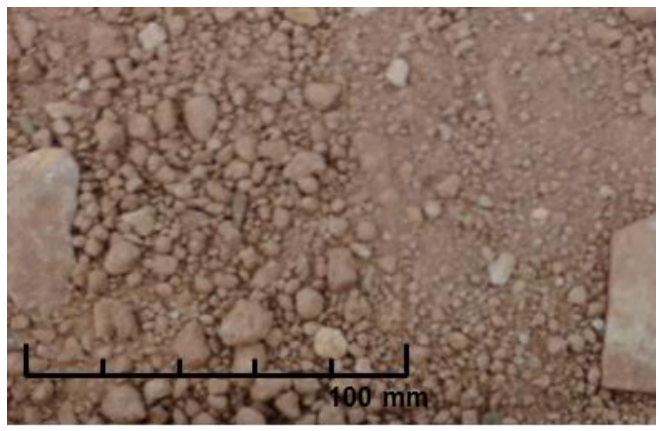

(c)

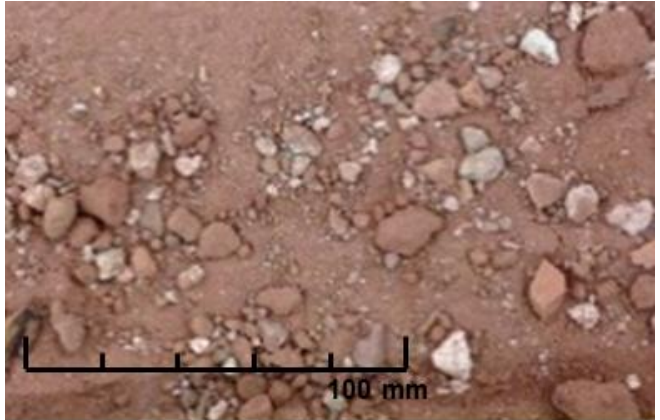

(e)
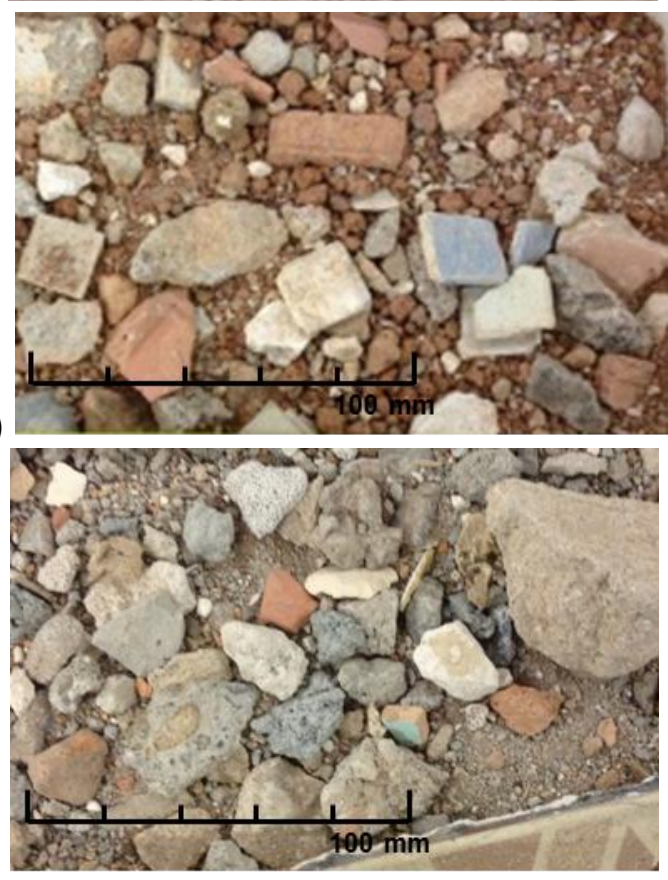

(b)

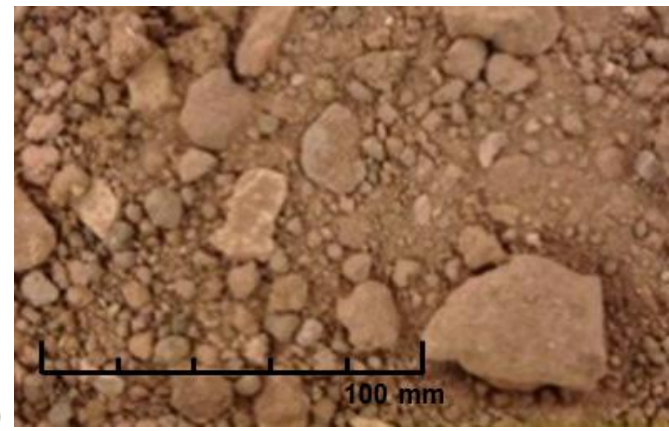

(d)

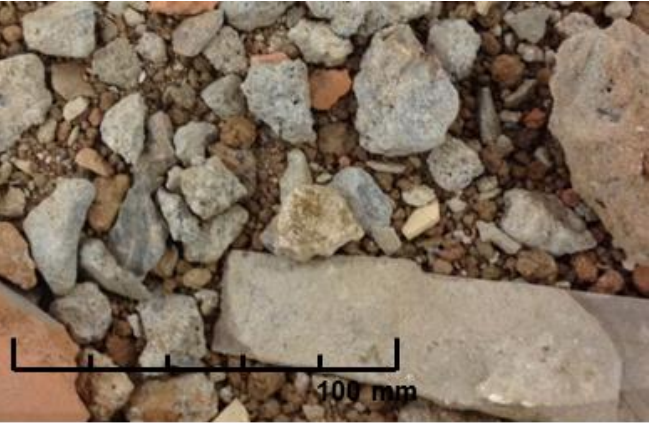

(f)

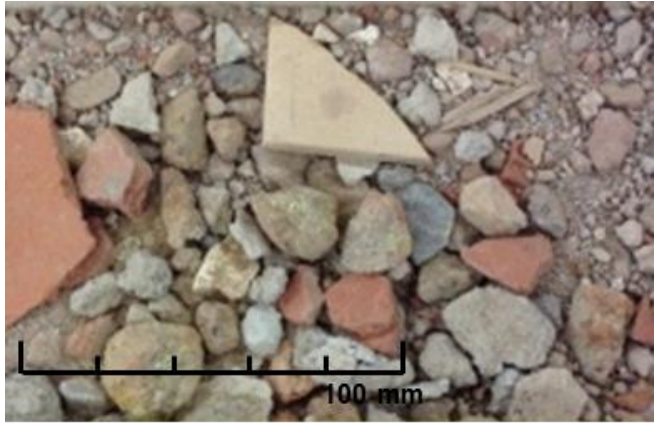

(h)

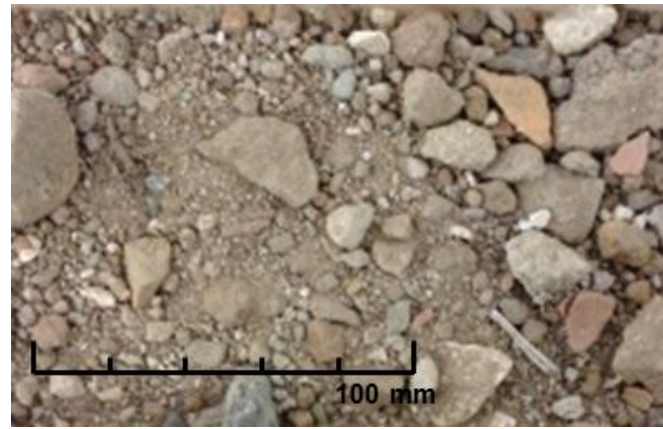

Figura 4-7. Classificação visual preliminar de amostras (a) B-23, (b) B-15 e (c) B-7 com predominância de solos, e amostras (d) B-12, (e) B-4, (f) B-5, (g) B-19 e (h) B-22 constituídas por misturas de solos e outros tipos de RCC (majoritariamente materiais cimentícios). 
(a)

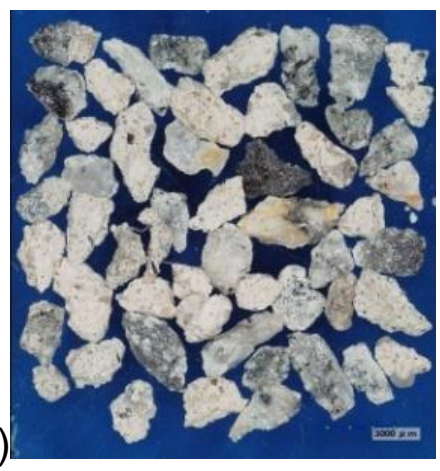

(b)

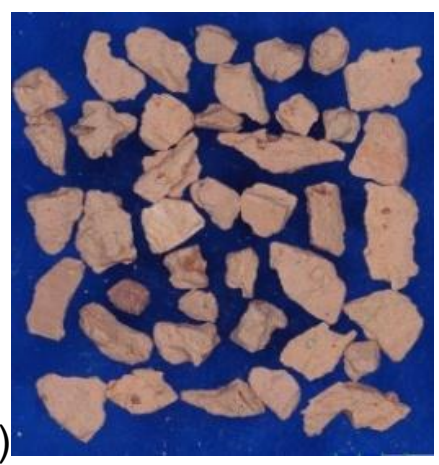

(c)

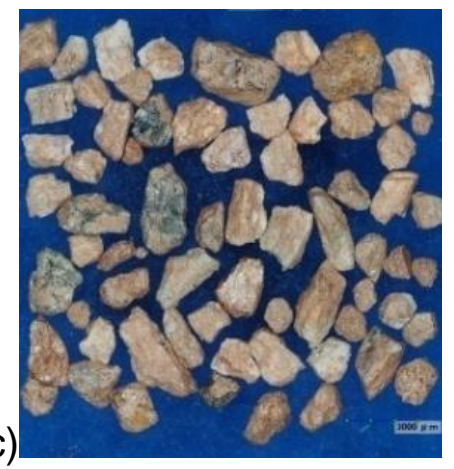

4-8. Observac̃ão em microscópio digital de: (a) grãos de cimento com diâmetro entre $0,6 \mathrm{~mm}$ e $0,4 \mathrm{~mm}$, (b) grãos cerâmicos com diâmetro entre $0,6 \mathrm{~mm}$ e $0,4 \mathrm{~mm}$, e (c) grãos de solo com diâmetro entre $1,2 \mathrm{~mm}$ e $0,6 \mathrm{~mm}$.

\subsection{Caracterização química e mineralógica}

A composição química das amostras foi determinada, no LMCC/IPT, por fluorescência de raios-x (FRX), equipamento Panalytical (modelo Minipal Cement) seguindo diretrizes gerais da ISO/FDIS 29581-2:2009 (E) "Cement Test Methods - Part 2: Chemical analysis by X-ray fluorescence". O ensaio foi realizado a partir de pastilhas fundidas em máquina de fusão marca Claisse modelo M4, utilizando-se fundentes à base de mistura de tetraborato de lítio/metaborato de lítio marca MAXXIFLUX $\left(66,67 \%\right.$ de $\mathrm{Li}_{2} \mathrm{~B}_{4} \mathrm{O}_{7}, 32,83 \%$ de $\mathrm{LiBO}_{2}$ e $0,50 \%$ de $\mathrm{LiBr}$ ), com proporção de $0,6 \mathrm{~g}$ de amostra calcinada e $6,75 \mathrm{~g}$ de fundente. Os resultados são estimados por análise semiquantitativa utilizando-se padrões internos do fabricante e a curva denominada "OMNIAN" e foram normalizados a $100 \%$ na base volátil.

A análise mineralógica das amostras foi realizada por método de difração de raios-x (DRX) no LMCC/IPT, com equipamento Rigaku (modelo Windmax 2000), operando na radiação $K \alpha$ do cobre com $40 \mathrm{kV}-30 \mathrm{~mA}$ e varredura de $0.5 \% \mathrm{~min}$.

A identificação dos compostos foi obtida pelo método de relação de intensidade de referência (RIR) utilizando o fator de escala e valores RIR do ICCD (International Center for Diffraction Data) e o software X-pert HighScore Plus versão 2.2 (Panalytical ${ }^{\mathrm{TM}}$ ).

As amostras também foram submetidas ao ensaio de azul de metileno para determinação da capacidade de troca catiônica (CTC) (ASTM C837-09). 


\subsection{Caracterização ambiental}

Foram realizados ensaios de determinação do $\mathrm{pH}$, teor de matéria orgânica (perda de massa por ignição) e concentração de compostos dissolvidos em extrato solubilizado (ABNT, 2004b). Devido ao período entre coleta, armazenamento, preparo e ensaio das amostras (mais de um ano), não foram analisados os compostos orgânicos.

\subsection{Caracterização geotécnica}

As 8 (oito) amostras de residuos de escavação (solos e misturas) foram submetidas às análises de distribuição granulométrica (peneiramento e sedimentação) e limites de consistência, para classificação como materiais geotécnicos, de acordo com o Sistema Unificado de Classificação de Solos (SUCS, do inglês). As 3 amostras RCC-solo também foram submetidas à classificação MCT, desenvolvida para caracterização geotécnica de solos tropicais (NOGAMI; COZZOLINO; VILLIBOR, 1990).

Ensaios de compactação, resistência ao cisalhamento direto e mini-CBR foram realizados para determinar as propriedades geotécnicas dos materiais. As 3 amostras RCC-solo foram testadas individualmente. As 5 amostras RCCmistura foram misturadas e tratadas como uma única amostra - RCC-mistura (composição), uma vez que misturas de RCC são comumente dispostas e gerenciadas sem segregação em usinas de reciclagem.

- distribuição granulométrica: curvas de distribuição granulométrica conforme procedimento padrão (ABNT, 1995; ASTM, 2009). Os resultados auxiliam a previsão do comportamento geotécnico do solo; por exemplo, pedregulhos tendem a ser resistentes com comportamento friccional, enquanto siltes e argilas possuem baixa permeabilidade.

- índices de consistência: a capacidade de expansão, contração e compressibilidade de solos finos está relacionada ao limite de plasticidade (ABNT, 2016a; ASTM, 2010) e limite de liquidez (ABNT, 2016b; ASTM, 2010). Siltes não são coesivos, enquanto 
argilas tendem a expandir e contrair de acordo com teor de umidade.

- compactação: diferentes tipos de solo resultam em diferentes curvas de compactação. De forma geral, solos argilosos apresentam densidade seca máxima baixa e umidade ótima elevada; solos arenosos apresentam densidade seca máxima alta e umidade ótima baixa, e solos siltosos apresentam valores intermediários (MASSAD, 2010; TERZAGHI; PECK; MESRI, 1996). Foi utilizada energia de compactação Proctor Normal nos ensaios (ABNT, 2016c; ASTM, 2012). A compactação é utilizada para melhorar as propriedades de engenharia do solo - maior resistência, menores deformabilidade e permeabilidade.

- classificação MCT (Miniatura, Compactada, Tropical): método complementar (DNER, 1996) às tradicionais classificações geotécnicas, adaptado das classificações geotécnicas tradicionais (AASTHO, HRB e USCS), desenvolvido por Nogami \& Villibor (1995) para o estudo de solos tropicais para aplicação em pavimentação e, eventualmente, outros tipos de obras com solos compactados. O método classifica os materiais de acordo com as propriedades de resistência, deformabilidade e permeabilidade de corpos de prova compactados, com dimensões reduzidas. Solos de comportamento laterítico são menos suscetíveis à erosão e, quando compactados adequadamente, apresentam baixa permeabilidade e, mesmo quando imersos em água, elevadas resistência e capacidade de suporte (NOGAMI; VILLIBOR, 1995). Assim, podem ser utilizados em aterros, proteção de taludes contra erosão, estruturas de pavimentos como reforços de subleito, subbase e bases (GODOY; BERNUCCI, 2002).

- resistência ao cisalhamento: 0 ensaio de resistência ao cisalhamento direto (ASTM, 2011) fornece a envoltória de resistência de Mohr-Coulomb, isto é, os parâmetros de resistência mecânica - coesão e ângulo de atrito -, fundamentais para 
projetos de estruturas de terra. As amostras foram compactadas no ponto de umidade ótimo sob energia de Proctor Normal, moldadas em caixa de seção transversal quadrada de $5 \mathrm{~cm}$ de lado e $2 \mathrm{~cm}$ de altura, saturadas, consolidadas por aplicação de tensão normal e testadas a uma velocidade de deslocamento constante de 4 $\mathrm{mm} / \mathrm{h}$. Para cada amostra, 3 (três) ensaios foram realizados com tensões normais de 100, 200 e 400 kPa.

- mini-CBR (California Bearing Ratio) e expansão após imersão: 0 ensaio mini-CBR (ABNT, 2016d) é uma adaptação do ensaio CBR (ABNT, 1987; ASTM, 2016) - utilizado para construção de rodovias - para corpos de prova de dimensões reduzidas, e determina a resistência à penetração e o comportamento expansivo do material. O Mini-CBR sem imersão, que mostraria a perda de capacidade de suporte por saturação, não foi realizado por falta de material. Optou-se, portanto, por investigar a situação mais desfavorável do ponto de visto de solicitação que seria o material saturado. Procurou-se realizar os ensaios com corpos de prova em três situações em termos de umidade de compactação: i) ramo seco,ii) teor de umidade ótima e iii) ramo úmido, ou seja, desvios de umidade de $\pm 2 \%$ em relação ao teor ótimo.

\subsection{Proposição de fluxograma de triagem para potenciais reusos}

A partir da revisão bibliográfica identificaram-se os principais critérios ambientais para reuso de solos e as obras de terra e infraestrutura urbanas com os respectivos critérios técnicos dos materiais utilizados para construção.

Realizou-se estudo de caracterização ambiental e geotécnica de resíduos de escavações destinados a um aterro de RCC, cujos resultados foram confrontados com os principais critérios técnicos e ambientais para reuso de solos em obras de terra e infraestrutura urbana. A seguir, determinaram-se os potenciais reusos dos materiais de escavação estudados. 
Para cada um dos potenciais reusos identificados, elaborou-se um fluxograma de triagem considerando os respectivos critérios técnicos para seleção do material a ser utilizado.

Elaborou-se então um único fluxograma de triagem com base nos principais critérios técnicos para todos os possíveis reusos sugeridos aos materiais de escavação estudados.

\section{RESULTADOS DA CARACTERIZAÇÃO DOS MATERIAIS}

\subsection{Composição visual}

As amostras dos materiais foram identificadas como 'RCC-solo' ou 'RCCmistura' por análise visual preliminar, sendo $38 \%$ das amostras estudadas classificadas como 'RCC-solo', e 62 \% como 'RCC-mistura'.

A partir das imagens obtidas por microscopia foi realizada a contagem de grãos naturais (solo) ou cimentícios (Apêndice / Tabela A-2 e Tabela A-3). Diferentemente do que se esperava, a porcentagem de materiais cimentícios nas amostras não diminuiu necessariamente conforme diminuição da granulometria. Para as amostras RCC-solo B-4 e B-12, foi possível identificar que em torno de $50 \%$ da fração com diâmetro menor do que $2,0 \mathrm{~mm}$ é composta por solos (silte, argila e areia). Nas outras 3 amostras RCC-mistura, a porcentagem de solo nas frações estudadas não foi significativa (Figura 5-1).

Em grãos com diâmetro maior do que 2,0 mm observou-se a predominância de material natural (solo) nas amostras RCC-solo (Figura 4-7 a, b, c), e predominância de material artificial (cerâmicos e cimentícios) nas amostras RCC-mistura (Figura 4-7 d, e, f, g, h). 


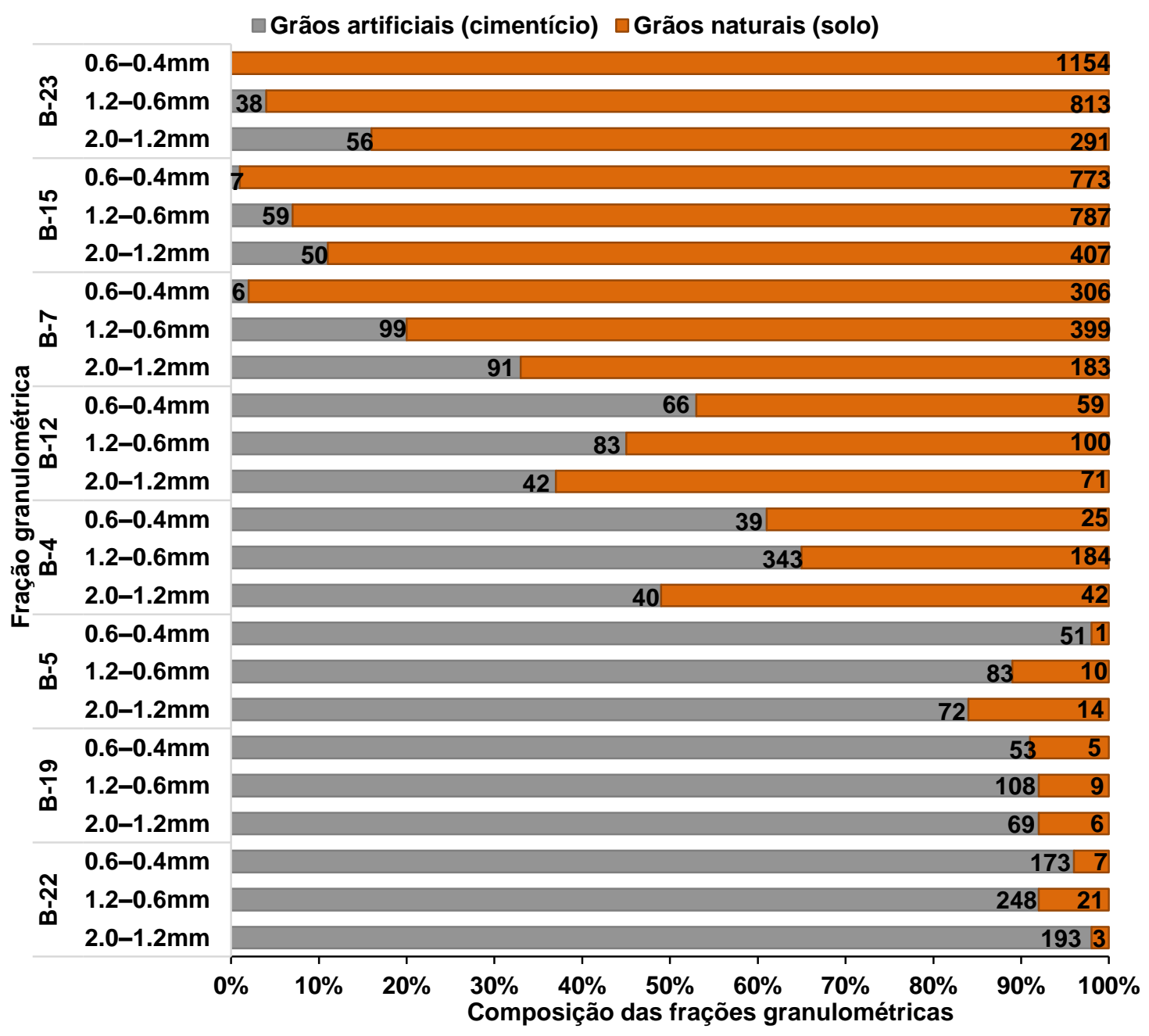

Figura 5-1. Composição das amostras em termos de grãos naturais ou artificiais, com diâmetro entre 2,0 e $0,4 \mathrm{~mm}$, por observação de imagens de microscopia. Os números nas barras indicam as quantidades de grãos naturais ou artificiais em cada fração, contadas individualmente.

\subsection{Composição química e mineralógica}

Solos são compostos por minerais como silicatos (quartzo, mica, feldspato, argilominerais, óxidos-hidróxidos (hematita, goetita, gibbsita) e uma fração menor de matéria orgânica (MIRSAL, 2008). Calcita está presente de forma mais significativa em materiais cimentícios e calcários (ROJAS; CINCOTTO, 2013; SCRIVENER; SNELLINGS; LOTHENBACH, 2015; ULSEN et al., 2013).

As 3 (três) amostras de RCC-solo apresentaram maiores teores de caulinita, gibbsita, hematita e goethita do que as 5 (cinco) amostras da RCC-mistura (Figura 5-2 e Figura 5-3). Por outro lado, quanto maior o conteúdo de materiais cimentícios em cada amostra (Figura 5-1), maior o teor de calcita (Figura 5-3). Também foram identificados traços de dolomita na RCC-mistura B-19. 
As amostras RCC-solo apresentaram os maiores teores de sílica, e óxidos de alumínio e ferro (Tabela 5-1). As amostras RCC-mistura também apresentaram conteúdos significativos destes compostos, embora menores.

Observou-se que as amostras RCC-mistura apresentaram maior teor de $\mathrm{CaO}$ e $\mathrm{SO}_{3}$ do que as amostras RCC-solo, devido à presença de cimento, argamassas e materiais de gesso (ANGULO et al., 2009; JANG; TOWNSEND, 2001, 2001; TOWNSEND; JANG; THURN, 1999; WAHLSTRÖM et al., 2000).

Todas as amostras apresentaram picos intensos de quartzo (Figura 5-2 e Figura 5-3), e elevado teor de sílica (Tablea 5-1), característicos de material cristalino não reativo, presente em solos siltosos e agregados de RCC.

Tabela 5-1 Composição química (\%) semi-quantitativa das amostras determinada por FRX.

\begin{tabular}{|c|c|c|c|c|c|c|c|c|}
\hline & \multicolumn{3}{|c|}{ "RCC-solo" } & \multicolumn{4}{|c|}{ "RCC-mistura" } & \multirow[b]{2}{*}{ B-22 } \\
\hline & B-23 & B-15 & B-7 & B-12 & B-4 & B-5 & B-19 & \\
\hline $\mathrm{SiO}_{2}$ & 64.20 & 67.5 & 71.5 & 56.8 & 61.6 & 70.8 & 69.5 & 72.0 \\
\hline $\mathrm{Al}_{2} \mathrm{O}_{3}$ & 17.10 & 10.2 & 10.9 & 12.0 & 13.5 & 8.4 & 5.9 & 9.7 \\
\hline $\mathrm{Fe}_{2} \mathrm{O}_{3}$ & 6.6 & 3.2 & 2.9 & 3.9 & 4.2 & 2.3 & 2.1 & 3.1 \\
\hline $\mathrm{CaO}$ & 0.3 & 4.9 & 3.7 & 8.1 & 4.2 & 5.8 & 8.8 & 3.8 \\
\hline $\mathrm{K}_{2} \mathrm{O}$ & 2.4 & 1.1 & 1.5 & 0.9 & 1.1 & 1.2 & 1.3 & 1.3 \\
\hline $\mathrm{MgO}$ & 0.2 & 1.0 & 0.5 & 0.3 & 0.5 & 0.8 & 1.0 & 0.5 \\
\hline $\mathrm{TiO}_{2}$ & 0.8 & 0.6 & 0.5 & 0.7 & 0.8 & 0.4 & 0.4 & 0.5 \\
\hline $\mathrm{SO}_{3}$ & 0.1 & 0.5 & 0.6 & 1.3 & 0.5 & 0.5 & 1.2 & 0.5 \\
\hline $\mathrm{MnO}$ & 1.1 & $<0.1$ & $<0.1$ & $<0.1$ & $<0.1$ & $<0.1$ & $<0.1$ & $<0.1$ \\
\hline Outros $^{a}$ & $<0.1$ & $<0.1$ & $<0.1$ & $<0.1$ & $<0.1$ & $<0.1$ & $<0.1$ & $<0.1$ \\
\hline Perda ao fogo ${ }^{b}$ & 6.8 & 10.9 & 7.8 & 16.0 & 13.4 & 9.7 & 9.5 & 8.4 \\
\hline
\end{tabular}




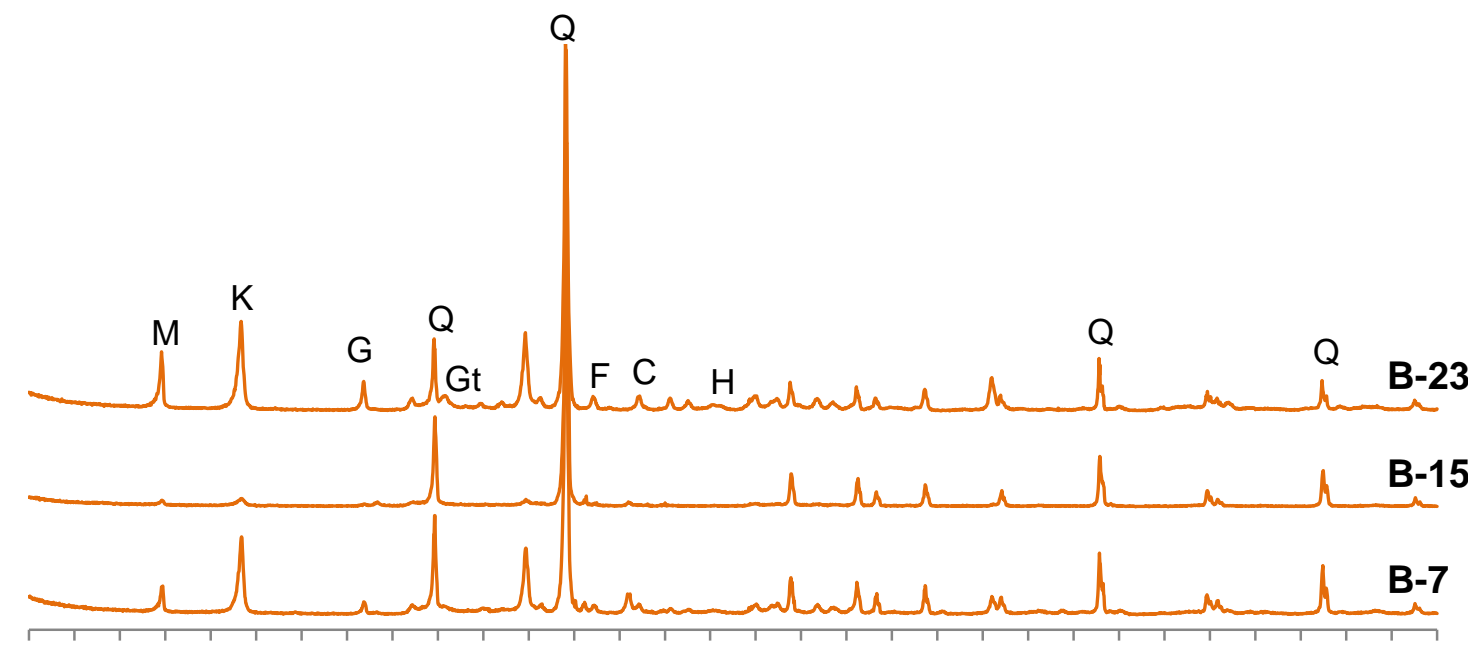

357911131517192123252729313335373941434547495153555759616365

Position [ ${ }^{\circ} 2 \theta$ CuKa]

Figura 5-2 Padrões DRX das amostras RCC-solo. São indicados os picos principais de caolinita $(K)$, muscovita $(M)$, quartzo $(Q)$, gibbsita $(G)$, feldspato $(F)$, hematita $(H)$, goethita (Gt) e calcita (C).

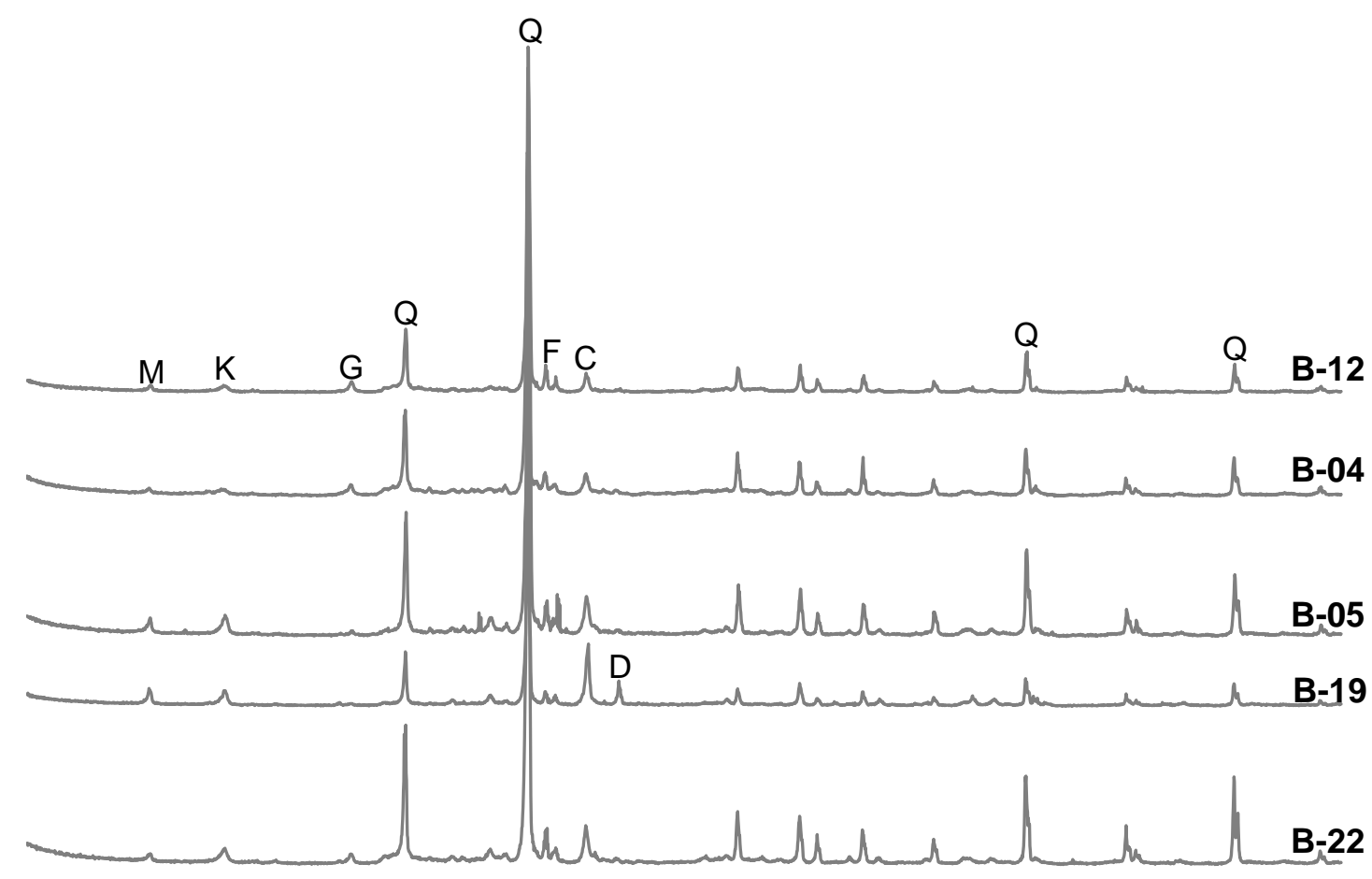

357911131517192123252729313335373941434547495153555759616365 Position [ $\left.{ }^{\circ} 2 \theta \mathrm{CuKa}\right]$

Figura 5-3 Padrões DRX das amostras RCC-mistura. São indicados os picos principais de caolinita (K), muscovita (M), quartzo $(Q)$, gibbsita $(G)$, feldspato $(F)$, e calcita $(C)$. 
Os valores de CTC das amostras RCC-solo e RCC-mistura (Tabela 5-3) foram próximos a faixa de caulinita (3 - 15 meq / 100g) (GHOSH \& BHATTACHARYYA, 2002). Isso foi coerente, pois a caulinita foi o principal argilomineral identificado nas análises de DRX (Figura 5-2 e Figura 5-3). Valores moderados a baixos de CTC são também identificados em clorita e ilita, enquanto que materiais não argilosos tendem a ter valores de CTC muito baixos a nulos, como feldspato e quartzo. Fadigas et al. (2002) estudaram 162 solos argilosos brasileiros e verificaram que $79 \%$ das amostras apresentaram CTC menor que $10 \mathrm{meq} / 100 \mathrm{~g}$, que está de acordo com os resultados obtidos para as três amostras RCC-solo.

Não foi observada correlação entre os valores de CTC e teor de argila das amostras (Figura 5-4a) ou valor de pH (Figura 5-4b). De qualquer caso, tanto o teor de argila como o CTC foram baixos, e o $\mathrm{pH}$ variou de 7,3 a 9,4.

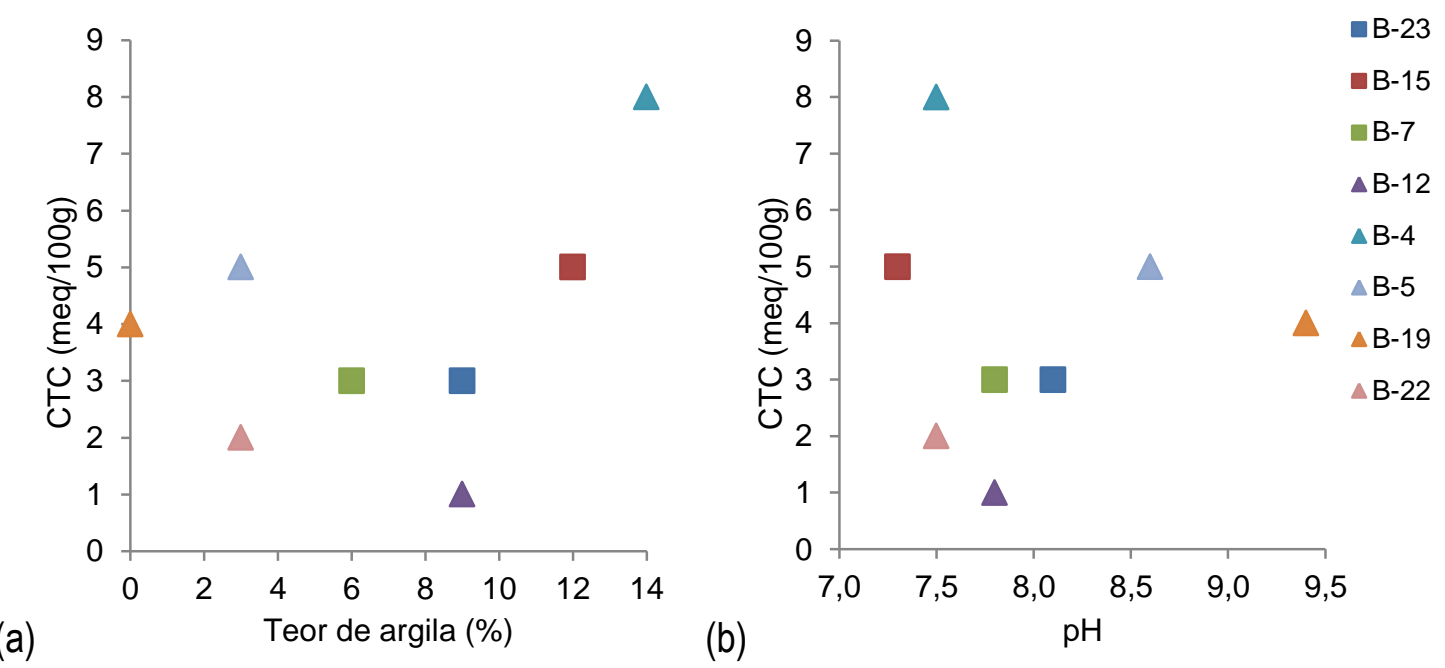

Figura 5-4 Correlação entre CTC e (a) teor de argila, e (b) pH.

A CTC é considerada um indicativo da capacidade de reter metais e outros poluentes. Solos tropicais finos, apesar de geralmente apresentarem baixa CTC, podem apresentar alta capacidade de retenção, provavelmente devido à carga variável dos óxidos de ferro e alumínio (BOSCOV, 2010).

\subsection{Caracterização ambiental}

Observou-se que 6 (seis) amostras (B-4, B-5, B-7, B-12, B-19 e B-22) apresentaram sulfato $\left(\mathrm{SO}_{4}{ }^{2-}\right)$ em concentrações acima do VMP estabelecido 
para resíduos inertes (ABNT, 2004a) (Tabela 5-2); 5 (cinco) amostras (B-4, B-7, B-12, B-15 e B-22) apresentaram concentrações de nitrato $\left(\mathrm{NO}_{3}^{-}\right)$acima do VMP (ABNT, 2004a) (Tabela 5-2).

Exceto pela amostra RCC-solo B-23, todas as demais amostras apresentaram ao menos um destes contaminantes (sulfato ou nitrato) em concentrações no extrato solubilizado acima dos respectivos VMP para resíduos inertes (ABNT, 2004a) e padrões de potabilidade de água segundo a legislação brasileira (BRASIL, 2011).

Tabela 5-2 Concentração (mg/l) de compostos em extrato solubilizado dissolvidos e respectivos Valores Máximos Permitidos (VMP).

\begin{tabular}{|c|c|c|c|c|c|c|c|c|c|}
\hline \multirow{2}{*}{ Composto } & \multirow{2}{*}{$\begin{array}{l}\text { VMP } \\
(\mathrm{mg} / \mathrm{l})\end{array}$} & \multicolumn{3}{|c|}{ "RCC-solo" } & \multicolumn{5}{|c|}{ "RCC-mistura" } \\
\hline & & B-23 & B-15 & B-7 & B-12 & B-4 & $B-5$ & B-19 & B-22 \\
\hline Sulfato $\left(\mathrm{SO}_{4}{ }^{2-}\right)$ & 250,0 & 64,0 & 201,0 & 412,0 & 356,0 & 962,0 & 559,0 & $1,143,0$ & 385,0 \\
\hline Nitrato $\left(\mathrm{NO}_{3}^{-}\right)$ & 10,0 & 6,0 & 34,0 & 14,0 & 25,7 & 20,7 & 8,2 & 5,4 & 15,6 \\
\hline Cloreto $\left(\mathrm{Cl}^{-}\right)$ & 250,0 & 6,70 & 8,59 & 9,99 & 10,46 & 29,70 & 10,60 & 25,00 & 4,53 \\
\hline$\left(\mathrm{F}^{-}\right)$ & 1,5 & 09 & 0,31 & 0,40 & 0,33 & 0,17 & 0,41 & 0,19 & 0,36 \\
\hline (Al) & 0,2 & 0,05 & $<0,05$ & $<0,05$ & $<0,05$ & $<0,05$ & $<0,05$ & $<0,05$ & $<0,05$ \\
\hline rsênio (As) & 0,01 & $<0,01$ & $<0,01$ & $<0,01$ & $<0,01$ & $<0,01$ & $<0,01$ & $<0,01$ & $<0,01$ \\
\hline ario $(\mathrm{Ba})$ & 07 & $<0,05$ & $<0,05$ & $<0,05$ & $<0,05$ & 0,03 & $<0,05$ & $<0,05$ & $<0,05$ \\
\hline $\operatorname{admin}(C d)$ & 001 & 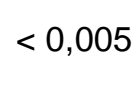 & $<0,0$ & - & & 0 & 00 & n & $\begin{array}{l}< \\
0,005\end{array}$ \\
\hline Chumbo (Pb) & 0,01 & $<0,01$ & $<0,01$ & $<0,01$ & $<0,01$ & $<0,01$ & $<0,01$ & $<0,01$ & $<0,01$ \\
\hline Jobre (Cu) & 2,0 & $<0,03$ & $<0,03$ & $<0,03$ & $<0,03$ & $<0,03$ & $<0,03$ & $<0,03$ & $<0,03$ \\
\hline Cromo total $(\mathrm{Cr})$ & 0,05 & $<0,05$ & $<0,05$ & $<0,05$ & $<0,05$ & $<0,05$ & $<0,05$ & $<0,05$ & $<0,05$ \\
\hline Ferro (Fe) & 0,3 & $<0,05$ & $<0,05$ & $<0,05$ & $<0,05$ & $<0,05$ & $<0,05$ & $<0,05$ & $<0,05$ \\
\hline Manganes (Mn) & 0,1 & $<0,02$ & $<0,02$ & $<0,02$ & $<0,02$ & $<0,02$ & $<0,02$ & $<0,02$ & $<0,02$ \\
\hline Mercurio $(\mathrm{Hg})$ & 0,001 & 001 & & & & & & & $\begin{array}{l}< \\
0,001\end{array}$ \\
\hline Prata $(\mathrm{Ag})$ & 0,05 & $<0,05$ & $<0,05$ & $<0,05$ & $<0,05$ & $<0,05$ & $<0,05$ & $<0,05$ & $<0,05$ \\
\hline Selenio (Se) & 0,01 & $<0,01$ & $<0,01$ & $<0,01$ & $<0,01$ & $<0,01$ & $<0,01$ & $<0,01$ & $<0,01$ \\
\hline Sodio (Na) & 200,0 & $<0,1$ & 0,17 & 0,29 & 0,22 & 0,46 & 0,72 & 0,65 & 0,21 \\
\hline Zinco (Zn) & 5,0 & $<0,05$ & $<0,05$ & $<0,05$ & $<0,05$ & $<0,05$ & $<0,05$ & $<0,05$ & $<0,05$ \\
\hline
\end{tabular}

O teor de matéria orgânica das amostras RCC-solo variou de 2 a 5\%; nas amostras RCC-mistura variou de 2 a 8\% (Figura 5-5). Fadigas et al. (2002) estudaram 162 solos argilosos brasileiros e verificaram que $91 \%$ das amostras apresentaram teor de matéria orgânica inferior a $2 \%$. A perda de massa por ignição a $440^{\circ} \mathrm{C}$ pode resultar na perda de íons hidroxilas e água de constituição atribuída aos compostos de carbono (ABNT, 1996), além de 
substâncias orgânicas, resultando em um teor de matéria orgânica maior do que o real.

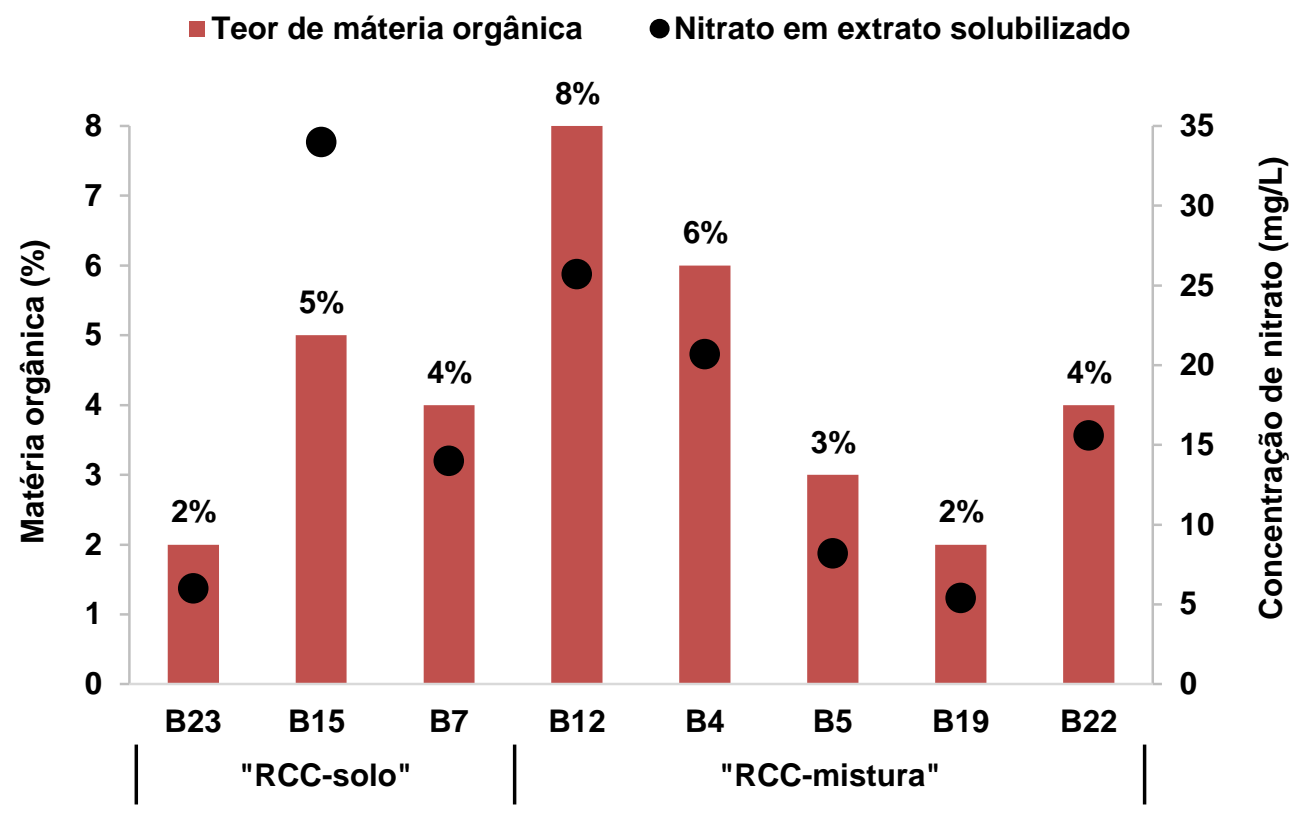

Figura 5-5 Correlação entre teor de matéria orgânica e concentração de nitrato das amostras.

A lixiviação de substâncias é fortemente influenciada pelo $\mathrm{pH}$ da solução que percola através do solo, sendo mais intenso quanto menor o $\mathrm{pH}$ (BÖHMER et al., 2008). De acordo com estudo de Fadigas et al. (2002), 89\% das amostras analisadas apresentaram valor de $\mathrm{pH}$ abaixo de 6 . As 8 (oito) amostras estudadas apresentam solução alcalina com pH entre 7,3 e 9,4 (Tabela 5-3), que pode estar relacionado ao RCC em cada amostra, e reduz o risco de lixiviação de nitrato e sulfato das amostras RCC-solo e RCC-mistura por infiltração ou escape de água.

A determinação do $\mathrm{pH}$ deve ser realizada imediatamente após a coleta da amostra no campo, o que não ocorreu com as amostras estudadas. 
Tabela 5-3 Teor de matéria orgânica, pH e capacidade de troca catiônica (CTC).

\begin{tabular}{llllll}
\hline Ensaio & $\begin{array}{l}\text { Perdas de massa por } \\
\text { ignição }\end{array}$ & $\mathrm{pH}$ & $\begin{array}{l}\text { Azul de } \\
\text { metileno }\end{array}$ & $\begin{array}{l}\text { Concentração } \\
\text { em extrato } \\
\text { solubilizado }\end{array}$ \\
\hline Parâmetro & $\begin{array}{l}\text { Teor de matéria orgânica } \\
(\%)\end{array}$ & $\mathrm{pH}$ & $\begin{array}{l}\mathrm{CTC} \\
(\mathrm{meq} / 100 \mathrm{~g})\end{array}$ & {$\left[\mathrm{SO}_{4}{ }^{2}{ }^{-}\right]$} & {$\left[\mathrm{NO}_{3}{ }^{-}\right]$} \\
\hline B-23 (RCC-solo) & 2 & 8,1 & 3 & 64 & 6.0 \\
B-15 (RCC-solo) & 5 & 7,3 & 5 & 201 & 34.0 \\
B-7 (RCC-solo) & 4 & 7,8 & 3 & 412 & 14.0 \\
B-12 (RCC-mistura) & 8 & 7,8 & 8 & 356 & 25.7 \\
B-4 (RCC-mistura) & 6 & 7,5 & 5 & 962 & 20.7 \\
B-5 (RCC-mistura) & 3 & 8,6 & 4 & 559 & 8.2 \\
B-19 (RCC-mistura) & 2 & 9,4 & 2 & 1143 & 5.4 \\
B-22 (RCC-mistura) & 4 & 7,5 & 6 & 385 & 15.6 \\
\hline
\end{tabular}

A ocorrência de nitrato e sulfato pode estar relacionada à degradação da matéria orgânica, como resíduos de jardinagem, restos de alimentos, efluentes domésticos e industriais (RESENDE, 2002; VEDRONI, 2007). As concentrações de nitrato aparentemente estão correlacionadas com o teor de matéria orgânica (Figura 5-5). O sulfato também pode resultar da oxidação do sulfeto (sulfeto de ferro / pirita) e da dissolução de solos e rochas, tais como sulfato de magnésio $\left(\mathrm{MgSO}_{4}\right)$ e gesso $\left(\mathrm{CaSO}_{4}\right)$. Vale ressaltar que o concreto moído e materiais de gesso também podem apresentar alto teor de sulfato (JANG; TOWNSEND, 2001).

As maiores concentrações de sulfato foram identificadas nas 5 amostras RCCmistura e na amostra RCC-solo B-7, que apresentaram maior fração de material cimentício (Figura 5-1) que as demais amostras RCC-solo (B-15 e B23). Isto indica que a mistura com outros tipos de RCC (concreto e gesso) pode ter aumentado o teor de sulfato nas amostras.

A solubilização e a lixiviação de nitrato podem apresentar risco de contaminação de água. Nitratos podem levar à eutrofização de corpos d'água e, consequentemente, à morte de peixes e outros organismos (RESENDE, 2002). Em água de abastecimento, tem sido associado a distúrbios gastrointestinais e intoxicação infantil, conhecida como "síndrome do bebê azul" (AVERY, 1999; KNOBELOCH et al., 2000; RESENDE, 2002; WHO, 2017). A síndrome do bebê azul está relacionada com altos níveis de formação de metaemoglobina em lactantes; em estudos epidemiológicos, a 
metaemoglobinemia não foi relatada em crianças em áreas onde a água potável continha menos de $50 \mathrm{mg}$ de nitrato por litro (WHO, 2017). Todas as amostras estudadas apresentaram concentração de nitrato abaixo de $50 \mathrm{mg} / \mathrm{L}$, parâmetro adequado para proteção de lactantes e, conseqüentemente, para crianças mais velhas e adultos.

A presença de sulfato em água potável pode causar sabor perceptível, e também, efeito laxante em seres humanos. O comprometimento do sabor varia com a natureza do cátion associado ao íon sulfato; variando entre $250 \mathrm{mg} / \mathrm{L}$ para sulfato de sódio e $1000 \mathrm{mg} / \mathrm{L}$ para sulfato de cálcio (OMS, 2017). Geralmente, considera-se que a deterioração do paladar é mínima em níveis inferiores a $250 \mathrm{mg} / \mathrm{L}$ (OMS, 2017). Estudos com voluntários indicaram um efeito laxante devido à ingestão de água contendo concentrações de sulfato entre 1000 e 1200 mg/L, no entanto, sem aumento de casos de diarréia, desidratação ou perda de peso (OMS, 2017). Exceto a amostra RCC-mistura B-19, as concentrações de sulfato nas demais amostras foram determinadas abaixo de $1000 \mathrm{mg} / \mathrm{L}$, que protege adequadamente a saúde humana.

O cimento está sujeito à deterioração por exposição prolongada a ataques químicos de íons agressivos como cloreto e sulfato, que pode resultar em falha estrutural (Neville, 2004; WHO, 2017). As normas de agregados estabelecem teores limites de cloretos e sulfatos em diferentes tipos de concretos (ABNT, 2009b). No entanto, a corrosão das estruturas de concreto não depende somente das concentrações de cloreto e sulfato nos agregados, mas também da composição do concreto, temperatura, $\mathrm{pH}$, fontes de sulfatos e cloretos, entre outros fatores. O controle da corrosão de concreto pode ser realizado ajustando $\mathrm{pH}$ (para 8,5 ou mais), aumentando a alcalinidade ou a dureza (WHO, 2017).

O risco de contaminação por sulfato e nitrato também depende do uso pretendido da construção, seja industrial, residencial ou agrícola, permeabilidade do solo, precipitação, profundidade, proximidade com aqüíferos e outras condições ambientais locais. A avaliação de risco local identifica a relação entre contaminantes, receptores e vias de exposição, incluindo os caminhos de contaminação do solo para seres humanos, aquíferos e águas subterrâneas (NATHANAIL, 2005; RODRIGUES et al., 2009). A partir da 
avaliação de risco, são definidas as possíveis aplicações e condições nas quais os materiais devem ser reutilizados de forma segura.

\subsection{Propriedades geotécnicas}

As amostras RCC-solo apresentaram fração de pedregulho variando entre 7\% e $23 \%$, e fração de finos $(\leq 0,075 \mathrm{~mm}$ ) entre $33 \%$ e $49 \%$ (Tabela $5-4)$. As amostras RCC-mistura apresentaram fração de pedregulho variando entre $34 \%$ e $56 \%$, e fração de finos ( $\leq 0,075 \mathrm{~mm}$ ) entre $9 \%$ e $24 \%$ (Tabela $5-4$ ).

As curvas de distribuição granulométrica das amostras RCC-solo apresentaram maior porcentagem de finos do que as amostras RCC-mistura (Figura 5-6), o que está de acordo com a observação visual (discutida no item 5.1).

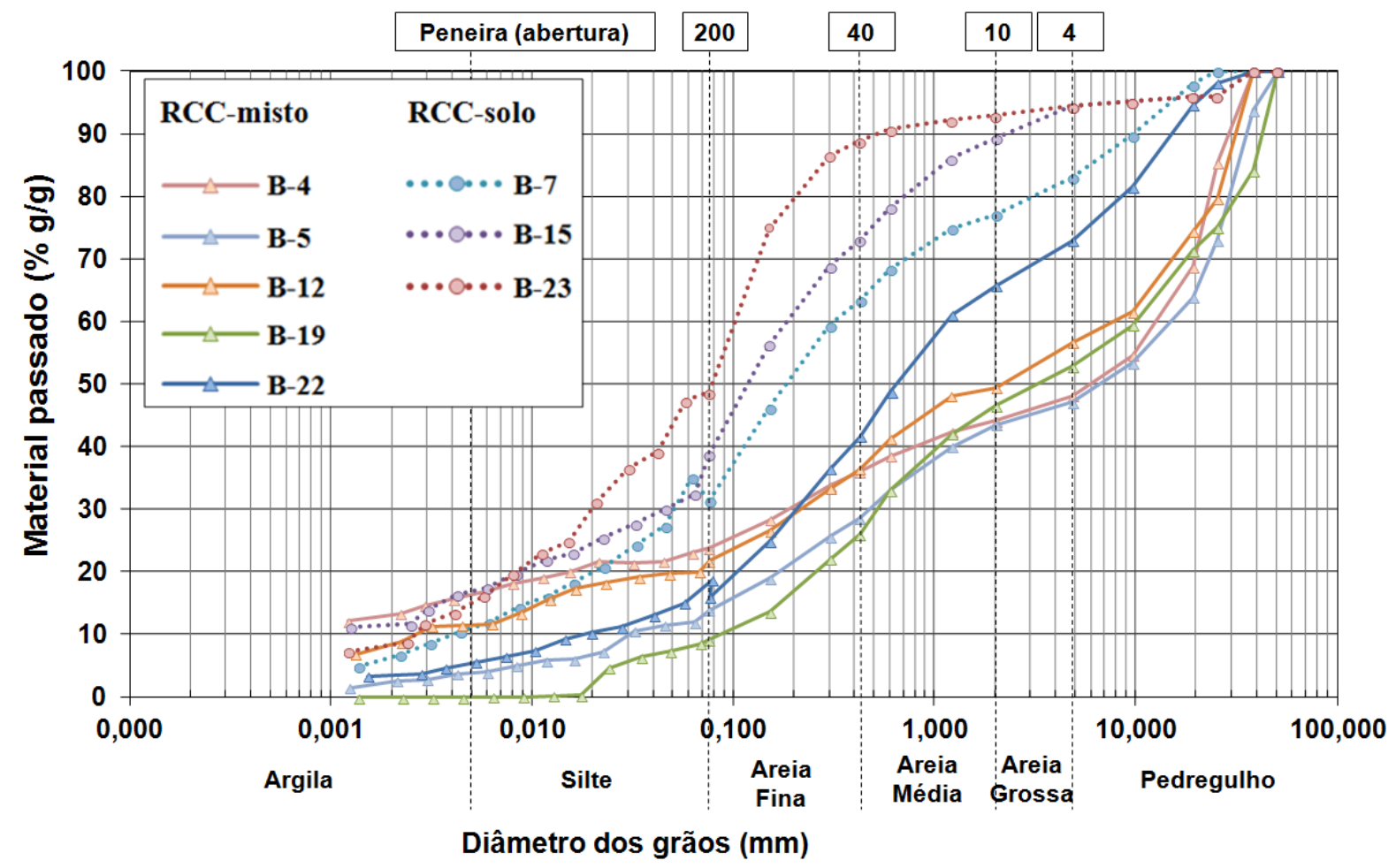

Figura 5-6 Curvas de distribuição granulométrica.

Verificou-se que 2 (duas) de 3 (três) amostras RCC-solo apresentaram fração $\leq$ 0,42 mm com plasticidade compatível com argila (B-15) e com silte (B-23) (Tabela 5-4). As amostras RCC-mistura, apesar de pequena porcentagem de fração $\leq$ 0,42 mm, apresentaram alguma plasticidade em 3 (três) de 5 (cinco) amostras (Tabela 5-4). A mistura com materiais cimentícios ou a 
predominância de solo, portanto, não fornece uma indicação consistente da plasticidade dos finos. De acordo com o Sistema Unificado de Classificação de Solos (SUCS), as amostras RCC-solo foram classificadas como areias, e as amostras RCC-mistura, como pedregulhos.

Para amostra B-7 (RCC-solo), o teor de umidade ótimo de 18,5\% corresponde a uma densidade seca máxima de $1,66 \mathrm{~g} / \mathrm{cm}^{3}$ (Figura 5-7). Para a amostra B15 (RCC-solo), o teor de umidade ótimo de 18,3\% corresponde a uma densidade máxima de 1,72 g / cm³ (Figura 5-7). Para amostra B-23 (RCC-solo), o teor de umidade ótimo de 17,8\% correspondeu a uma densidade seca máxima de 1,69 g / cm³ (Figura 5-7). Para amostra RCC-mistura (composição), o teor de umidade ótimo de 19,5\% correspondeu a uma densidade seca máxima de $1,67 \mathrm{~g} / \mathrm{cm}^{3}$ (Figura 5-7).

Tabela 5-4 Propriedades físicas e classificação.

\begin{tabular}{|c|c|c|c|c|c|c|c|c|c|c|}
\hline \multirow{2}{*}{$\begin{array}{l}\text { Ensaio } \\
\text { Parametro }\end{array}$} & \multirow{2}{*}{$\begin{array}{l}\text { Composição } \\
\text { visual }\end{array}$} & \multicolumn{4}{|c|}{$\begin{array}{c}\text { Granulometria } \\
\text { (peneiramento / sedimentação) }\end{array}$} & \multicolumn{3}{|c|}{$\begin{array}{l}\text { Limites de } \\
\text { consistência }\end{array}$} & \multicolumn{2}{|r|}{ SUCS } \\
\hline & & $\begin{array}{l}\text { Finos } \\
(\%)\end{array}$ & $\begin{array}{l}\text { Areia } \\
(\%)\end{array}$ & $\begin{array}{l}\text { Pedregulho } \\
(\%)\end{array}$ & $\begin{array}{l}\text { Densidade } \\
\text { grãos } \\
\left(\mathrm{g} / \mathrm{cm}^{3}\right)\end{array}$ & $\begin{array}{l}\mathrm{LL} \\
(\%)\end{array}$ & $\begin{array}{l}\text { LP } \\
(\%)\end{array}$ & $\begin{array}{l}\text { IP } \\
(\%)\end{array}$ & & \\
\hline B-23 & solo & 48,64 & 45,72 & 5,64 & 2,852 & 33 & 27 & 6 & SM & areia siltosa \\
\hline B-15 & solo & 38,74 & 55,61 & 5,65 & 2,703 & 30 & 22 & 8 & SC & areia argilosa \\
\hline B-7 & solo & 31,37 & 51,52 & 17,11 & 2,692 & 27 & * & * & SM & areia siltosa \\
\hline B-12 & mistura & 21,83 & 34,83 & 43,35 & 2,567 & 32 & 19 & 13 & GC & $\begin{array}{l}\text { pedregulho } \\
\text { argiloso }\end{array}$ \\
\hline B-4 & mistura & 23,86 & 24,31 & 51,83 & 2,637 & 28 & 25 & 3 & GC & $\begin{array}{l}\text { pedregulho } \\
\text { argiloso }\end{array}$ \\
\hline B-5 & mistura & 13,94 & $+33,23$ & 52,83 & 2,784 & 29 & 21 & 8 & GM & $\begin{array}{l}\text { pedregulho } \\
\text { siltoso }\end{array}$ \\
\hline B-19 & mistura & 9,24 & 43,65 & 47,11 & 2,709 & * & * & * & GP-GN & $\begin{array}{l}\text { pedregulho } \\
\text { M mal graduado } \\
\text { com silte }\end{array}$ \\
\hline B-22 & mistura & 16,01 & 56,94 & 27,05 & 2,222 & 27 & 18 & 9 & GC & $\begin{array}{l}\text { pedregulho } \\
\text { argiloso }\end{array}$ \\
\hline
\end{tabular}

$\mathrm{LL}=$ limite de liquidez; $\mathrm{LP}=$ limite de plasticidade; $\mathrm{IP}=$ índice de plasticidade

$\left({ }^{*}\right)$ fração de finos sem plasticidade 


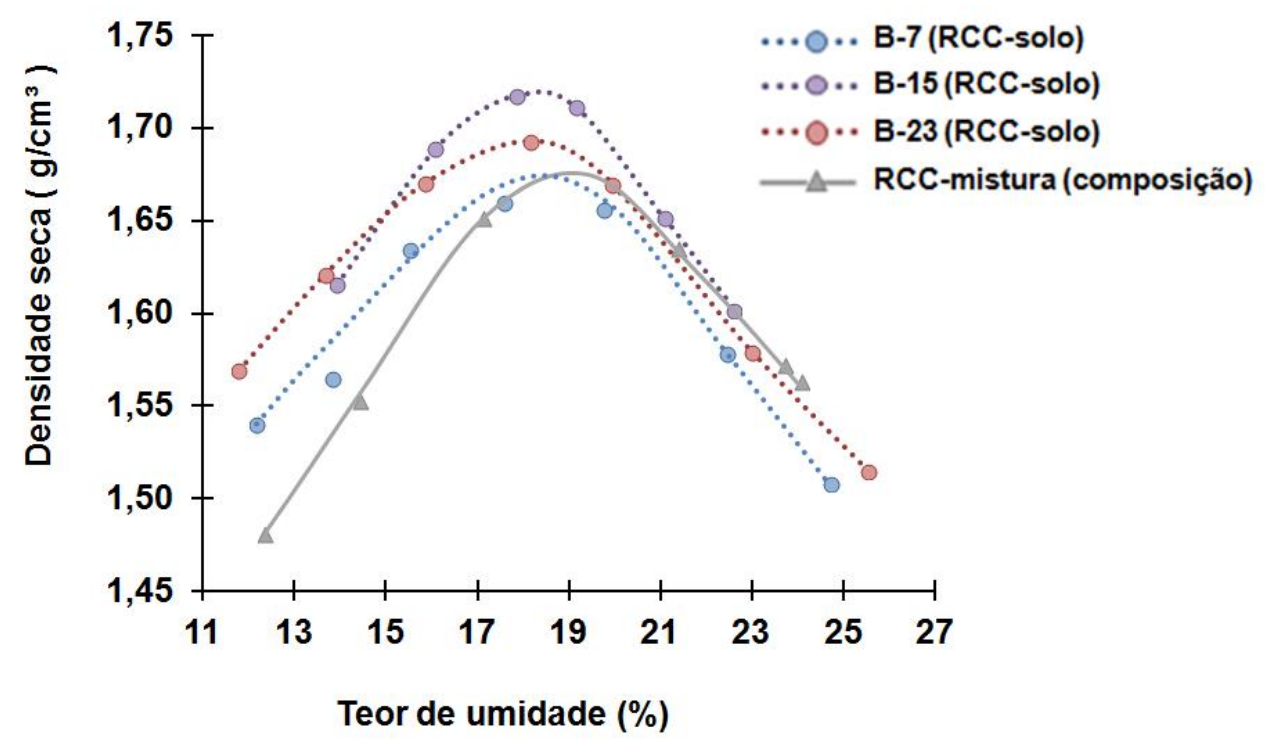

Figura 5-7 Curvas de compactação.

De acordo com a classificação MCT (Tabela 5-5), as amostras RCC-solo são não lateríticas. 2 (duas) amostras (B-23 e B-7) são classificadas como NS', que são solos com alta expansão, média contração e baixo a médio coeficiente de permeabilidade. 1 (uma) amostra (B-15) é NA', que são solos com baixa expansão, baixa a média contração, e baixo coeficiente de permeabilidade. Com base nestes resultados, as 2 (duas) amostras classificadas como NS' não são apropriadas para infraestrutura de pavimento, e a amostra classe NA' poderia ser aplicada em proteção contra erosão e camada de base.

A Figura 5-8 e a Tabela 5-5 apresentam as envoltórias de resistência das amostras RCC-solos e RCC-mistura (composição), com base nas curvas de tensão de cisalhamento em função da deformação para cada amostra (ver Apêndices). Apesar de classificado como areia argilosa de acordo com o SUCS, RCC-solo B-15 não apresentou coesão, enquanto RCC-solo B-7 com fração de finos não-plásticos apresentou um intercepto de coesão de 9,6 kPa. O RCC-solo B-23 foi classificado como NS' e apresentou comportamento granular, com ângulo de atrito de $30^{\circ}$. Em geral, as amostras RCC-solo mostraram-se não a ligeiramente coesivas (coesão de 0 a $10 \mathrm{kPa}$ ) e possuem comportamento granular (ângulo de atrito de $29^{\circ}$ a $34^{\circ}$ ), e a amostra RCCmistura (composição) apresentou a maior resistência ao cisalhamento (ângulo de atrito de $38^{\circ}$ ) e comportamento não-coesivo. 
Dentre as 3 amostras RCC-solo, a amostra B-7 com a maior fração de materiais cimentícios apresentou maior coesão e menor ângulo de atrito; a amostra RCC-mistura (composição) apresentou o maior ângulo de atrito.

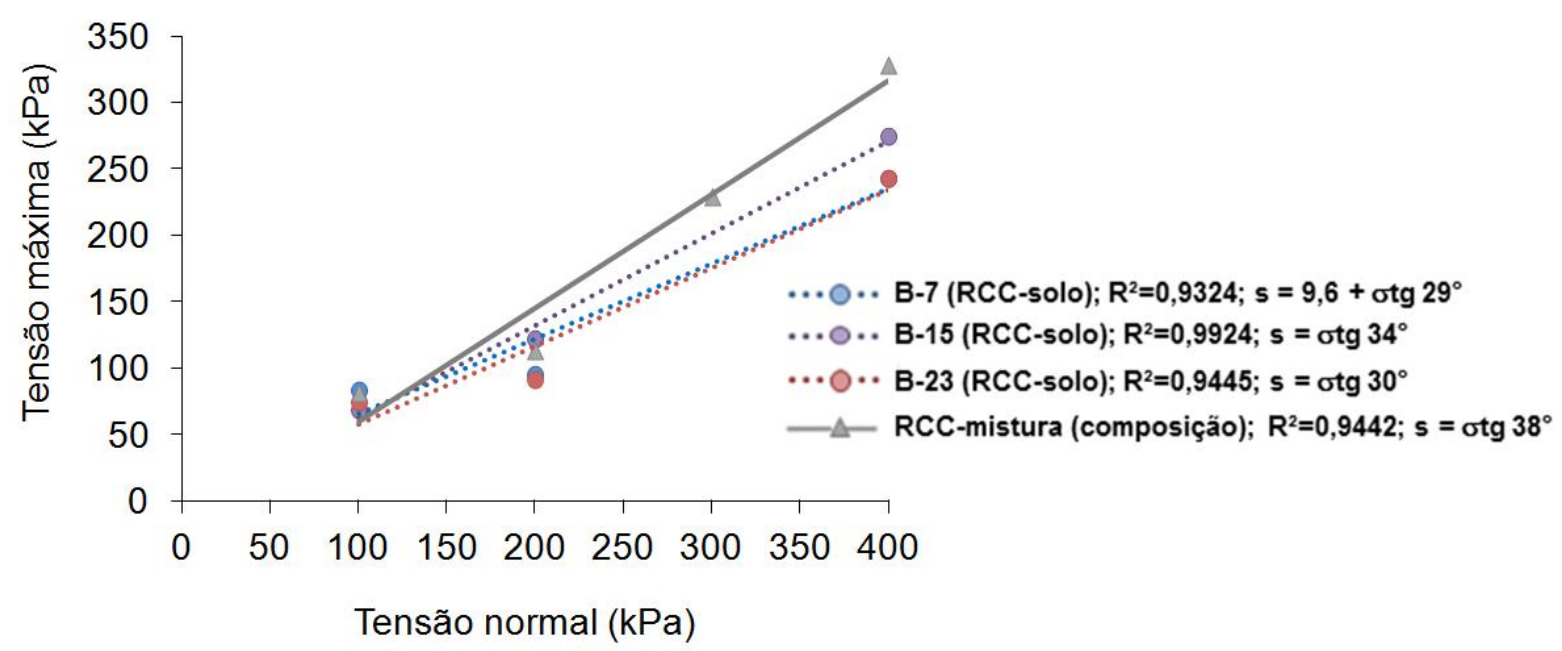

Figura 5-8 Envoltórias de resistência.

As amostras RCC-solo B-7 e B-23 apresentaram mini-CBR menor que 4\% para os três teores de umidade testados (Figura 5-9). Observa-se que, para as amostras B15 e RCC-mistura (composição), os três teores de umidade localizaram-se no ramo úmido. A amostra RCC-solo B-15 apresentou mini-CBR de $11 \%$ no teor de umidade ótimo, e $2 \%$ para o desvio de umidade de $+2,8 \%$ (Figura 5-9). Estes resultados estão de acordo com os estudos realizados por Nogami \& Villibor (1995) com solos não-lateríticos: materiais classificados como NS' têm alta expansão e perda de capacidade de suporte quando saturados, e os materiais NA' têm maior capacidade de suporte e baixa expansão (Tabela 5-5).

Para as 3 (três) amostras RCC-solo, a expansão diminui com o aumento da umidade de compactação (Figura 5-9), conforme esperado. A amostra B-23 apresentou alta expansão de 3,5\% no lado seco e 2,5\% no teor de umidade ótimo, enquanto as amostras B-7 e B-15 apresentaram menor expansão na condição de umidade ótima (1,1\% e 0,4\% respectivamente) (Figura 5-9).

A amostra RCC-mistura (composição) apresentou mini-CBR de 16\% na condição de umidade ótima, que é reduzida a $4 \%$ para o desvio de umidade de cerca de 3,0 \% (Figura 5-9). A amostra RCC-mistura (composta) apresentou 
uma expansão muito baixa $(0,04 \%)$ nos três teores de umidade testados (Figura 5-9). Nesse sentido, a amostra RCC-mistura (composição) apresentou maior capacidade de suporte e menor expansão que as amostras RCC-solo (Tabela 5-5).
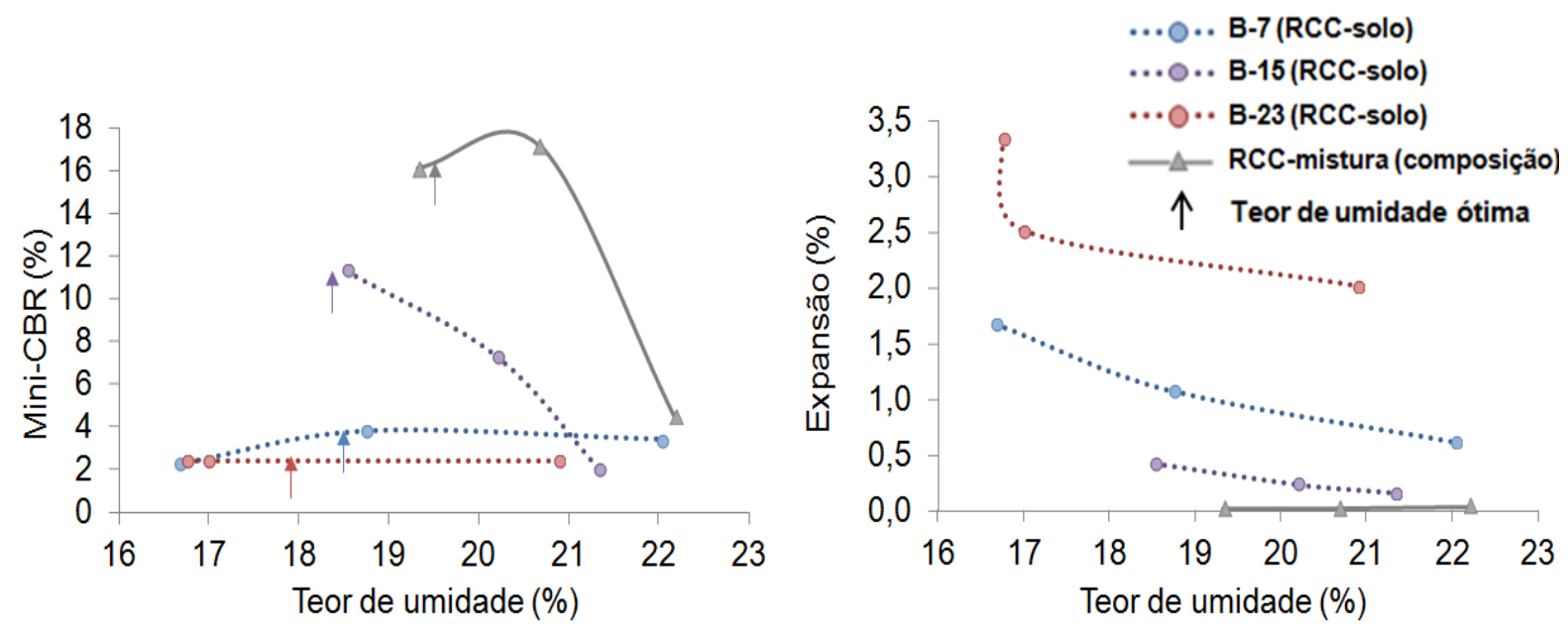

Figura 5-9 Curvas mini-CBR e expansão após imersão.

Tabela 5-5 Propriedades mecânicas.

\begin{tabular}{|c|c|c|c|c|c|c|c|c|}
\hline \multirow{2}{*}{$\begin{array}{l}\text { Ensaio } \\
\text { Parametro }\end{array}$} & \multicolumn{2}{|c|}{ Compactação } & \multicolumn{2}{|c|}{ MCT } & \multicolumn{2}{|c|}{$\begin{array}{c}\text { Resistência ao } \\
\text { cisalhamento }\end{array}$} & \multicolumn{2}{|c|}{ Mini-CBR } \\
\hline & $\begin{array}{l}\text { Umidade } \\
\text { ótima } \\
(\%)\end{array}$ & $\begin{array}{l}\text { Densidade } \\
\text { seca } \\
\text { máxima } \\
\left(\mathrm{g} / \mathrm{cm}^{3}\right)\end{array}$ & $\begin{array}{l}\text { Perda de } \\
\text { massa } \\
(\mathrm{PI} \%)\end{array}$ & Classe & $\begin{array}{l}\text { Coesão } \\
(\mathrm{kPa})\end{array}$ & $\begin{array}{l}\text { Ângulo } \\
\text { de } \\
\text { atrito } \\
\left({ }^{\circ}\right)\end{array}$ & $\begin{array}{l}\text { Expansão* } \\
(\%)\end{array}$ & $\begin{array}{l}\text { CBR } \\
(\%)\end{array}$ \\
\hline B-23 (RCC-solo) & 17,8 & 1,69 & 285 & NS' & 0 & 30 & 2,5 & 2 \\
\hline B-15 (RCC-solo) & 18,3 & 1,72 & 110 & NA' & 0 & 34 & 0,4 & 11 \\
\hline B-7 (RCC-solo) & 18,5 & 1,66 & 290 & NS' & 9,6 & 29 & 1,1 & 4 \\
\hline $\begin{array}{l}\text { RCC-mistura } \\
\text { (composição) }\end{array}$ & 19,5 & 1,67 & $x$ & $\mathrm{x}$ & 0 & 38 & 0,0 & 16 \\
\hline
\end{tabular}

$\left({ }^{*}\right)$ valores referentes ao teor de umidade ótimo.

\subsection{Reusos potenciais}

As Figura 5-10 eFigura 5-11 apresentam, respectivamente, a proposta de um critério preliminar de triagem na chegada ao aterro ou usina de reciclagem para potenciais reusos de RCC-solo e RCC-mistura.

Ressalta-se que o potencial de aproveitamento dos solos escavados seria maior com a segregação dos diferentes tipos de RCC na origem (obras de construção). 


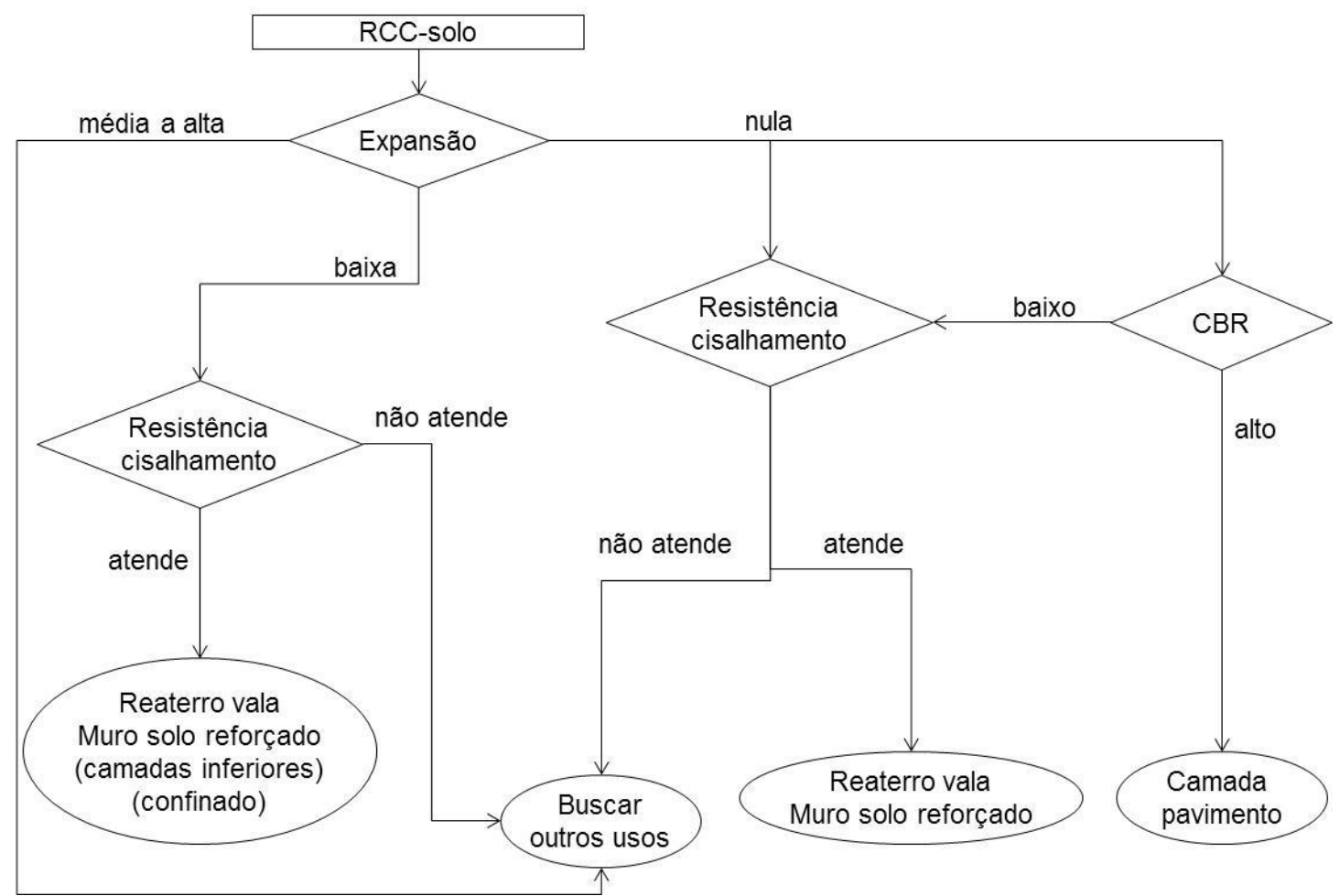

Figura 5-10 Proposta de critério preliminar de triagem para potenciais reusos de RCCsolo.

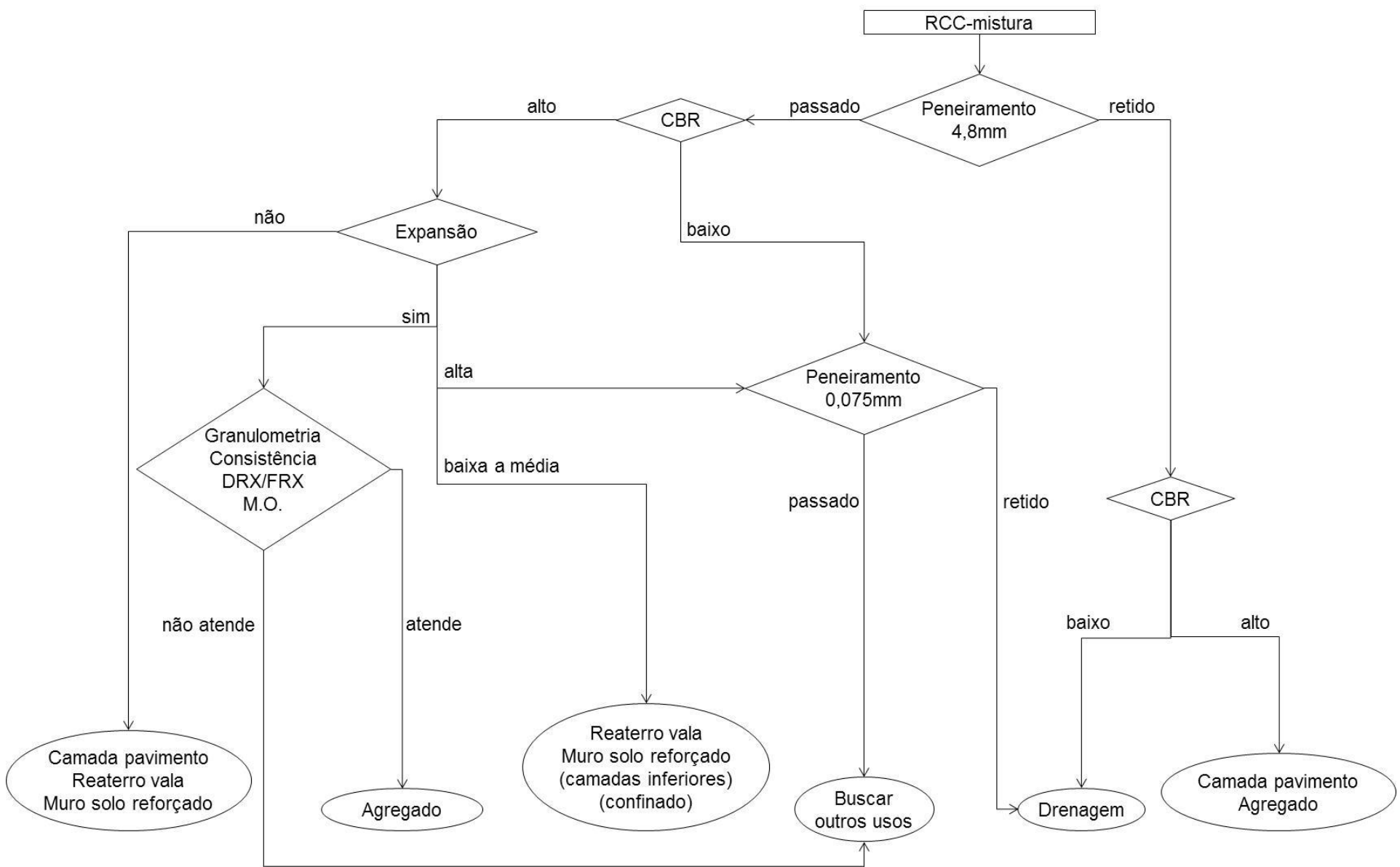

Figura 5-11 Proposta de critério preliminar de triagem para potenciais reusos de RCCmistura. 
RCC-solo

Areias com pouca fração de finos ( 0 a $22 \%$ ), os finos podem apresentar plasticidade ou não (plasticidade analisada pelo limite de liquidez e pelo índice de plasticidade de acordo com o SUCS). Porém, as amostras RCC-solos são expansivas (expansão de 0,4 a 3,5\% no teor ótimo de umidade) e têm pouca ou nenhuma coesão (coesão de 0 a $10 \mathrm{kPa}$ ). Os materiais apresentaram um comportamento granular com ângulo de atrito variando de 29 a $34^{\circ}$. O valor de mini-CBR após a imersão variou de 2 a $11 \%$.

Solos que apresentam dilatação e perda da capacidade de suporte por saturação não são recomendados para construção de pavimentos (DNER, 1996). Entretanto, solos NS' da RMSP, apesar de apresentarem alta expansão, têm baixa pressão de expansão (Nogami \& Villibor 1995); e, portanto, os materiais podem não expandir se saturados sob cargas relativamente leves. Isto possibilita sua utilização em diversos tipos de aplicações geotécnicas onde solos são confinados, como preenchimento de valas (esgoto, água, gás, etc.), preenchimento de muros de contenção, e muros de solo reforçado. Estas também são potenciais reutilizações para amostras de RCC-solo, desde que submetidas a sobrecargas iguais ou maiores que a pressão de expansão, não sendo aplicadas em camadas superficiais. As amostras RCC-solo também poderiam ser utilizadas como materiais de drenagem se peneiradas para separar a fração de finos.

RCC- mistura

Pedregulho com baixa fração de finos ( 0 a $22 \%$ ), os finos podem apresentar ou não plasticidade. Os materiais não expansivos (expansão de 0,04 \% no teor ótimo de umidade) e não apresentam coesão. Os materiais possuem comportamento granular com ângulo de atrito de $38^{\circ}$, porcentagem Mini-CBR após imersão de $16 \%$. Consequentemente, além dos usos anteriores para solos, estes materiais também poderiam ser usados em bases ou sub-bases de pavimentação. 


\section{CONCLUSÕES}

As caracterizações ambientais e geotécnicas de resíduos de escavação destinados a aterro de RCC localizado na Região Metropolitana de São PauloSP permitiram concluir que:

- os materiais de escavação destinados ao aterro não eram constituídos somente por solo de escavação, mas, principalmente, por uma mistura de solos e outros tipos de RCC - materiais cimentícios foram identificados em todas as frações granulométricas;

- as propriedades geotécnicas dos solos de escavação não foram prejudicadas pela mistura com outros tipos de RCC;

- os materiais apresentaram curvas de distribuição granulométrica não uniformes (bem graduadas) e propriedades mecânicas apropriada para aplicações geotécnicas ou em pavimentação. Observou-se que os parâmetros geotécnicos mostraram-se de acordo com os solos locais. Verificou-se que as frações finas podem apresentar ou não expansão e, visto que a expansão limita o uso de solos em diversos tipos de aplicações nas construções, recomenda-se que este parâmetro seja considerado um critério técnico para determinar potenciais reutilizações. Para os materiais com predominância de RCC, sugere-se que o teor de finos também seja um critério;

- sulfatos e nitratos dissolvidos podem poluir aquíferos e águas superficiais. A concentração máxima permitida dessas substâncias é baseada em normas internacionais de potabilidade de água, que são muito restritivas. Com base nos valores recomendados pelas normas internacionais, os materiais estudados não apresentam riscos à saúde humana em relação a presença de sulfatos e nitratos. Se houver concentrações acima dos valores máximos permitidos, a avaliação de riscos a possíveis receptores deve ser realizada de acordo com a finalidade da construção para identificação de potenciais reusos. Nesse contexto, a separação do 
gesso na fonte (obras de construção) possibilitaria reduzir a concentração de sulfato dissolvido em materiais de escavação;

- foi proposto um critério preliminar de triagem para potenciais reusos sugeridos para materiais de escavação da RMSP, baseado em ensaios comuns de caracterizações geotécnicas e ambientais. Vale ressaltar que a segregação dos solos de escavação dos outros tipos de RCC no local de origem (obras de construção) pode beneficiar e aumentar potenciais reusos de RCC.

- Segregação do material antes da remoção do local

\subsection{Sugestões de futuras pesquisas}

A partir do estudo realizado, são sugeridas as seguintes pesquisas futuras:

- verificar melhorias nas propriedades geotécnicas ao longo do tempo devido à presença de materiais cimentícios em mistura de solos e outros tipos de RCC;

- analisar visualmente, por meio de microscopia digital, os grãos sem lavagem prévia, de modo a perceber a existência de pequenos torrões de partículas de solo;

- obter envoltórias de resistência de cisalhamento direto com tensões normais abaixo de $100 \mathrm{kPa}$, considerando aplicações geotécnicas sob baixas tensões confinantes. 


\section{REFERÊNCIAS}

ABNT. NBR 9895. NBR 9895 - Solo - Indice de suporte califórnia. . 1987.

ABNT. NBR 6.502. NBR 6.502 - Rochas e solos - Terminologia. . 1995.

ABNT. NBR 10.004. NBR 10.004 - Resíduos sólidos - Classificação. . 2004 a.

ABNT. NBR 10.006. NBR 10.006 - Procedimento para obtenção de extrato solubilizado de resíduos sólidos. . 2004 b.

ABNT. NBR 11.682. NBR 11.682 - Estabilidade de encostas. . 2009 a, p. 33.

ABNT. NBR 7211. NBR7211: Agregado para concreto - Especificação. . 2009 b.

ABNT. NBR 7180. NBR 7180 - Solo - Determinação do limite de plasticidade. .2016 a.

ABNT. NBR 6459. NBR 6459 - Solo - Determinação do limite de liquidez. . 2016 b.

ABNT. NBR 7182. NBR 7182 - Solo - Ensaio de compactação. . 2016 c.

ABNT. NBR 9895. NBR 9895 - Solo - Índice de Suporte Califórnia. . 2016 d.

ABRELPE. Panorama dos resíduos sólidos no Brasil 2014. [s.I.] Abrelpe, $2014 . \quad$ Disponível em: <http://www.abrelpe.org.br/Panorama/panorama2014.pdf>. Acesso em: 2 out. 2015.

ANDREOLA, F.; COSTA, L. M.; OLSZEVSKI, N. Influence of winter winter plant cover and organic and, or, mineral fertilizer on the physical properties of a Structured "Terra Roxa". Revista Brasileira de Ciência do Solo, v. 24, n. 4, p. 857-865, dez. 2000.

ANGULO, S. C. et al. Chemical-mineralogical characterization of C\&D waste recycled aggregates from São Paulo, Brazil. Waste Management, v. 29, n. 2, p. 721-730, fev. 2009.

ANGULO, S. C. et al. Resíduos de construção e demolição: avaliação de métodos de quantificação. Engenharia Sanitaria e Ambiental, v. 16, n. 3, p. 299-306, set. 2011.

ANGULO, S. C.; MUELLER, A. Determination of construction and demolition recycled aggregates composition, in considering their heterogeneity. Materials and Structures, v. 42, n. 6, p. 739-748, 7 ago. 2008.

ASTM. ASTM D6913. ASTM D6913 - Standard Test Methods for Particle-Size Distribution (Gradation) of Soils Using Sieve Analysis. . 2009. 
ASTM. ASTM D4318. ASTM D4318 - Standard Test Methods for Liquid Limit, Plastic Limit, and Plasticity Index of Soils. . 2010.

ASTM. ASTM D3080. ASTM D3080 - Standard Test Method for Direct Shear Test of Soils Under Consolidated Drained Conditions. . 2011.

ASTM. ASTM D698. ASTM D698 - Standard Test Methods for Laboratory Compaction Characteristics of Soil Using Standard Effort (12 $400 \mathrm{ft}-\mathrm{lbf} / \mathrm{ft} 3$ (600 $\mathrm{kN}-\mathrm{m} / \mathrm{m} 3))$. . 2012.

ASTM. D1883. ASTM D1883 - Standard Test Method for California Bearing Ratio (CBR) of Laboratory-Compacted Soils. . 2016.

AUSTRALIAN GOVERNMENT, D. OF THE E. Construction and demolition waste status report - management of construction and demolition waste in Australia. [s.I.] Department of Sustainability, Environment, Water, Population and Communities of Australian Government, 2011. Disponível em: $<$ https://www.environment.gov.au/protection/national-waste-

policy/publications/construction-and-demolition-waste-status-report>. Acesso em: 21 nov. 2015.

AVERY, A. A. Infantile methemoglobinemia: Reexamining the role of drinking water nitrates. Environmental Health Perspectives, v. 107, n. 7, p. 583-586, 1999.

BENJAMIM, C. V. S.; BUENO, B. S.; ZORNBERG, J. G. Field monitoring evaluation of geotextile-reinforced soil-retaining walls. Geosynthetics International, v. 14, n. 2, p. 100-118, 2007.

BERGSDAL, H.; BOHNE, R. A.; BRATTEBO, H. Projection of Construction and Demolition Waste in Norway. Journal of Industrial Ecology, v. 11, n. 3, p. 2739, 1 jul. 2007.

BHUIYAN, Z. I.; ALI, F. H.; SALMAN, F. A. Frictional behaviour of segmental retaining wall units infilled with recycled concrete aggregate. In: SYMPOSIUM ON BUSINESS, ENGINEERING AND INDUSTRIAL APPLICATIONS (ISBEIA). Langkawi, Malaysia: 2011

BIONDI, C. M. Teores naturais de metais pesados nos solos de referência do Estado de Pernambuco. Tese (Doutorado)_Pernambuco: Universidade Federal Rural de Pernambuco, 2010.

BLENGINI, G. A.; GARBARINO, E. Resources and waste management in Turin (Italy): the role of recycled aggregates in the sustainable supply mix. Journal of Cleaner Production, v. 18, n. 10-11, p. 1021-1030, jul. 2010.

BÖHMER, S. et al. Aggregates case study - Final report. Viena: Umweltbundesamt, 2008.

BOSCOV, M. E. G. Brazilian experience in geo-environmental applications of tropical soils. 6th International Congress on Environmental Geotechnics. Anais... In: 6ICEG. New Delhi: 2010 
BRASIL. Portaria $n^{0} 2914$. Portaria $n^{0} 2914$ - Dispõe sobre os procedimentos de controle e de vigilância da água para consumo humano e seu padrão de potabilidade. . de dezembro de 2011.

BRODERSEN, J.; JUUL, J.; JACOBSEN, H. Review of selected waste streams: Sewage sludge, construction and demolition waste, waste oils, waste from coal-fired power plants and biodegradable municipal waste $2002 . \quad$ Disponível em: <http://www.eea.europa.eu/publications/technical_report_2001_69>. Acesso em: 20 nov. 2015

CAIRES, S. M. Determinação dos teores naturais de metais pesados em solos do estado de Minas Gerais como subsídio ao estabelecimento dos valores de referência de qualidade. Tese (Doutorado)-[s.l.] Universidade Federal de Viçosa, 2009.

CHITTOORI, B. et al. Sustainable Reutilization of Excavated Trench Material. In: GeoCongress 2012. [s.I.] American Society of Civil Engineers, 2012. p. 4280-4289.

COCHRAN, K. et al. Estimation of regional building-related C\&D debris generation and composition: Case study for Florida, US. Waste Management, v. 27, n. 7, p. 921-931, 2007.

CONAMA. 307. Resolução $n^{\circ}$ 307. . 7 maio 2002.

CORONADO, M. et al. Estimation of Construction and Demolition Waste (C\&DW) Generation and Multicriteria Analysis of C\&DW Management Alternatives: A Case Study in Spain. Waste and Biomass Valorization, v. 2, n. 2, p. 209-225, 18 fev. 2011.

DE MELO, A. B.; GONÇALVES, A. F.; MARTINS, I. M. Construction and demolition waste generation and management in Lisbon (Portugal). Resources, Conservation and Recycling, v. 55, n. 12, p. 1252-1264, out. 2011.

DEFRA. Construction Code of Practice for the Sustainable Use of Soils on Construction Sites. Reino Unido: DEPARTMENT FOR ENVIRONMENT, FOOD AND RURAL AFFAIRS, 2009.

DELGADO, L. et al. End-of-waste criteria: final report. [s.l.] European Commission, 2009. Disponível em: <http://ftp.jrc.es/EURdoc/JRC53238.pdf>. Acesso em: 2 out. 2015.

DESTATIS. Environment: Waste Balance 2011Federal Statistical Office, , 2013. Disponível em: $<$ https://www.destatis.de/EN/FactsFigures/NationalEconomyEnvironment/Enviro nment/EnvironmentalSurveys/WasteManagement/Tables/WasteBalance2011.p df?_blob=publicationFile>. Acesso em: 26 nov. 2015 
DNER. DNER-CLA 259/96. Classificação de solos tropicais para finalidades rodoviárias utilizando corpos-de-prova compactados em equipamento miniatura. . 1996.

DOAK, M. The future of excavated contaminated/brownfield site materials: new policy and practice across the EU. Land Contamination and Reclamation, v. 12, n. 4, p. 309-322, 2004.

DUAN, H.; WANG, J.; HUANG, Q. Encouraging the environmentally sound management of $C \& D$ waste in China: An integrative review and research agenda. Renewable and Sustainable Energy Reviews, v. 43, p. 611-620, mar. 2015.

EHRLICH, M.; BECKER, L. D. B. Reinforced soil wall measurements and predictions. . In: 9TH INTERNATIONAL CONFERENCE ON GEOSYNTHETICS - GEOSYNTHETICS: ADVANCED SOLUTIONS FOR A CHALLENGING WORLD, ICG 2010. 2010

ENVIRONMENTAL PROTECTION DEPARTMENT. Monitoring of solid waste in Hong Kong - Waste Statistics for 2014. [s.I.] Environmental Protection Department of Hong Kong, 2015.

ERAS, J. J. C. et al. Improving the environmental performance of an earthwork project using cleaner production strategies. Journal of Cleaner Production, Cleaner Production: initiatives and challenges for a sustainable worldCP Initiatives \& Challenges. v. 47, p. 368-376, maio 2013.

ESIN, T.; COSGUN, N. A study conducted to reduce construction waste generation in Turkey. Building and Environment, v. 42, n. 4, p. 1667-1674, abr. 2007.

EUROSTAT. Waste statistics, 2012. [s.I: s.n.]. Disponível em: $<$ http://ec.europa.eu/eurostat/statistics-explained/index.php/Waste_statistics>. Acesso em: 12 jan. 2015.

FADIGAS, F. DE S. et al. Natural contents of heavy metals in some brazilian soil classes. Bragantia, v. 61, n. 2, p. 151-159, ago. 2002.

FERREIRA, J. G. Avaliação de parâmetros ambientais em aterros sanitários: estudo de caso. Dissertação (Mestrado)-[s.l.] Universidade de Taubaté, 2006.

FRAYE, J.; VISSER, E. L. The interaction between soil and waste legislation in ten European Union Countries. Network for Industrially Contaminated Land in Europe. [s.l: s.n.].

GANGOLELLS, M. et al. Predicting on-site environmental impacts of municipal engineering works. Environmental Impact Assessment Review, v. 44, p. 4357, jan. 2014. 
GODOY, H. DE. Identificação e classificação geotécnica de latossolos do Estado de São Paulo pelo método das pastilhas MCT. Tese (Doutorado)[s.l.] Universidade de São Paulo, 9 maio 1997.

GRIFFITHS, J. S.; RADFORD, T. An introduction to earthworks in Europe. Geological Society, London, Engineering Geology Special Publications, v. 26, n. 1, p. 1-4, 1 jan. 2012.

GÜNTHER, W. M. R. Áreas contaminadas no contexto da gestão urbana. São Paulo em Perspectiva, v. 20, n. 2, p. 105-117, 2006.

HAO, J. L.; HILLS, M. J.; HUANG, T. A simulation model using system dynamic method for construction and demolition waste management in Hong Kong. Construction Innovation, v. 7, n. 1, p. 7-21, 23 jan. 2007.

HASHIMOTO, S.; TANIKAWA, H.; MORIGUCHI, Y. Where will large amounts of materials accumulated within the economy go? - A material flow analysis of construction minerals for Japan. Waste Management, v. 27, n. 12, p. 17251738, 2007.

HOWARD, A. The Five Types of Pipeline Trenches. In: ICPTT 2011. [s.I.] American Society of Civil Engineers, 2011. p. 1104-1114.

HOWARD, A. et al. Lean, Green, and Mean: The IPL Project. In: ICSDEC 2012. [s.I.] American Society of Civil Engineers, 2013. p. 359-366.

HUANG, S.-L.; HSU, W.-L. Materials flow analysis and emergy evaluation of Taipei's urban construction. Landscape and Urban Planning, v. 63, n. 2, p. $61-74,15$ abr. 2003a.

HUANG, S.-L.; HSU, W.-L. Materials flow analysis and emergy evaluation of Taipei's urban construction. Landscape and Urban Planning, v. 63, n. 2, p. 61-74, 15 abr. 2003b.

JANG, Y.-C.; TOWNSEND, T. Sulfate leaching from recovered construction and demolition debris fines. Advances in Environmental Research, v. 5, n. 3, p. 203-217, 2001.

KARTAM, N. et al. Environmental management of construction and demolition waste in Kuwait. Waste Management, v. 24, n. 10, p. 1049-1059, 2004.

KENLEY, R.; HARFIELD, T. Greening procurement: a research agenda for optimizing mass-haul during linear infrastructure construction. 2011.

KNOBELOCH, L. et al. Blue babies and nitrate-contaminated well water. Environmental Health Perspectives, v. 108, n. 7, p. 675-678, 2000.

KOFOWOROLA, O. F.; GHEEWALA, S. H. Estimation of construction waste generation and management in Thailand. Waste Management, v. 29, n. 2, p. 731-738, fev. 2009. 
LAMBE, T. W. Soil Testing for Engineers. 1. ed. New York: John Wiley \& Sons, Inc., 1951. v. 1

LLATAS, C. A model for quantifying construction waste in projects according to the European waste list. Waste Management, v. 31, n. 6, p. 1261-1276, jun. 2011 a.

LLATAS, C. A model for quantifying construction waste in projects according to the European waste list. Waste Management, v. 31, n. 6, p. 1261-1276, jun. $2011 b$.

LOPES, A. S. Acidez do solo e calagem. Boletim Técnico, v. 1, p. 22, 1990.

MAGNUSSON, S. et al. Sustainable management of excavated soil and rock in urban areas - A literature review. Journal of Cleaner Production, v. 93, p. 1825, 15 abr. 2015.

MÁLIA, M. et al. Construction and demolition waste indicators. Waste management \& research: the journal of the International Solid Wastes and Public Cleansing Association, ISWA, v. 31, n. 3, p. 241-255, mar. 2013.

MANFREDI, S.; RANA, P. A. N. T. Supporting Environmentally Sound Decisions for Construction and Demolition (C\&D) Waste Management - A practical guide to Life Cycle Thinking (LCT) and Life Cycle Assessment (LCA). [s.I.] European Commission, 2011.

MASSAD, F. Obras de terra: curso básico de Geotecnia. 2. ed. São Paulo: Oficina de Textos, 2010.

MERINO, M. DEL R.; GRACIA, P. I.; AZEVEDO, I. S. W. Sustainable construction: construction and demolition waste reconsidered. Waste Management \& Research, v. 28, n. 2, p. 118-129, 1 fev. 2010.

MIRSAL, I. A. Soil pollution origin, monitoring \& remediation. 2nd ed. ed. Berlin: Springer, 2008.

MONIER, V. et al. Study on the management of construction and demolition waste in the E.U. [s.I: s.n.].

MOON, H. et al. Earth Information System (EIS) for the Reuse of Resources between Construction Sites. Journal of Asian Architecture and Building Engineering, v. 6, n. 2, p. 267-274, 2007.

MYHRE, L. The state of deconstruction in Norway. In: Overview of Deconstruction in Selected Countries. Amsterdam: International Council for Research and Innovation in Building Construction, 2000. p. 144-157.

NATHANAIL, C. P. Generic and site-specific criteria in assessment of human health risk from contaminated soil. Soil Use and Management, v. 21, p. 500507, 1 dez. 2005. 
NEVILLE, A. The confused world of sulfate attack on concrete. Cement and Concrete Research, v. 34, n. 8, p. 1275-1296, ago. 2004.

NOGAMI, J. S.; COZZOLINO, V. M. N.; VILLIBOR, D. F. Meaning of coefficients and index of MCT soil classification for tropical soils. Proc. 12th international conference on soil mechanics and foundation engineering, Rio de Janeiro, 1989. Vol. 1, p. 547-550, 1990.

NOGAMI, J. S.; VILLIBOR, D. F. Pavimentação de baixo custo com solos lateríticos. São Paulo: Villibor, 1995.

NOMACHI, R. Y. G.; BOSCOV, M. E. G. Caracterização do material escalpado de resíduos de construção civil reciclados para uso geotécnico. 2016. Universidade de São Paulo: Conselho Nacional de Desenvolvimento Científico e Tecnológico, 2016.

PALMEIRA, E. M. Soil-geosynthetic interaction: Modelling and analysis. Geotextiles and Geomembranes, v. 27, n. 5, p. 368-390, out. 2009.

PETERSEN, L.; MINKKINEN, P.; ESBENSEN, K. H. Representative sampling for reliable data analysis: Theory of Sampling. Chemometrics and Intelligent Laboratory Systems, FESTSCHRIFT HONOURING PROFESSOR D.L. MASSARTMassart S.I. v. 77, n. 1-2, p. 261-277, 28 maio 2005.

PINHEIRO, R. A.; FISCH, S. T. V.; ALMEIDA, A. DE. A cobertura vegetal e as características do solo em área de extração de areia. Revista Biociências, v. 10, n. 3, 31 ago. 2008.

PMSP. IR-01/2004. IR - 01: Instrução de reparação de pavimentos flexíveis danificados por abertura de valas. . 2004.

POON, C. S. et al. Quantifying the Impact of Construction Waste Charging Scheme on Construction Waste Management in Hong Kong. Journal of Construction Engineering and Management, v. 139, n. 5, p. 466-479, 2013.

RESENDE, Á. V. DE. Agriculture and water quality: water contamination by nitrateEmbrapa, , 2002.

RICCIO, M.; EHRLICH, M. Prediction of tension in the reinforcement in a full scale block-faced geogrid reinforced soil wall using Fine-grained tropical soil as backfill. . In: 9TH INTERNATIONAL CONFERENCE ON GEOSYNTHETICS - GEOSYNTHETICS: ADVANCED SOLUTIONS FOR A CHALLENGING WORLD, ICG 2010. 2010

RODRIGUES, S. M. et al. A review of regulatory decisions for environmental protection: part I - challenges in the implementation of national soil policies. Environment International, v. 35, n. 1, p. 202-213, jan. 2009.

ROJAS, C. M.; CINCOTTO, M. A. Influence of polycarboxylate molecular structure on Portland cement hydration. Ambiente Construído, v. 13, n. 3, p. 267-283, set. 2013. 
SABESP. NTS 224. NTS 224: SOPAC - Sistema otimizado de pavimentação concomitante. . 2006.

SAEFL. Reuse of excavated soils guidelines (soil excavation guideline). Suíça: Swiss Agency for the Environment, Forests and Landscape, 2002.

SÁEZ, P. V. et al. European Legislation and Implementation Measures in the Management of Construction and Demolition Waste. The Open Construction and Building Technology Journal, v. 5, n. 1, p. 156-161, 22 dez. 2011.

SANTOS, E. C. G. DOS. Aplicação de resíduos de construção e demolição reciclados (RCD-R) em estruturas de solo reforçado. Dissertação (Mestrado)—[s.I.] Universidade de São Paulo, 6 mar. 2007.

SANTOS, E. C. G. DOS. Avaliação experimental de muros reforçados executados com resíduos de construção e demolição reciclados (RCD-R) e solo fino. Tese (Doutorado) - [s.I.] Universidade de Brasília, Faculdade de Tecnologia, Departamento de Engenharia Civil, 2011.

SANTOS, F. C.; ALBUQUERQUE FILHO, M. R. Importância da Matéria Orgânica e Cobertura Vegetal para os Solos Arenosos do Cerrado. Grupo Cultivar, p. 1, 2007.

SCRIVENER, K.; SNELLINGS, R.; LOTHENBACH, B. A Practical Guide to Microstructural Analysis of Cementitious Materials. [s.I.] CRC Press, 2015.

SEPA. Regulatory guidance: promoting the sustainable reuse of greenfield soils in constructionScottish Environment Protection Agency, , 2010.

SHANG, C.; ZHU, Y.; ZHANG, Z. A glance at the world. Waste Management, v. 33, n. 2, p. 489-492, fev. 2013.

SINDUSCON-SP. Manual Gestão Ambiental de Resíduos da Construção CivilSinduscon-SP, $2015 . \quad$ Disponível em: <http://www.sindusconsp.com.br/biblioteca/manual-gestao-ambienta-de-

residuos-da-construcao-civil/>. Acesso em: 21 nov. 2015

SMA; CETESB. Panorama dos resíduos sólidos do Estado de São Paulo versão preliminar. São Paulo: Secretaria do Meio Ambiente e Companhia Ambiental do Estado de São Paulo, 2015.

SMA; SINDUSCON-SP. Resíduos da construção civil e o Estado de São Paulo. [s.l: s.n.]. Disponível em: <http://www.sindusconsp.com.br/envios/2012/informativo/residuos/residuos_co nstrucao_civil_sp.pdf>. Acesso em: 2 out. 2015.

SMITH, K.; O'FARRELL, K.; BRINDLEY, F. Waste and Recycling in Australia 2011. [s.l.] Department of Sustainability, Environment, Water, Population and Communities of Australian Government, 2011. Disponível em: <https://www.environment.gov.au/system/files/resources/b4841c02-229b-4ff48b3b-ef9dd7601d34/files/waste-recycling2011.pdf>. Acesso em: 26 nov. 2015. 
SOUZA PINTO, C. Curso básico de Mecânica dos Solos. São Paulo: Oficina de Textos, 2000.

SUER, P.; WIK, O.; ERLANDSSON, M. Reuse and recycle - Considering the soil below constructions. Science of The Total Environment, v. 485-486, p. 792-797, 1 jul. 2014.

SUSSET, B.; GRATHWOHL, P. Leaching standards for mineral recycling materials - A harmonized regulatory concept for the upcoming German Recycling Decree. Waste Management, Environmental Implications of Alternative Materials in Construction and Treatment of Waste. v. 31, n. 2, p. 201-214, fev. 2011.

TAYLOR, D. W. Fundamentals of Soil Mechanics. 5. ed. New York: John Wiley \& Sons, Inc., 1948. v. 1

TERZAGHI, K.; PECK, R. B.; MESRI, G. Soil mechanics in engineering practice. 3. ed. New York: John Wiley \& Sons, Inc., 1996. v. 1

TOWNSEND, T.; JANG, Y.; THURN, L. Simulation of Construction and Demolition Waste Leachate. Journal of Environmental Engineering, v. 125, n. 11, p. 1071-1081, 1 nov. 1999.

ULSEN, C. et al. Separability studies of construction and demolition waste recycled sand. Waste Management, Special Thematic Issue: Urban MiningUrban Mining. v. 33, n. 3, p. 656-662, mar. 2013.

VEDRONI, J. W. Estudo de caso sobre a utilização do RCD (residuos de construção e demolição) em reaterros de valas nos pavimentos de Piracicaba SP. Dissertação (Mestrado)-[s.I.] Universidade Estadual de Campinas, 27 fev. 2007.

VILLIBOR, D. F. et al. Pavimentos de baixo custo para vias urbanas. 2. ed. São Paulo: Arte \& Ciência, 2009.

WAHLSTRÖM, M. et al. Environmental quality assurance system for use of crushed mineral demolition wastes in road constructions. Waste Management, v. 20, n. 2-3, p. 225-232, abr. 2000.

WALLACE, S. Sustainable waste management in contaminated land redevelopment. Land Contamination \&amp; Reclamation, v. 12, n. 2, p. 101107, 2004.

WEISLEDER, S.; NASSERI, D. Construction and demolition waste management in Germany. Hamburg: Zebau, G., 2006.

WHO. Guidelines for drinking-water quality - 4th edition incorporating the first addendumWorld Health Organization, , 2017. Disponível em: <http://www.who.int/water_sanitation_health/publications/drinking-water-qualityguidelines-4-including-1st-addendum/en/>. Acesso em: 21 fev. 2017 
WRAP. Identifying opportunities for recycling of excavated spoil from utility works within local authority areas, and promoting the use of recycled materials through good practice in procurement. Reino Unido: WRAP AND RESOURCES ACTION PROGRAM, 2005.

WRAP. Recycled and Stabilised Materials in Trench Reinstatement. Reino Unido: WRAP AND RESOURCES ACTION PROGRAM, 2007.

WRAP. Sustainable geosystems in civil engineering applications. Reino Unido: WRAP AND RESOURCES ACTION PROGRAM, 2010. 


\section{Apêndice A - Cálculo da massa mínima representativa}

A massa minima representativa das amostras (Tabela A-1) foi calculada pelas equações 1-3 (ANGULO \& MUELLER, 2008; PETERSEN; MINKKINEN; ESBENSEN, 2005).

A massa representativa necessária de amostra foi calculada de acordo com a Eq. A.1

$M=\frac{C \times d^{3}}{\left(\frac{s}{100}\right)^{2}}$

onde $C$ é a constante de amostragem $\left(\mathrm{g} / \mathrm{cm}^{3}\right)$ calculada pela Eq. A.2, $d o$ diâmetro máximo das partículas $(\mathrm{cm}), s$ o coeficiente de variação $(10 \%)$.

$C=c \times \mathrm{f} \times \mathrm{g} \times \beta$

onde $C$ é a constant de amostragem $\left(\mathrm{g} / \mathrm{cm}^{3}\right), c$ é o fator de composição do RCC $\left(\mathrm{g} / \mathrm{cm}^{3}\right)$ calculado pela Eq. A.3, $f$ o fator de forma das partículas (assumido como 0,5 , equivalente à forma cúbica ou esférica), $g \circ$ fator de distribuição de tamanho que considera a variação no tamanho das partículas $(0,5), \beta$ o fator de liberaçãor $(1,0$, equivalente a fases totalmente liberadas, quando o solo $\mathrm{e}$ grãos de cimento / cerâmica de RCC são comparados)

$c=\frac{(1-a / \alpha)^{2}}{a / \alpha} \times \rho_{c}+(1-a / \alpha) \times \rho_{g}$

onde $c$ é o fator composicional para os materiais artificias (RCC) $\left(\mathrm{g} / \mathrm{cm}^{3}\right), a / \alpha$ é o teor de RCC $(\mathrm{kg} / \mathrm{kg}), \rho_{c}$ a densidade do RCC $\left(2,60 \mathrm{~g} / \mathrm{cm}^{3}\right), \rho_{g}$ a densidade do solo $\left(2,20 \mathrm{~g} / \mathrm{cm}^{3}\right)$. 
Tabela A-1 Massa mínima representativa das frações granulométricas observadas em imagens de microscopia

\begin{tabular}{|c|c|c|c|c|c|c|c|c|}
\hline Amostra & $\% \mathrm{RCC}^{*}$ & C & $f$ & $g$ & $\beta$ & C & $\begin{array}{l}\text { Fração } \\
\text { granulométrica } \\
(\mathrm{mm})\end{array}$ & $\begin{array}{l}\text { Massa mínima } \\
\text { (g) }\end{array}$ \\
\hline \multirow{4}{*}{ B-23 } & \multirow{4}{*}{0.07} & \multirow{4}{*}{34.17} & \multirow{4}{*}{0.50} & \multirow{4}{*}{0.50} & \multirow{4}{*}{1.00} & \multirow{4}{*}{8.54} & $2.0-1.2$ & 6.83 \\
\hline & & & & & & & $1.2-0.6$ & 1.48 \\
\hline & & & & & & & $0.6-0.4$ & 0.18 \\
\hline & & & & & & & $0.4-0.1$ & 0.05 \\
\hline \multirow{4}{*}{ B-15 } & \multirow{4}{*}{0.11} & \multirow{4}{*}{20.68} & \multirow{4}{*}{0.50} & \multirow{4}{*}{0.50} & \multirow{4}{*}{1.00} & \multirow{4}{*}{5.17} & $2.0-1.2$ & 4.14 \\
\hline & & & & & & & $1.2-0.6$ & 0.89 \\
\hline & & & & & & & $0.6-0.4$ & 0.11 \\
\hline & & & & & & & $0.4-0.1$ & 0.03 \\
\hline \multirow{4}{*}{ B-7 } & \multirow{4}{*}{0.23} & \multirow{4}{*}{8.40} & \multirow{4}{*}{0.50} & \multirow{4}{*}{0.50} & \multirow{4}{*}{1.00} & \multirow{4}{*}{2.10} & $2.0-1.2$ & 1.68 \\
\hline & & & & & & & $1.2-0.6$ & 0.36 \\
\hline & & & & & & & $0.6-0.4$ & 0.05 \\
\hline & & & & & & & $0.4-0.1$ & 0.01 \\
\hline \multirow{4}{*}{ B-12 } & \multirow{4}{*}{0.51} & \multirow{4}{*}{2.34} & \multirow{4}{*}{0.50} & \multirow{4}{*}{0.50} & \multirow{4}{*}{1.00} & \multirow{4}{*}{0.59} & $2.0-1.2$ & 0.47 \\
\hline & & & & & & & $1.2-0.6$ & 0.10 \\
\hline & & & & & & & $0.6-0.4$ & 0.01 \\
\hline & & & & & & & $0.4-0.1$ & 0.004 \\
\hline & & & & & & & $2.0-1.2$ & 0.38 \\
\hline & & & & & & & $1.2-0.6$ & 0.08 \\
\hline B-4 & 0.56 & 1.89 & 0.50 & 0.50 & 1.00 & 0.47 & $0.6-0.4$ & 0.01 \\
\hline & & & & & & & $0.4-0.1$ & 0.003 \\
\hline & & & & & & & $2.0-1.2$ & 0.37 \\
\hline$D_{5}$ & 0,0 & & & & & 018 & $1.2-0.6$ & 0.08 \\
\hline B-5 & 0.56 & 1.84 & 0.50 & 0.50 & 1.00 & 0.46 & $0.6-0.4$ & 0.01 \\
\hline & & & & & & & $0.4-0.1$ & 0.003 \\
\hline & & & & & & & $2.0-1.2$ & 0.42 \\
\hline & & & & & & 0 & $1.2-0.6$ & 0.09 \\
\hline B-19 & 0.53 & 2.08 & 0.50 & 0.50 & 1.00 & 0.52 & $0.6-0.4$ & 0.01 \\
\hline & & & & & & & $0.4-0.1$ & 0.003 \\
\hline & & & & & & & $2.0-1.2$ & 0.95 \\
\hline & & & & & & & $1.2-0.6$ & 0.20 \\
\hline B-22 & 0.34 & 4.74 & 0.50 & 0.50 & 1.00 & 1.18 & $0.6-0.4$ & 0.03 \\
\hline & & & & & & & $0.4-0.1$ & 0.008 \\
\hline
\end{tabular}

* porcentagem de grãos com diâmetro mais que $4,8 \mathrm{~mm}$ (por peneiramento), assumidos como misturas de RCC por observação visual

c, f, g, $\beta, C$ são parâmetros definidos nas Eq. (A2) and Eq. (A3) 
Tabela A-2 Composição das amostras RCC-solo por imagens de microscopia

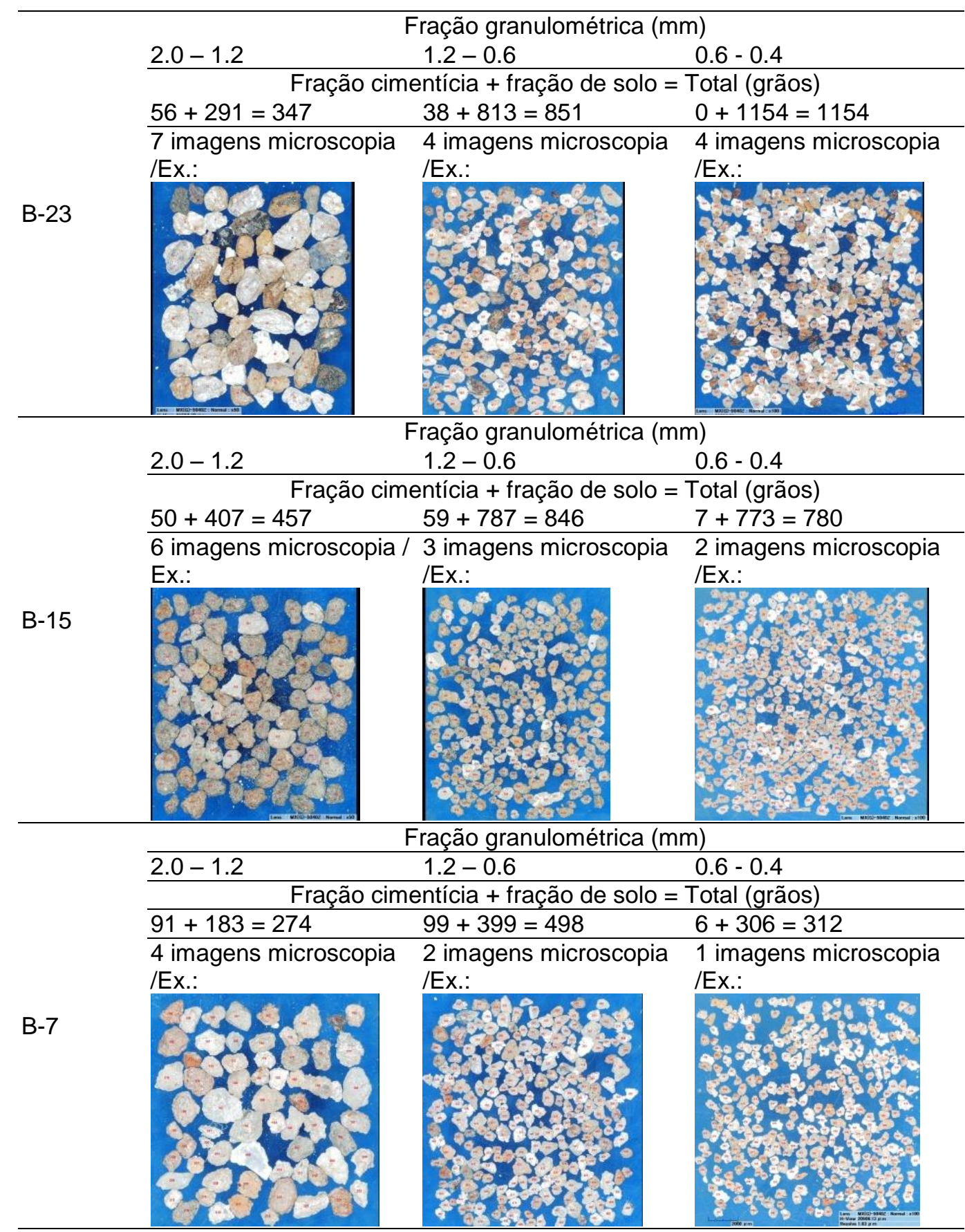


Tabela A-3 Composição das amostras RCC-mistura por imagens de microscopia

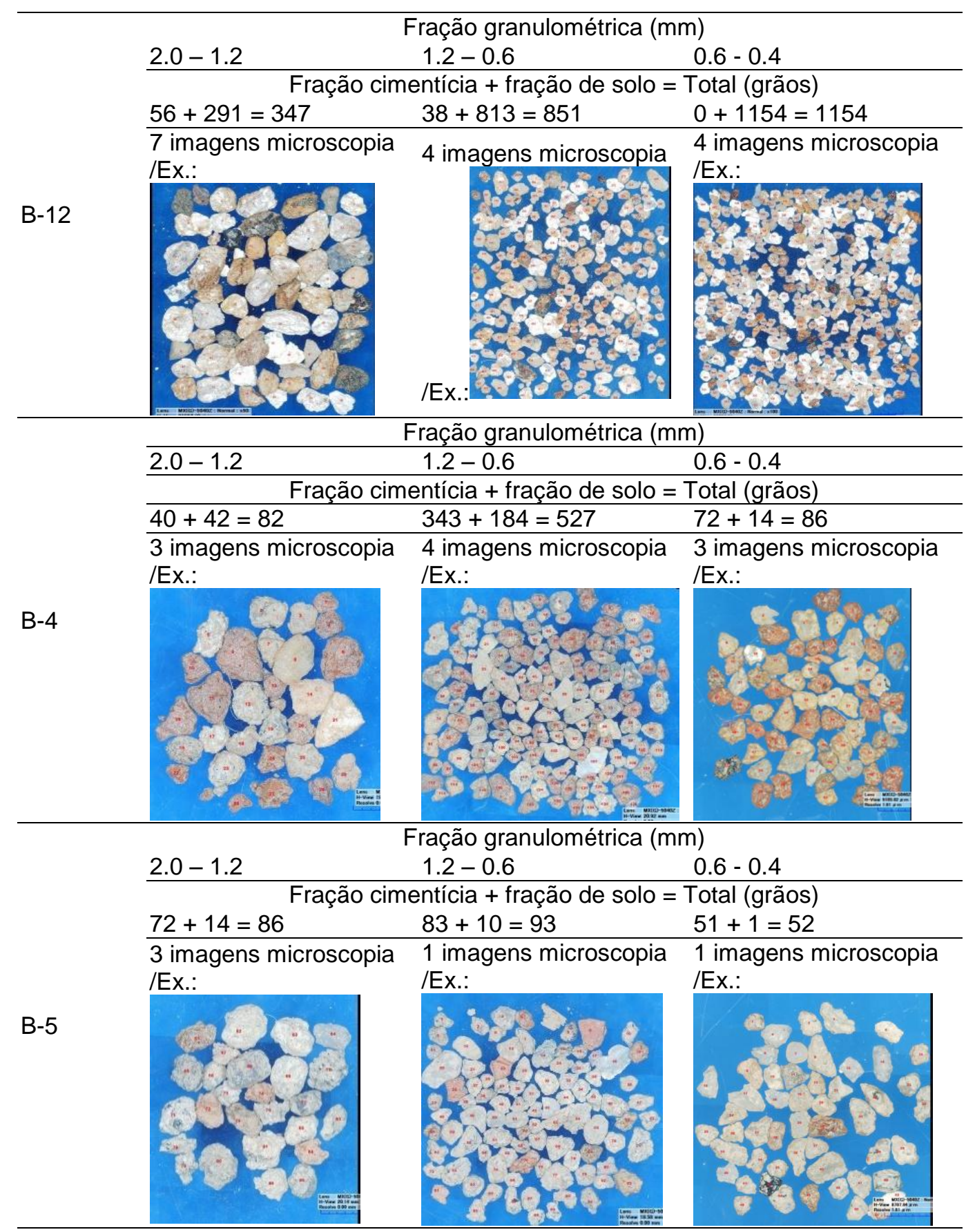


Tabela A-3 (continuação) Composição das amostras RCC-mistura por imagens de microscopia

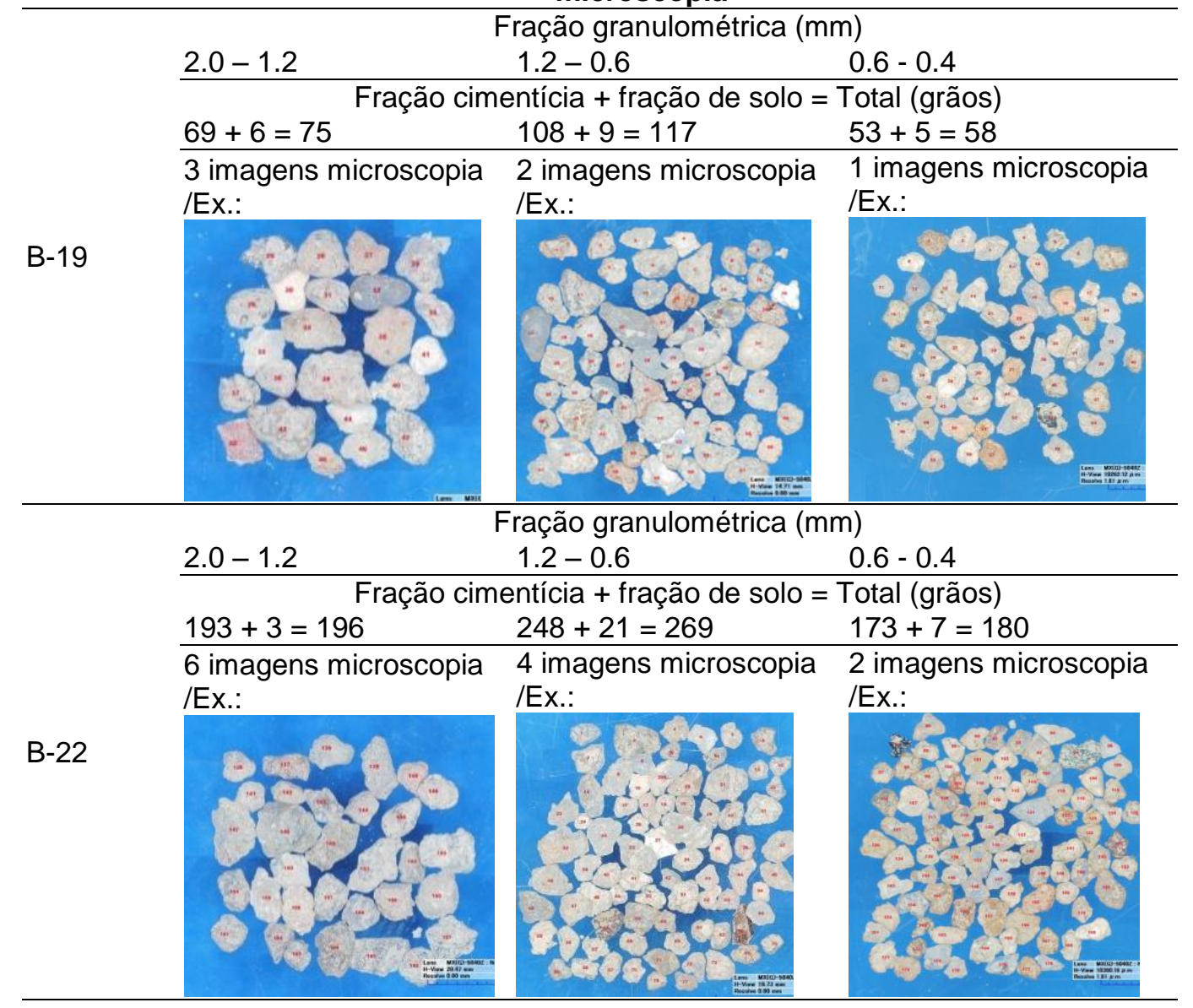




\section{Apendice B - Resultados dos ensaios geotécnicos da amostra B-7}

A amostra B-7 foi classificada visualmente como Solo.

\section{Granulometria}

A curva granulométrica está apresentada na Figura B-1. O solo é composto aproximadamente $33 \%$ de finos, $23 \%$ de pedregulho e $44 \%$ de areia.

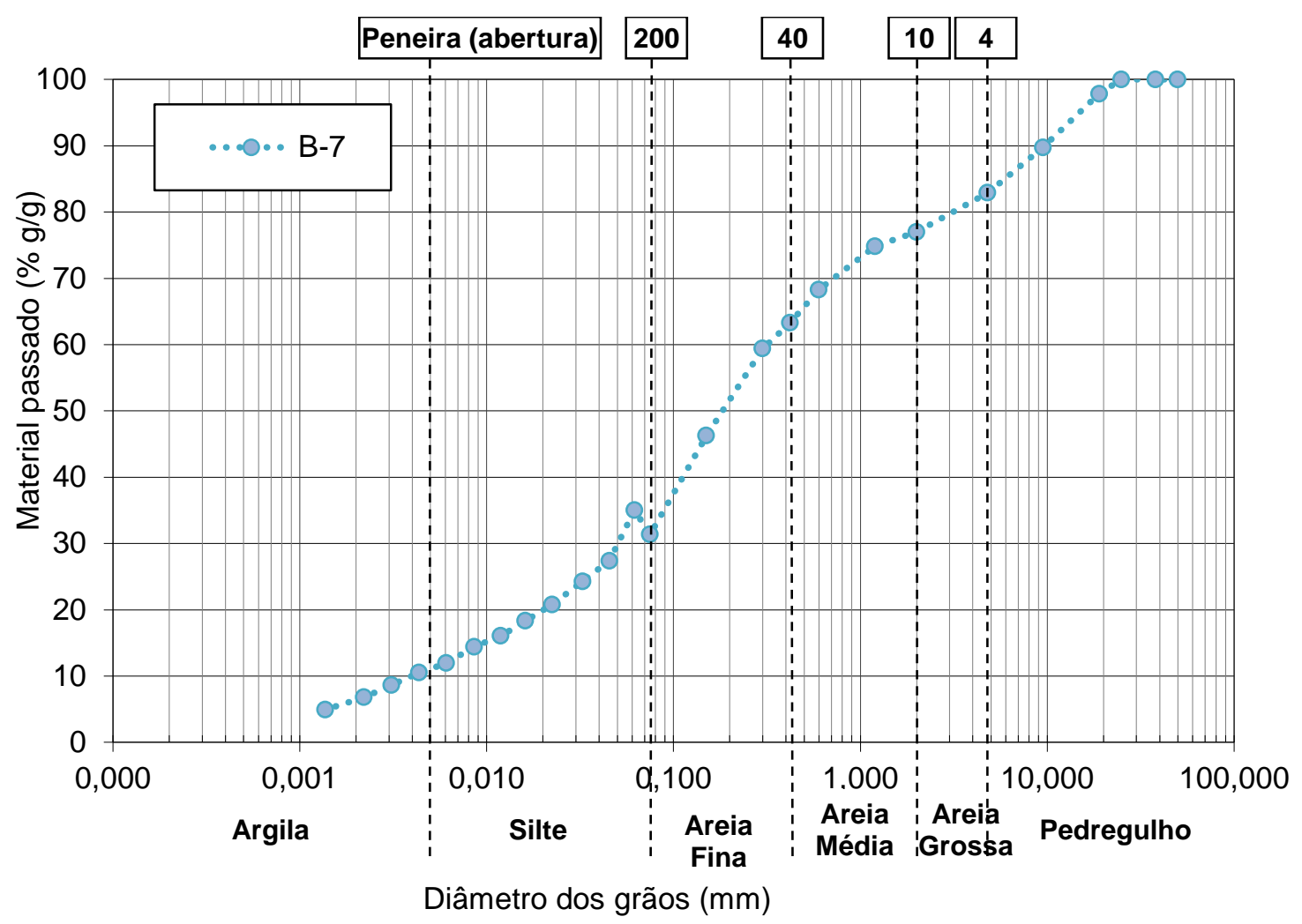

Figura B-1 Curva de distribuição granulométrica da amostra B-7

\section{LL, LP e Classificação}

No gráfico de teor de umidade (\%) por logaritmo de número de golpes podemos ajustar uma reta aos pontos experimentais (Figura B-2). Ao substituir o valor de $\mathrm{x}$ da equação da reta por 25 , temos o valor de $\mathrm{LL}$ de aproximadamente $27 \%$.

$$
L L=-2,672 \ln (25)+35,355 \cong 27 \%
$$

Entretanto, não conseguimos gerar o valor de LP, pois a amostra não conseguiu formar um cilindro. Os finos da amostra são, portanto, não plásticos. Sua classificação pelo Sistema Unificado de Classificação de Solos é, portanto, SM: 
- $S$ - Pois $44 \%$ da massa seca é de fração arenosa.

- M - Pois os finos são não plásticos.

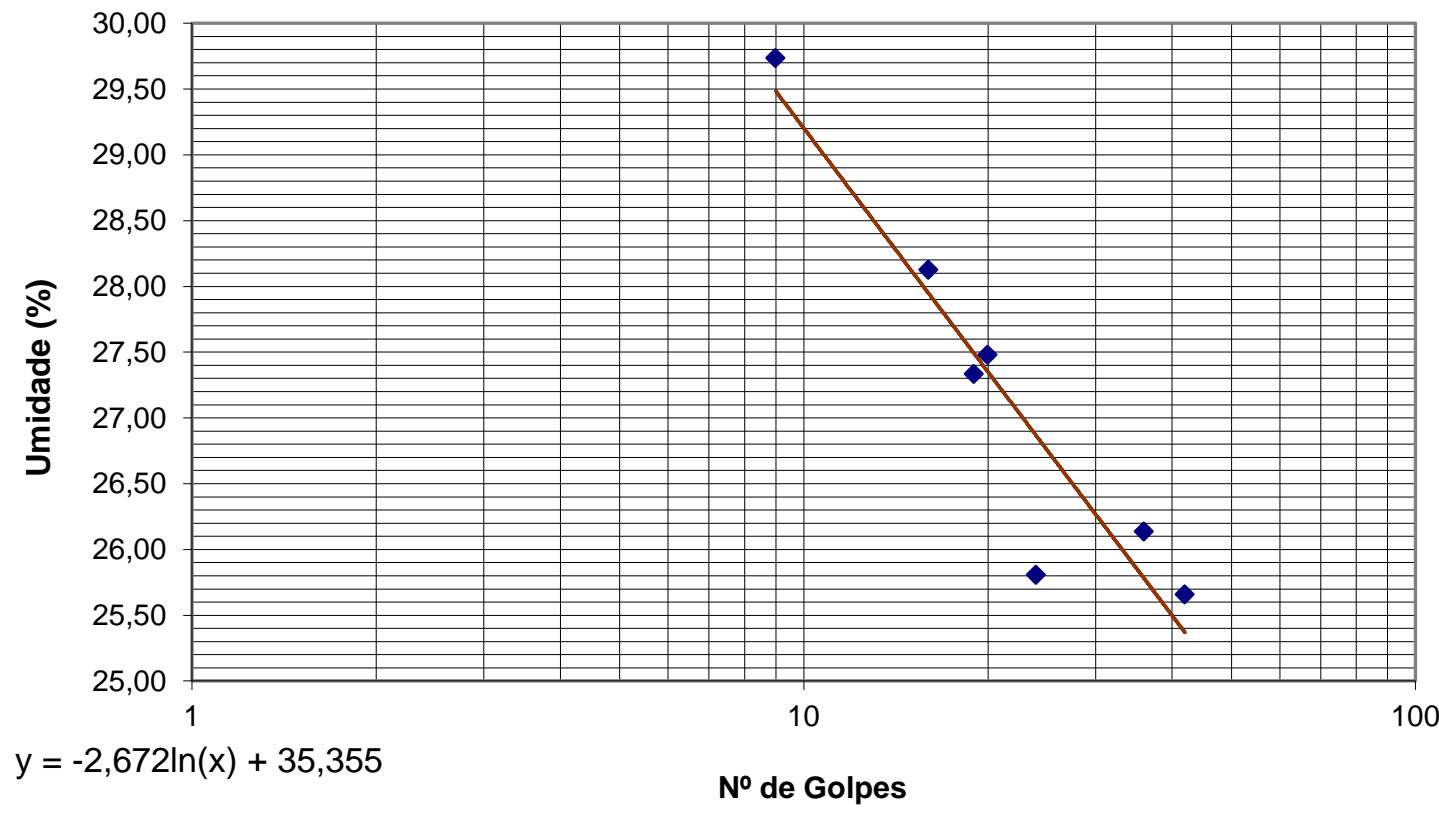

Figura B- 2 Teor de umidade em função do número de golpes (ensaio para determinar LL) para a amostra B-7

\section{Compactação}

Por meio do ensaio de compactação pode-se determinar a umidade que gera a maior densidade seca. Para a amostra B-7, a umidade ótima de 18,5\% gera uma densidade seca máxima de $1,66 \mathrm{~g} / \mathrm{cm}^{3}$ (Figura B- 3 .

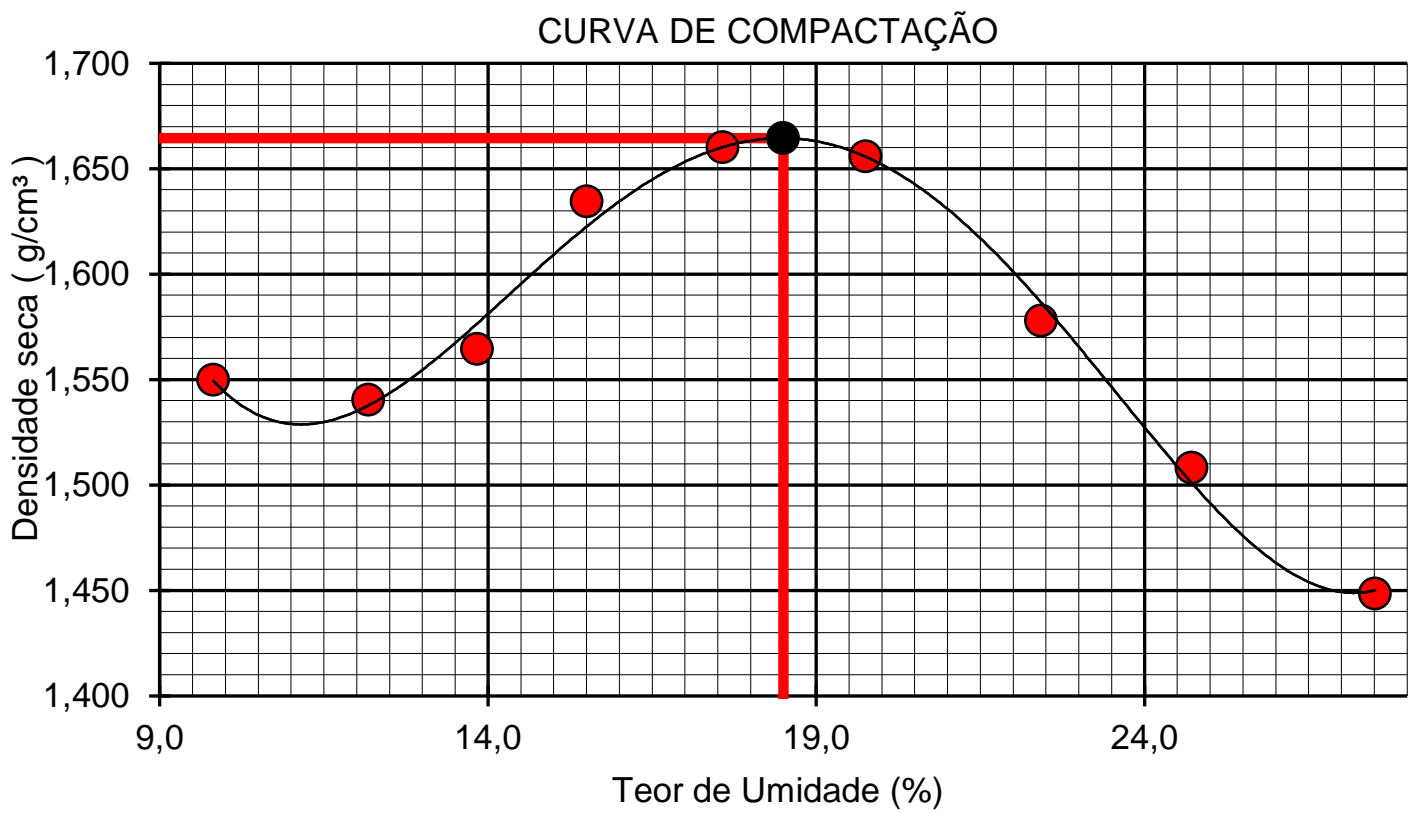

Figura B- 3 Curva de compactação da amostra B-7. 
$M C T$

Os gráficos fundamentais para conseguir os parâmetros da classificação MCT estão apresentados na Figura B- 4 e Figura B- 5. O primeiro gráfico representa a densidade seca em função do teor de umidade para cada número predeterminado de golpes. O segundo gráfico apresenta An (altura do corpode-prova medida no último golpe menos a medida do golpe anterior) em função do número de golpes. Cada série é uma parte da amostra com certo teor de umidade definido. Os parâmetros para a classificação do solo estão na Tabela B- 1.

Tabela B- 1 Parâmetros para classificação MCT - Amostra B-7

\begin{tabular}{ll}
\hline$C^{\prime}$ & 1,14 \\
\hline $\mathrm{Pl}$ & 290 \\
\hline $\mathrm{d}^{\prime}$ & 22,2 \\
\hline $\mathrm{e}^{\prime}$ & 1,56 \\
\hline Classe & $\mathrm{NS}^{\prime}$ \\
\hline
\end{tabular}

Portanto, a partir desses parâmetros podemos classificar o solo como NS', ou seja, é um solo não laterítico siltoso.

\section{Teor de Umidade x Densidade}

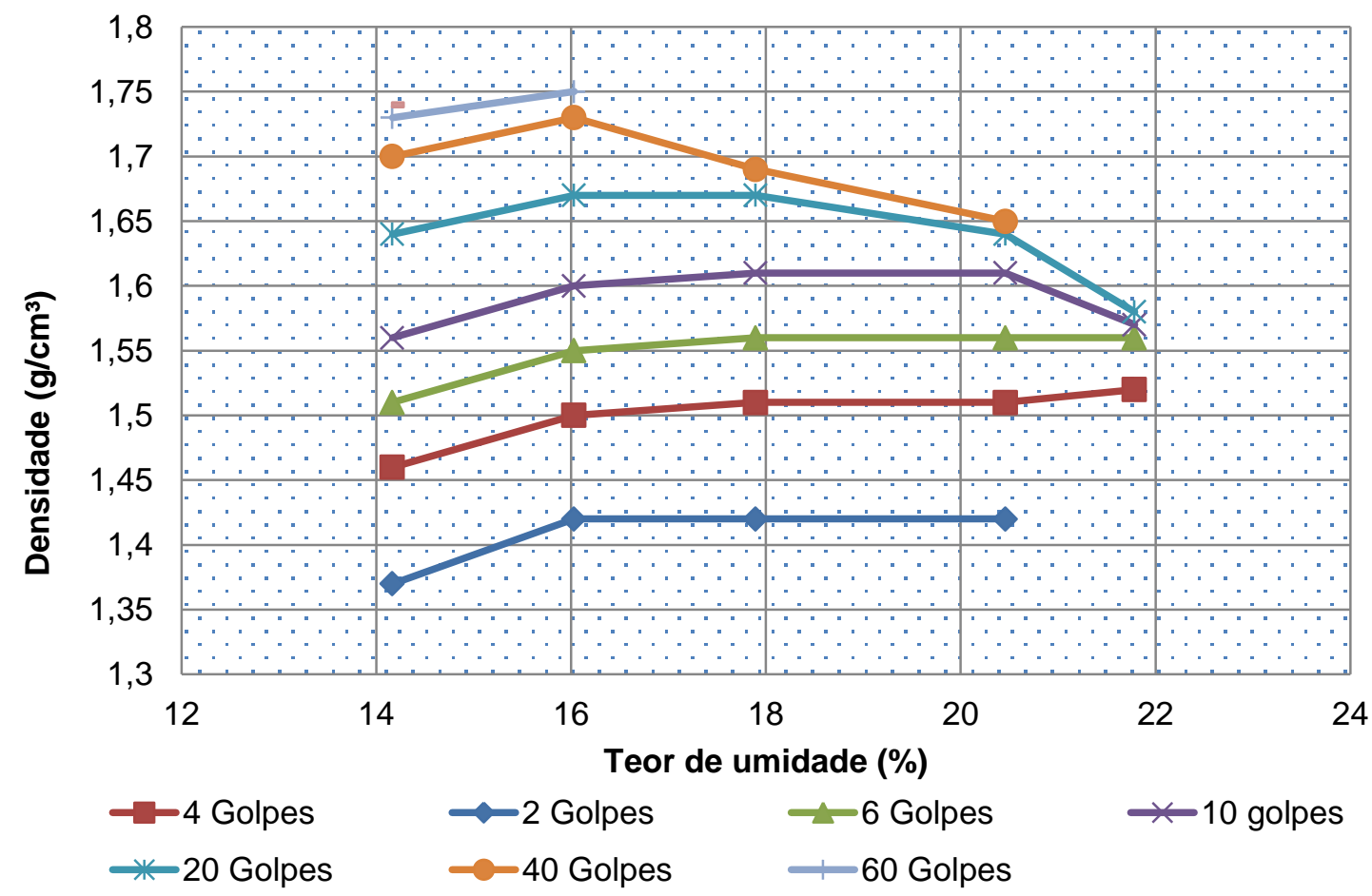

Figura B- 4 - Classificação MCT - Densidade seca x teor de umidade - Amostra B-7 


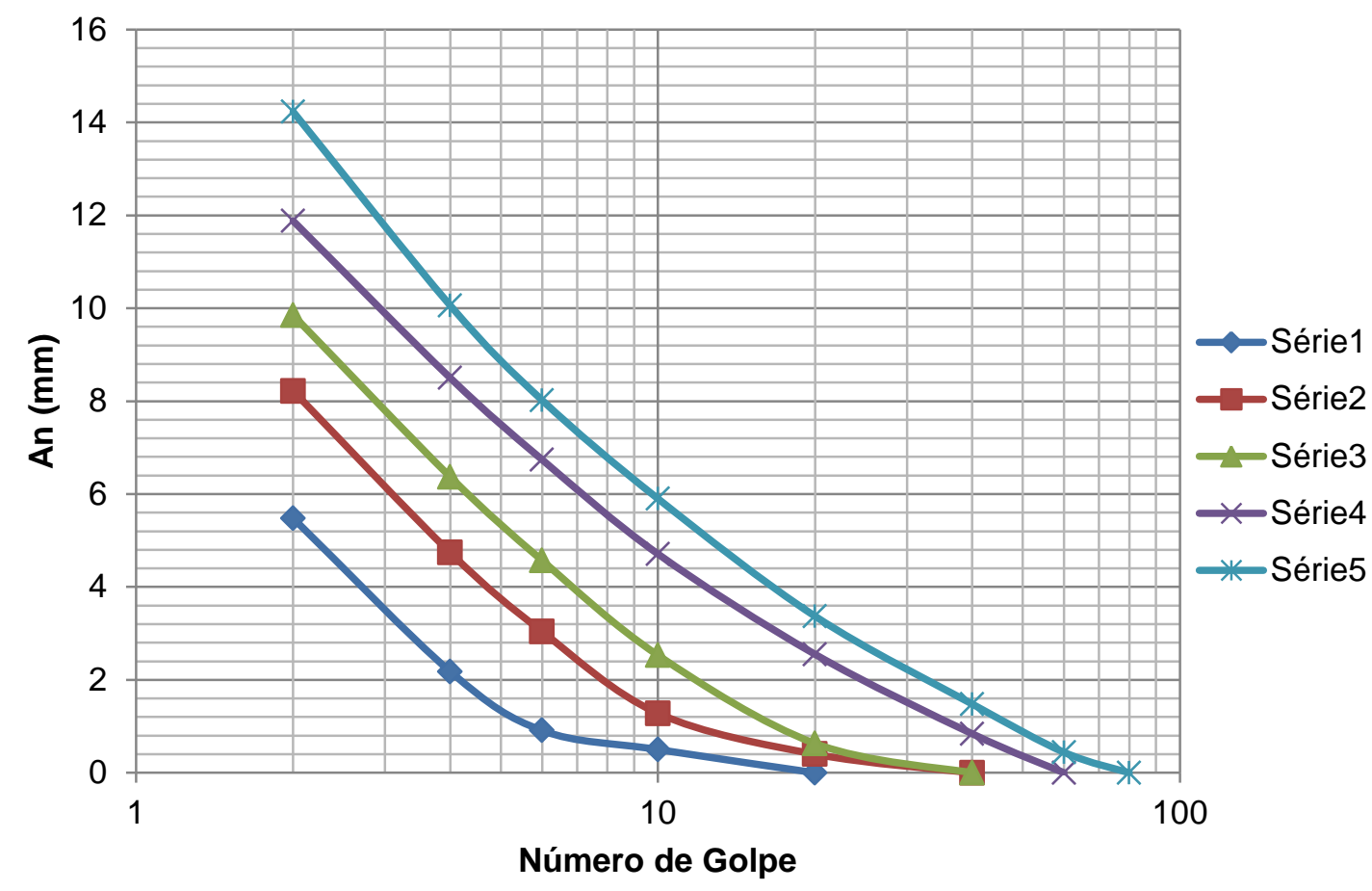

Figura B- 5 - Classificação MCT - An x número de golpes - Amostra B-7

\section{Resistência ao Cisalhamento}

Para cada ensaio de cisalhamento direto, foram obtidas as curvas de tensão de cisalhamento $(\mathrm{kPa})$ pelo deslocamento $(\mathrm{mm})$. A amostra foi ensaiada para tensões verticais de $100 \mathrm{kPa}, 200 \mathrm{kPa}$ e $400 \mathrm{kPa}$. Os resultados dos três ensaios estão apresentados na Figura B- 6 (NOMACHI \& BOSCOV, 2016). A Figura B- 7 (NOMACHI \& BOSCOV, 2016) mostra os pontos máximos desses ensaios, a partir dos quais pode-se determinar a envoltória de resistência do solo e os parâmetros c (coesão) e $\varphi$ (ângulo de atrito). 


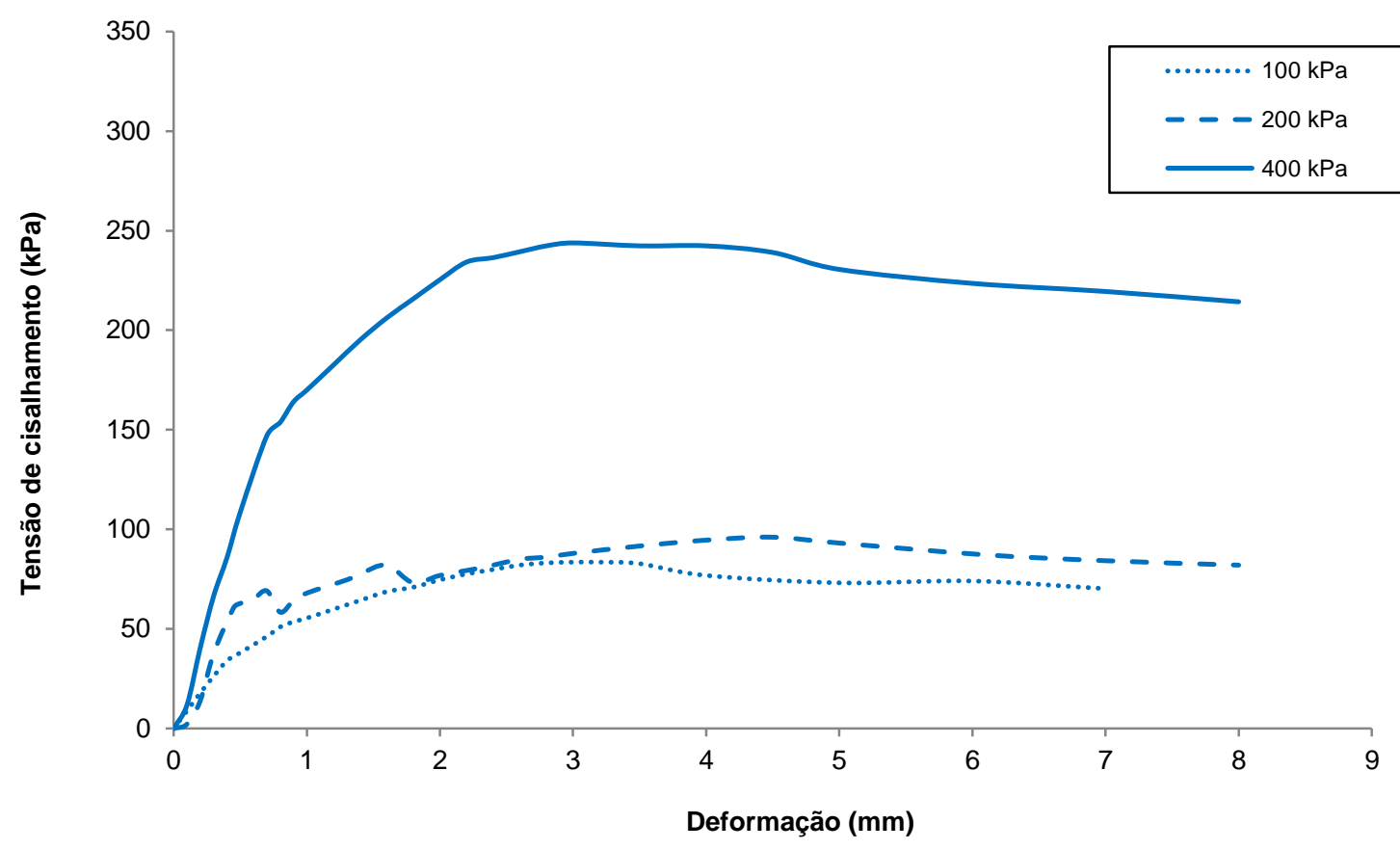

Figura B- 6 - Ensaios de cisalhamento direto com a amostra B-7

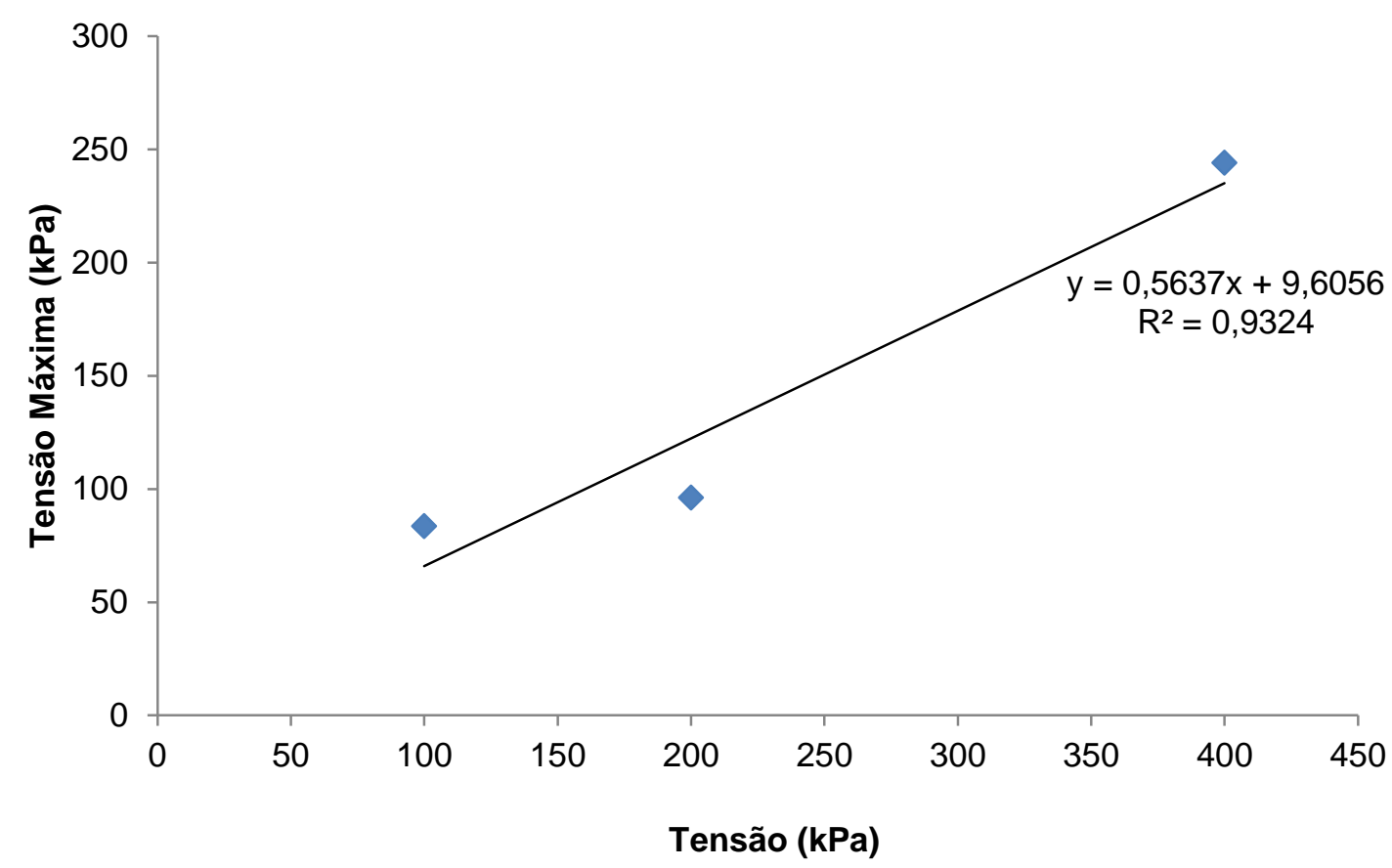

Figura B- 7 - Envoltória de resistência da amostra B-7.

A coesão e o ângulo de atrito são, respectivamente: c $=9,6 \mathrm{kPa}$ e $\varphi=29,4^{\circ}$. 
Mini-CBR e Expansão

A Figura B- 8 e a Figura B- 9 mostram, respectivamente, a variação do MiniCBR após imersão e da expansão em função do teor de umidade de compactação.

A amostra B-7 apresentou Mini-CBR menor que $4 \%$ para os três teores de umidade ensaiados.

A expansão diminui com o aumento da umidade de compactação, conforme 0 esperado. Amostra B-7 apresentou baixa expansão no ponto ótimo $(1,6 \%)$.

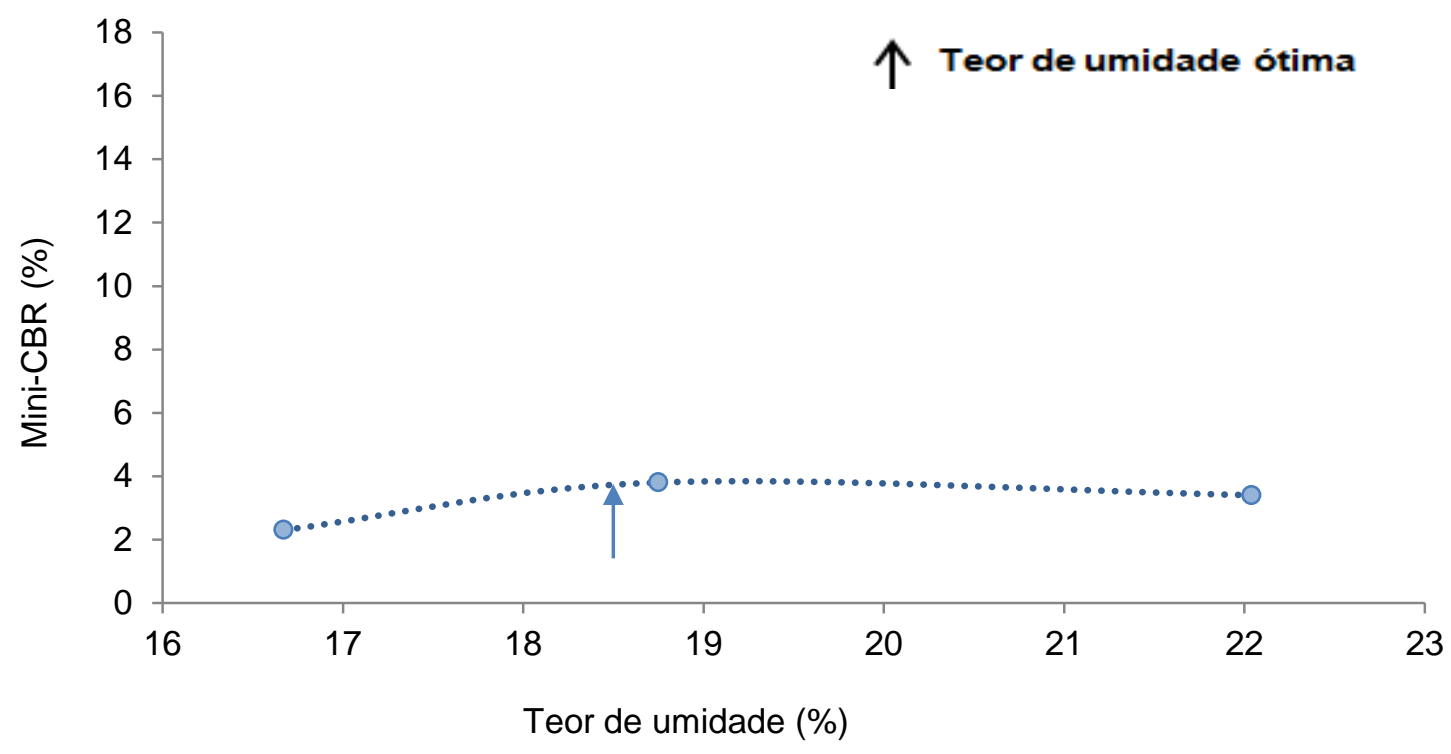

Figura B- 8 - Curva Mini-CBR da amostra B-7

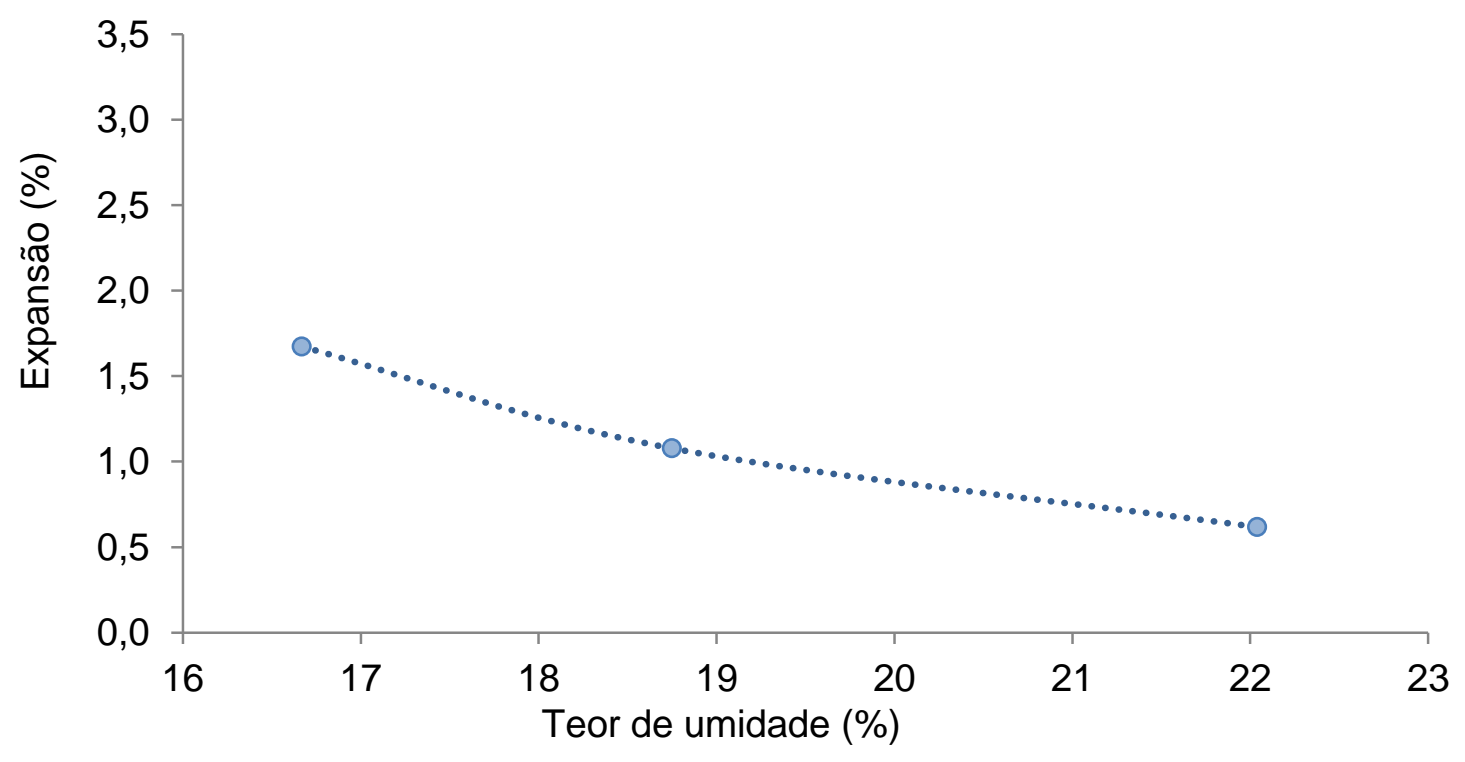

Figura B- 9 - Curva de expansão da amostra B-7 


\section{Apendice C - Resultados dos ensaios geotécnicos da amostra B-15}

A amostra B-15 foi classificada visualmente como Solo.

\section{Granulometria}

A curva granulométrica está apresentada na Figura C-1. O solo é composto por $38,75 \%$ de finos, $10,75 \%$ de pedregulhos e $50,50 \%$ de areia.

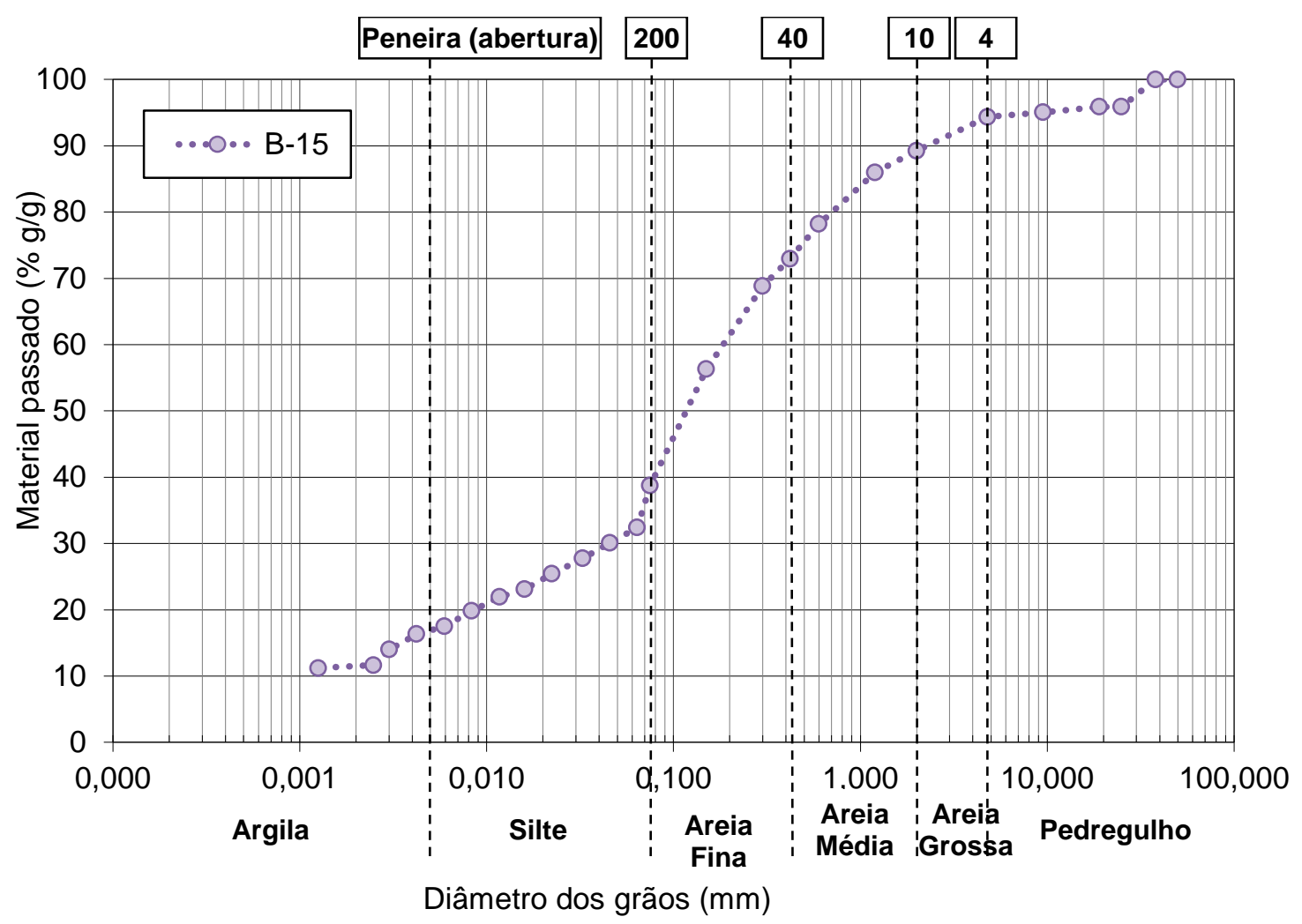

Figura C-1 Curva de distribuição granulométrica da amostra B-15

\section{LL,LP e Classificação}

No gráfico de teor de umidade (\%) por logaritmo de número de golpes podemos ajustar uma reta aos pontos experimentais (Figura C- 2). Ao substituir o valor de $x$ da equação da reta por 25, temos o valor de LL de aproximadamente $30 \%$.

$$
L L=-4,603 \ln (25)+44,552 \cong 30 \%
$$




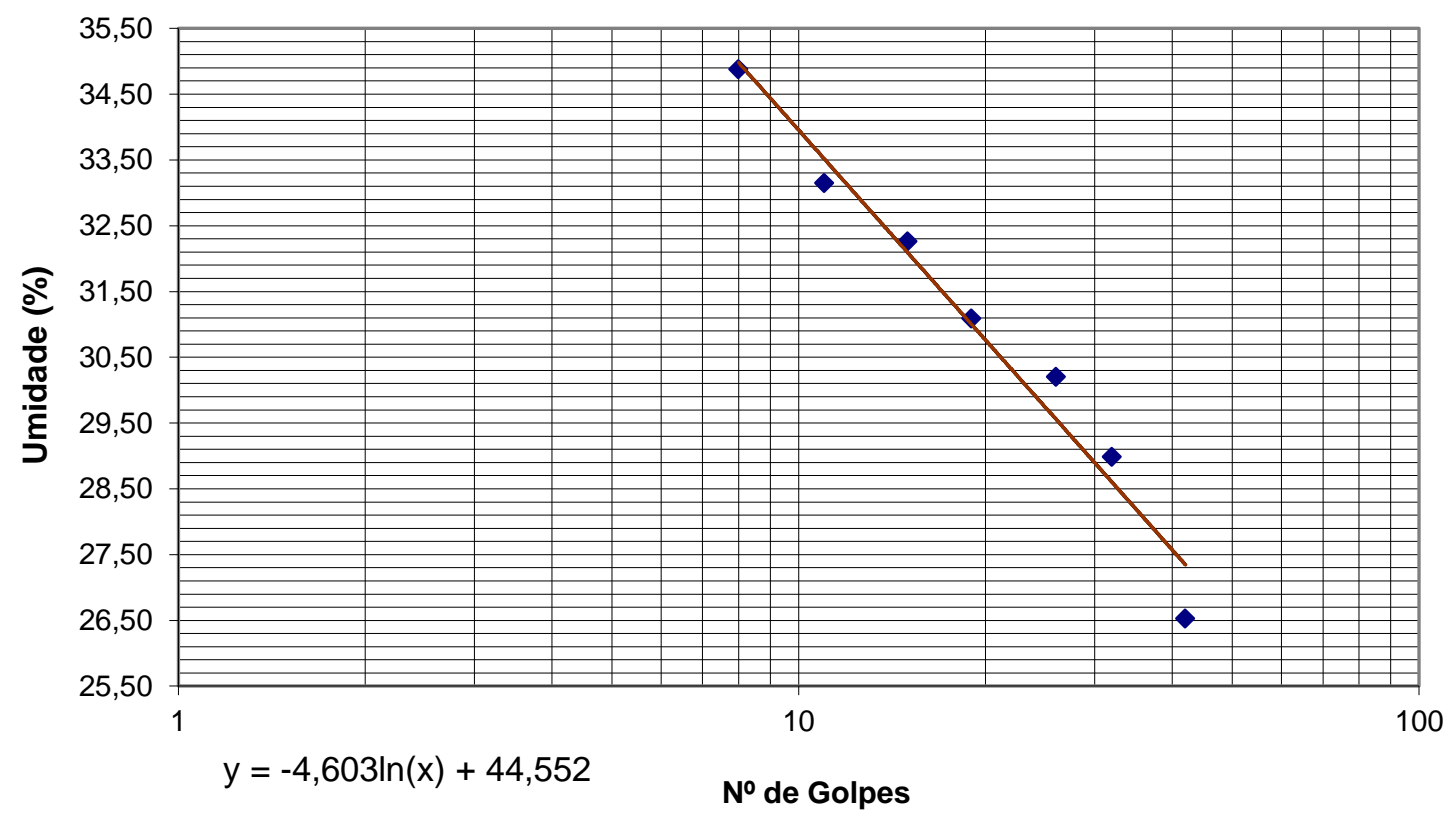

Figura C- 2 Teor de umidade em função do número de golpes (ensaio para determinar LL) para a amostra B-15

O LP, segundo os dados apresentados na Tabela C- 1, é de $22 \%$ e, portanto, temos que o IP é $8 \%$.

Tabela C- 1 Limites de plasticidade da amostra B-15

\begin{tabular}{|c|c|c|c|c|c|c|c|}
\hline \\
\hline \multicolumn{8}{|l|}{$\begin{array}{l}\text { Recipiente } \mathrm{n}^{\circ} \\
\text { ReAS ICIDADE }\end{array}$} \\
\hline Amostra + tara + água & 56,19 & 38,51 & 39,39 & 39,17 & 57,11 & 52,49 & 56,69 \\
\hline Amostra + tara & 56,06 & 38,39 & 39,25 & 39,06 & 56,96 & 52,34 & 56,52 \\
\hline Água & 0,13 & 0,12 & 0,14 & 0,11 & 0,15 & 0,15 & 0,17 \\
\hline Tara & 55,52 & 37,84 & 38,59 & 38,54 & 56,33 & 51,67 & 55,71 \\
\hline Amostra seca & 0,544 & 0,553 & 0,661 & 0,519 & 0,627 & 0,669 & 0,81 \\
\hline Umidade, $\mathrm{h}$ & $23,90 \%$ & $21,70 \%$ & $21,18 \%$ & $21,19 \%$ & $23,92 \%$ & $22,42 \%$ & $20,99 \%$ \\
\hline
\end{tabular}

$\mathrm{Na}$ Carta de Plasticidade o solo localiza-se na região da argila (C), pois seu LL é menor que $50 \%$ e está acima da Linha A cuja equação é:

$$
I P=0,73 \cdot(L L-20)
$$

Sua classificação pelo Sistema Unificado de Classificação de Solos é, portanto, SC:

- S - Pois $50,75 \%$ da massa seca é de fração arenosa.

- C - Pois de finos temos $38,75 \%$ da massa seca e devido a sua classificação na Carta de Plasticidade. 


\section{Compactação}

Por meio da compactação podemos determinar a umidade que gera a maior a maior densidade. Para a amostra B-15, a umidade ótima de 18,3\% gera uma densidade máxima de $1,72 \mathrm{~g} / \mathrm{cm}^{3}$ (Figura C- 3).

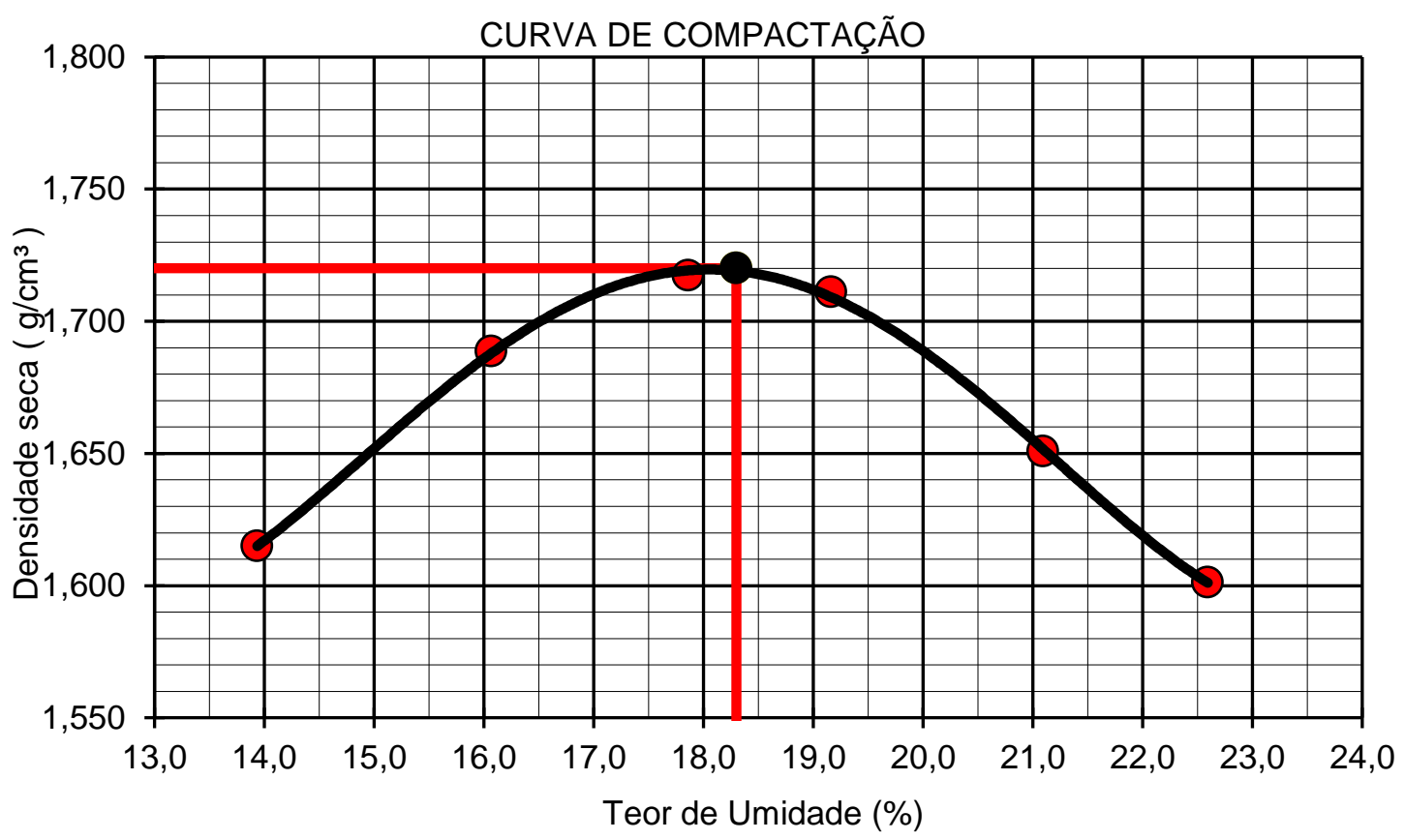

Figura C- 3 Curva de compactação da amostra B-15

\section{MCT}

Os gráficos fundamentais para conseguir os parâmetros da classificação MCT estão apresentados na Figura C- 4 e Figura C- 5. O primeiro gráfico representa a densidade seca em função do teor de umidade para cada número predeterminado de golpes. O segundo gráfico apresenta An (altura do corpode-prova medida no último golpe menos a medida do golpe anterior) em função do número de golpes. Cada série é uma parte da amostra com certo teor de umidade definido. 


\section{Densidade $\mathrm{x}$ Teor de umidade}

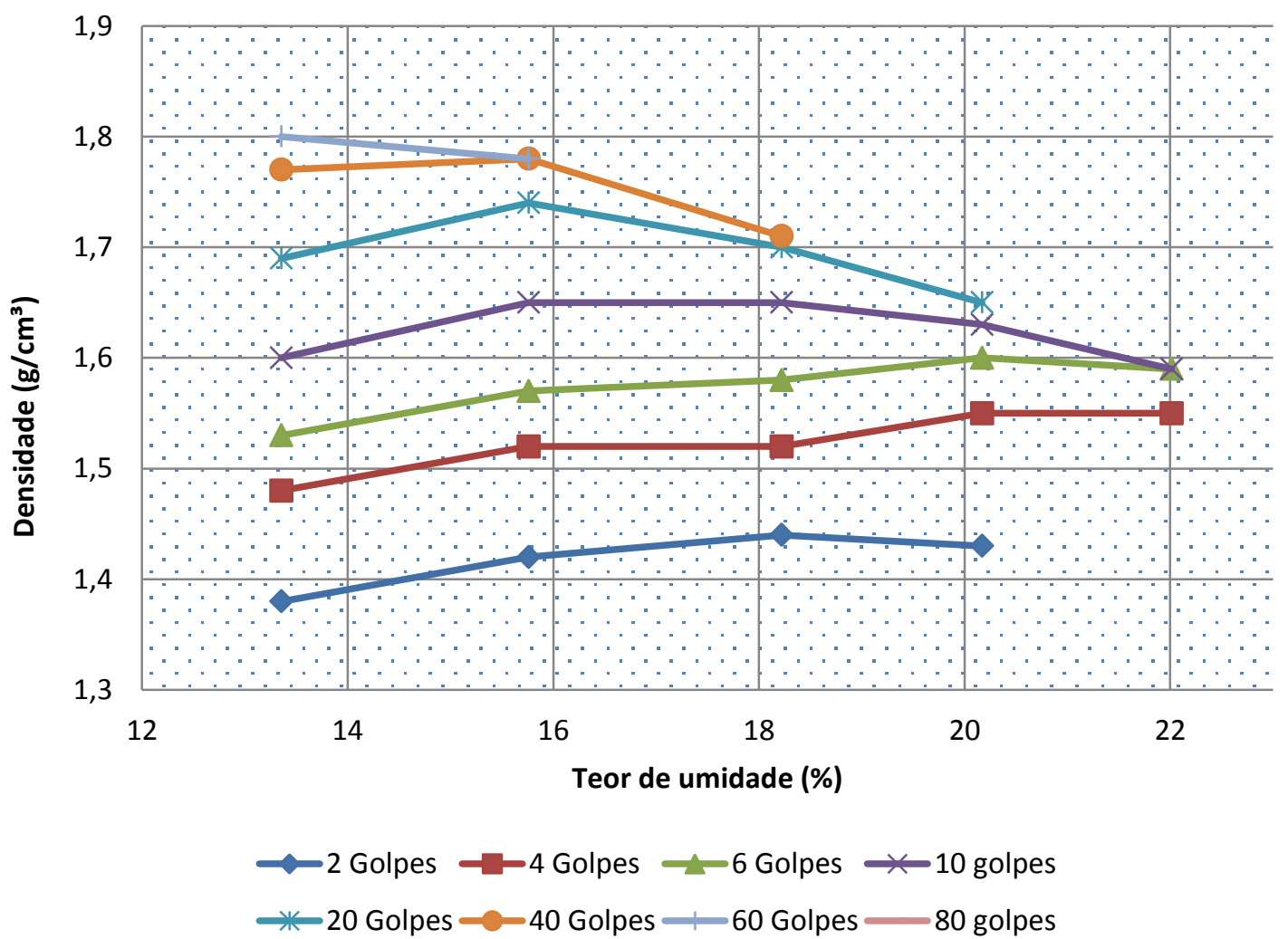

Figura C- 4 Classificação MCT - Densidade seca $x$ teor de umidade - Amostra B-15

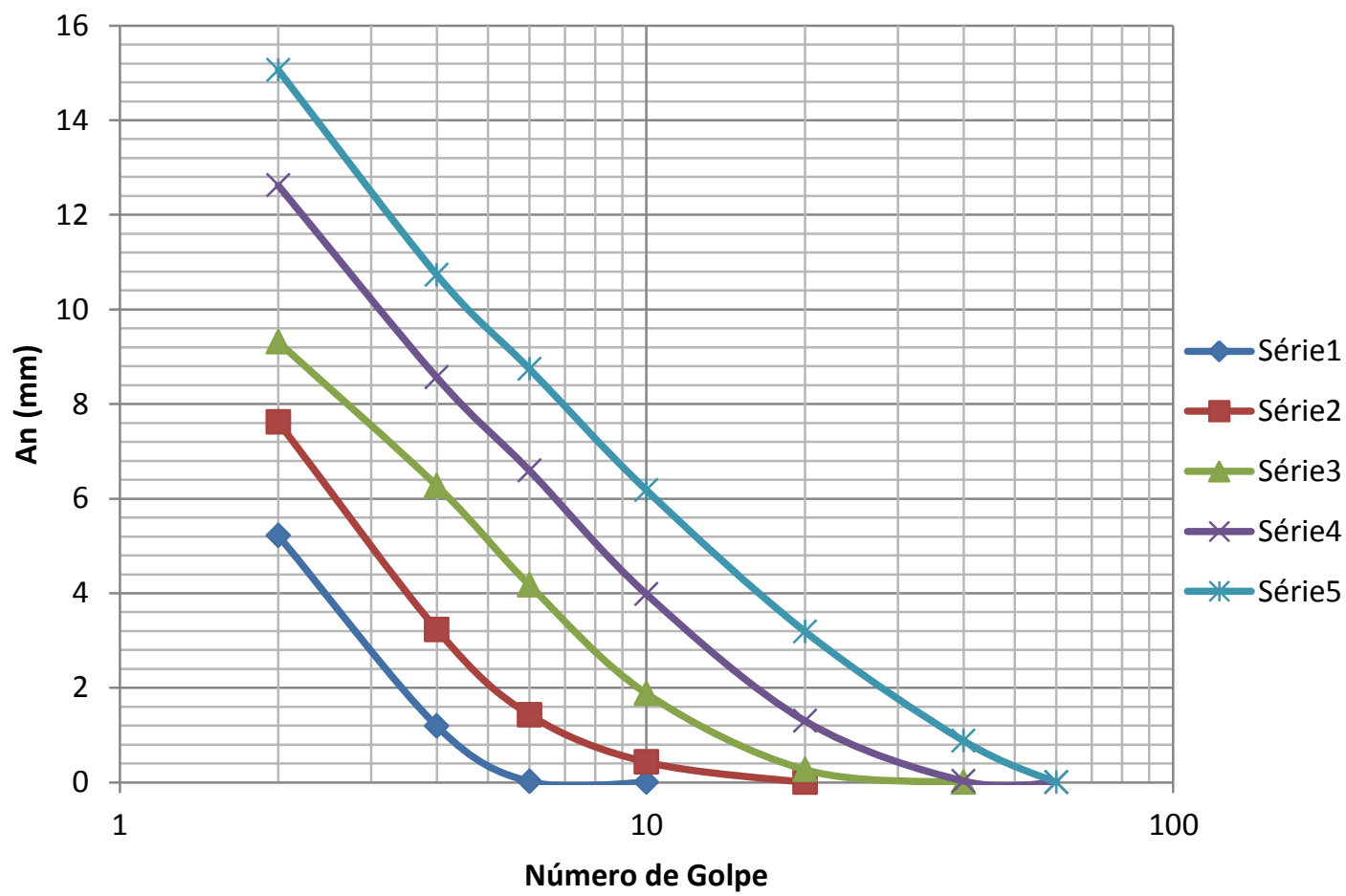

Figura C- 5 Classificação MCT - An x número de golpes - Amostra B-15 
Os parâmetros para a classificação do solo estão na Tabela C- 2 .

Tabela C- 2 Parâmetros para a classificação do MCT - Amostra B-15

\begin{tabular}{ll}
\hline$C^{\prime}$ & 1,26 \\
\hline$P I$ & 110 \\
\hline$d^{\prime}$ & 20,83 \\
\hline$e^{\prime}$ & 1,27 \\
\hline Classe & $N^{\prime}$ \\
\hline
\end{tabular}

Portanto, a partir desses parâmetros podemos classificar o solo como NA', ou seja, é um solo não laterítico arenoso.

Resistência ao Cisalhamento

Para cada ensaio de cisalhamento direto, foram obtidas as curvas de tensão de cisalhamento $(\mathrm{kPa})$ pelo deslocamento $(\mathrm{mm})$. A amostra foi ensaiada para tensões verticais de $100 \mathrm{kPa}, 200 \mathrm{kPa}$ e $400 \mathrm{kPa}$. Os resultados dos três ensaios estão apresentados na Figura C- 6 (NOMACHI \& BOSCOV, 2016).

A Figura C- 7 (NOMACHI \& BOSCOV, 2016) mostra os pontos máximos desses ensaios, a partir dos quais pode-se determinar a envoltória de resistência do solo e os parâmetros c (coesão) e $\varphi$ (ângulo de atrito).

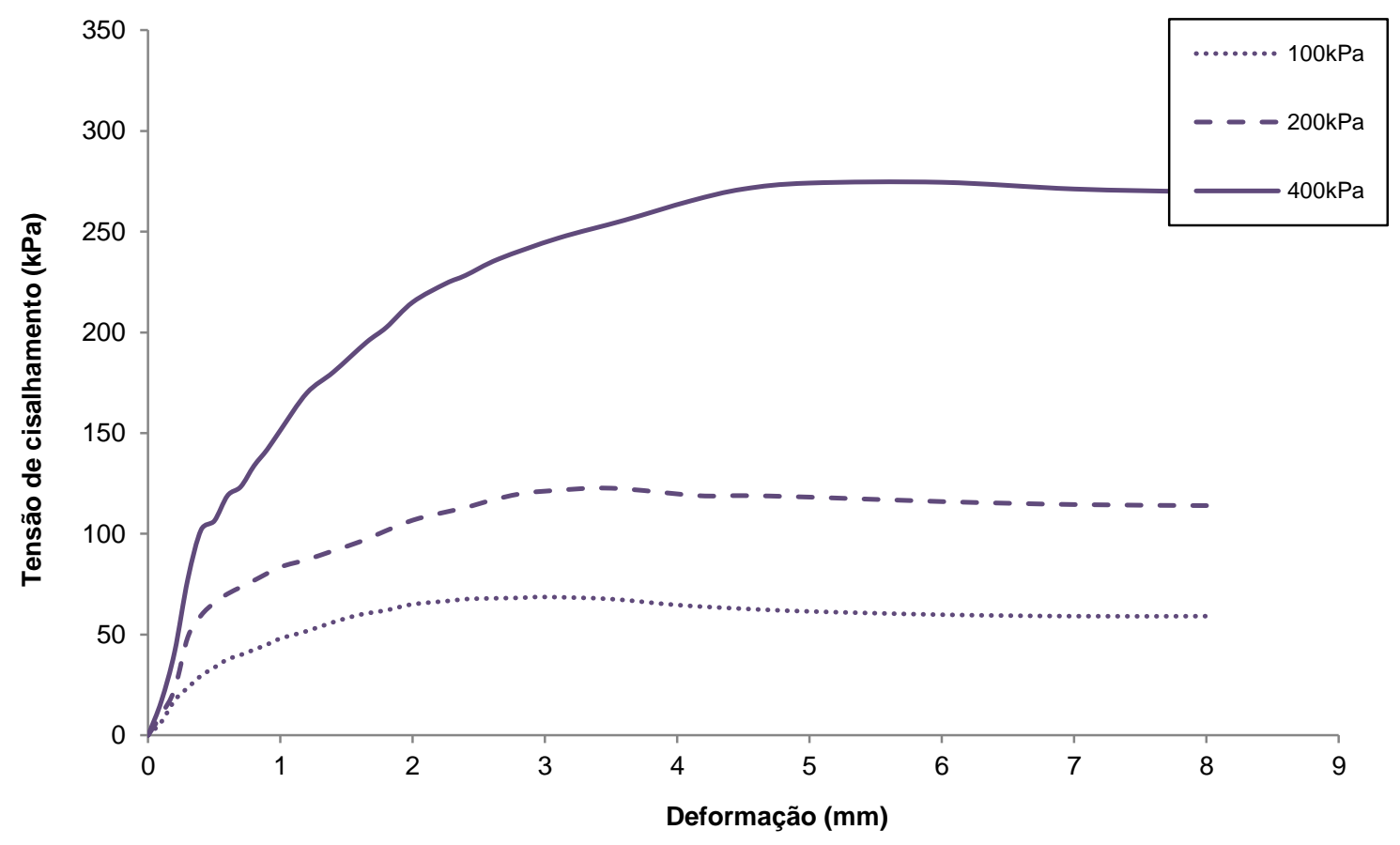

Figura C- 6 Ensaios de cisalhamento direto com a amostra B-15 


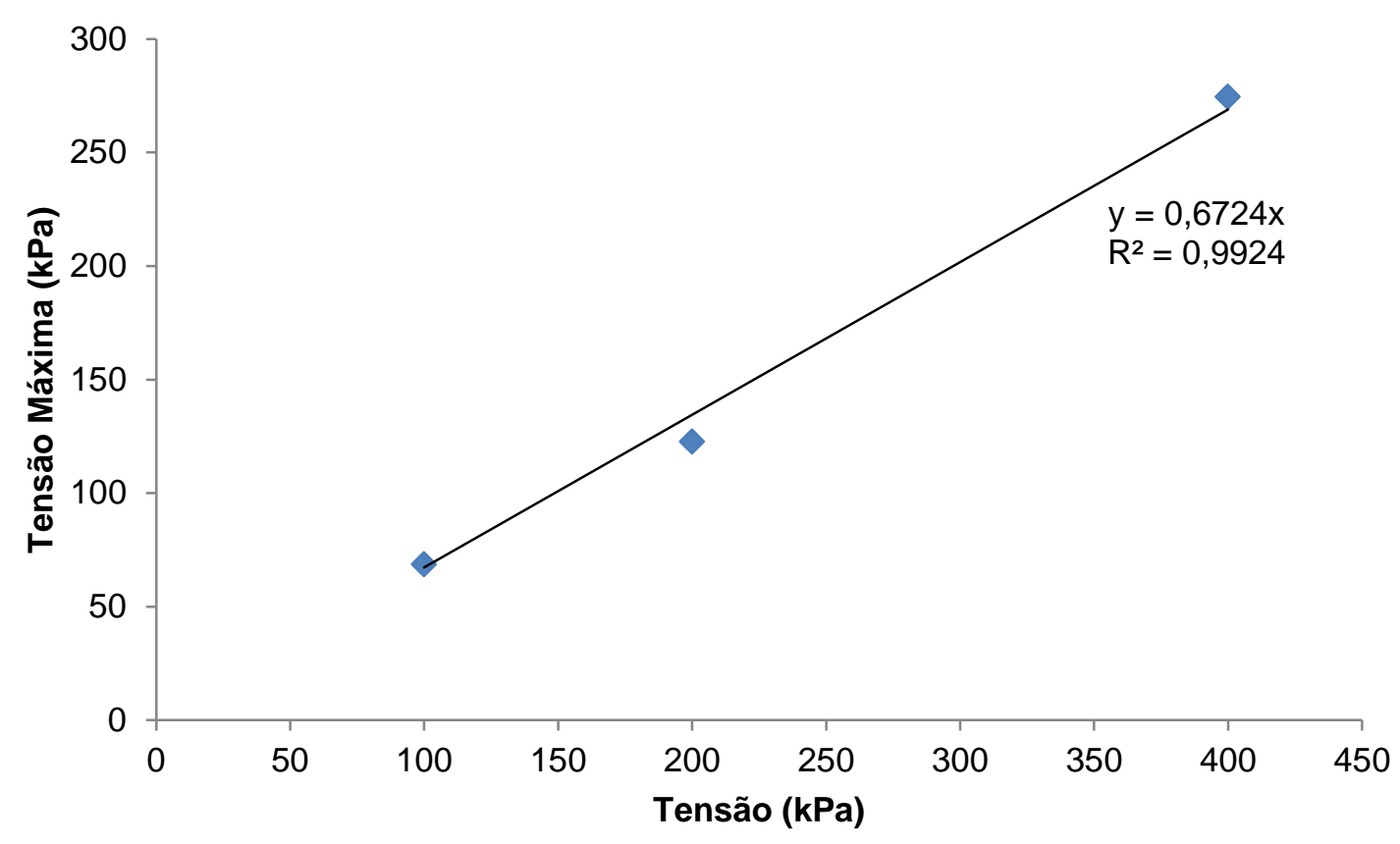

Figura C- 7 Envoltória de resistência da amostra B-15.

A coesão e o ângulo de atrito são, respectivamente: $\mathrm{c}=0 \mathrm{kPa} e \varphi=33,9^{\circ}$.

\section{Mini-CBR e Expansão}

A Figura C-8 e a Figura C-9 mostram respectivamente a variação do Mini-CBR após imersão e da expansão em função do teor de umidade de compactação. Procurou-se realizar os ensaios com corpos de prova em três situações em termos de umidade de compactação: ramo seco, teor de umidade ótima e ramo úmido. Contudo, os ensaios na amostra B-15 foram realizadas no ponto ótimo e no ramo úmido; não houve material suficiente para realizar novos ensaios no ramo seco.

A amostra B-15, apresentou Mini-CBR de $11 \%$ no ponto ótimo e de $4 \%$ para desvio de umidade igual a $3,5 \%$.

A expansão diminui com o aumento da umidade de compactação, conforme o esperado. Amostra B-15 apresentou baixa expansão no ponto ótimo $(0,4 \%)$. 


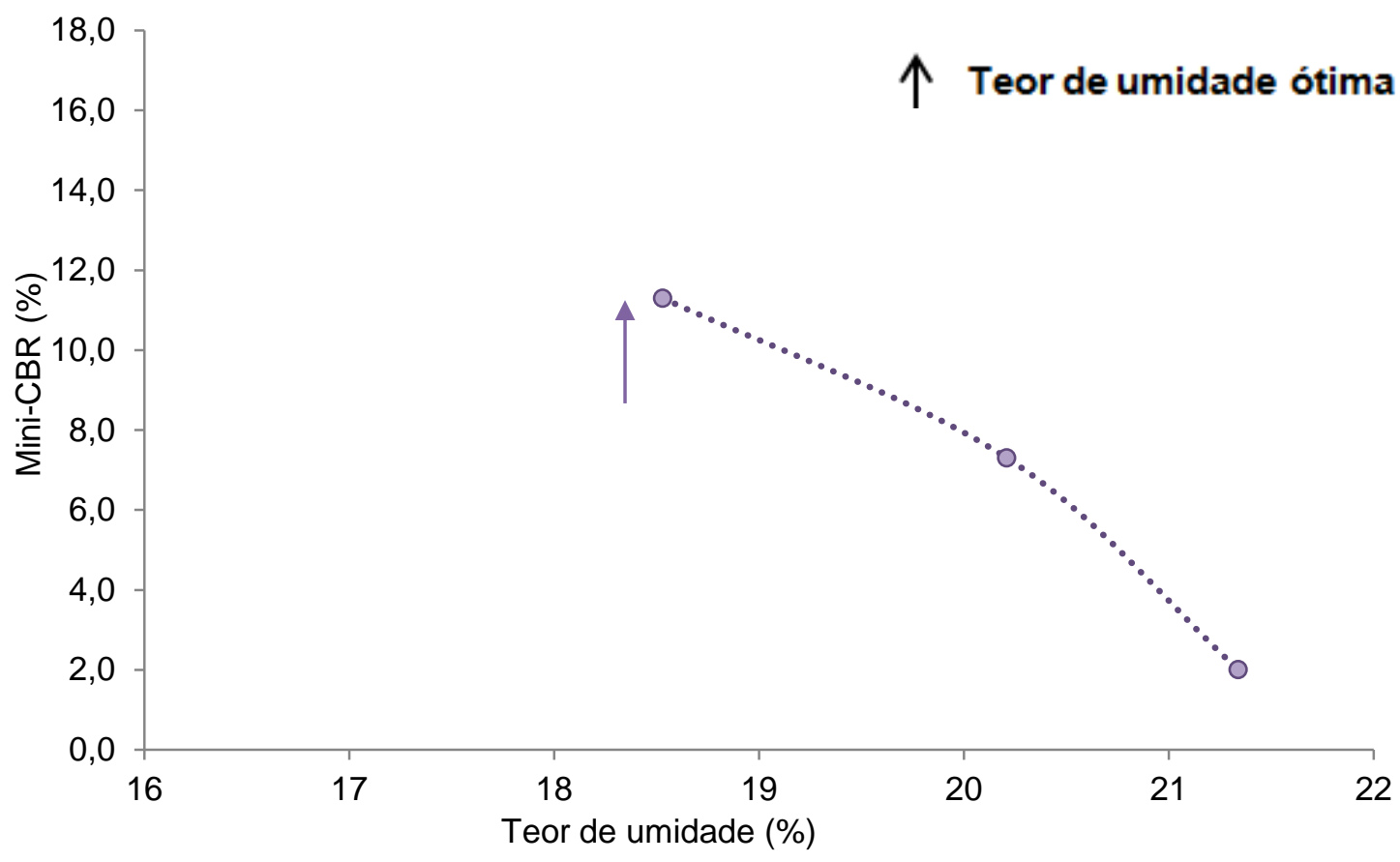

Figura C-8 - Curva Mini-CBR da amostra B-15

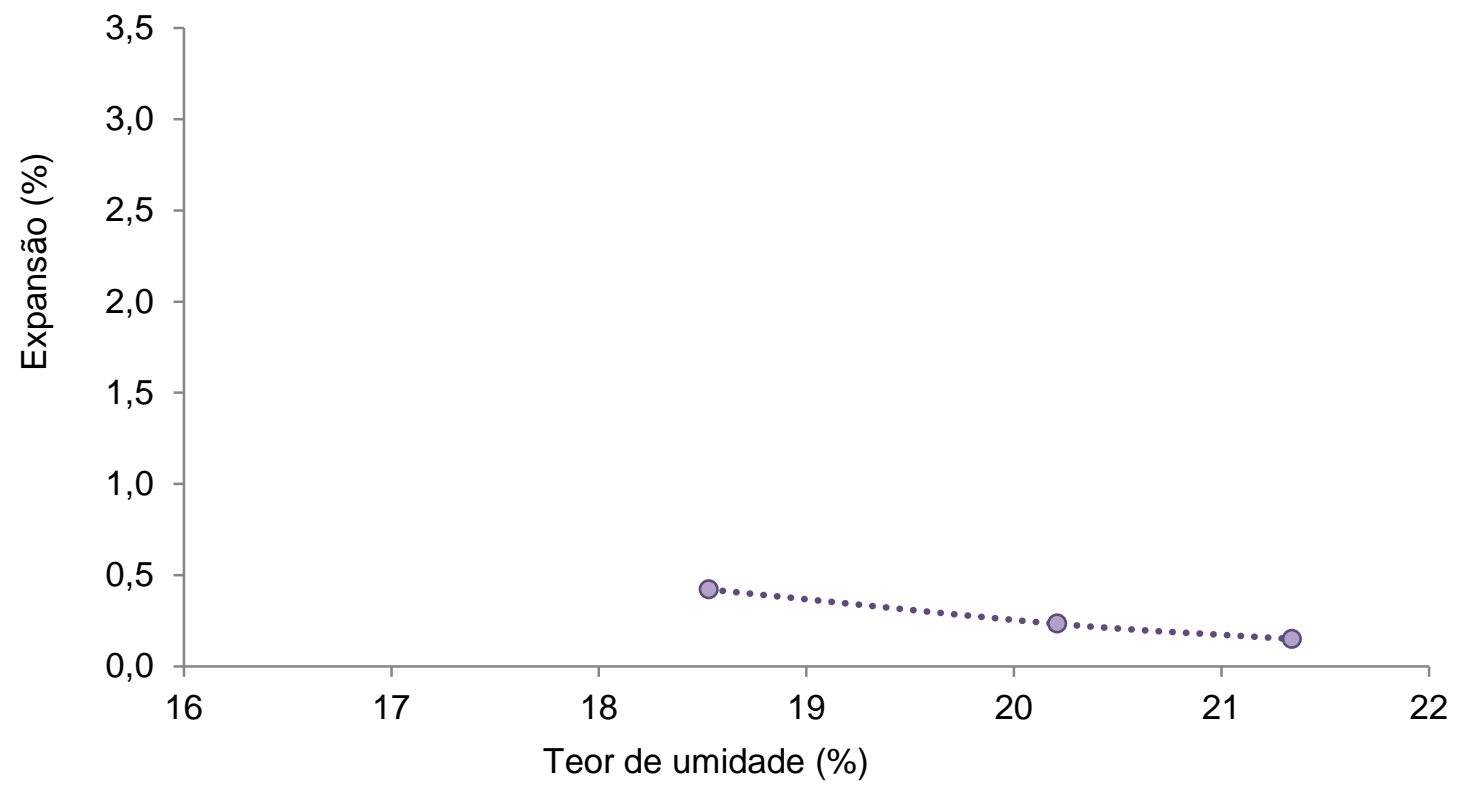

Figura C-9 - Curva de expansão da amostra B-15 


\section{Apendice D - Resultados dos ensaios geotécnicos da amostra B-23}

A amostra B-23 foi classificada visualmente como Solo.

\section{Granulometria}

A curva granulométrica está apresentada na Figura D-1. O solo é composto por aproximadamente $48,64 \%$ de grãos finos, $7,17 \%$ de pedregulhos e $49,19 \%$ de areia.

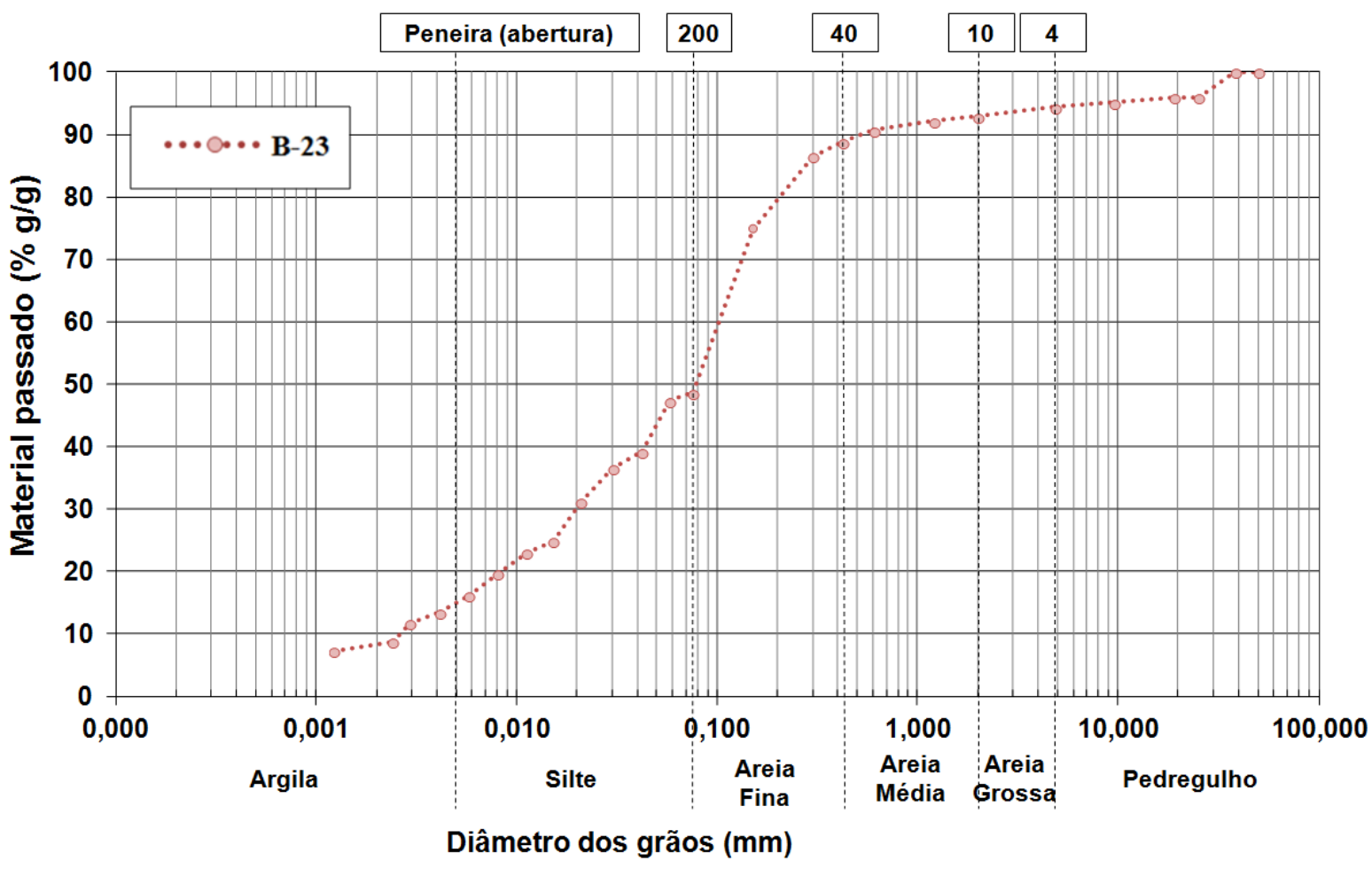

Figura D-1 - Curva de distribuição granulométrica da amostra B-23

\section{LL,LP e Classificação}

No gráfico de teor de umidade (\%) por logaritmo de número de golpes podemos ajustar uma reta aos pontos experimentais (Figura D- 2). Ao substituir o valor de $\mathrm{x}$ da equação da reta por 25 , temos o valor de $\mathrm{LL}$ de aproximadamente $33 \%$.

$$
L L=-7,537 \ln (25)+57,329 \cong 33 \%
$$

O LP, segundo os dados apresentados na Tabela D- 1, é $27 \%$ e, portanto, temos que o IP é $6 \%$. 


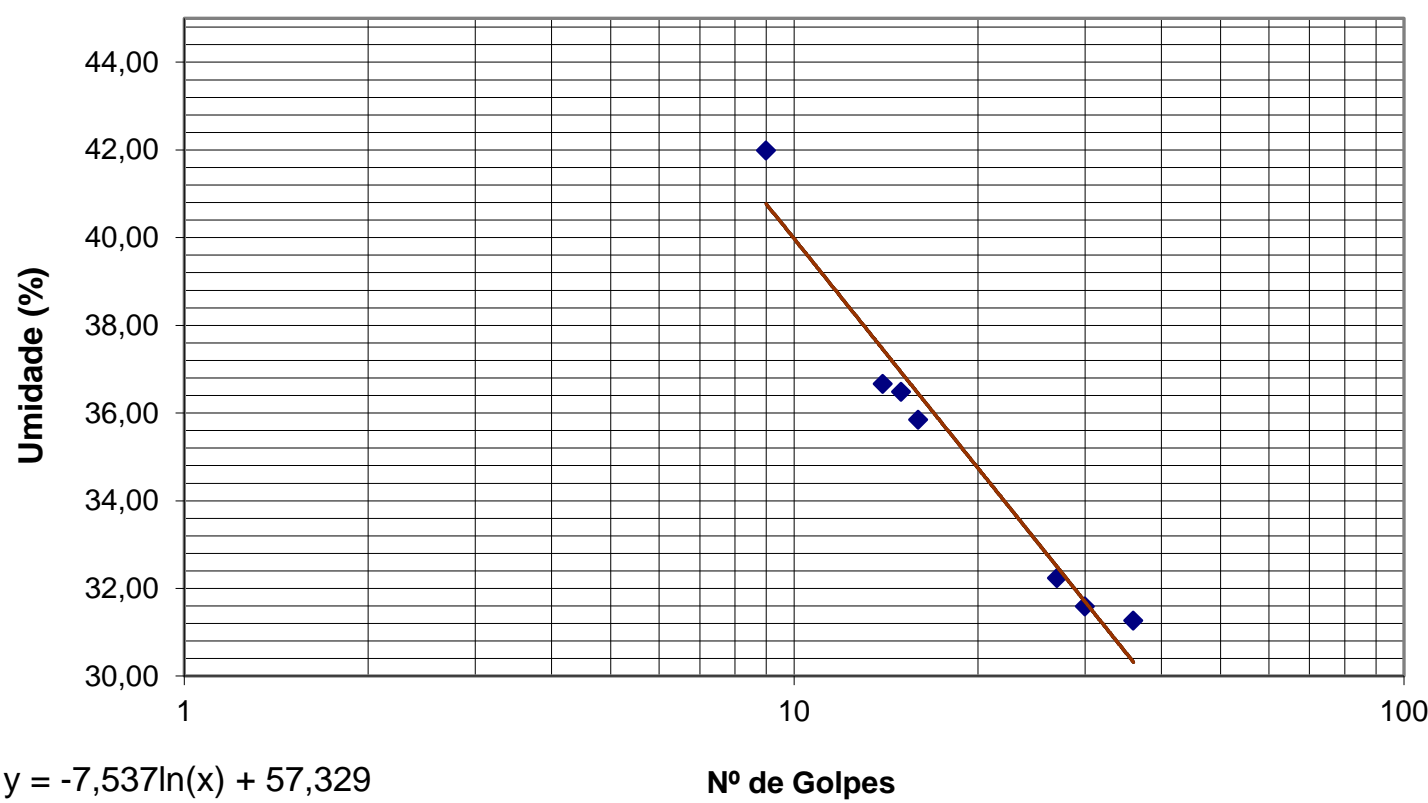

Figura D- 2 - Teor de umidade em função do número de golpes (ensaio para determinar LL) para a amostra B-23

Tabela D- 1 Limite de plasticidade de amostra B-23

\begin{tabular}{|c|c|c|c|c|c|c|c|}
\hline \multicolumn{8}{|l|}{ LIMITE DE PLASTICIDADE } \\
\hline \multirow{7}{*}{$\begin{array}{ll}\text { Recipiente } \mathrm{n}^{\circ} & \mathrm{g} \\
\text { Amostra + tara + água } & \mathrm{g} \\
\text { Amostra + tara } & \mathrm{g} \\
\text { Água } & \mathrm{g} \\
\text { Tara } & \mathrm{g} \\
\text { Amostra seca } & \mathrm{g} \\
\text { Umidade } \mathrm{h} & \%\end{array}$} & 52 & 51 & 100 & 68 & 84 & 81 & 20 \\
\hline & 55,51 & 51,14 & 42,47 & 41,40 & 40,80 & 40,64 & 44,4 \\
\hline & 55,36 & 51,03 & 42,23 & 41,26 & 40,60 & 40,46 & 44,32 \\
\hline & 0,15 & 0,11 & 0,24 & 0,14 & 0,20 & 0,18 & 0,08 \\
\hline & 54,82 & 50,62 & 41,34 & 40,61 & 39,75 & 39,84 & 43,728 \\
\hline & 0,537 & 0,413 & 0,894 & 0,648 & 0,849 & 0,624 & 0,592 \\
\hline & $27,93 \%$ & $26,63 \%$ & $26,85 \%$ & $21,60 \%$ & $23,56 \%$ & $28,85 \%$ & $13,51 \%$ \\
\hline
\end{tabular}

$\mathrm{Na}$ Carta de Plasticidade o solo localiza-se na região de silte (M), pois seu LL é menor que $50 \%$ e está abaixo da Linha A, cuja equação é:

$$
I P=0,73 \cdot(L L-20)
$$

Sua classificação pelo Sistema Unificado de Classificação de Solos é, portanto, SM:

- $S$ - Pois $49,19 \%$ da massa seca é de fração arenosa.

- $M$ - Pois $48,64 \%$ são de grãos finos e devida a sua classificação na Carta de Plasticidade. 


\section{Compactação}

Por meio da compactação podemos determinar a umidade que gera a maior a maior densidade. Para a amostra B-23 temos que a umidade $17,8 \%$ gera uma densidade máxima de $1,69 \mathrm{~g} / \mathrm{cm}^{3}$ (Figura D- 3).

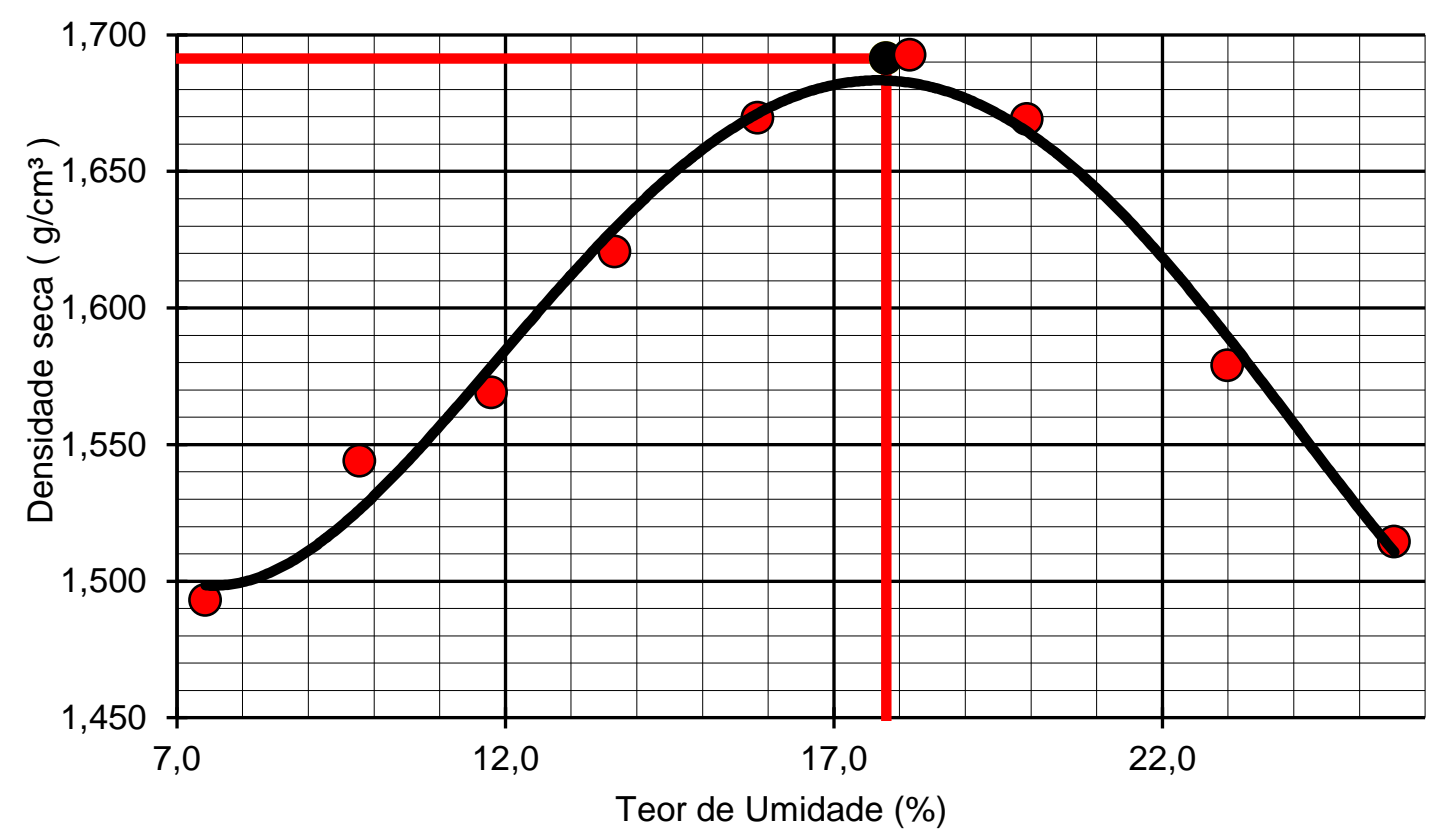

Figura D- 3 - Curva de compactação da amostra B-23

MCT

Os gráficos fundamentais para conseguir os parâmetros da classificação MCT estão apresentados na Figura D- 4 e Figura D- 5. O primeiro gráfico representa a densidade seca em função do teor de umidade para cada número predeterminado de golpes. O segundo gráfico apresenta An (altura do corpode-prova medida no último golpe menos a medida do golpe anterior) em função do número de golpes. Cada série é uma parte da amostra com certo teor de umidade definido. 


\section{Densidade $\mathrm{x}$ Teor de umidade}

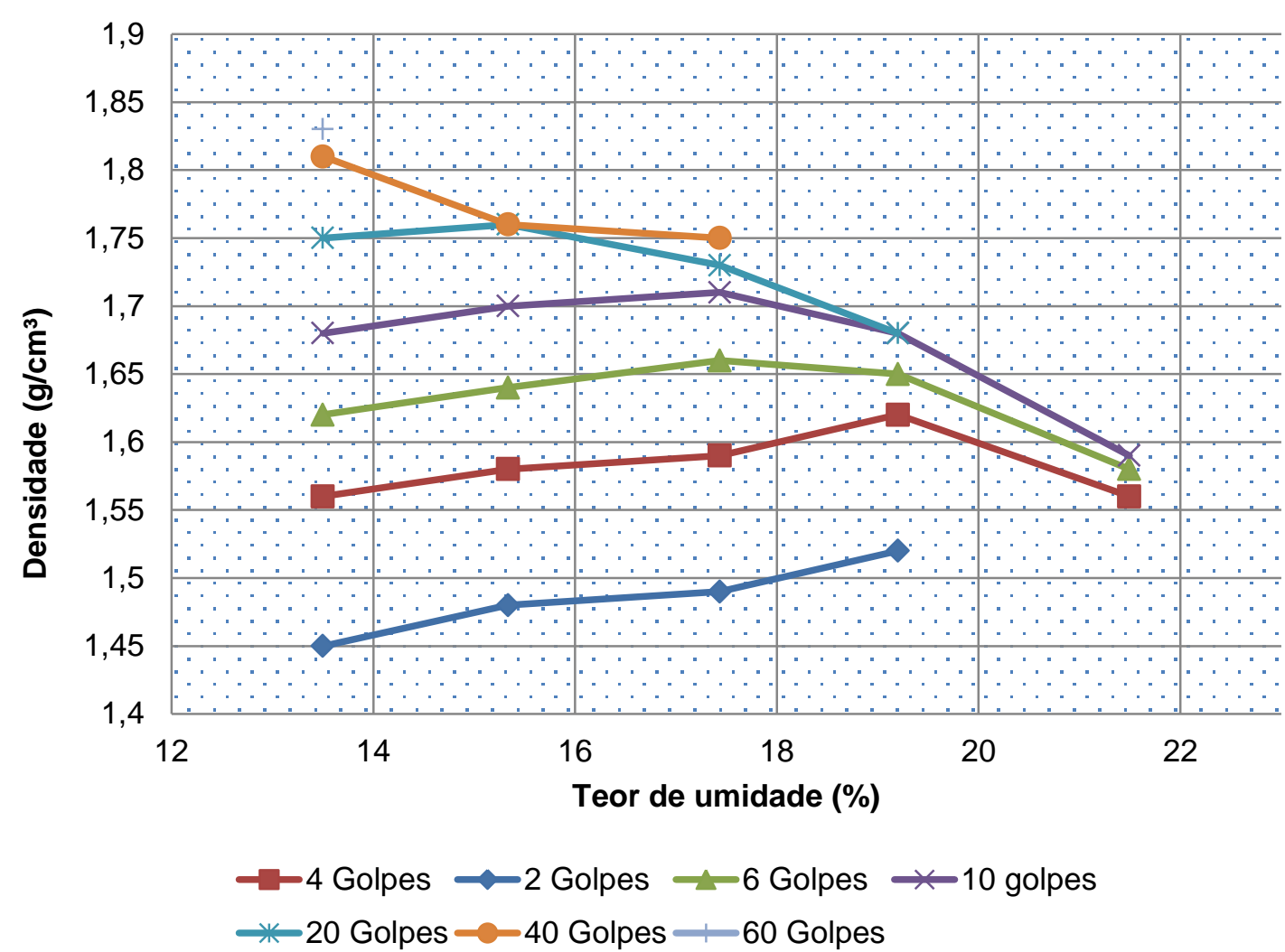

Figura D- 4 - Classificação MCT - Densidade seca $x$ teor de umidade - Amostra B-23

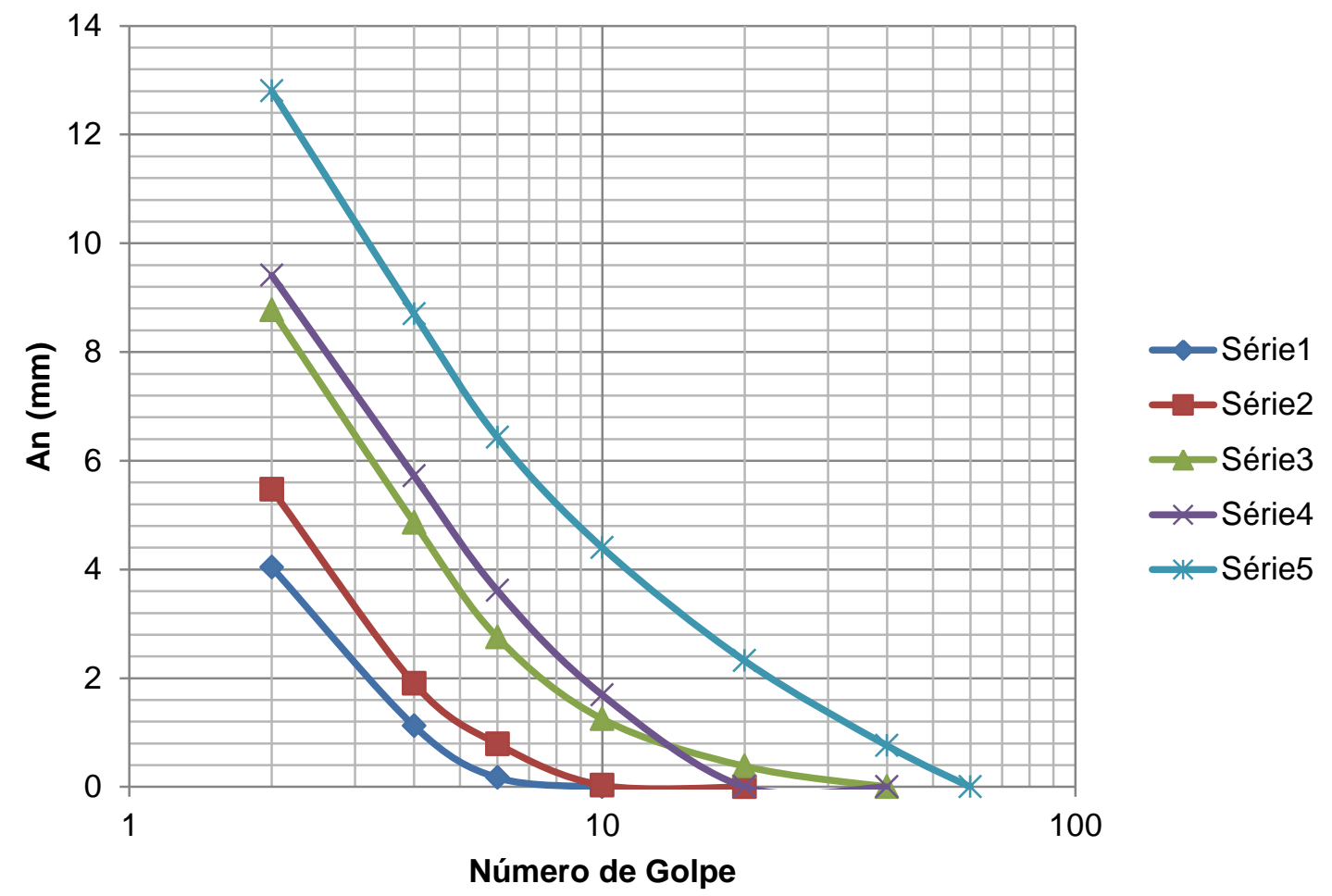

Figura D- 5 - Classificação MCT - An x número de golpes - Amostra B-23 
Os parâmetros para a determinação da classificação MCT do solo estão na Tabela D- 2.

Tabela D- 2 - Parâmetros para a classificação MCT -Amostra B-23

\begin{tabular}{ll}
\hline $\mathrm{C}^{\prime}$ & 1,09 \\
\hline $\mathrm{Pl}$ & 285 \\
\hline $\mathrm{d}^{\prime}$ & 11,11 \\
\hline $\mathrm{e}^{\prime}$ & 1,67 \\
\hline Classe & $\mathrm{NS}^{\prime}$
\end{tabular}

Portanto, a partir desses parâmetros pode-se classificar o solo como NS', ou seja, é um solo não laterítico siltoso,

\section{Resistência ao Cisalhamento}

Para cada ensaio de cisalhamento direto, foram obtidas as curvas de tensão de cisalhamento $(\mathrm{kPa})$ pelo deslocamento $(\mathrm{mm})$. A amostra foi ensaia para tensões verticais de $100 \mathrm{kPa}, 200 \mathrm{kPa}$ e $400 \mathrm{kPa}$. Os resultados dos três ensaios estão apresentados na Figura D- 6 (NOMACHI \& BOSCOV, 2016).

A Figura D- 7 (NOMACHI \& BOSCOV, 2016) mostra os pontos máximos desses ensaios, a partir dos quais pode-se determinar a envoltória de resistência do solo e os parâmetros c (coesão) e $\varphi$ (ângulo de atrito).

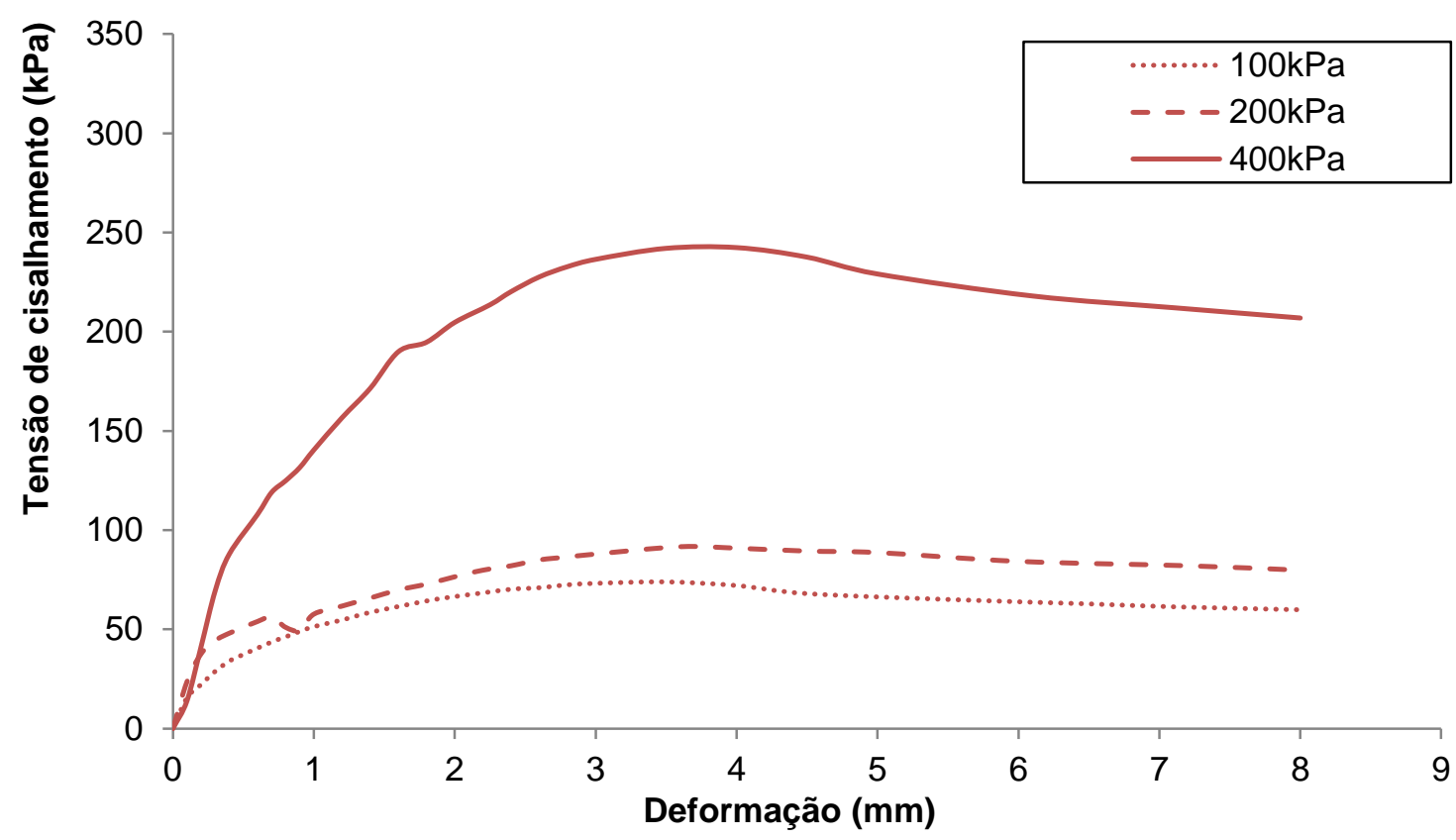

Figura D- 6 - Ensaios de cisalhamento direto com a amostra B-23 


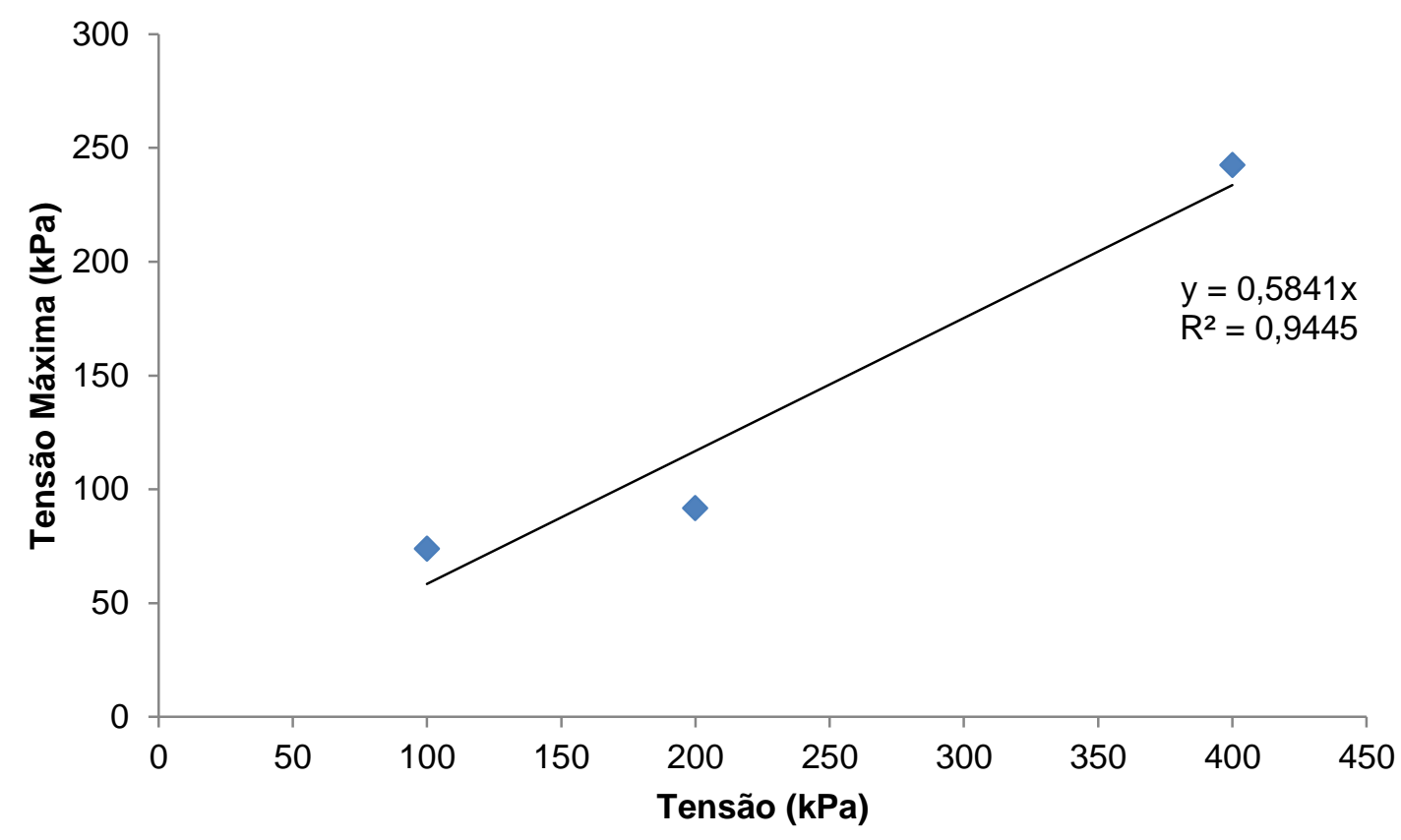

Figura D- 7 - Envoltória de resistência da amostra B-23

A coesão e o ângulo de atrito são, respectivamente: $c=0 \mathrm{kPa}$ e $\varphi=30,3^{\circ}$.

\section{Mini-CBR e Expansão}

A Figura D- 8 e Figura D- 9 mostram respectivamente a variação do Mini-CBR após imersão e da expansão em função do teor de umidade de compactação. Procurou-se realizar os ensaios com corpos de prova em três situações em termos de umidade de compactação: ramo seco, teor de umidade ótima e ramo úmido. Contudo, os ensaios na amostra B-15 foram realizadas no ponto ótimo e no ramo úmido; não houve material suficiente para realizar novos ensaios no ramo seco.

A amostra B-23, apresentou Mini-CBR menor que 4\% para os três teores de umidade ensaiados.

A expansão diminui com o aumento da umidade de compactação, conforme 0 esperado. Amostra B-23 apresentou 3,5\% de expansão no ponto de umidade ótima. 


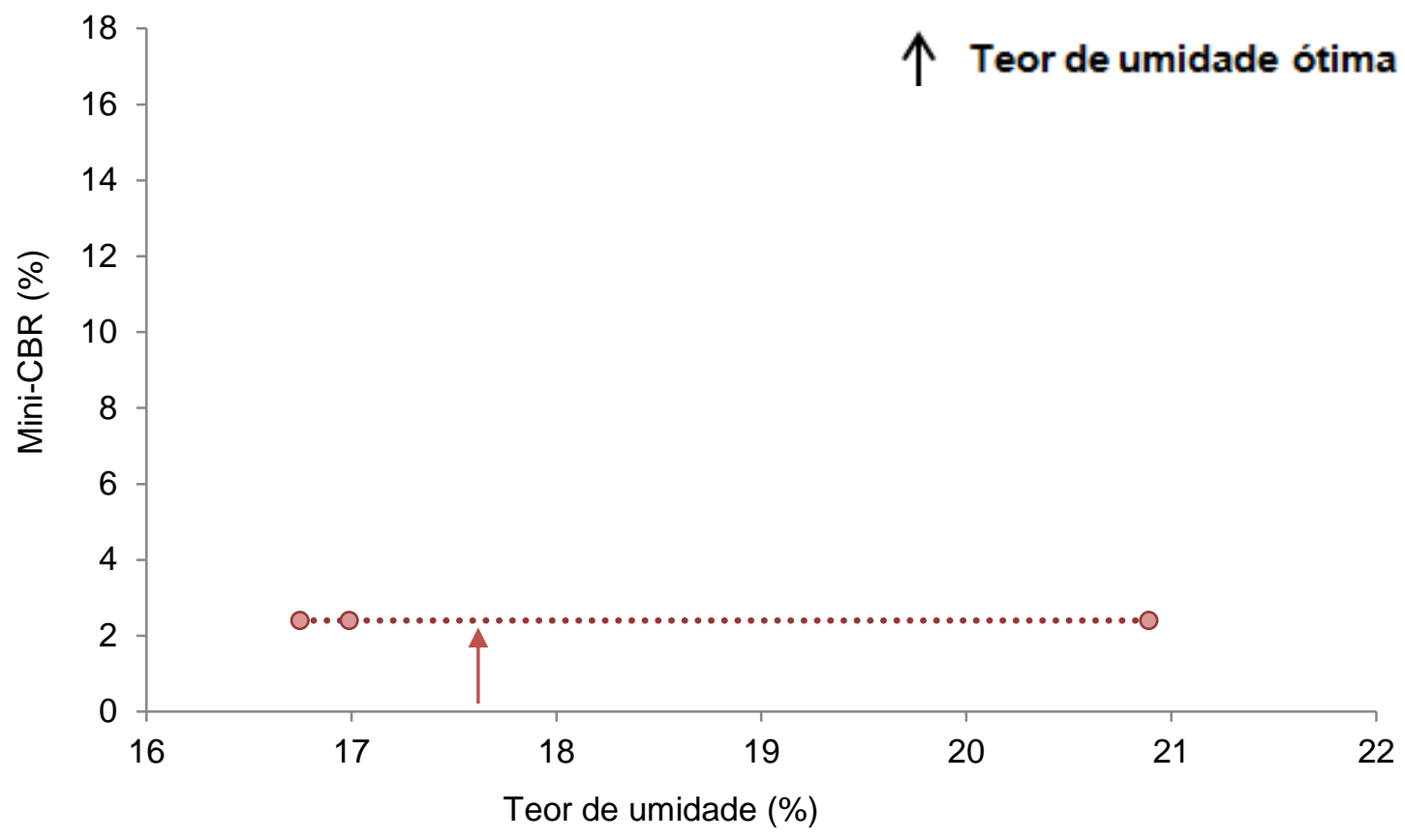

Figura D- 8 Curva Mini-CBR da amostra B-23

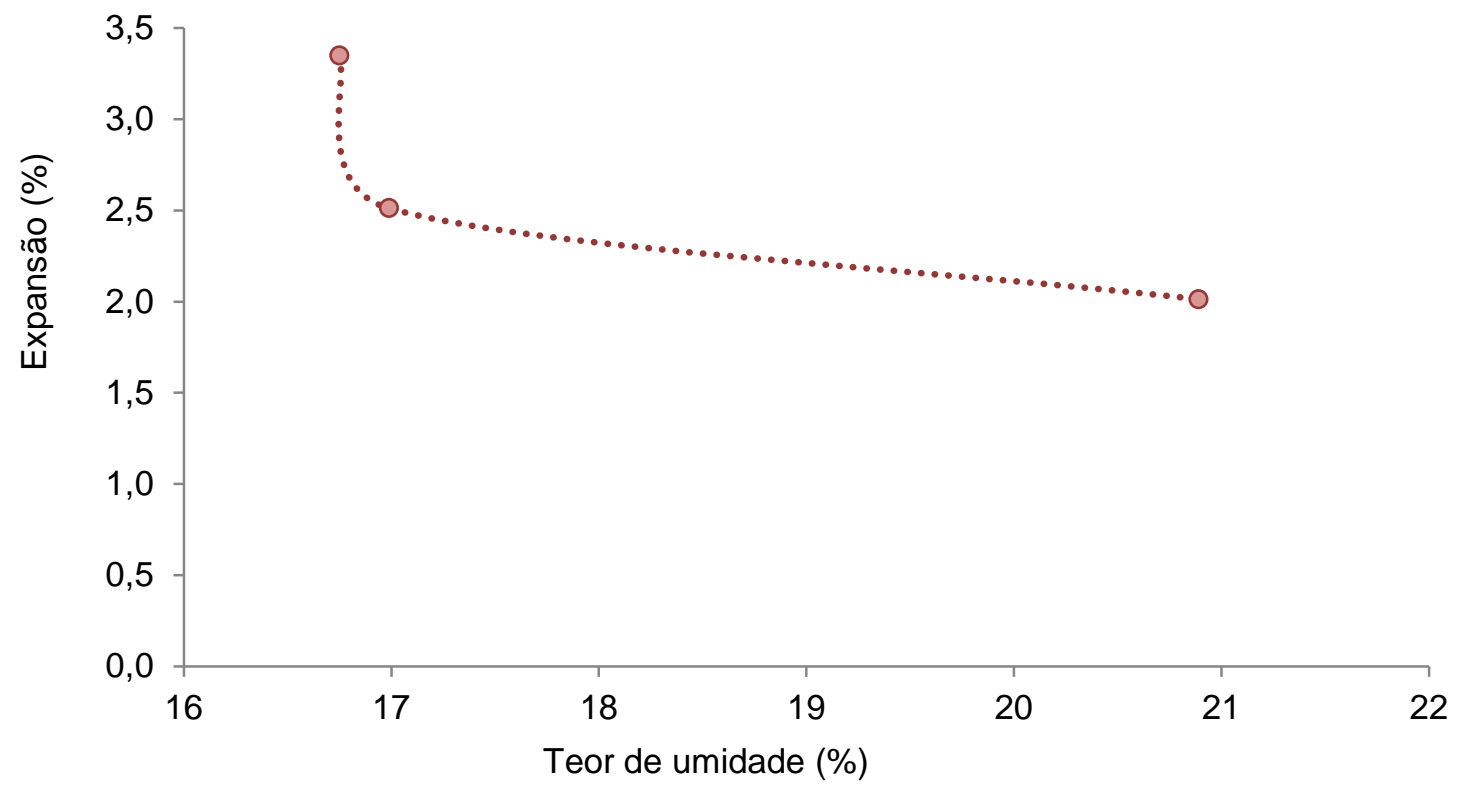

Figura D- 9 - Curva de expansão da amostra B-23 


\section{Apendice E - Resultados dos ensaios geotécnicos da amostra B-4}

A amostra B-4 foi classificada visualmente como RCC.

\section{Granulometria}

A curva granulométrica está apresentada na Figura E-1. O material é composto por $23,86 \%$ de grãos finos, $55,75 \%$ de pedregulhos e $20,38 \%$ de areia.

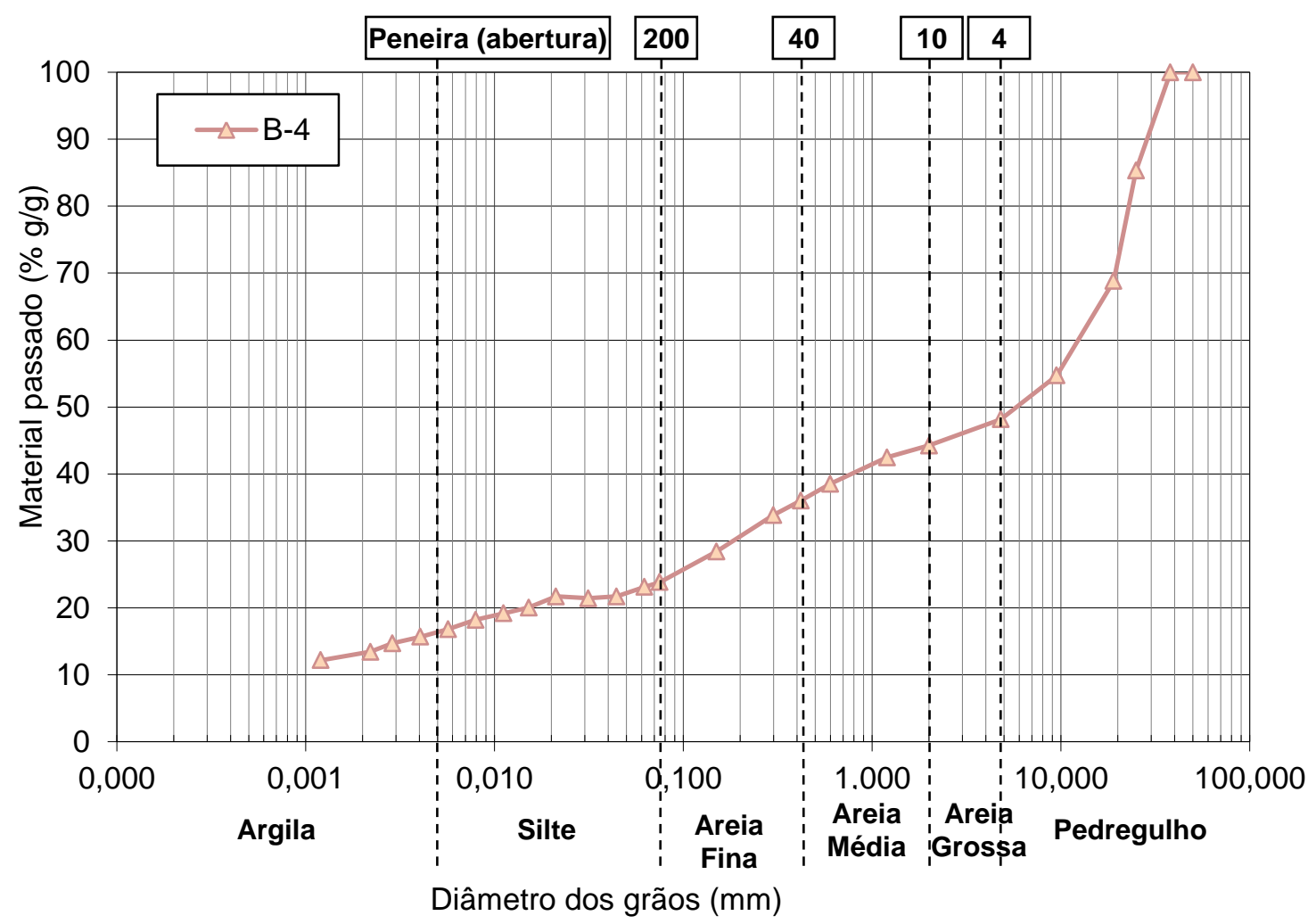

Figura E-1 Curva de distribuição granulométrica da amostra B-4

\section{LL, LP e Classificação}

No gráfico de teor de umidade (\%) por logaritmo de número de golpes podemos ajustar uma reta aos pontos experimentais (Figura E- 2). Ao substituir o valor de $\mathrm{x}$ da equação da reta por 25 , temos o valor de LL de aproximadamente $29 \%$.

$$
L L=-3,048 \ln (25)+38,802 \cong 29 \%
$$




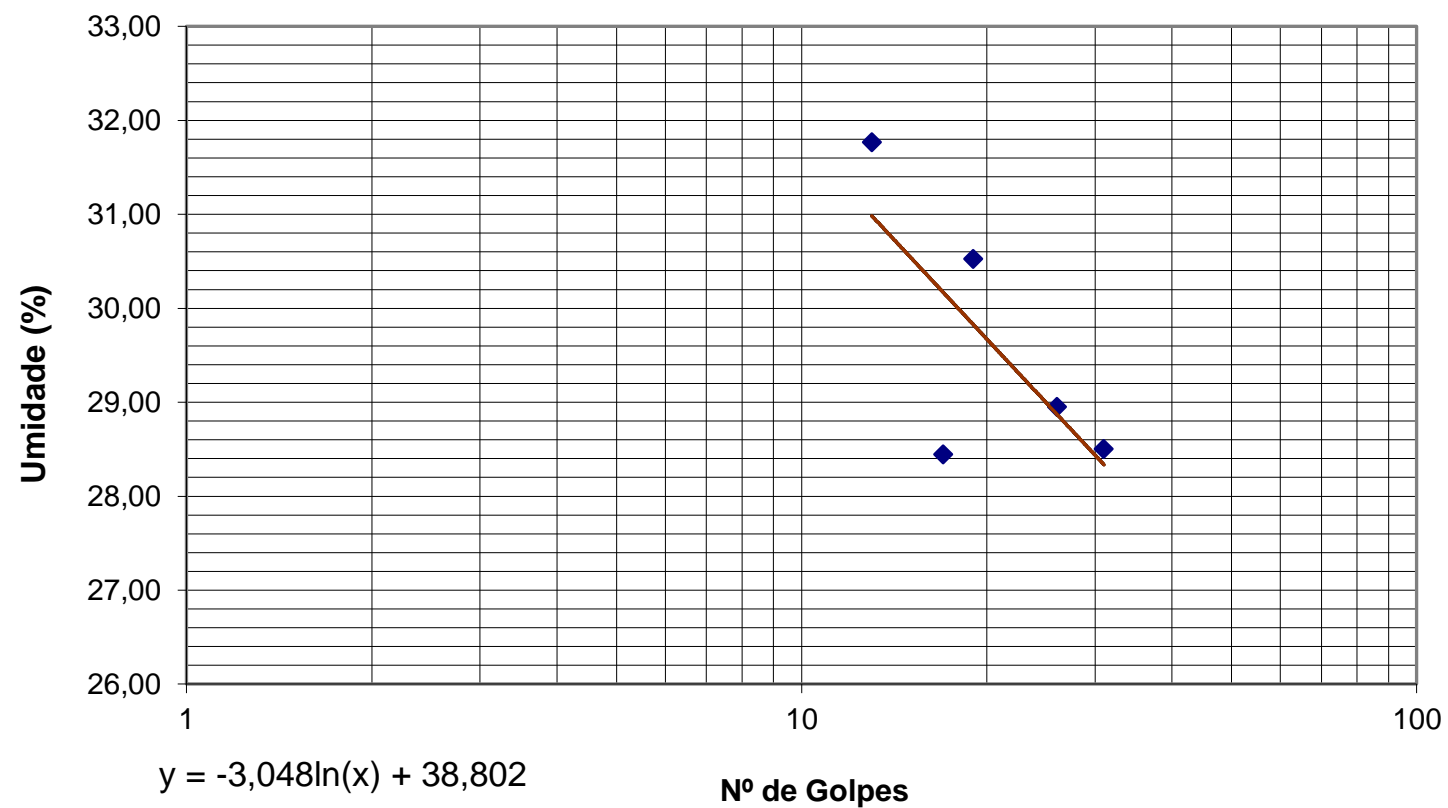

Figura E- 2 Teor de umidade em função do número de golpes (ensaio para determinar LL) para a amostra B-4

O LP, segundo os dados apresentados na Tabela E- 1, é $21 \%$ e, portanto, temos que o IP é $8 \%$.

Tabela E- 1 Limite de plasticidade da amostra B-4

\begin{tabular}{|c|c|c|c|c|c|c|c|}
\hline \multicolumn{8}{|l|}{ LIMITE DE PLASTICIDADE } \\
\hline \multicolumn{8}{|l|}{$\begin{array}{ll}\text { Recipiente } n^{0} & \mathrm{~g}\end{array}$} \\
\hline Amostra + tara + água & 42,33 & 57,28 & 56,54 & 49,77 & 50,77 & 57,70 & 54,96 \\
\hline Amostra + tara & 42,15 & 57,00 & 56,38 & 49,63 & 50,59 & 57,59 & 54,83 \\
\hline Água & 0,18 & 0,28 & 0,16 & 0,14 & 0,18 & 0,11 & 0,13 \\
\hline Tara & 41,34 & 55,95 & 55,71 & 48,94 & 49,74 & 56,69 & 54,27 \\
\hline Amostra seca & 0,814 & 1,047 & 0,670 & 0,689 & 0,849 & 0,896 & 0,56 \\
\hline Umidade, $\mathrm{h}$ & $22,11 \%$ & $26,74 \%$ & $23,88 \%$ & $20,32 \%$ & $21,20 \%$ & $12,28 \%$ & $23,21 \%$ \\
\hline
\end{tabular}

$\mathrm{Na}$ Carta de Plasticidade o solo localiza-se na região de argila $(\mathrm{C})$, pois seu LL é menor que $50 \%$ e está acima da Linha $A$, cuja equação é:

$$
I P=0,73 .(L L-20)
$$

Com essas informações é possível classificar a amostra B-4 como sendo GC:

- $\mathrm{G}$ - Pois $50,75 \%$ da massa seca é de fração arenosa.

- C - Pois $23,86 \%$ é de grãos finos e devido a sua classificação na Carta de Plasticidade. 


\section{Apendice F - Resultados dos ensaios geotécnicos da amostra B-5}

A amostra B-5 foi classificada visualmente como RCC.

\section{Granulometria}

A curva granulométrica está apresentada na Figura F-1. O material é composto por $13,94 \%$ de grãos finos, $56,40 \%$ de pedregulhos e $29,66 \%$ de areia.

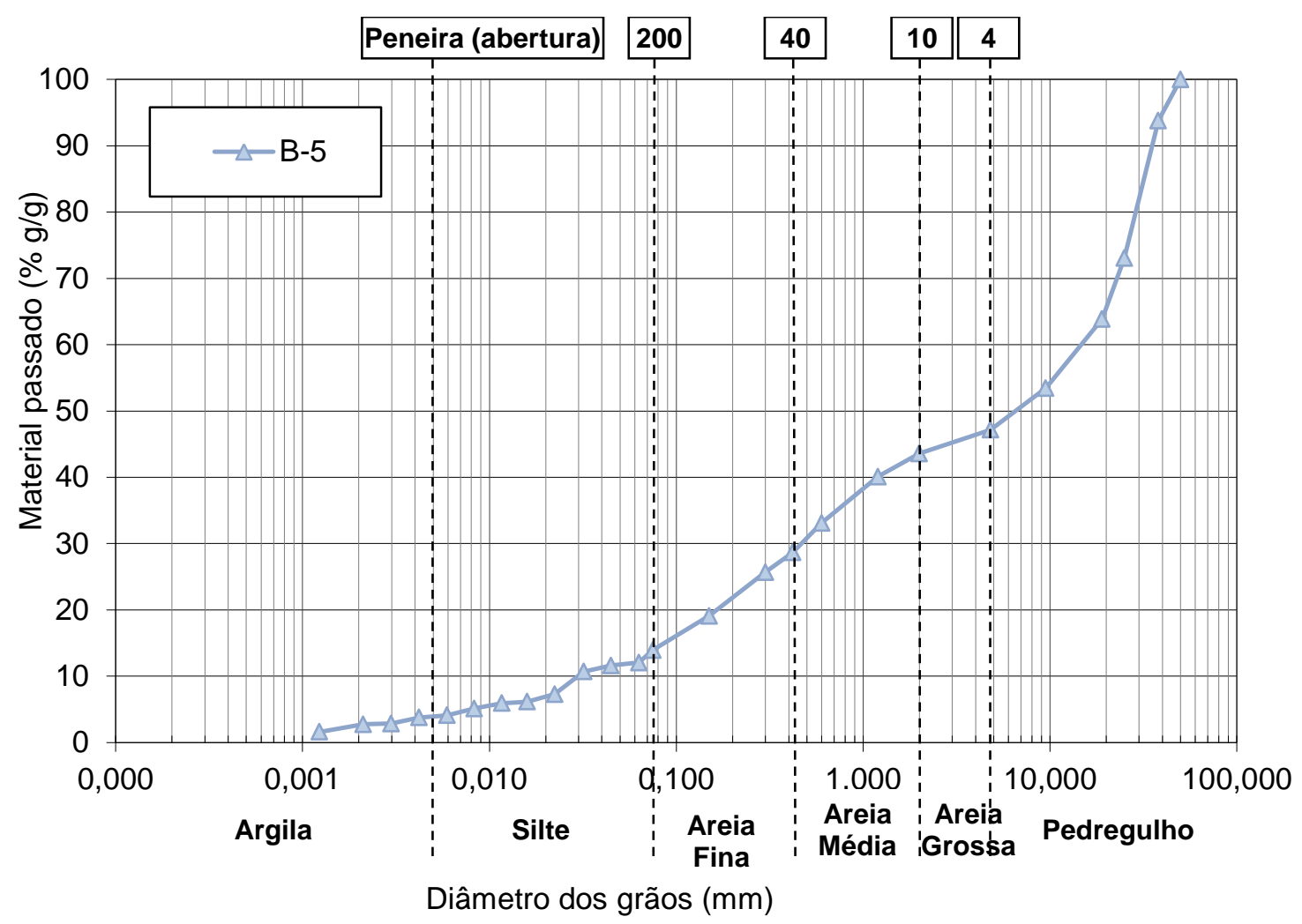

Figura F-1 Curva de distribuição granulométrica da amostra B-5

\section{LL, LP e Classificação}

No gráfico de teor de umidade (\%) por logaritmo de número de golpes podemos ajustar uma reta aos pontos experimentais (Figura F- 2). Ao substituir o valor de $\mathrm{x}$ da equação da reta por 25 , temos o valor de LL de aproximadamente $28 \%$.

$$
L L=-4,843 \ln (25)+44,064 \cong 28 \%
$$




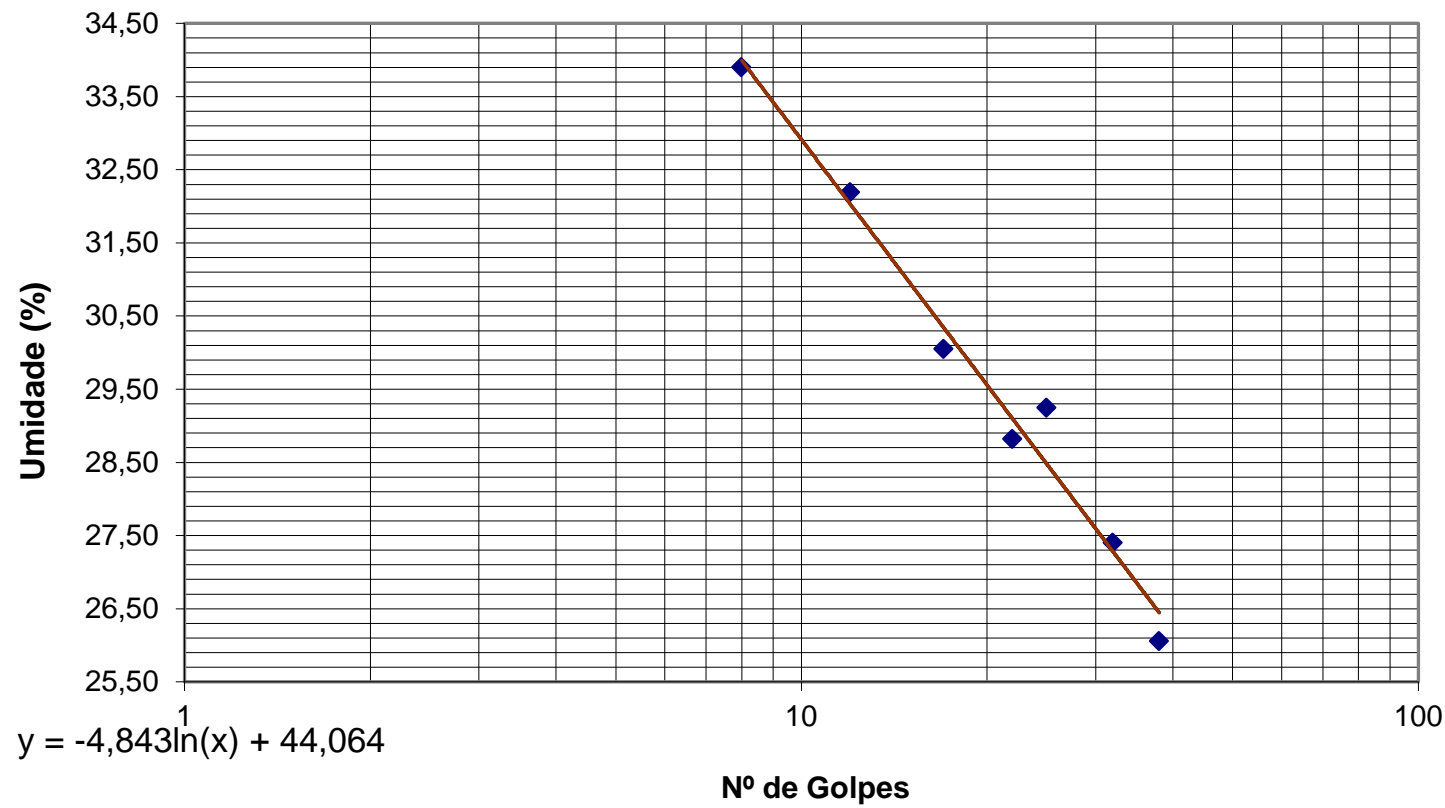

Figura F- 2 Teor de umidade em função do número de golpes (ensaio para determinar LL) para a amostra B-5

O LP, segundo os dados apresentados na Tabela F- 1, é $25 \%$ e, portanto, temos que o IP é 3\%.

Tabela F- 1 Limite de plasticidade para amostra B-5

\begin{tabular}{|c|c|c|c|c|c|c|c|}
\hline \multicolumn{8}{|l|}{ LIMITE DE PLASTICIDADE } \\
\hline \multirow{4}{*}{$\begin{array}{ll}\text { Recipiente } \mathrm{n}^{\circ} & \mathrm{g} \\
\text { Amostra + tara + água } & \mathrm{g} \\
\text { Amostra + tara } & \mathrm{g} \\
\text { Água } & \mathrm{g}\end{array}$} & 12 & 50 & 47 & 82 & 22 & 48 & 58 \\
\hline & 58,28 & 58,64 & 51,68 & 39,14 & 56,47 & 52,94 & 53,25 \\
\hline & 57,86 & 58,26 & 51,34 & 38,89 & 56,23 & 52,61 & 52,94 \\
\hline & 0,42 & 0,38 & 0,34 & 0,25 & 0,24 & 0,33 & 0,31 \\
\hline \multirow{3}{*}{$\begin{array}{ll}\text { Tara } & \mathrm{g} \\
\text { Amostra seca } & \mathrm{g} \\
\text { Umidade,h } & \%\end{array}$} & 56,28 & 56,80 & 49,88 & 37,84 & 55,30 & 51,30 & 51,65 \\
\hline & 1,585 & 1,458 & 1,457 & 1,053 & 0,926 & 1,315 & 1,293 \\
\hline & $26,50 \%$ & $26,06 \%$ & $23,34 \%$ & $23,74 \%$ & $25,92 \%$ & $25,10 \%$ & $23,98 \%$ \\
\hline
\end{tabular}

Na Carta de Plasticidade o solo localiza-se na região de silte (M), pois seu LL é menor que $50 \%$ e está abaixo da Linha A, cuja equação é:

$$
I P=0,73 .(L L-20)
$$

Com essas informações é possível classificar a amostra B-5 como sendo GM:

- $\mathrm{G}$ - Pois $56,40 \%$ da massa seca é fração de pedregulho.

- $\quad M$ - Pois $13,94 \%$ é de grãos finos e devido a sua classificação na Carta de Plasticidade. 


\section{Apendice G - Resultados dos ensaios geotécnicos da amostra B-12}

A amostra B-12 foi classificada visualmente como RCC.

\section{Granulometria}

A curva granulométrica está apresentada na Figura G-1. O material é composto por $21,83 \%$ de grãos finos, $50,56 \%$ de pedregulhos e $27,61 \%$ de areia.

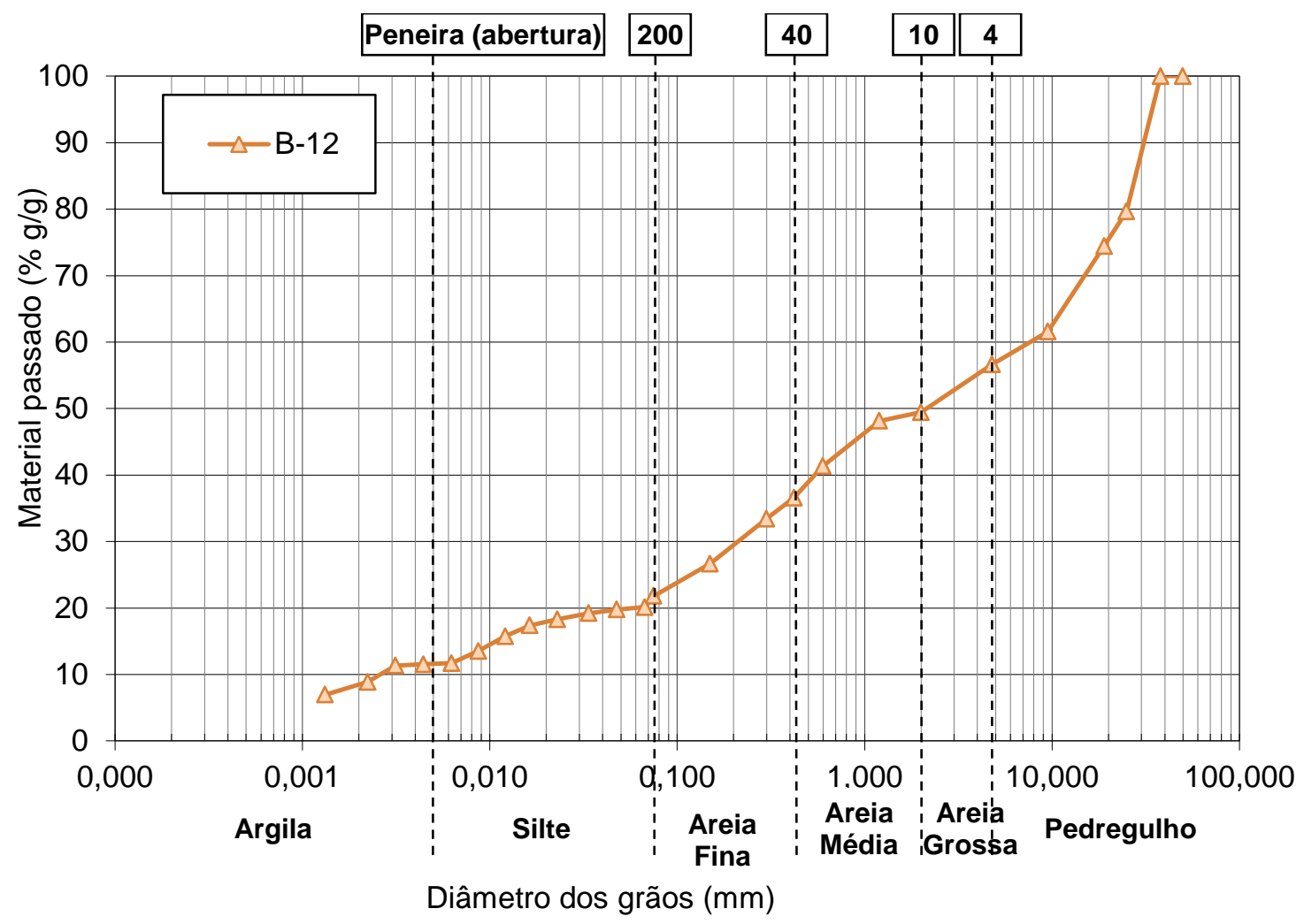

Figura G-1 Curva de distribuição granulométrica da amostra B-12

\section{LL, LP e Classificação}

No gráfico de teor de umidade (\%) por logaritmo de número de golpes podemos ajustar uma reta aos pontos experimentais (Figura G-2 Teor de umidade em função do número de golpes (ensaio para determinar LL) para a amostra B-12). Ao substituir o valor de $x$ da equação da reta por 25 , temos 0 valor de LL de aproximadamente $32 \%$.

$$
L L=-3,885 \ln (25)+44,554 \cong 32 \%
$$




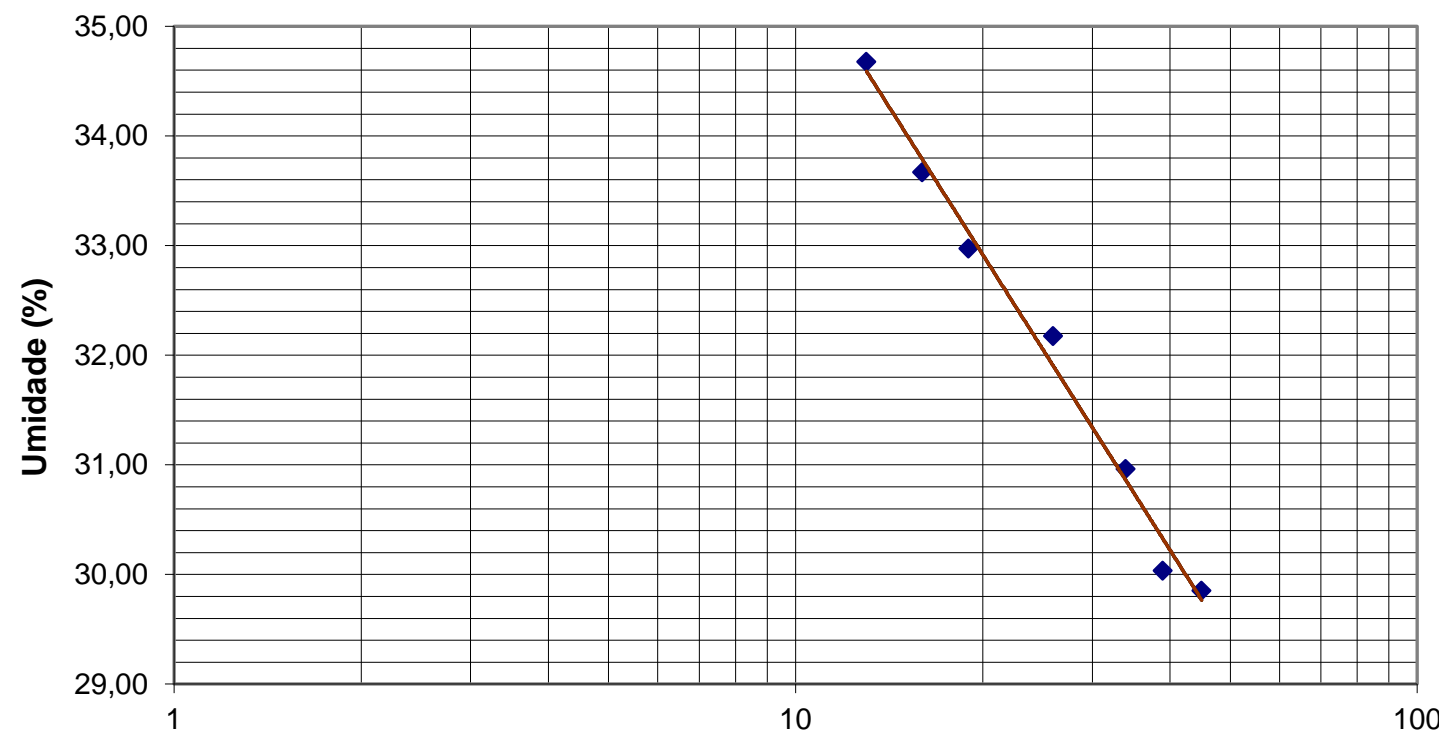

$y=-3,885 \ln (x)+44,554$

№ de Golpes

Figura G-2 Teor de umidade em função do número de golpes (ensaio para determinar LL) para a amostra B-12

O LP, segundo os dados apresentados na Tabela G- 1,é 19\% e, portanto, temos que o IP é $13 \%$.

Tabela G- 1- Limite de plasticidade da amostra B-12

\begin{tabular}{|c|c|c|c|c|c|c|c|}
\hline \multicolumn{8}{|l|}{ LIMITE DE PLASTICIDADE } \\
\hline \multicolumn{8}{|l|}{ Recipiente $\mathrm{n}^{\circ}$} \\
\hline Amostra + tara + água & 45,72 & 52,56 & 40,02 & 44,27 & 50,16 & 55,79 & 56,17 \\
\hline Amostra + tara & 45,59 & 52,41 & 39,80 & 44,19 & 50,01 & 55,64 & 56,06 \\
\hline Água & 0,13 & 0,15 & 0,22 & 0,08 & 0,15 & 0,15 & 0,11 \\
\hline Tara & 44,96 & 51,67 & 38,81 & 43,66 & 49,19 & 54,82 & 55,52 \\
\hline Amostra seca & 0,629 & 0,739 & 0,991 & 0,533 & 0,823 & 0,817 & 0,544 \\
\hline Umidade, $\mathrm{h}$ & $20,67 \%$ & $20,30 \%$ & $22,20 \%$ & $15,01 \%$ & $18,23 \%$ & $18,36 \%$ & $20,22 \%$ \\
\hline
\end{tabular}

$\mathrm{Na}$ Carta de Plasticidade o solo localiza-se na região de argila $(\mathrm{C})$, pois seu LL é menor que $50 \%$ e está acima da Linha $A$, cuja equação é:

$$
I P=0,73 \cdot(L L-20)
$$

Com essas informações é possível classificar a amostra B-12 como sendo GC:

- G - Pois 55,75\% da massa seca é de fração de pedregulho.

- C - Pois $21,83 \%$ de grãos finos e devida a sua classificação na Carta de Plasticidade. 


\section{Apendice H - Resultados dos ensaios geotécnicos da amostra B-19}

A amostra B-19 foi classificada visualmente como RCC.

\section{Granulometria}

A curva granulométrica está apresentada na Figura $\mathrm{H}-1$. O material é composto por $9,24 \%$ de grãos finos, $53,40 \%$ de pedregulhos e $37,36 \%$ de areia. Material é mal graduado porque, embora o parâmetro CNU seja 127, Cc é menor do que 1.

$$
C N U=\frac{D_{60}}{D_{10}} \approx \frac{9,5}{0,075} \cong 127 \quad \text { e } \quad C c=\frac{D_{30} 2}{D_{10} D_{60}} \approx 0.4
$$

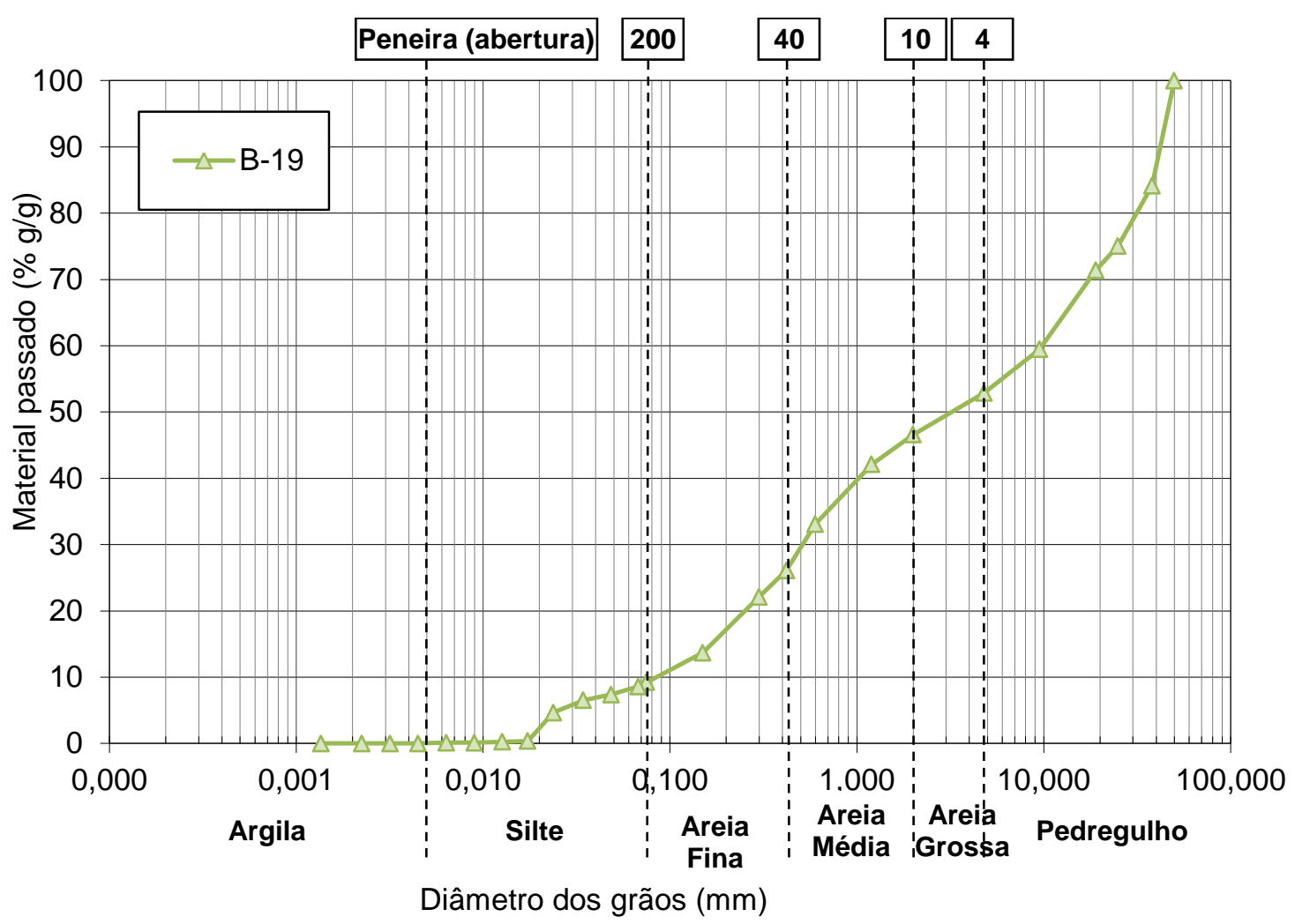

Figura H-1 Curva de distribuição granulométrica da amostra B-19 
LL, LP e Classificação

Devido às suas características não plásticas a amostra não apresentou LL e nem LP.

Com essas informações é possível classificar a amostra B-19 como sendo GPGM:

- $G$ - Pois $53,40 \%$ da massa seca é de fração de pedregulhos.

- M - Pois é não plástico

- P - Pois é mal graduado

- Fração de finos entre $5 \%$ e $12 \%$ 


\section{Apendice I - Resultados dos ensaios geotécnicos da amostra B-22}

A amostra B-22 foi classificada visualmente como RCC.

\section{Granulometria}

A curva granulométrica está apresentada na Figura I- 1 . O material é composto por $16,01 \%$ de grãos finos, $34,20 \%$ de pedregulhos e $49,79 \%$ de areia.

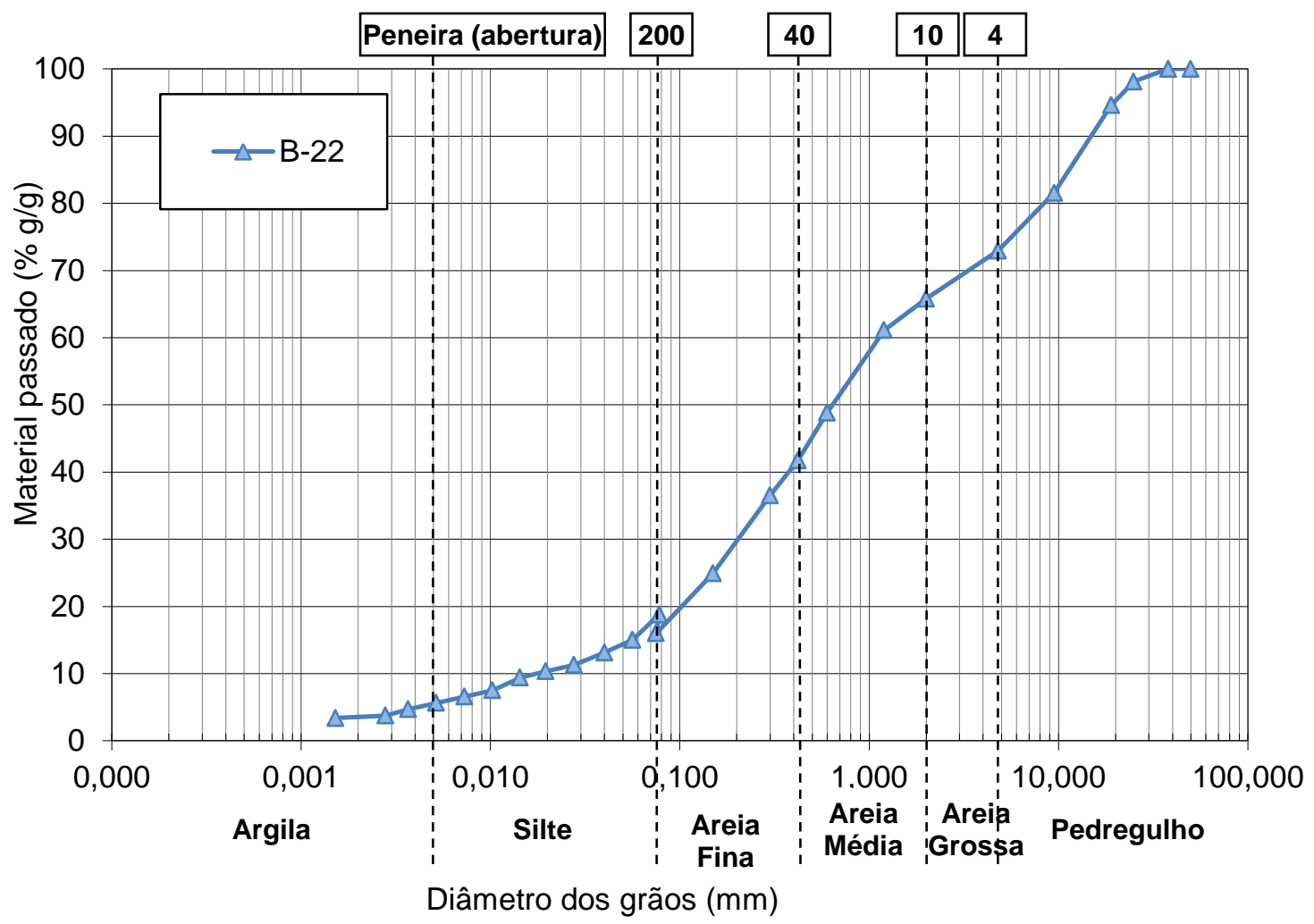

Figura I- 1 Curva de distribuição granulométrica da amostra B-22

\section{LL, LP e Classificação}

No gráfico de teor de umidade (\%) por logaritmo de número de golpes podemos ajustar uma reta aos pontos experimentais (Figura I- 2). Ao substituir o valor de $x$ da equação da reta por 25 , temos o valor de $L L$ de aproximadamente $27 \%$.

$$
L L=-4,27 \ln (25)+40,919 \cong 27 \%
$$




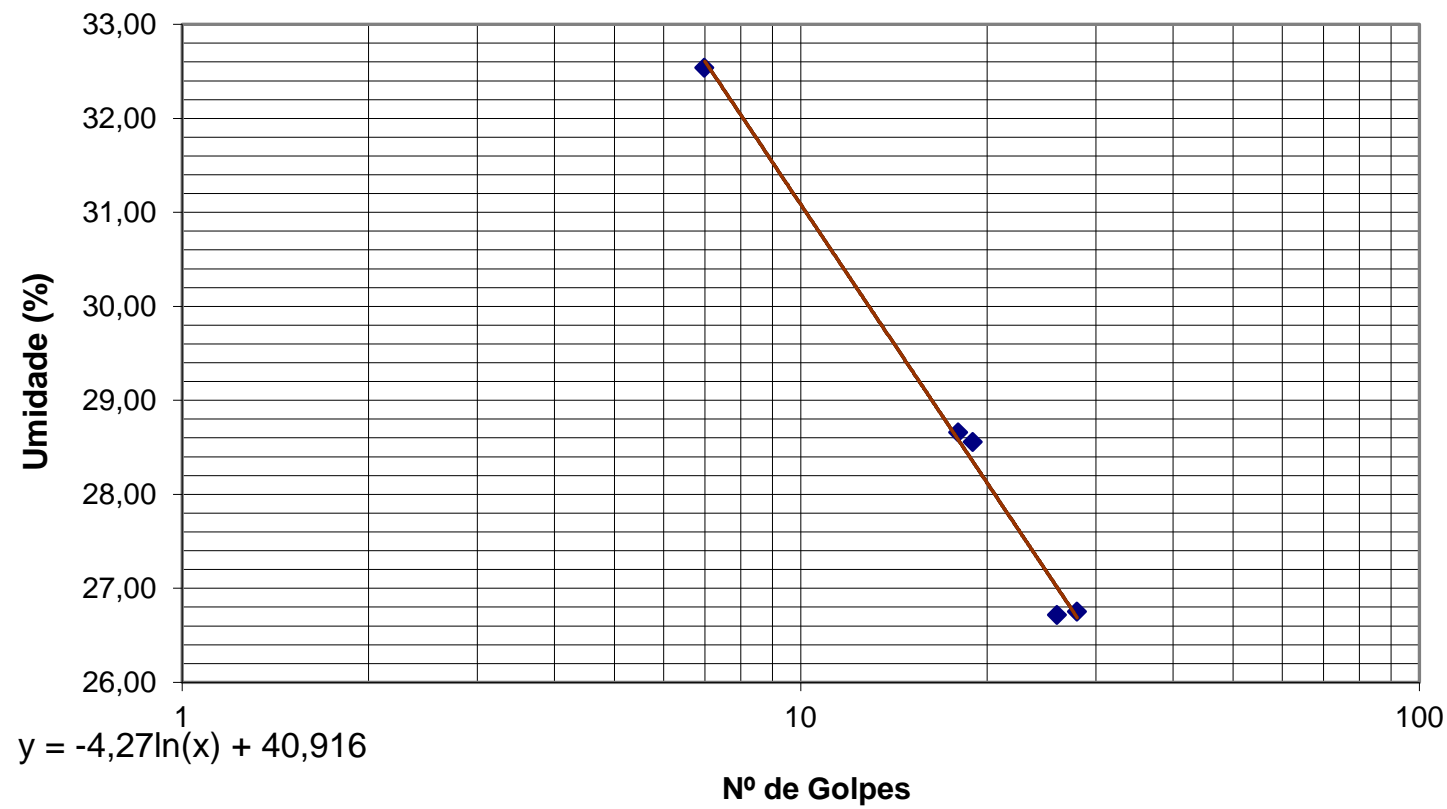

Figura l- 2 Teor de umidade em função do número de golpes (ensaio para determinar LL) para a amostra B-22

O LP, segundo os dados apresentados na Tabela I- 1, é $18 \%$ e, portanto, temos que o IP é $9 \%$.

Tabela I- 1 Limite de plasticidade da amostra B-22

\begin{tabular}{|c|c|c|c|c|c|c|c|}
\hline \multicolumn{8}{|l|}{ LIMITE DE PLASTICIDADE } \\
\hline Recipiente $\mathrm{n}^{0}$ & 67 & 85 & 70 & 68 & 72 & 52 & 5 \\
\hline Amostra + tara + água & 39,54 & 38,61 & 38,99 & 41,29 & 40,97 & 55,65 & 49,99 \\
\hline Amostra + tara & 39,36 & 38,52 & 38,89 & 41,19 & 40,85 & 55,52 & 49,86 \\
\hline Água & 0,18 & 0,09 & 0,10 & 0,10 & 0,12 & 0,13 & 0,13 \\
\hline Tara & 38,47 & 37,98 & 38,30 & 40,61 & 40,20 & 54,82 & 49,187 \\
\hline Amostra seca & 0,893 & 0,541 & 0,587 & 0,578 & 0,650 & 0,697 & 0,673 \\
\hline Umidade, $\mathrm{h}$ & $20,16 \%$ & $16,64 \%$ & $17,04 \%$ & $17,30 \%$ & $18,46 \%$ & $18,65 \%$ & $19,32 \%$ \\
\hline
\end{tabular}

Na Carta de Plasticidade o solo localiza-se na região de argila (C), pois seu LL é menor que $50 \%$ e está acima da Linha $A$, cuja equação é:

$$
I P=0,73 .(L L-20)
$$

Com essas informações é possível classificar a amostra B-22 como sendo SC;

- $\mathrm{S}$ - Pois $49,79 \%$ da massa seca é de fração arenosa.

- C - Pois $16,01 \%$ é de grãos finos e devido a sua classificação na Carta de Plasticidade. 


\section{Apendice $\mathbf{J}$ - Resultados dos ensaios geotécnicos da amostra RCC- mistura (composição)}

\section{Compactação}

Para a amostra RCC-misot (composição), a umidade ótima de 18,6\% gera uma densidade seca máxima de $1,675 \mathrm{~g} / \mathrm{cm}^{3}$ (Figura J-1).

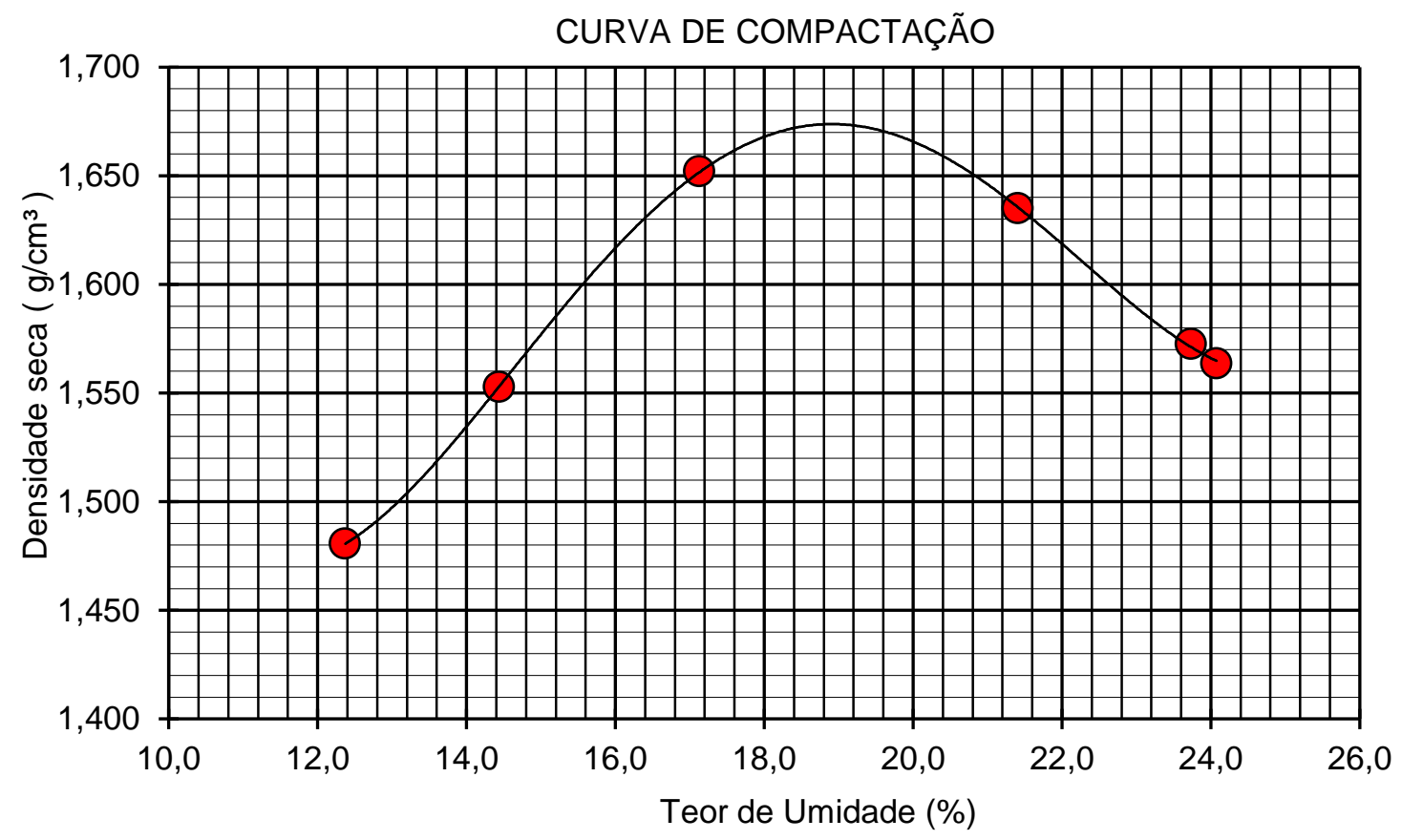

Figura J-1 Curva de compactação da amostra de RCC-mistura (composição).

\section{Resistência ao Cisalhamento}

Para o ensaio de cisalhamento direto, foram obtidas as curvas de tensão de cisalhamento $(\mathrm{kPa})$ pelo deslocamento $(\mathrm{mm})$. A amostra foi ensaiada para tensões verticais de $100 \mathrm{kPa}, 200 \mathrm{kPa}, 300 \mathrm{kPa}, 400 \mathrm{kPa}$ e $500 \mathrm{kPa}$. Os resultados dos cinco ensaios estão apresentados na Figura J-2 (NOMACHI \& BOSCOV, 2016). A Figura J-3 (NOMACHI \& BOSCOV, 2016) mostra os pontos máximos desses ensaios, a partir dos quais pode-se determinar a envoltória de resistência do solo e os parâmetros c (coesão) e $\varphi$ (ângulo de atrito). 


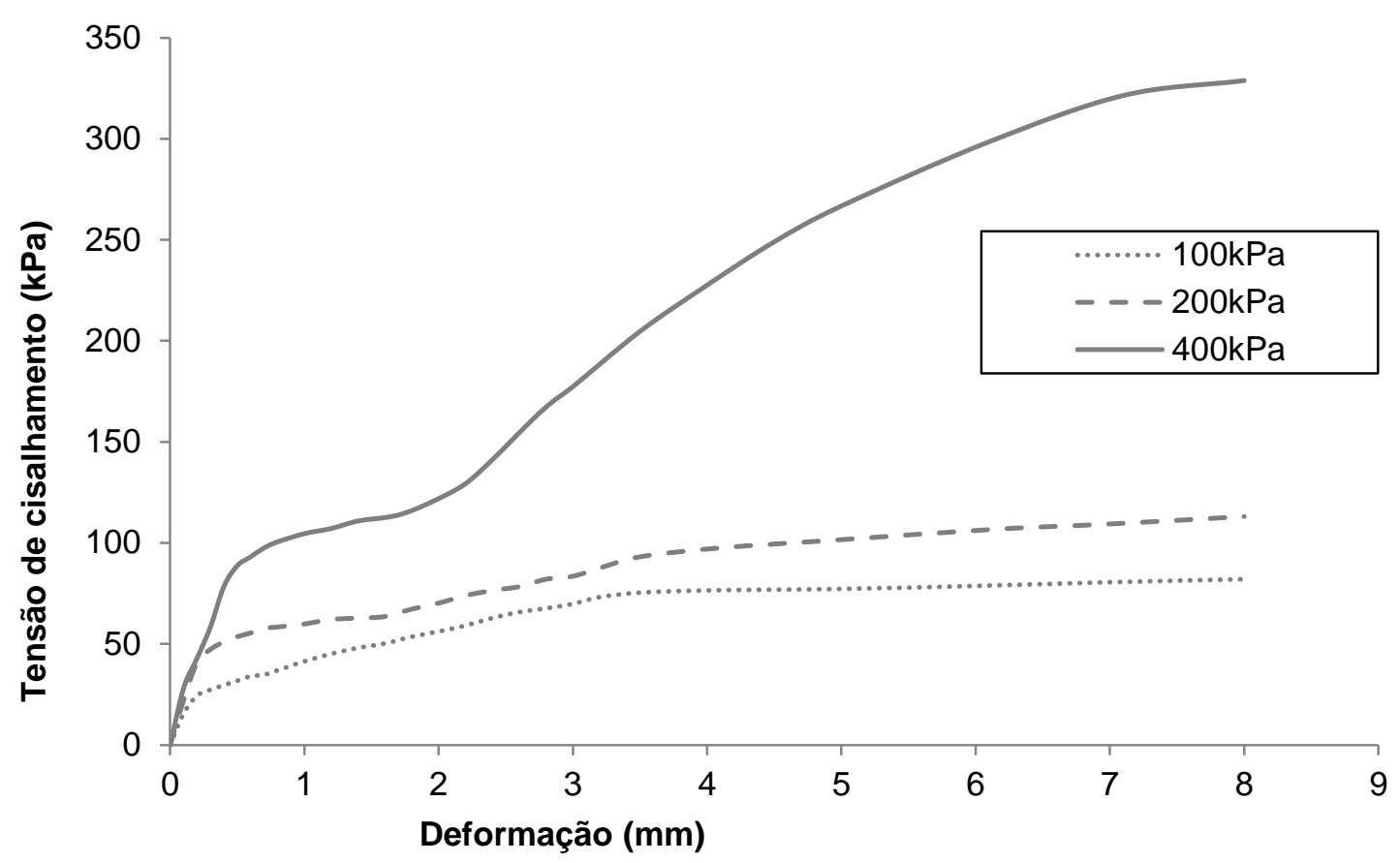

Figura J-2 Ensaios de cisalhamento direto com a amostra RCC-mistura (composição).

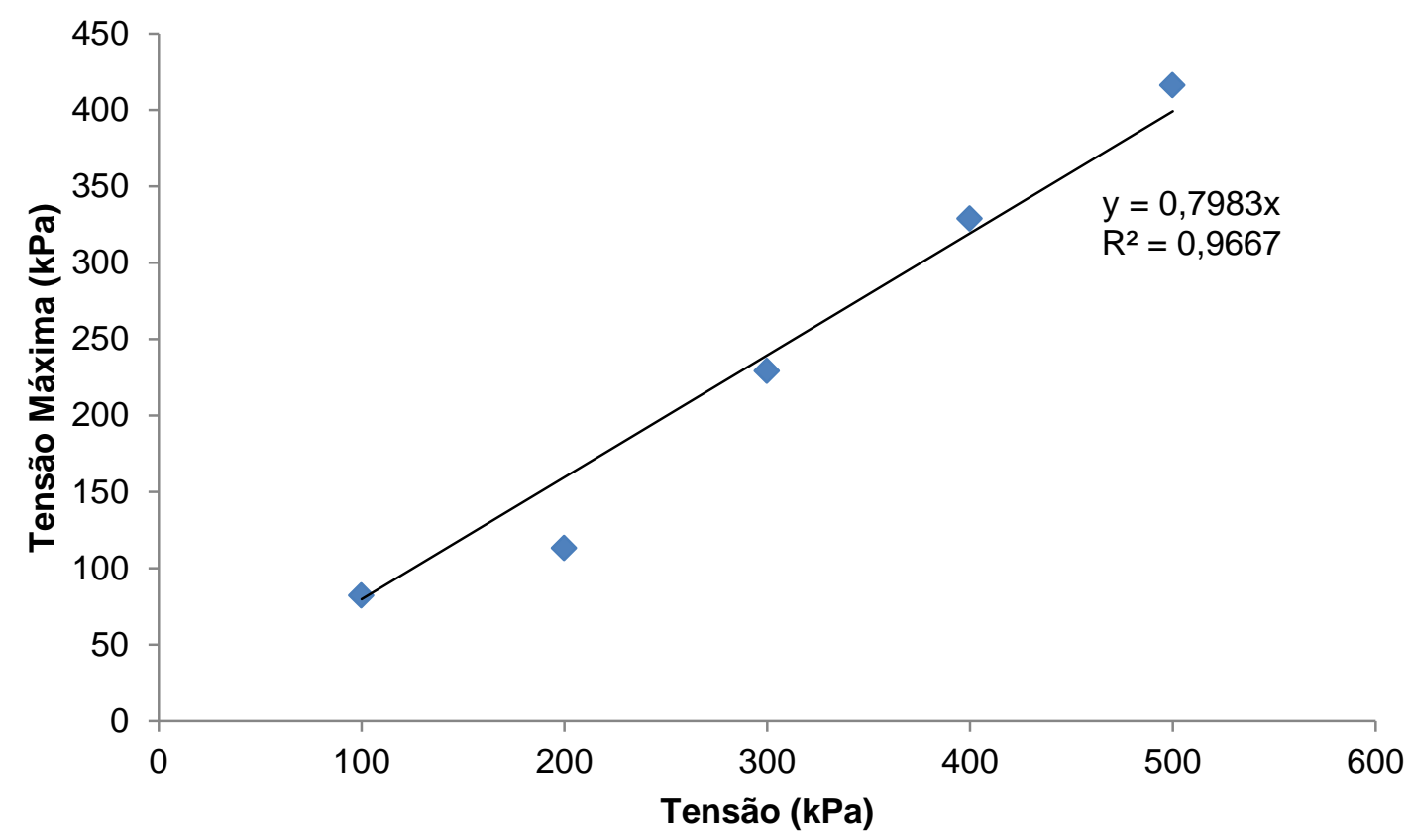

Figura J-3 Envoltória de resistência da amostra RCC-mistura (composição)

Para a amostra RCC-mistura (composição), a coesão e o ângulo de atrito são, respectivamente: $\quad \mathrm{C}=0 \mathrm{kPa}$ e $\varphi=38,58^{\circ}$. 


\section{Mini-CBR}

A Figura J- 4 e a Figura J- 5 mostram respectivamente a variação do Mini-CBR após imersão e da expansão em função do teor de umidade de compactação. Procurou-se realizar os ensaios com corpos de prova em três situações em termos de umidade de compactação: ramo seco, teor de umidade ótima e ramo úmido. Os três ensaios, contudo, foram realizadas no ponto ótimo e no ramo úmido. Infelizmente não houve material suficiente para realizar novos ensaios no ramo seco.

A amostra RCC-mistura (composição) apresentou Mini-CBR na ordem de 16\% no ponto ótimo de umidade e este valor cai para $4 \%$ para desvio de umidade igual a $3 \%$.

A amostra RCC-mistura (composição) apresentou expansão muito baixa nos três teores de umidade estudados (menor que 0,04\%).

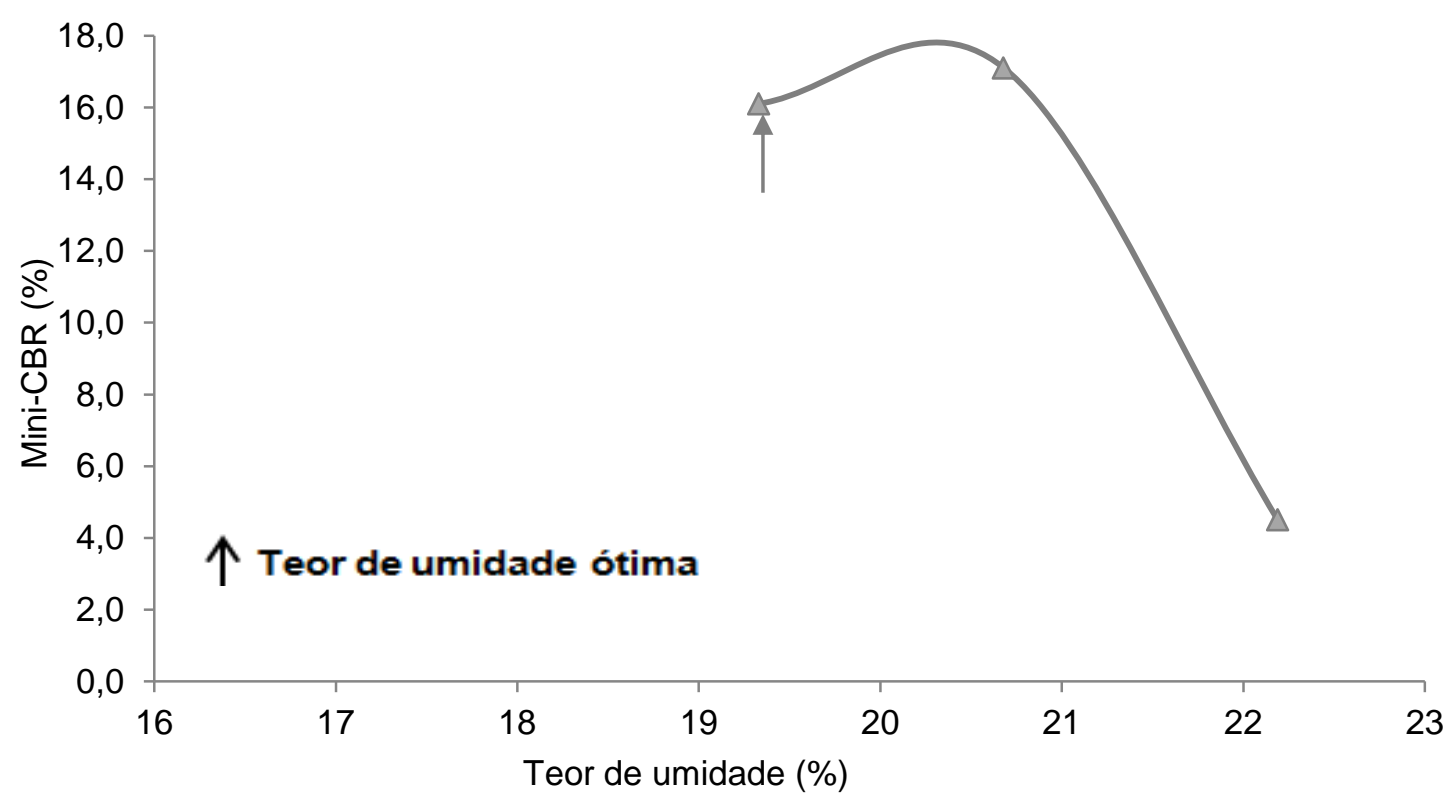

Figura J- 4 Curva de Mini-CBR da amostra RCC-mistura (composição). 


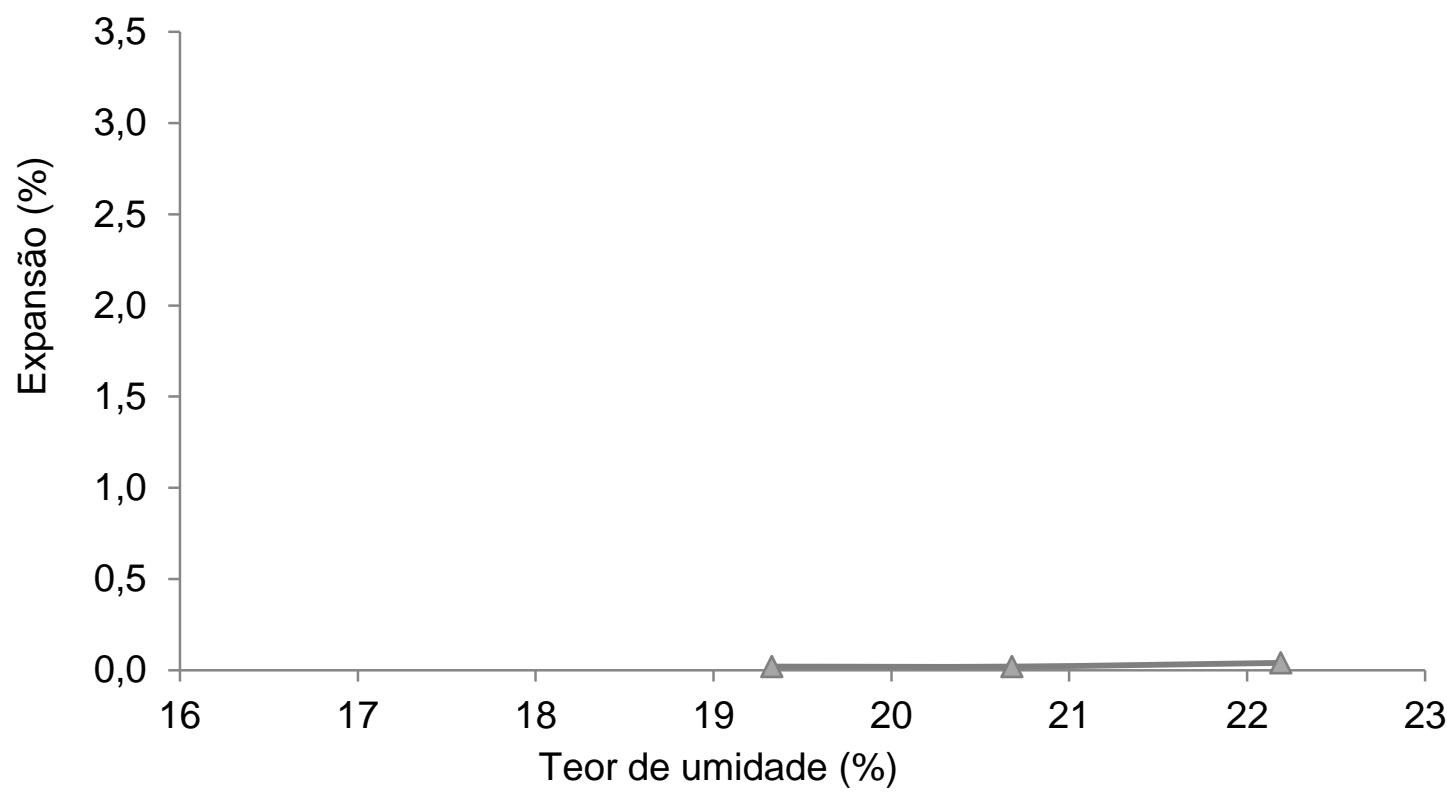

Figura J- 5 Curva de expansão da amostra de RCC-mistura (composição). 